\title{
Strukturelle Charakterisierung der \\ C-terminalen Domäne des spleißosomalen DExD/H-Box Proteins hPrp22
}

\author{
Dissertation \\ zur Erlangung des Doktorgrades \\ der Mathematisch-Naturwissenschaftlichen Fakultäten \\ der Georg-August-Universität Göttingen
}

vorgelegt von

Denis Kudlinzki

aus Mühlhausen/Thüringen

Göttingen 2007 
D7

Referent: Herr Prof. Dr. Ralf Ficner

Institut für Mikrobiologie \& Genetik

Abteilung für Molekulare Strukturbiologie

Georg-August-Universität Göttingen

Koreferent: Herr Prof. Dr. Oliver Einsle

Institut für Mikrobiologie \& Genetik

Abteilung für Molekulare Strukturbiologie

Georg-August-Universität Göttingen

Tag der mündlichen Prüfung: 22.01.2008 
für Marion und Til.

"Es ist nicht wenig Zeit, die wir haben, sondern es ist viel Zeit, die wir nicht nützen." 


\section{Inhaltsverzeichnis}

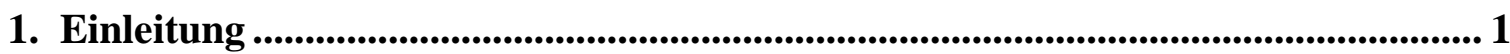

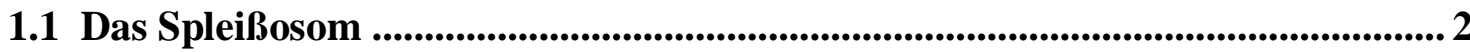

1.2 Intronklassen und Intronerkennung............................................................................ 3

1.3 Der Reaktionsmechanismus des Spleißens ....................................................4

1.4 Der Reaktionszyklus des Spleißens ….............................................................5

1.5 DExD/H-Box RNA-Helikasen ................................................................................ 8

1.6 Die DEAH-Box RNA-Helikasen hPRP2 und hPRP22 ..................................... 12

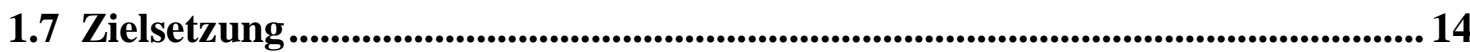

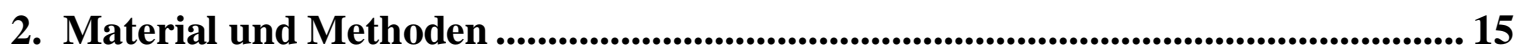

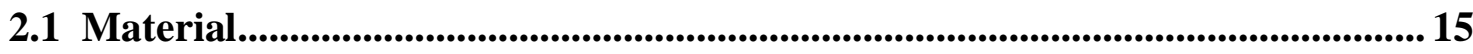

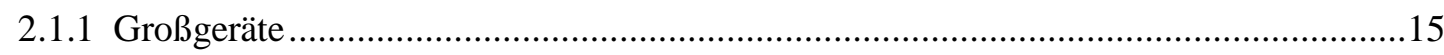

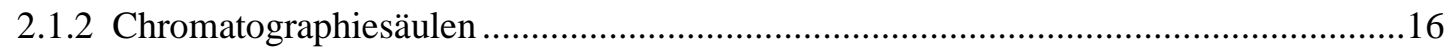

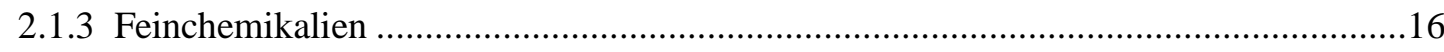

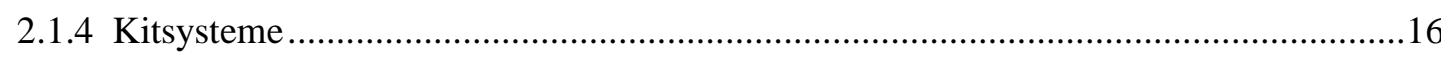

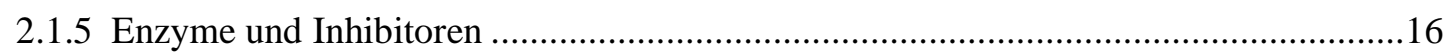

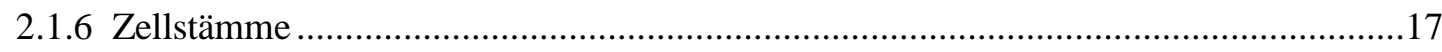

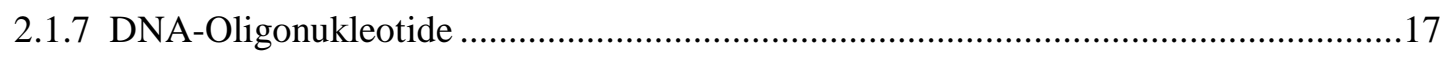

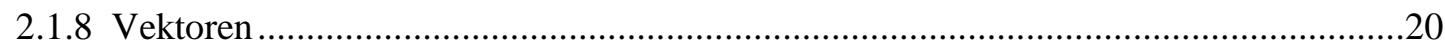

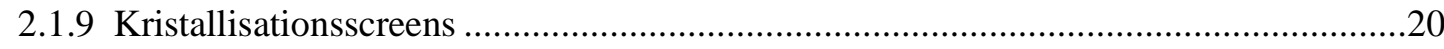

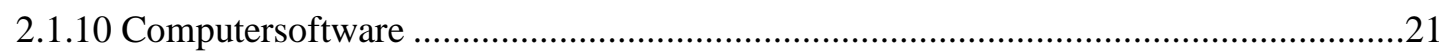

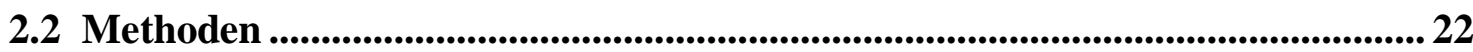

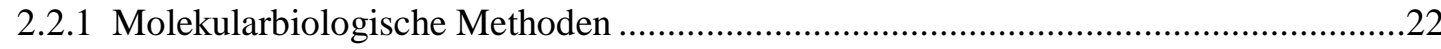

2.2.1.1 Polymerasekettenreaktion (PCR) ……………..........................................................22

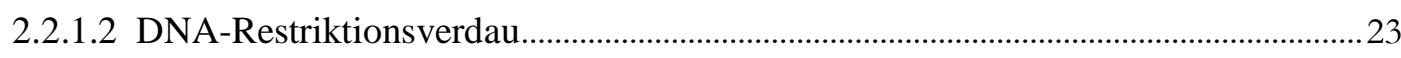

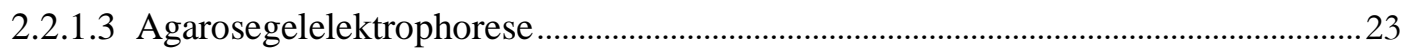


2.2.1.4 DNA-Ligation . .23

2.2.1.5 Plasmidpräparation .24

2.2.2 Mikrobiologische Methoden .24

2.2.2.1 Medien für die Aufzucht von E.coli .24

2.2.2.2 Transformation chemisch kompetenter E.coli-Zellen ..................................................26

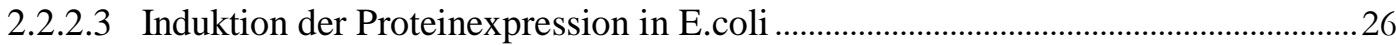

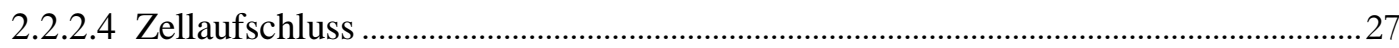

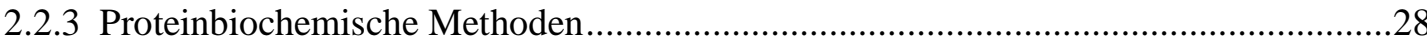

2.2.3.1 Affinitätschromatographie über Strep-Tactin-Sepharose .........................................28

2.2.3.2 Affinitätschromatographie über Glutathion-Sepharose.............................................28

2.2.3.3 Proteolytische Spaltung von GST-Fusionsproteinen mit PreScission Protease......29

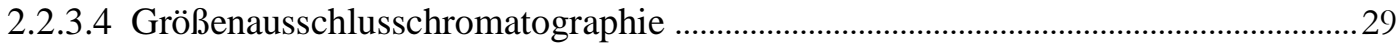

2.2.3.5 Diskontinuierliche SDS-Polyacrylamidgelelektrophorese (SDS-PAGE) .................30

2.2.4 Reinigungsprotokolle der verwendeten Proteine …......................................................30

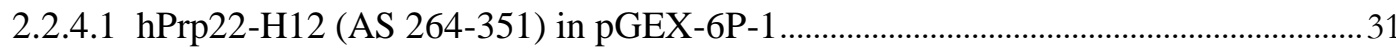

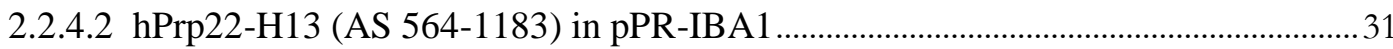

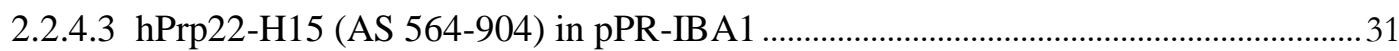

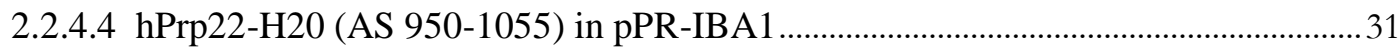

2.2.4.5 hPrp22-H20 (AS 950-1055) in pPR-IBA1 Selenomethionin-Derivat ........................32

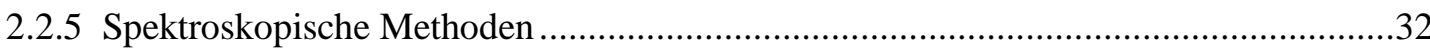

2.2.5.1 Bestimmung nativer molarer Extinktionskoeffizienten ..............................................32

2.2.5.2 Konzentrationsbestimmung von Proteinen und Nukleinsäuren ....................................33

2.2.5.3 Enzymgekoppelter ATPase-Test ............................................................................33

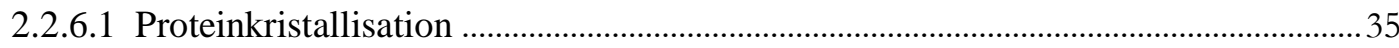

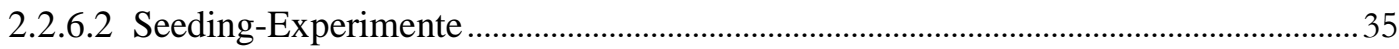

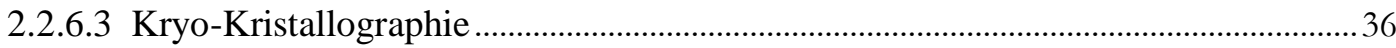

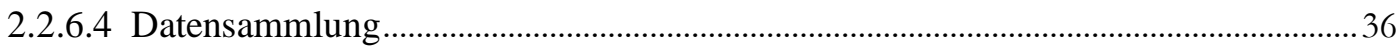

2.2.6.5 Phasenbestimmung und Kalkulation der Elektronendichteverteilung ........................37

2.2.6.6 Modellbau und Verfeinerung der Struktur .....................................................................39 


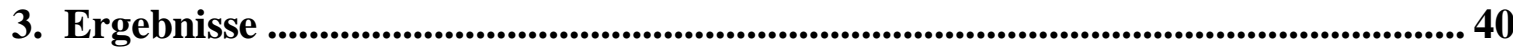

3.1 Klonierung und Reinigung des hPrp2 Volllängenproteins ............................. 40

3.2 Klonierung und Reinigung des hPrp22 Volllängenproteins .............................. 42

3.3 Design und Klonierung von Deletionsmutanten von hPrp22 und hPrp2 ........ 43

3.4 Reinigung und Kristallisation einiger Verkürzungen von hPrp22 .................... 46

3.4.1 Reinigung und Kristallisation der hPrp22-Deletionsmutante H12 …..........................46

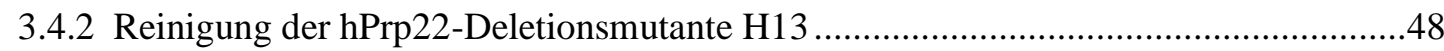

3.4.3 Reinigung der hPrp22-Deletionsmutante H15 …......................................................49

3.4.4 Reinigung und Kristallisation der hPrp22-Deletionsmutante $\mathrm{H} 20$...............................50

3.5 Strukturelle Charakterisierung des C-Terminus von hPrp22 (H20)................. 52

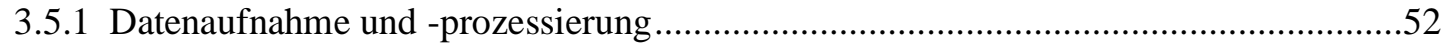

3.5.2 Bestimmung der Phasen durch SAD und MAD …..................................................54

3.5.3 Modellbau, Strukturverfeinerung und Qualität des Modells .......................................55

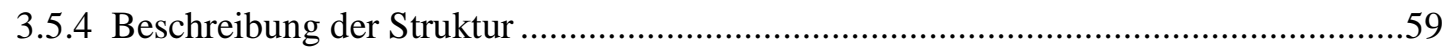

3.6 Biochemische Untersuchungen der ATPase-Aktivität ....................................... 60

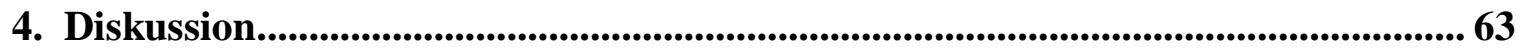

4.1 Klonierung und Reinigung der Volllängenproteine und Deletionsmutanten

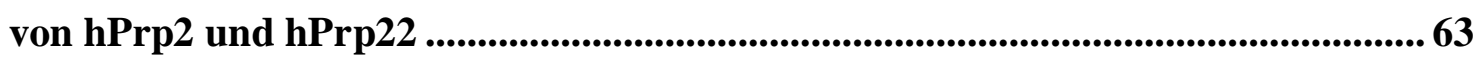

4.2 Strukturaufklärung der Deletionsmutante H20 von hPrp22 ........................... 64

4.3 Modellierung homologer C-terminaler Domänen .............................................. 68

4.4 Einfluss der C-terminalen Domäne von hPrp22 auf die ATPase-Aktivität .... 70

5. Zusammenfassung ......................................................................................................................... 72

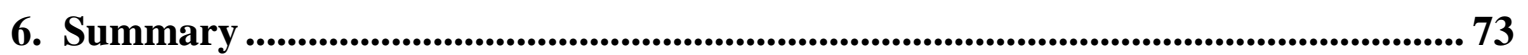

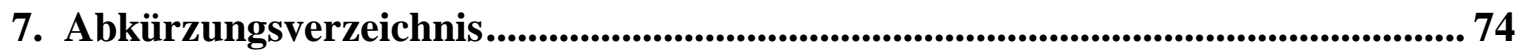

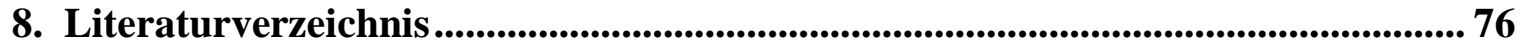

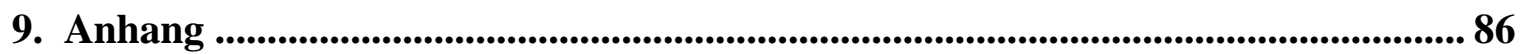

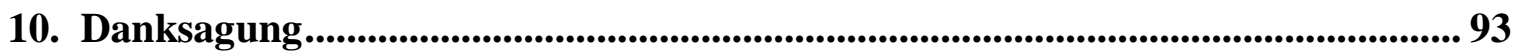




\section{Einleitung}

Die genetische Information eukaryotischer Organismen liegt als doppelsträngige chromosomale DNA im Zellkern vor. Die Nukleinsäuresequenz dieser DNA enthält den Schlüssel für die Synthese von Proteinen. Die Erbinformation wird Gen für Gen von RNA-Polymerasen abgelesen und so auf einzelsträngige RNAs übertragen. Bei diesem Vorgang, der Transkription, wird eine Vorstufe der Boten-RNA (prämessenger-RNA) synthetisiert. Diese prä-mRNA wird anschließend durch verschiedene Prozesse zur reifen mRNA modifiziert, die aus dem Zellkern in das Zytoplasma transportiert wird. Ihre Nukleinsäureabfolge wird während der Proteinbiosynthese an den Ribosomen in die Aminosäuresequenz translatiert. Die Primärstruktur der Aminosäuren bestimmt maßgeblich die Gestalt und damit die biologische Funktion des synthetisierten Polypeptids. Der gesamte Prozess kann auch als Fluss der genetischen Information bezeichnet werden (Abb.1).

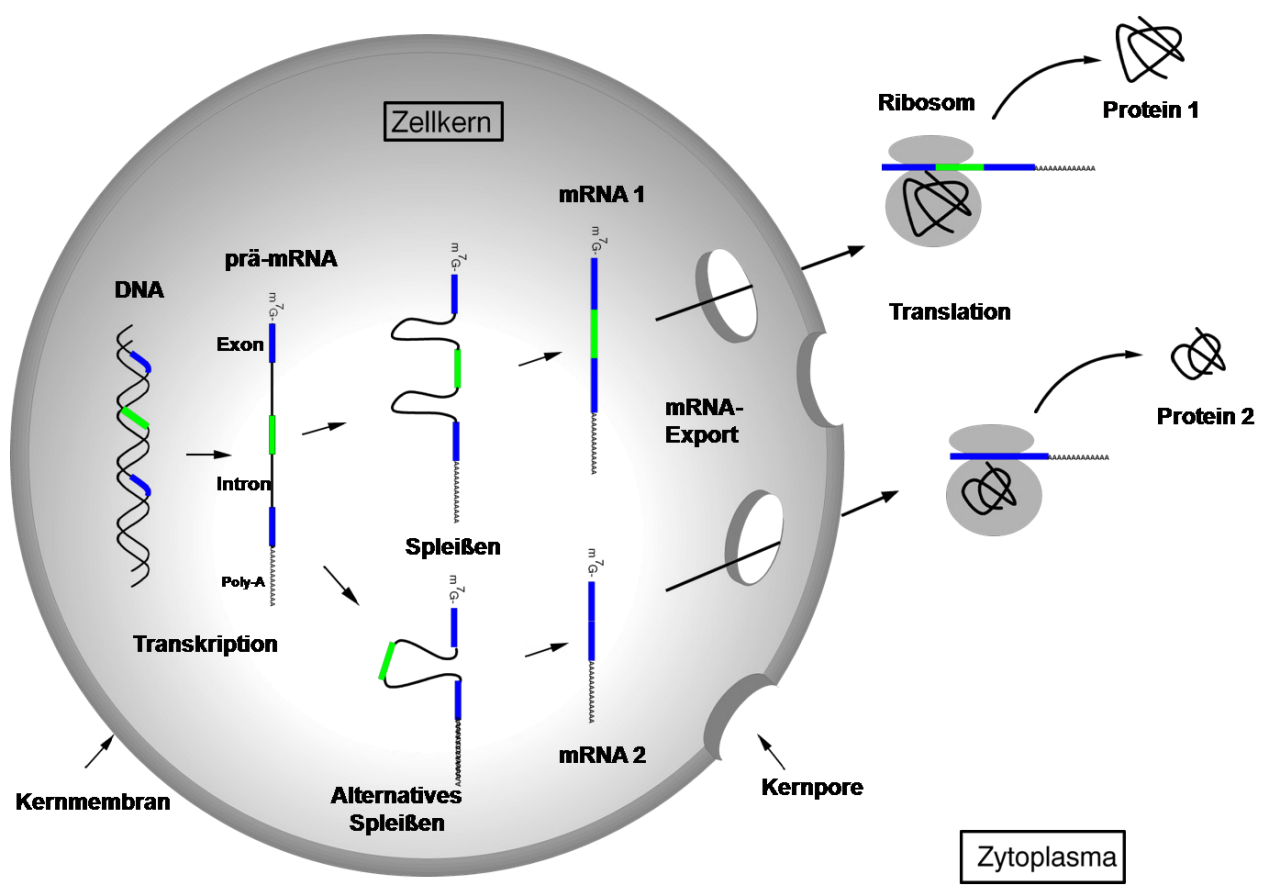

[Abb.1] Fluss der genetischen Information in Eukaryoten. Transkription der DNA in prä-mRNA, Modifikation der prämRNA, Spleißen der prä-mRNA, Export der reifen mRNA ins Zytoplasma, Translation an den Ribosomen, Faltung der translatierten Proteine. Alternatives Spleißen führt zu veränderten Proteinen (nach Lührmann, 2006).

Neben der Anheftung einer 5'-Guanosin-Kappe (5'-cap) und dem Anhängen von zahlreichen Adeninen (Poly-A), kommt es auch zu spezifischen Veränderungen der Länge der prä-mRNA. Die genetische Information der DNA ist diskontinuierlich, das heißt sie enthält kodierende (Exons) und nicht kodierende (Introns, engl. intervening sequences) Sequenzabschnitte (Berget et al., 1977; Chow et al., 1977). Der Grad dieser Diskontinuität und Anzahl der Introns nimmt mit der Komplexität der Organismen zu. Prokaryotische DNA besitzt keine Introns. 
Einfache Eukaryoten (z.B. Hefe) besitzen nur wenige Mosaikgene mit wenigen Introns und höhere Eukaryoten (z.B. Mensch) haben kaum Gene ohne Introns. Die meisten Gene besitzen zahlreiche nicht-kodierende Sequenzabschnitte größerer Länge.

Da Introns nicht für Proteine kodieren, werden sie aus der mRNA entfernt. Gleichzeitig müssen die Exons miteinander verknüpft werden, um eine kontinuierliche genetische Information zu gewährleisten. Dieser Schritt der RNA-Prozessierung wird Spleißen genannt und wird durch das Spleißosom katalysiert. Ein Vorteil von Introns in den Genen eukaryotischer Organismen liegt in der Möglichkeit des alternativen Spleißens. Dabei werden aus einer prä-mRNA nur ganz bestimmte Exons für die mRNA verknüpft, die je nach Funktion des Proteins unterschiedlich kombiniert werden können. Dieser modulare Aufbau der Gene erhöht die Anzahl möglicher Proteinprodukte pro Gen und stellt eine Möglichkeit dar, die Sequenzen des Genoms vielfältiger zu nutzen. Des Weiteren sinkt die Mutagenesewahrscheinlichkeit in den Exons.

\subsection{Das Spleißosom}

Das Spleißosom ist ein hochdynamischer Protein-RNA Komplex mit einer Masse von bis zu 2 MDa (Übersicht in Burge et al., 1999; Hastings et al., 2001; Brow, 2002; Will et al., 2006). Es katalysiert Reaktionen, die das präzise Entfernen der Introns und das Ligieren der Exons zur Folge haben. Eukaryoten haben mit zunehmendem Evolutionsgrad komplexere Spleißosomen mit zahlreicheren interagierenden Proteinen ausgebildet.

Der spleißosomale Protein-RNA-Komplex wird nach und nach aus fünf Ribonukleoproteinkomplexen (small nuclear ribonucleoprotein particles, snRNPs) um das prämRNA Substrat herum aufgebaut. Beim Menschen wurden zwei Spleißosomformen gefunden, das Hauptspleißosom (major spliceosome) und das Nebenspleißosom (minor spliceosome) (Übersicht in Burge et al., 1999). Durch das Hauptspleißosom (Abb.2) werden Introns des Typs U2 entfernt, während das Nebenspleißosom seltenere Introns vom Typ U12 entfernt (Tarn et al., 1996; Staley et al., 1998; Jurica et al., 2003; Will et al., 2005).

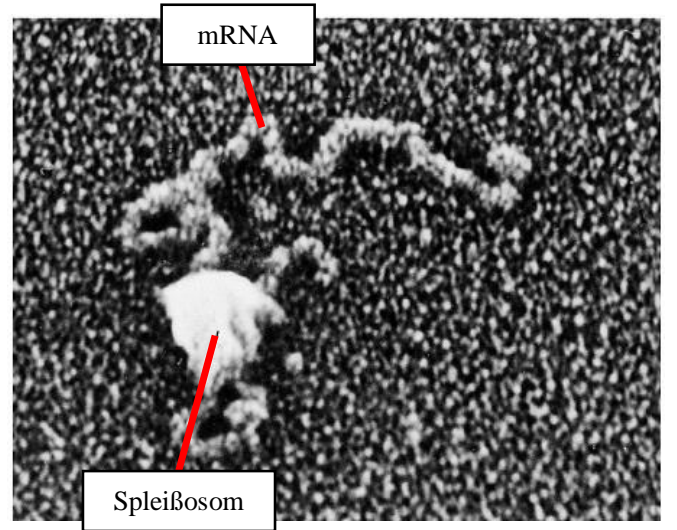

[Abb.2] EM-Aufnahme des menschlichen Hauptspleißosomens mit gebundener mRNA (http://web.uconn.edu/mcb201/lecture23.html). 
Das Hauptspleißosom besteht aus den snRNPs U1, U2, U4, U5 und U6, sowie assoziierten nichtspleißosomalen Proteinen (Hartmuth et al., 2002). U snRNPs bestehen jeweils aus 100-200 Nukleotide langen, uridinreichen UsnRNAs (Guthrie et al., 1988) und den 7 Sm Proteinen B, D1, D2, D3, E, F, G (bei U6 sind es die zu den Sm-Proteinen homologen Lsm Proteine) (Übersicht in Will et al., 2001, 2006) sowie assoziierten, U snRNP-spezifischen Proteinen (Abb.3).

Des Weiteren gibt es noch zahlreiche nicht-snRNP Proteine, die für das Spleißen von großer Bedeutung sind. Beim Menschen mehr als 100 spleißosomale Proteine beschrieben (Jurica et al., 2002; Makarov et al., 2002; Mougin et al., 2002; Rappsilber et al., 2002; Zhou et al., 2002). In Saccharomyces cerevisiae wurden viele dieser Proteine mit Prp bezeichnet, um ihre Funktion in der prä-mRNA-Prozessierung (pre-mRNA processing) zu kennzeichnen. Alle beteiligten Proteine wurden in drei Klassen eingeteilt. Die Sm und Lsm Proteine werden als core snRNP Proteine, die U snRNP spezifischen Proteine als integrale snRNP Proteine und die nicht-snRNP Proteine als externe snRNP Proteine bezeichnet (Übersicht in Will et al., 2006).

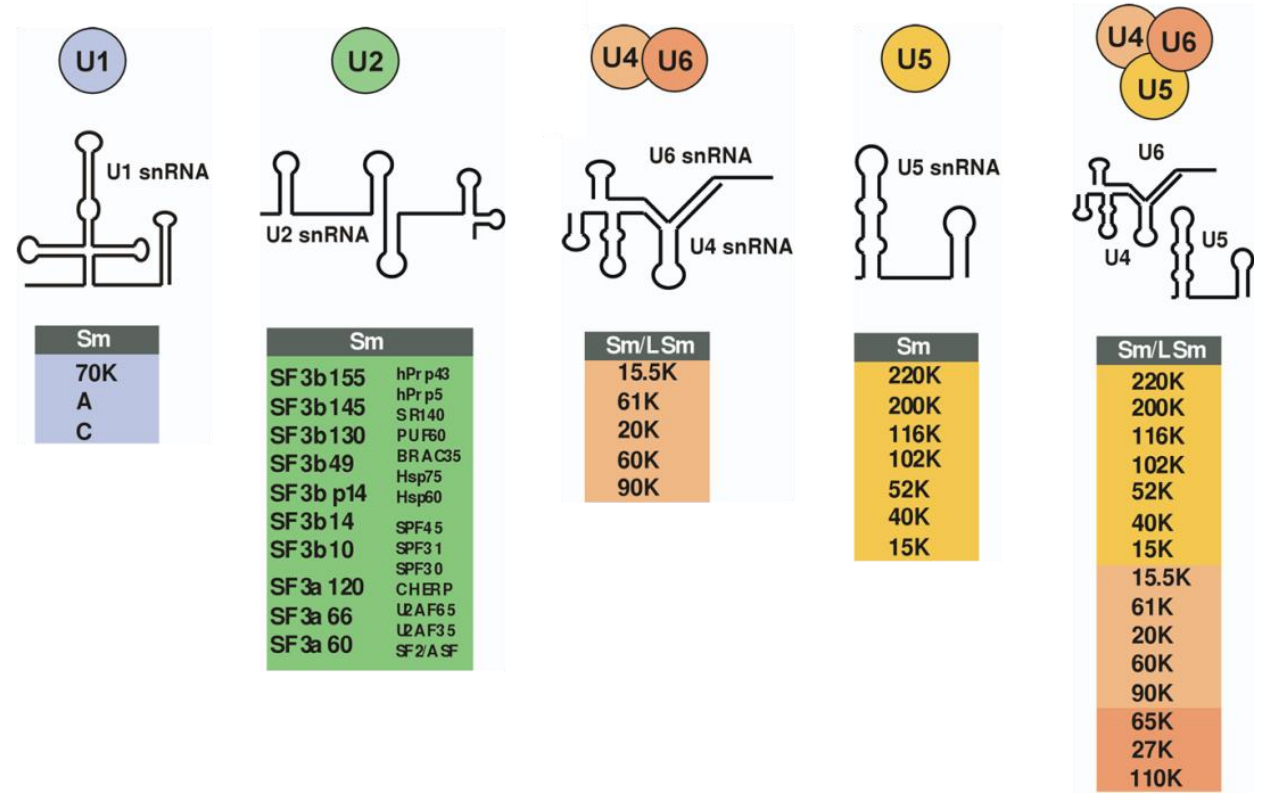

[Abb.3] Aufstellung der U UsnRNAs des Menschen mit ihren zugehörigen Protein-Komponenten, die zusammen im Komplex die U snRNPs formen und das Spleißosom bilden (nach Lührmann, 2006).

\subsection{Intronklassen und Intronerkennung}

Es gibt verschiedene Intronklassen, die Unterschiede in ihrer Sequenz, Sekundärstruktur und hinsichtlich des Mechanismus durch den sie gespleißt werden aufweisen. Die bekannten Klassen sind die Gruppen I und II der selbst-spleißenden Introns (self-splicing introns), t-RNA Introns und spleißosomale Introns.

Selbst-spleißenden Introns der Gruppen I und II wurden in Protozoen rRNAs, in Mitochondrien und Chloroplasten von Pilzen und Pflanzen und in Eubakterien gefunden (Übersicht in Cech, 
1993; Zaug et al., 1983). Diese beiden Intronklassen unterscheiden sich in ihren Reaktionsmechanismen (Peebles et al., 1986; van der Veen et al., 1986; Madhani et al., 1992) und können ohne katalytischen Einfluss von Proteinen die Spleißreaktion selbst durchzuführen. Der Reaktionsmechanismus ähnelt dem Spleißen durch das Spleißosom (1.3) (Übersicht in Moore et al., 1993; Nilsen, 1998). Spleißosomale Introns sind am häufigsten und sind charakteristisch für Eukaryoten.

Die Erkennung dieser Introns erfolgt durch hochkonservierte Sequenzabschnitte in bestimmten Bereichen dieser. Untereinheiten des Spleißosoms erkennen bestimmte Konsensussequenzen (Abb.4) und binden daran (Padgett et al., 1986). Die 5'-Schnittstelle markiert den Anfang, die 3'Schnittstelle das Ende des Introns. Die konservierten Sequenzabschnitte erstrecken sich über den Bereich der Exon-Intron-Grenze hinaus. Der für die Spleißreaktion wichtige Verzweigungspunkt (branchpoint) liegt 100-18 Nukleotide aufwärts der 3'-Schnittstelle und unterscheidet sich stark zwischen höheren und niederen Eukaryoten. Ein zentrales Adenosin ist Mittelpunkt der Spleißreaktion. In höheren Eukaryoten gibt es eine pyrimidinreiche Region, die zwischen dem branchpoint und der 3'-Schnittstelle liegt (Senapathy et al., 1990; Lopez et al., 1999).

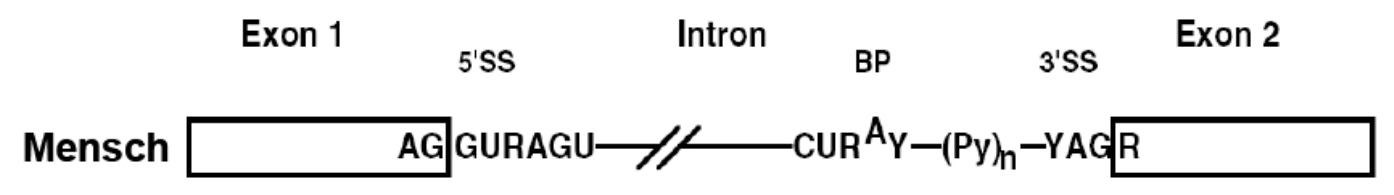

[Abb.4] Intron-Konsensussequenzen von Homo sapiens. Konsensussequenzen der 5'-Schnittstelle (5'SS), des branchpoints (BP) und der 3'-Schnittstelle (3'SS), A=Adenin, C=Cytosin, G=Guanin, U=Uracil, R=Purin, Y=Pyrimidin, pyrimidinreiche Region (Py)n, N kann A, U, G, C oder sein (nach Burge et al., 1998).

\subsection{Der Reaktionsmechanismus des Spleißens}

Der Reaktionsmechanismus des Spleißens basiert auf zwei aufeinander folgenden Umesterungen. In der ersten chemischen Reaktion erfolgt ein nukleophiler Angriff der 2'-Hydroxylgruppe des branchpoint Adenins auf das Phosphat der Base an der 5'-Schnittstelle. Durch diese Reaktion entsteht ein freies 5'-Exon mit einer freien 3'-Hydroxylgruppe und eine lassoförmige RNAStruktur (Lariat-Zwischenprodukt), das durch die 2'-5'-Phosphodiesterbindung des branchpointAdenins und dem Guanin der 5'-Schnittstelle gebildet wird (Abb.5, nach der ersten Umesterung). Bei der zweiten Reaktion findet ein nukleophiler Angriff der freien 3'-Hydroxylgruppe des Exons 1 auf das Phosphat der 3'-Schnittstelle statt (Abb.5, nach der zweiten Umesterung). Die beiden Exons werden durch eine Phosphodiesterbindung verknüpft und es entsteht ein freies IntronLariat (Grabowski et al., 1984; Ruskin et al., 1984; Padgett et al., 1984).

Dieser Mechanismus des Spleißens findet sowohl in Menschen als auch in niederen Eukaryoten statt (Ng et al., 1980). Diese Reaktionsfolge benötigt keine zusätzliche Energie, da die 
Phosphodiesterbindungen nur umgelagert werden. Der beschriebene Mechanismus wird CisSpleißen genannt, da dasselbe RNA-Molekül sowohl Donor als auch Akzeptor für die Reaktion ist. Es gibt noch eine weitere Art des Spleißens (Trans-Spleißen), in der zwei getrennte prämRNA Moleküle verbunden werden (Übersicht in Nilsen, 1997).

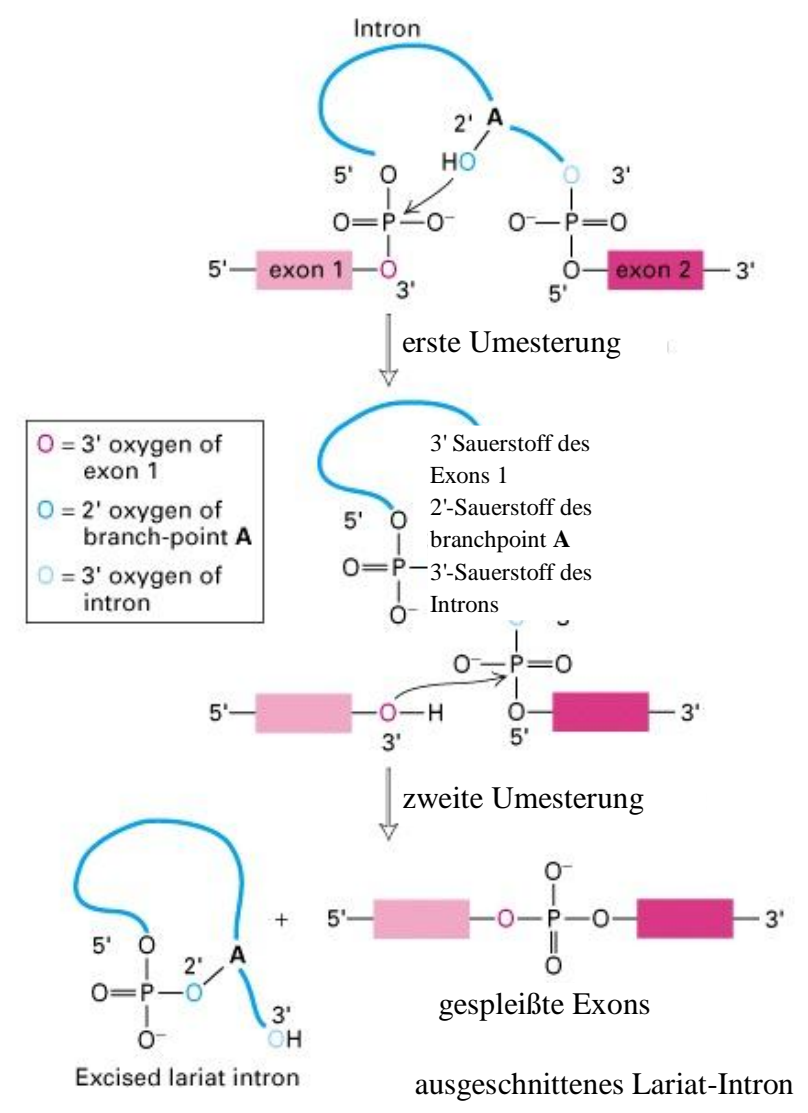

[Abb.5] Die zweimalige Umesterungen beim Spleißen führt zur Entfernung des Introns und der Ligation der Exons (Lodish et al., 1995).

\subsection{Der Reaktionszyklus des Spleißens}

Die U snRNPs spielen die zentrale Rolle im Spleißzyklus (Tab.1). So werden von ihnen die Schnittstellen erkannt und die Grenzen von Introns und Exons festgelegt. Dafür ist ein komplexes Netzwerk wechselnder Interaktionen der snRNPs untereinander und mit der prä-mRNA in einer definierten Reihenfolge notwendig. Diese Interaktionen werden meist in Form von Basenpaarungen der RNAs oder durch Protein-RNA Wechselwirkungen zwischen den beteiligten Komponenten verwirklicht. Acht ATP-abhängige DExD/H-Box RNA-Helikasen (1.5, Tab.2) werden benötigt, um den Zyklus anzutreiben. Sie induzieren die strukturellen Umordnungen von RNA-RNA- und Protein-RNA Interaktionen während des Spleißens von prä-mRNA (Madhani et al., 1994; Ares et al., 1995; Nilsen, 1998; Staley et al., 1998; Brow, 2002). ATP wird ausschließlich für die Umlagerungen verbraucht, nicht für die Umesterungsreaktionen. 


\begin{tabular}{cl} 
U snRNP & Funktion \\
\hline U1 & 5'-Schnittstellen Erkennung \\
U2 & Bildung des katalytischen Zentrums mit U6, branchpoint Erkennung \\
U4 & Chaperon für U6 \\
U5 & 5'-und 3'-Schnittstellen Erkennung \\
U6 & Bildung des katalytisches Zentrums mit U2
\end{tabular}

[Tab.1] Übersicht der Funktionen der U snRNPs während des Spleißzyklus

Die Assemblierung des Spleißosoms (Abb.6) wird durch die Bindung des U1 snRNPs an die 5'Schnittstelle der prä-mRNA initiiert. Dieser Schritt ist ATP-unabhängig und geschieht durch RNA-Basenpaarung der U1 RNA mit der Sequenz der Schnittstelle (Seraphin et al., 1989). Sie bilden den E-Komplex (Du et al., 2001, 2002). Die branchpoint Sequenz wird erst durch das branchpoint-bindende Protein (BBP) erkannt (Berglund et al., 1997) und im darauf folgenden Schritt bindet das U2 snRNP am branchpoint innerhalb des Introns und ersetzt das BBP (Das et al., 2000). Die notwendige Aktivierung der U2 RNA geschieht durch eine intramolekulare Umordnung, die in einer Konformationsänderung resultiert (Zavanelli et al., 1994). Die Bindung des U2 snRNPs an den branchpoint benötigt ATP. Zwei DExD/H-Box Helikasen, UAP56 und Prp5 sind daran beteiligt. U2 interagiert mit U1 und der prä-mRNA und formt den präspleißosomalen Komplex A (Makarov et al. 2002; Hartmuth et al., 2002).

Das bereits zuvor assemblierte tri-snRNP U4/U5/U6 wird anschließend in diesen Komplex integriert und bildet kurzzeitig den penta-snRNP Komplex (Komplex B) (Stevens et al., 2002; Malca et al., 2003), dessen Existenz jedoch bisher noch nicht vollständig bewiesen ist. Anschließend wird dieser Komplex B in das aktive Spleißosom, den Komplex B*, umgewandelt (Pikielny et al., 1986; Konarska et al., 1987; Cheng et al., 1987). Die U6 RNA interagiert dabei mit der 5'-Schnittstelle und verdrängt U1, das vor der ersten Katalyse aus dem Komplex verdrängt wird (Tarn et al., 1994; Lesser et al., 1993). Dieser Prozess wird durch die integrale DExD/H-Box Helikase Prp28 hervorgerufen (Staley et al., 1998). U6 ist im tri-snRNP mit U4 über zwei stabile RNA-Helices verbunden, wird aber durch einige Umlagerungen während der Bindung von U6 an die prä-mRNA abgelöst und verlässt das Spleißosom (Yean et al., 1991; Kim et al., 1996). Für die Trennung der Basenpaarungen von U4 und U6 ist die integrale DExD/H-Box Helikase Brr2 essentiell (Kim et al., 1999; Laggerbauer et al., 1998; Raghunathan et al., 1998). Im nun aktiven Spleißosom interagiert U6 mit der für die erste Umesterung wichtigen 5'Schnittstelle und U2 bindet am branchpoint. Eine weitere essentielle ATP-abhängige DExD/HBox Helikase, Prp2, ordnet den Komplex vor dem ersten katalytischen Schritt nochmals um (Cheng et al., 1987; Yean et al., 1991). 
Die für die Katalyse notwendigen Nukleotide befinden sich nun in unmittelbarer Nähe zueinander, da die prä-mRNA durch die Umlagerung des Spleißosoms verbogen wird (King et al., 1990; Kim et al., 1993; Plumpton et al., 1994). Das aktive Spleißosom, bestehend aus U2/U5/U6 und der prä-mRNA, katalysiert nun die erste Umesterung (Madhani et al., 1992; Übersicht in Brow, 2002). Nach der ersten Umesterung findet eine weitere Umordnung im Spleißosom statt und Komplex C wird generiert, damit die 3'-Schnittstelle und die 5'-Schnittstelle dicht genug für die Ausbildung einer Phosphodiesterbindung zusammen liegen (Übersicht in Staley et al., 1998). Der Zusammenhalt der beiden Schnittstellen erfolgt dabei vermutlich über die gleichzeitige Interaktion mit einer Schleife der U5 snRNA (Stevens et al., 2002), woran die DExD/H-Box Helikase Prp16 ist beteiligt ist (Schwer et al., 1991; Kim et al., 1996). Nach dieser Umlagerung wird die zweite Umesterung katalysiert.

Abschließend wird der post-spleißosomale Komplex aufgelöst und die einzelnen U snRNPs werden für weitere Spleißzyklen regeneriert. Die DExD/H-Box Helikase Prp22 löst dabei die Interaktionen zwischen der mRNA und dem Spleißosom (Schwer et al., 1998; Wagner et al., 1998). Die reife mRNA wird nun freigesetzt. Im letzten Schritt löst Prp43 das Intron als Lariat vom Spleißosom ab (Arenas et al., 1997; Martin et al., 2002) und der Komplex zerfällt in die U snRNPs, die in einen neuen Zyklus eintreten können. Das Lariat wird anschließend abgebaut. Die reife mRNA wird dann aus dem Zellkern transportiert und kann an den Ribosomen translatiert werden (Übersicht in Jurica et al., 2003).

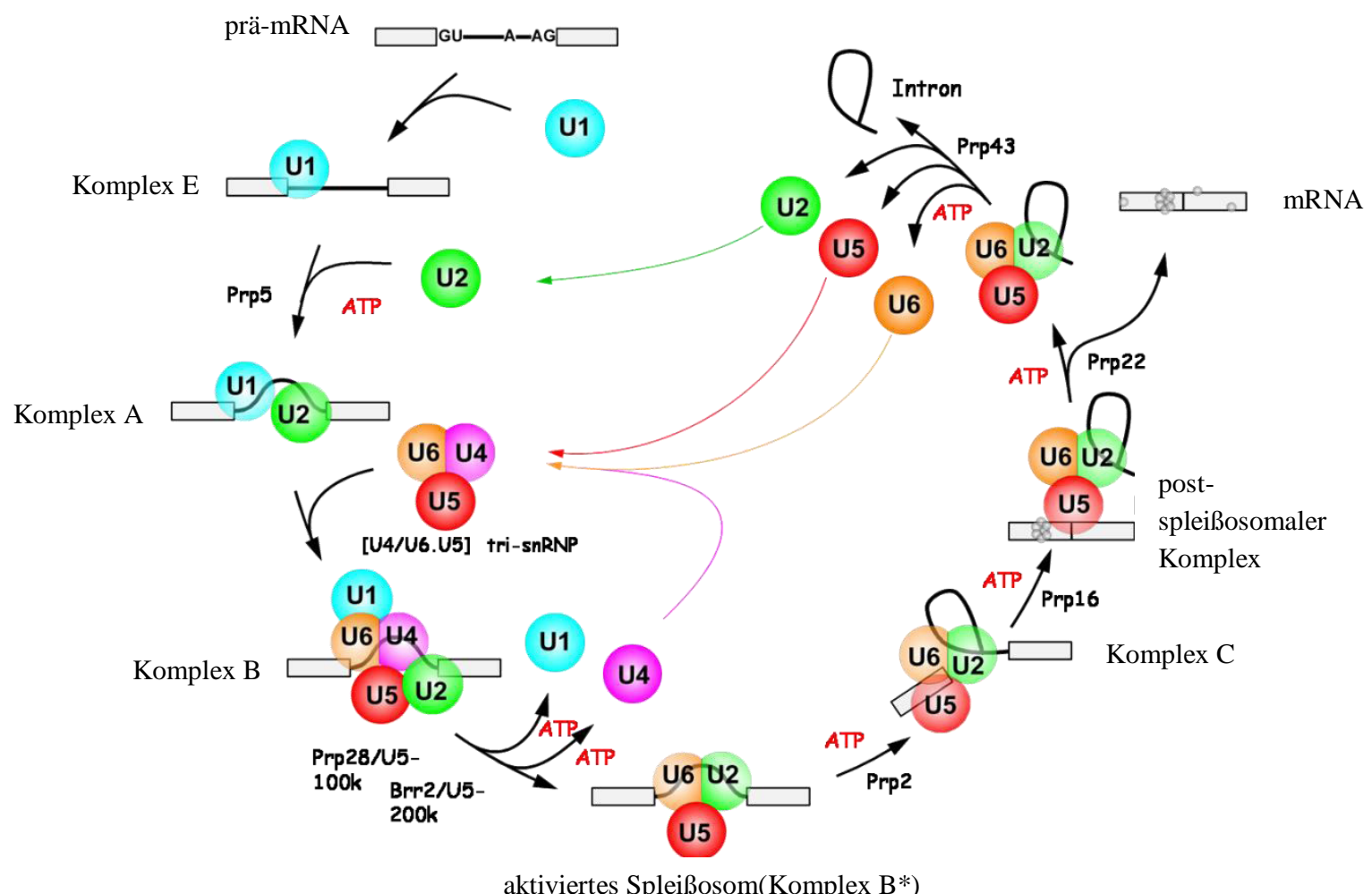

[Abb.6] Der Spleißzyklus. Assemblierung der spleißosomalen Untereinheiten U1, U2, U4, U5 und U6 an ein Intron und Freisetzung der mRNA, des gespleißten Introns-Lariats und der Untereinheiten unter Mitwirkung der DExD/H-Box RNAHelikasen (nach Lührmann, 2005). 


\subsection{DExD/H-Box RNA-Helikasen}

Wie beschrieben, benötigt die eigentliche Spleißreaktion keine zusätzliche Energie. Zur Ausbildung oder Auflösung von RNA-RNA oder Protein-RNA Interaktionen zwischen U snRNPs und/oder der mRNA wird jedoch Energie benötigt. Für diese Umlagerungsprozesse sind DExD/H-Box RNA-Helikasen notwendig. Betrachtet man die RNA-Umordnungen genauer, ähnelt die Strategie des Spleißosoms einer allosterischen Kaskade. Die frühen Erkennungsschritte (U1 snRNP an der 5'-Schnittstelle) lösen Konformationsänderungen aus, die für darauf folgende Erkennungsschritte notwendig sind (U4/U5/U6 snRNPs bindet an die prä-mRNA). Diese wiederum sind Voraussetzung für die katalytische Aktivität des Spleißosoms. Die Katalyse wird also nur erreicht, wenn das Intron die richtigen Merkmale besitzt und in die richtige Position gebracht wird. Die DExD/H-Box RNA-Helikasen liefern durch ATP-Hydrolyse die Energie für die notwendigen Konformationsänderungen. Proteine dieses Typs besitzen konservierte Aminosäuremotive (Abb.7), die für RNA-Interaktionen und ATP-Hydrolyse notwendig sind. Sind diese Motive in räumlicher Nähe zueinander, können die Helikasen doppelsträngige RNARegionen (dsRNA) unter ATP-Verbrauch entwinden (Silverman et al., 2003).

Das zentrale DExD/H Aminosäuremotiv, welches auch als Walker II Motiv bezeichnet wird, ist für die ATPase-Aktivität essentiell und namensgebend für diese Proteinklasse. Des Weiteren sind auch die Motive I (Walker I Motiv) und VI für die ATP-Hydrolyse essentiell. Die Aminosäuremotive Ia und V sind an der Bindung der prä-mRNA oder snRNA beteiligt, während die Motive Ib, III und IV für intramolekulare Interaktionen essentiell sind.

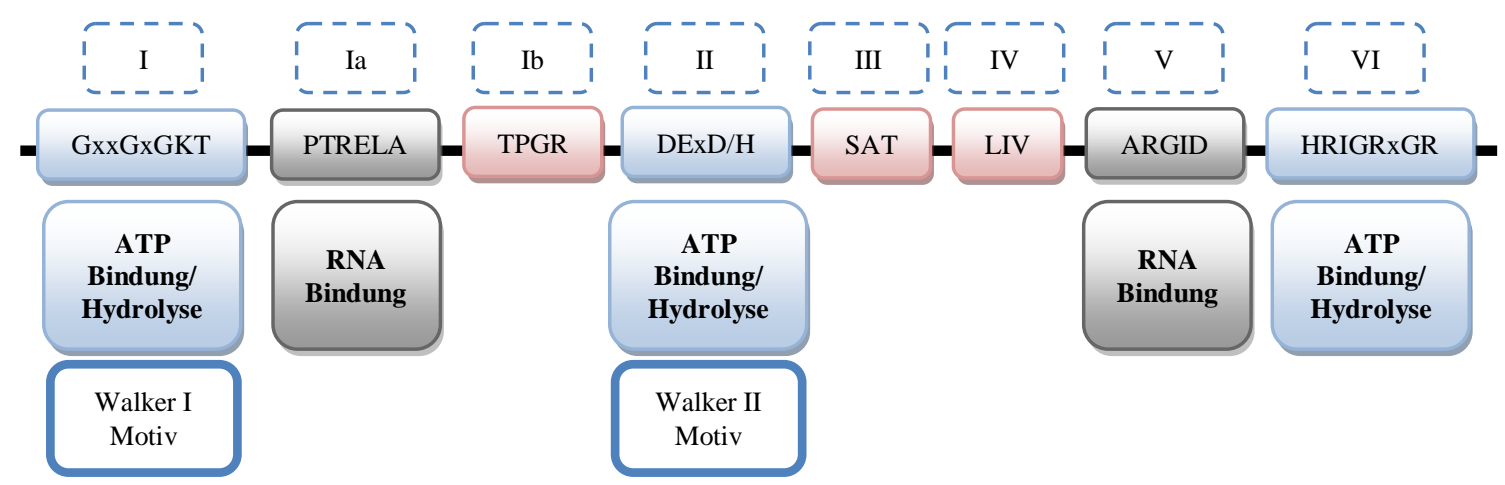

[Abb.7] Die 7 konservierten Aminosäuremotive von DExD/H-Box RNA-Helikasen. Die Motive I, II und VI sind essentiell für die ATP-Hydrolyse, Motiv Ia und V sind an der RNA-Interaktion beteiligt und Motiv Ib, III und IV sind für intramolekulare Interaktionen notwendig (nach Linder, 2003).

Acht verschiedene DExD/H-Box RNA-Helikasen sind am Spleißen beteiligt (Tab.2). Sie erkennen verschiedene Substrate und erfüllen somit spezifische Funktionen, die zur zielgerichteten Umordnungen des Spleißosoms führen. Trotzdessen katalysieren sie die gleiche Reaktion. Die strukturelle Organisation der Motive (Abb.7) in der Tertiärstruktur des Proteins ist entscheidend für das Verständnis ihrer Interaktion und katalytischen Funktion. 


\begin{tabular}{lll} 
DExD/H-Box Protein & Helikasemotiv & Putative Funktion \\
\hline UAP56 & DECD & U2 Addition \\
hPrp5 & DEAD & U2 Addition \\
hPrp28 (U5-100k) & DEAD & tri-snRNP Addition \\
Brr2 (U5-200k) & DEIH & Entwinden von U4/U6 \\
hPrp2 (DBP2) & DEAH & Katalytische Aktivierung \\
hPrp16 & DEAH & Umordnung für zweite Umesterung \\
hPrp22 (HRH1) & DEAH & mRNA Freisetzung \\
hPrp43 (mDEAH9) & DEAH & Lariat Freisetzung
\end{tabular}

[Tab.2] Spleißosomale DExD/H-Box RNA-Helikasen und ihre möglichen Funktion

Es wurden bereits Strukturen unterschiedlicher DExD/H-Box Helikasen der SF II publiziert, darunter Kristallstrukturen von: dem DNA-Reparaturenzym UvrB (Theis et al., 1999), der Helikase NS3 aus dem Hepatitis C Virus (Yao et al., 1997; Kim et al., 1998), dem funktionell unbeschriebenen MjDEAD aus Methanococcus jannashii (Story et al., 2001), dem humanen Spleißfaktor UAP56 (Shi et al., 2004), dem Translations-Initiationsfaktor eIF4A aus Saccharomyces cerevisiae (Caruthers et al., 2000), dem funktionell unbeschriebenen BstDEAD aus Bacillus stearothermophilus (Carmel et al., 2004), der RNA-Helikase Vasa aus Drosophila melanogaster (Sengoku et al., 2006) und dem am mRNA decapping beteiligten Enzym Dhh1p aus Saccharomyces cerevisiae (Cheng et al., 2005). Von all diesen Proteinen wurde im Wesentlichen nur die Helikasedomäne kristallisiert, während N- und C-terminale Erweiterungen fehlen. Einigen der Strukturen wurden mit gebundener RNA oder ATP gelöst (Übersicht in Cordin et al., 2006).

Bei allen Kristallstrukturen der SF II RNA-Helikasen ist klar erkennbar, dass die Helikasedomäne aus zwei kovalent verbundenen, globulären Subdomänen besteht, die jeweils aus fünf GFaltblättern aufgebaut sind, die von 5 V-Helices umgeben sind (Abb.8).
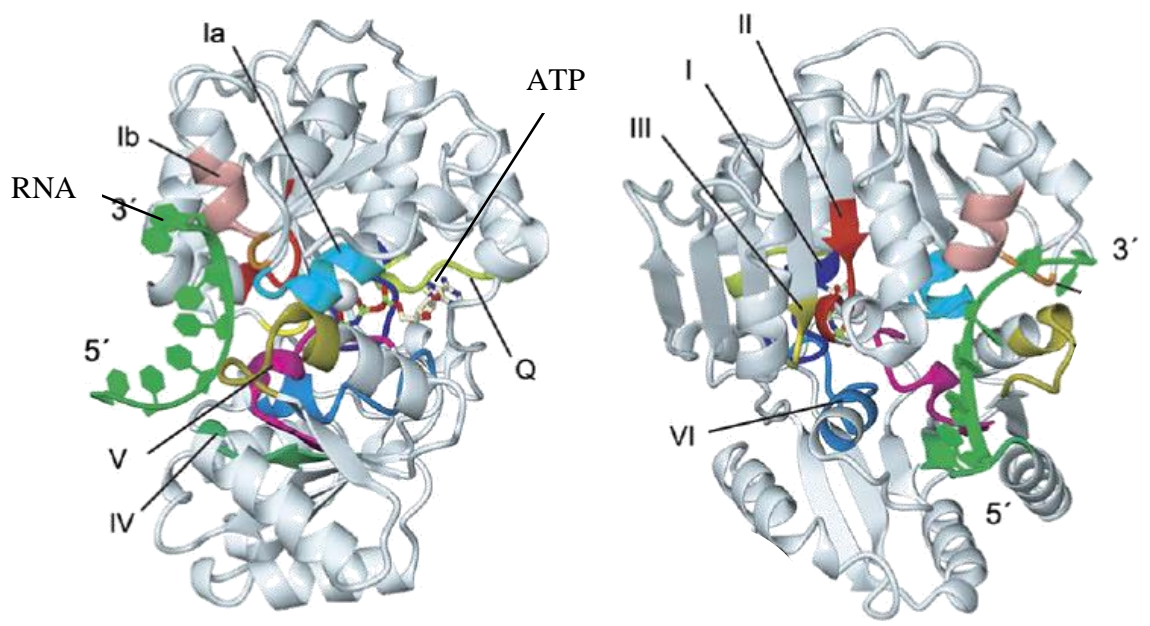

[Abb.8] Räumliche Orientierung der Helikasemotive (eingefärbt) von Vasa. Struktur mit gebunden RNA und ATP. Alle Motive sind in unmittelbarer Nähe zueinander, woraus die katalytische Aktivität resultiert (Sengoku et al., 2006). 
Die Anordnung der Strukturmotive entspricht der einer RecA ATPase (Cordin et al., 2006). Die Domänen 1 und 2 von Vasa bilden den Helikasekern und sind durch einen Spalt voneinander getrennt. Dort ist das ATP gebunden (Abb.8). Die sieben konservierten Motive der Helikasedomäne liegen im Innenraum dieser Spalte. Das Enzym ist katalytisch aktiv und hydrolysiert ATP. Die ATP-bindenden Motive befinden sich oberhalb des Zentrums des Proteins (ATP-Bindungstasche) (Sengoku et al., 2006). Die RNA-Bindungsmotive liegen im unteren Bereich des Proteins. Eine Überlagerung mehrerer Strukturen unterschiedlicher DEAD-Box Helikasen (Abb.9) zeigt, dass sich die Abstände und die Orientierungen der Domänen und einzelnen Motive zueinander deutlich unterscheiden können. Diese Mobilität zueinander hat direkten Einfluss auf die katalytische Aktivität. Ist der relative Abstand der Subdomänen zueinander zu groß, geht die Aktivität verloren. Vasa hat die kompakteste Orientierung der Subdomänen zueinander, während eIF4A die gestreckteste Konformation aufweist und somit katalytisch inaktiv ist. Diese Flexibilität der Subdomänen zueinander kann durch andere Proteine genutzt werden, um die Aktivität der RNA-Helikase zu steuern. Beispiel für diese Art der Regulation ist der exon junction complex (EJC), bei dem Mago und Y14 die Konformation der RNA-Helikase eIF4AIII von einer gestreckten in eine geschlossene Form konvertieren und so die Aktivität des Proteins induzieren (Bono et al., 2006).
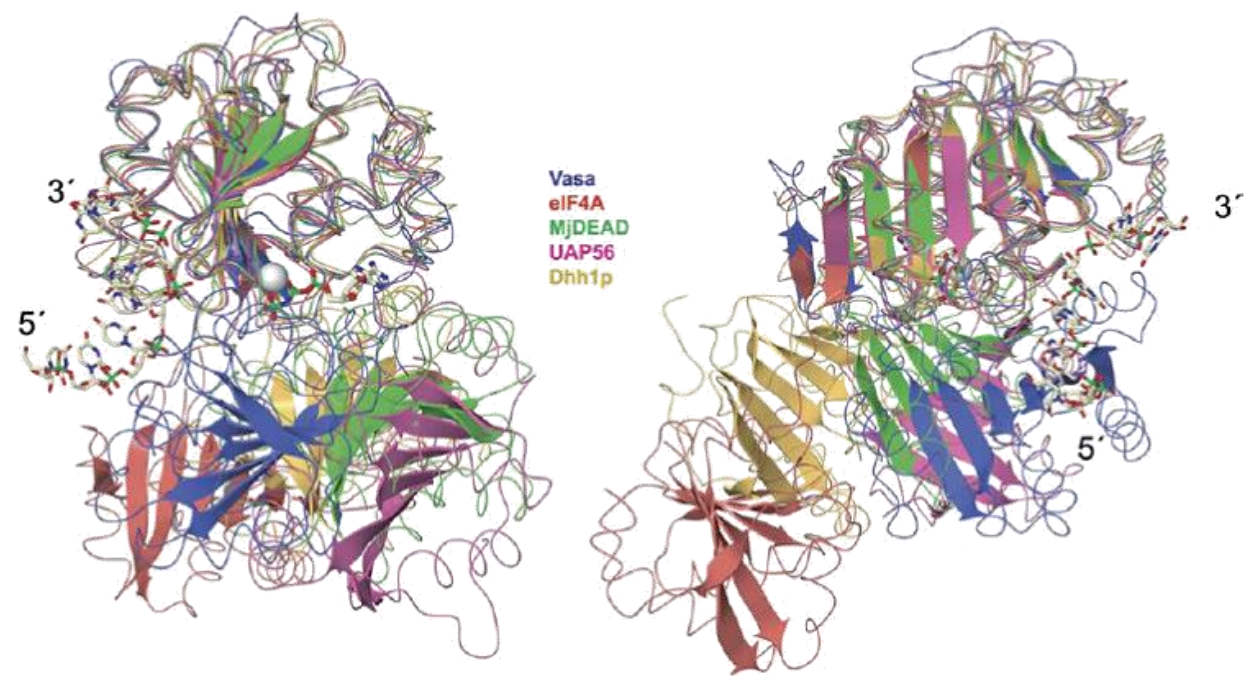

[Abb.9] Überlagerung der Strukturen von Vasa, eIF4A, MjDEAD, UAP56 und Dhh1p. Alle Proteine wurden nach der 1. Helikase-Subdomäne ausgerichtet. In gestreckter Form (eIF4A) sind die Proteine inaktiv, geschlossen (Vasa) sind sie aktiv. Mischformen (UAP56) weisen teilweise reduzierte ATPase-Aktivität auf. (Sengoku et al., 2006)

Die Helikasedomomänen zeigen bei allen DExD/H-Box Proteinen große Homologien, jedoch können sich die flankierenden $\mathrm{N}$-und C-terminalen Regionen stark in Länge und Sequenz unterscheiden. Sie dienen wahrscheinlich der Interaktion mit Substraten oder Kofaktoren, stabilisieren die jeweilige Konformation oder sie zeigen zusätzliche enzymatische Aktivitäten. 
Wie erwähnt besitzen zahlreiche RNA-Helikasen der DExD/H-Box Protein-Familie eine ATPaseAktivität. Sie ist teilweise von Einzelstrang-RNA (ssRNA) abhängig oder wird durch ssRNA stimuliert. In vitro ist die RNA-Spezifität gering. Es gibt nur eine Unterscheidung, ob es sich beim Substrat um RNA oder DNA handelt (Tanner et al., 2001; Rocak et al., 2004; Cordin et al., 2006). Die ATPase-Aktivität kann in einigen Fällen stark durch spezifische RNA-Sequenzen oder Strukturen gesteigert werden, die möglicherweise außerhalb der Helikasedomäne gebunden wird (Cordin et al., 2006). In vivo, beim Spleißen, wurde jedoch eine starke Substratspezifität beobachtet. Während des Spleißens befinden sind die Helikasen mit vielen anderen Proteinen und RNAs Teil eines großen Komplexes. Einige dieser Proteine binden an die Helikasen und erhöhen die Affinität für ein spezifisches Substrat (Tanner et al., 2001).

Einige RNA-Helikasen können dsRNA unter ATP-Verbrauch entwinden (Rogers et al., 2001; Bizebard et al., 2004). Es wurden unterschiedliche Direktionalitäten, entweder in 5'-3'oder 3'-5'Richtung, beschrieben. DEAD-Box RNA-Helikasen haben jedoch keine Richtungsspezifität beim Entwinden dsRNA (Cordin et al., 2006). Es werden 8-10 Basenpaare der RNA-Helix von der RNA-Helikasedomäne gebunden (Tanner et al., 2001) und vermutlich 5-6 bp in einem Schritt entwunden (Rogers et al., 1999). RNA-Helikasen haben im Vergleich zu DNA-Helikasen eine sehr viel geringere Prozessivität. Weiterhin gibt es Hinweise darauf, dass RNA-Helikasen nicht nur RNA-Doppelstränge trennen, sondern auch Protein-RNA-Interaktionen lösen können (Tanner et al., 2001). Der genaue Ablauf der Trennung von RNA-RNA- oder Protein-RNA-Interaktionen ist noch nicht geklärt.

Es gibt verschiedene Modelle, die den Reaktionsablauf des Entwindens von dsRNA zu erklären versuchen (Soultanas et al., 2000, 2001, Tanner et al., 2001; Caruthers et al., 2002; Rocak et al., 2004; Tuteja et al., 2004). Anerkannte Modelle sind das inchworm Modell (engl. für Spannerraupe) und das active rolling Modell. Das active rolling Modell setzt ein Helikase-Dimer voraus, während das inchworm Modell auch mit monomeren RNA-Helikasen funktionell ist. Im active rolling Modell liegen die Helikase-Dimere in unterschiedlichen Konformationen vor. Eine Konformation hat eine hohe Affinität zu Einzelstrang-RNA, während die andere Konformation an dsRNA bindet. Bindung und Hydrolyse von ATP führen jeweils zu einer Konformationsänderung der einzelnen Moleküle. Das Helikase-Dimer bewegt sich an der RNA entlang und entwindet doppelsträngige Regionen.

Beim inchworm Modell ändert sich die Konformation der Helikase durch Bindung und Hydrolyse von ATP. Die beiden Helikase-Subdomänen bewegen sich aufeinander zu oder voneinander weg. Die Subdomänen müssten sich abwechselnd kurz von der RNA lösen und an einer neuen Position binden (Tanner et al., 2001; Cordin et al., 2006). Dabei wird die dsRNA entwunden. Voraussetzung beider Modelle ist eine Konformationsänderung des Monomers oder Dimers. Die Modelle stimmen mit verschiedenen experimentellen Beobachtungen überein, aber keines der 
beiden genügt zur vollständigen Erklärung. Biochemische und strukturelle Analysen haben gezeigt, dass die Proteine während der ATP-Bindung und -Hydrolyse tatsächlich verschiedene Konformationen einnehmen können. Diese werden durch Bindung von ATP und RNA kontrolliert (Übersicht in Cordin et al., 2006). Die Induktion der Aktivität und Regulation der DExD/H-Box RNA-Helikasen wurden noch nicht näher beschrieben. Die Aufklärung der Proteinstrukturen mit und ohne gebundene Substrate oder Nukleotide, in verschiedenen Stadien der Katalyse, spielt eine wichtige Rolle zur Verbesserung des Verständnisses der Funktionsweise dieser Proteine.

\subsection{Die DEAH-Box RNA-Helikasen hPRP2 und hPRP22}

Funktionelle Untersuchungen der DExD/H-Box RNA-Helikasen wurden bisher ausschließlich am Modellorganismus Saccharomyces cerevisiae durchgeführt. Daten der homologen und funktionell äquivalenten Helikasen aus Homo sapiens existieren noch nicht. Die folgenden Funktionsbeschreibungen basieren auf den biochemischen Charakterisierungen in Bäckerhefe. Das Protein hPrp2 (accession number: NP_003578, Swissprot: spO60231, DHX16, DBP2) aus Homo sapiens ist eine DEAH-Box RNA-Helikase (Imamura et al., 1998), die für den ersten Umesterungsschritt beim Spleißen von prä-mRNA notwendig ist (Kim et al., 1996) (1.4). Die Helikase besteht aus 1041 Aminosäuren, hat ein Molekulargewicht von 119,2 kDa und einen theoretischen isoelektrischen Punkt von 6,31.

Auch das Protein hPrp22 (accession number: NP_004932, Swissprot: spQ14562, DHX8, HRH1) ist eine DEAH-Box RNA-Helikase (Ono et al., 1994; Ohno et al., 1996). Sie ist an der Ablösung der reifen mRNA vom Spleißosom beteiligt (Schwer et al., 1998; Wagner et al., 1998) (1.4). Die Helikase hat eine Länge von 1220 Aminosäuren, ein Molekulargewicht von 139,3 kDa und ihr theoretischer isoelektrischer Punkt liegt bei 8,54. Beide Proteine besitzen einen sehr ähnlichen modularen Aufbau (Abb.10) und haben, speziell am C-Terminus, hohe Sequenzhomologien (Abb.30). Ihre Funktionen, das Aufbrechen von RNA-RNA-Interaktionen, sind ähnlich, jedoch sind ihre Substrate, Aktivitäten und Eintrittszeitpunkte in den Spleißzyklus unterschiedlich. Beide Helikasen haben am N-Terminus ( ab AS 170) eine Lys $s_{4}$-Kernimporterkennungssequenz (NLS) und am C-Terminus 4 homologe Domänen (Abb.10), eine DEXDc- (DEXH-box delicates), eine HELICc (helicase superfamily c-terminal domain), eine HA2 (helicase associated domain) und eine DUF1605-Domäne (domain of unknown function). Sie sind sehr ähnlich angeordnet. Ein solcher, gut konservierter C-Terminus findet sich auch bei den spleißosomalen DEAH-Box Helikasen Prp16 und Prp43. Die DEXDc - und die HELICc-Domäne bilden bei beiden Proteinen die zentralen Helikasedomäne. Die 7 typischen Sequenzmotive für ATPase-Aktivität und RNABindung (1.5) sind auf diesen beiden Subdomänen verteilt. HA2 und DUF1605 sind weder funktionell, noch strukturell untersucht. Prp2 und Prp22 unterscheiden sich stark am N-Terminus. 
Während Prp2 keine weiteren Strukturmotive aufweist, sind bei Prp22 noch eine RS-Domäne (AS 180-230) und eine S1-Domäne (AS 260-350) lokalisiert. RS-Domänen, die gehäuft über ArgininSerin Motive verfügen, können phosphoryliert werden und so direkten Einfluss auf die Aktivität des Proteins oder Interaktion mir anderen Proteinen nehmen. S1-Domänen (ribosomal protein S1like RNA-binding domain) können Oligonukleotide, wie RNA, binden (OB-fold, CSD). Die Struktur einer homologen Domänen der RNase E wurde bereits aufgeklärt (Schubert et al., 2004).

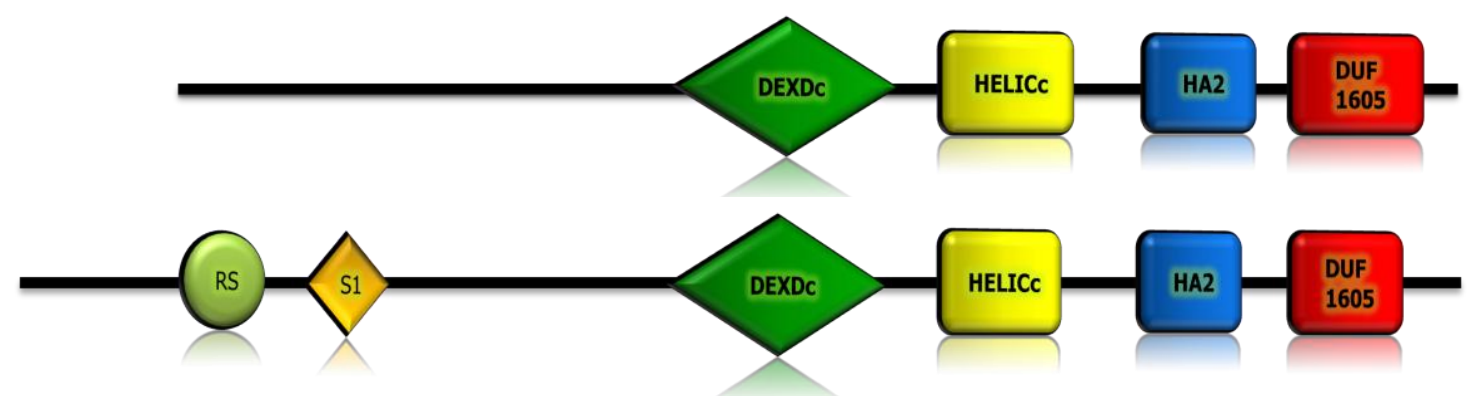

[Abb.10] Voraussage der Domänenanordnung von Prp2 (oben) und Prp22 (unten) (smart.embl-heidelberg.de).

Prp2 ist essentiell für den ersten Umesterungsschritt im Spleißzyklus. Die genaue Funktion ist aber noch nicht völlig geklärt (Lustig et al., 1986; King et al., 1990; Kim et al., 1993; Plumpton et al., 1994). Auch das Substrat und die RNA-Erkennungssequenz von Prp2 im Spleißosom sind bisher noch nicht beschrieben. Es gibt Hinweise, dass es eine Bindung an die prä-mRNA gibt (Teigelkamp et al., 1994). Das Protein bindet an das Spleißosom in Anwesenheit von ATP und wird nach dessen Hydrolyse wieder freigesetzt (Edwalds-Gilbert et al., 2000). Prp2 zeigt in vitro eine RNA-abhängige NTPase-Aktivität (Kim et al., 1992). Dabei wird ATP, als auch dATP im gleichen Maße hydrolysiert. Die Hydrolyseaktivität für GTP, CTP und UTP liegt zwischen 30\% und 70\% (Kim et al., 1993). Die Stimulation der NTPase Aktivität von Prp2 erfolgt durch Poly-U, Poly-A oder Poly-C RNA-Oligomere. Gereinigtes Prp2 zeigt in vitro keine Helikaseaktivität an dsRNA. Wahrscheinlich müssen weitere Proteine mit Prp2 interagieren, um zu einem bestimmten Zeitpunkt während des Spleißens Helikaseaktivität zu induzieren. Es wurde weiterhin festgestellt, dass neben der DEAH-Box Helikasedomäne auch der C-Terminus die Aktivität des Proteins während des Spleißens beeinflusst. Hefezellen mit Deletionen im C-Terminus waren nicht lebensfähig (Edwalds-Gilbert et al., 2000, 2004). Wahrscheinlich vermittelt der C-Terminus die Bindung an das Spleißosom. Das Fehlen des N-Terminus hat offenbar keine Auswirkungen auf die Aktivität von Prp2.

Prp22 ist ein essentielles Protein (Schwer et al., 2000). Wie erwähnt, spielt es eine wichtige Rolle während der zweiten Umesterung und katalysiert das Ablösen der reifen mRNA vom Spleißosom (Company et al., 1991). Dabei werden Basenpaarungen zwischen der U5 snRNA und der gespleißten mRNA entwunden. Die Erkennungssequenz ist jedoch noch nicht untersucht worden. Das Protein zeigt in vitro ATPase-Aktivität, die durch RNA (Poly-A) stimuliert wird und kann 
dsRNA entwinden (Schwer et al., 1998). Prp22 führt auch eine Lesekorrektur der Exon-Ligation durch. Das Protein prüft, ob die Verknüpfung der genetischen Information korrekt ist, um unerwünschte oder gar schädliche Zwischenprodukte der mRNA zu vermeiden (Mayas et al., 2006). Wie bei Prp2, hat auch bei Prp22 eine Verkürzung des N-Terminus keinen Einfluss auf die Aktivität (Schneider et al., 2001). Das Fehlen des C-Terminus führt zu einem Verlust an der ATPase-Aktivität und reduziert die RNA-Bindungskapazität (Tanaka et al., 2005).

\subsection{Zielsetzung}

Das Ziel dieser Arbeit bestand in der strukturellen und funktionellen Charakterisierung der DEAH-Box RNA-Helikasen hPrp2 und hPrp22 aus Homo sapiens. Es sollten Erkenntnisse über ihre dreidimensionalen Strukturen, Funktionsweisen, Aktivitäten und mögliche Interaktionen sollten gewonnen werden. Die Klonierung der Gene, Etablierung reproduzierbarer Expressionssysteme und die Generierung geeigneter Reinigungsprotokolle, um das Volllängenprotein und verkürzte Formen hochrein und in ausreichender Menge zu gewinnen, waren dazu notwendig. Dies war eine Voraussetzung für die Kristallisation und anschließende röntgenkristallographische Strukturaufklärung der Proteine. Mit Hilfe der Strukturen der Proteine können ihre Funktionsweisen im Spleißprozeß und Interaktionen mit anderen Proteinen genauer untersucht werden.

Da die Proteine eine ähnliche modulare Domänenanordnung besitzen, lagen weitere Schwerpunkte der Arbeit auf der Analyse verschiedener Fragmente der Proteine. Unterschiedlichste Verkürzungen mussten generiert und spezifische Reinigungsprotokolle entwickelt werden. Die Strukturen dieser Domänen sollten aufgeklärt und miteinander oder mit homologen Domänen, soweit verfügbar, verglichen werden. Zentrales Augenmerk lag dabei auf der Strukturaufklärung des C-Terminus der Proteine, da weder Faltung noch Funktion bekannt waren.

Des Weiteren sollte ein nicht-radioaktiver, reproduzierbarer ATPase-Test entwickelt werden, um biochemische Erkenntnisse über unterschiedliche Fragmente zu gewinnen. 


\section{Material und Methoden}

\subsection{Material}

\subsubsection{Großgeräte}

ABIPrism 3100 DNA Sequencer

Agarose Gelelektrophoresekammer

Äkta Prime \& Purifier

Binokulare

Frac900 Fraktionierer

Geldokumentationsgerät GelDoc

Inkubationsschrank Mytron

Microfluidizer 110 S

PCR Thermocycler

pH-Meter

Photometer

Röntgendiffraktometer Micromax 007

Röntgendiffraktometer $R U-H 3 R$

Röntgendetektor mar345

Rotoren JA-20, JA-30.50 Ti, JLA-8.1000

SDS-PAGE Elektrophoresekammer

Spektrofotometer Ultrospec 2100

Synchrotron Strahlrohre BL14.1, BL14.2

Synchrotron Strahlrohre BW7A, BW7B, X11

Taumelrollenmischer RM5

Thermomixer Comfort

Unitron Schüttelinkubatoren

Vortexer

Zentrifugen

Tischzentrifuge $5415 R$

Tischzentrifuge Allegra 21R

Ultrazentrifuge $J$-30 I

Vakuumzentrifuge Speedvac 5301

Zentrifuge $J$-20 XPI
Applied Biosystems, Darmstadt

BioRad, München

GE Healthcare, München

Leica, Solms

GE Healthcare, München

BioRad, München

Schütt, Göttingen

Microfluidics, USA

Biometra, Göttingen

Beckman Coulter, Krefeld

Eppendorf, Hamburg

Rigaku/MSC, Japan

Rigaku/MSC, Japan

Marresearch, Norderstedt

Beckman Coulter, Krefeld

GE Healthcare, München

GE Healthcare, München

BESSY, Berlin

DESY, Hamburg

Schütt, Göttingen

Eppendorf, Hamburg

Infors, Einsbach

Schütt, Göttingen

Eppendorf, Hamburg

Beckman Coulter, Krefeld

Beckman Coulter, Krefeld

Eppendorf, Hamburg

Beckman Coulter, Krefeld 


\subsubsection{Chromatographiesäulen}

Strep-Tactin-Sepharose XK 16/20

GSH-Sepharose FF XK 16/20

HiPrep Desalting 26/10

HisTrap Ni-NTA-Sepharose 5ml

Superdex 75 10/300 GL

Superdex 75 XK 16/60

Superdex 75 XK 26/60

Superdex 200 10/300 GL

Superdex 200 XK 16/60

Superdex 200 XK 26/60
IBA, Göttingen

GE Healthcare, München

GE Healthcare, München

GE Healthcare, München

GE Healthcare, München

GE Healthcare, München

GE Healthcare, München

GE Healthcare, München

GE Healthcare, München

GE Healthcare, München

\subsubsection{Feinchemikalien}

Alle verwendeten Feinchemikalien wurden von den Firmen Applichem (Darmstadt), BioRad (München), Fluka (Buchs), Merck (Darmstadt), Mettler-Toledo (Steinbach), Oxoid (Basingstoke, GB), Roth (Karlsruhe) oder Sigma-Aldrich (Steinheim) bezogen und besitzen den Reinheitsgrad pro analysis. Dabei wurde in der Regel der günstigste Anbieter gewählt.

\subsubsection{Kitsysteme}

Big Dye Terminator v1.1 Mix

Nucleospin Extract

Nucleospin Plasmid

Qiagen Plasmid Maxi Kit

Qiagen Plasmid Mini Kit

Qiaquick Gel Extraction Kit

Qiaquick PCR Purification Kit
Applied Biosystems, Darmstadt

Macherey-Nagel, Düren

Macherey-Nagel, Düren

QIAGEN, Hilden

QIAGEN, Hilden

QIAGEN, Hilden

QIAGEN, Hilden

\subsubsection{Enzyme und Inhibitoren}

Aprotinin

Calf Intestine Alkaline Phosphatase (CIAP)

Leupeptin

Pepstatin

Pfu Turbo Polymerase

Phusion Polymerase

PreScission Protease
Applichem, Darmstadt

New England Biolabs, Frankfurt

Applichem, Darmstadt

Applichem, Darmstadt

Stratagene, USA

New England Biolabs, Frankfurt

GE Healthcare, München 
Protease Inhibitor Cocktail "EDTA free"

RestriktionsendoNukleasen

Taq Polymerase

T4-DNA-Ligase

\subsubsection{Zellstämme}

BL21

BL21 (DE3)

B834 (DE3)

HMS174 (DE3)

Rosetta (DE3)

Rosetta 2 (DE3)

XL1-Blue
Roche Diagnostics, Mannheim

Fermentas, St. Leon-Rot

New England Biolabs, Frankfurt

Fermentas, St. Leon-Rot
Stammsammlung der AG Ficner

\subsubsection{DNA-Oligonukleotide}

Die Oligonukleotide (Primer) wurden HPSF-gereinigt von MWG-Biotech (München), Purimex (Grebenstein) oder IBA (Göttingen) bezogen und gemäß den Herstellerangaben gelöst und eingesetzt. Die Berechnung der Schmelztemperaturen Tm für die verwendeten DNAOligonukleotide erfolgte gemäß der unten angegebenen Formel.

$\mathrm{Tm}=81,5+0,41(\% \mathrm{GC})-(675 / \mathrm{N}) \quad$ mit $\mathrm{N}=$ Anzahl der Nukleotide

\begin{tabular}{|l|l|c|}
\hline Primer hPRP22 & Sequenz $\mathbf{5} \rightarrow \mathbf{3}$, & $\begin{array}{c}\text { Tm } \\
{\left[{ }^{\circ} \mathbf{C}\right]}\end{array}$ \\
\hline H27F - BamHI & ATAGGATCCTACCTGTCTTTGGTGTCA & 63,4 \\
\hline H264F - BamHI & ATAGGATCCATTGGTGACATTTATAATGGC & 62,7 \\
\hline H564F - BamHI & ATAGGATCCAGCCTGCCCATCTACAA & 64,8 \\
\hline H782F - BamHI & ATAGGATCCGGTCAGGAAGAAATTGATAC & 63,9 \\
\hline H950F - BamHI & TATGGATCCCCTATGGAAACTTTGATCAC & 63,9 \\
\hline H1068F - BamHI & ATAGGATCCCAGGCTCGTTCCCTG & 66,1 \\
\hline H351R - XhoI & ATACTCGAGCCGTCTATTTGGGTTTAG & 63,4 \\
\hline H561R - XhoI & ATACTCGAGCTGCTCAAGGATTGACAT & 63,4 \\
\hline H750R - XhoI & ATACTCGAGCTTTGTGTACAGTATTTCCA & 62,4 \\
\hline H904R - XhoI & ATACTCGAGTGTGTACAACCTGTAACAC & 63,7 \\
\hline H1055R - XhoI & ATACTCGAGGTTGTTCTTCCAGGAGTT & 63,4 \\
\hline H1183R - XhoI & ATACTCGAGGACCTTGAAGAAGGCTG & 64,8 \\
\hline HRH1-Eco-F & TAGAATTCCGCTGTGGCTGTAGCCATGGCGGGAGCC & 76,3 \\
\hline
\end{tabular}




\begin{tabular}{|l|l|c|}
\hline HRH1-Not-R & TAGCGGCCGCGCGCCGTCGGAAAGCTCGAGATATT & 76,5 \\
\hline HRH-Eag & TACGGCCGGCTGTGGCTGTAGCCATGGCGGGA & 77,2 \\
\hline H1_BAMECOF_ATG & AAAGGATCCGAATTCATGGCTGTGGCTGTAGCC & 70,7 \\
\hline H1_NOTSAL_R & AAAGCGGCCGCGTCGACGCGCCGTCGGAAAGCTCG & 80,0 \\
\hline H1P21_HIND_R & ATTAAGCTTCCGTCGGAAAGCTCGAGATATTC & 66,9 \\
\hline H1P21_NOT_R & ATTGCGGCCGCCCGTCGGAAAGCTCGAGATATTC & 74,3 \\
\hline H1P21_SAL_R & ATTGTCGACCCCGTCGGAAAGCTCGAGATATTC & 70,7 \\
\hline H642P21_BAM_F & CCAGGATCCAATAAAGTGAAGTCTAGATATCG & 65,6 \\
\hline H642P22B_BAM_F & CAAGGATCCGAATAAAGTGAAGTCTAGATATCG & 65,8 \\
\hline H1P22B_BAM_F & AAAGGATCCGATGGCTGTGGCTGTAGCCATG & 70,8 \\
\hline $\begin{array}{l}\text { HRH1-1051-C } \\
\text { EcoRI_FOR }\end{array}$ & CCGAATTCACGGCGAAATCTTGTCGGGGAGACCAATGAGG & 75,6 \\
\hline $\begin{array}{l}\text { HRH1-2760-C } \\
\text { EcoRI_FOR }\end{array}$ & CCGAATTCGCAGAGAACCAACTTAGCAAGCACAGTGC & 72,8 \\
\hline $\begin{array}{l}\text { HRH1-N-1050 } \\
\text { NotI_REV }\end{array}$ & TGCGGCCGCCCCTAGCTCTTGCGGCCGCA & 78,0 \\
\hline HRH1-V EcoRI_FOR & GAATTCGCTGTGGCTGTAGCCATGGCGGGAGCCTTAATC & 75,8 \\
\hline $\begin{array}{l}\text { HRH1-V } \\
\text { NotI+Strep_REV }\end{array}$ & $\begin{array}{l}\text { GCGGCCGCTTATTTTTCGAACTGCGGGTGGCTCCATCCAATTCCGCG } \\
\text { CCGTCGGAAAGCTCGAGA }\end{array}$ & 83,9 \\
\hline $\begin{array}{l}\text { MU_HRH1_SE } \\
\text { MU_HRH1_ANSE }\end{array}$ & TGGTGCTATGAGAACTTTATCCAGGCTCGTTCCCTGCGCCGGG & 70,4 \\
\hline
\end{tabular}

\begin{tabular}{|l|l|c|}
\hline \multicolumn{2}{|l|}{ Sequenzierprimer hPRP22 } & Tm \\
{$\left[{ }^{\circ} \mathbf{C}\right]$} \\
\hline SP_HRH1_523 & GATCGAAACCGAGATCGAGA & 57,3 \\
\hline SP_HRH1_1020 & TCTAAACCCAAATAGACGGCG & 57,9 \\
\hline SP_HRH1_1524 & TGCCTGATGCGGAAGGCA & 58,2 \\
\hline SP_HRH1_2023 & CGCGATCATCATGTTGGAC & 56,7 \\
\hline SP_HRH1_2524 & TGACTATTGATGGTATCTACTATGT & 56,4 \\
\hline SP_H1_255r & CATGGTTTGTATGAGACGCAG & 57,9 \\
\hline
\end{tabular}

\begin{tabular}{|l|l|c|}
\hline Primer hPRP2 & Sequenz 5, $\rightarrow \mathbf{3}$, & $\begin{array}{c}\text { Tm } \\
{\left[{ }^{\circ} \mathbf{C}\right]}\end{array}$ \\
\hline D9F - EcoRI & ATAGAATTCCGCTGGGTTCAGGACGA & 64,8 \\
\hline D385F - EcoRI & ATAGAATTCCAGGCCCAGCAGAAAGA & 63,2 \\
\hline D617F - EcoRI & ATAGAATTCGGACAGGAGGAGATTGAG & 63,4 \\
\hline D785F - EcoRI & ATAGAATTCCCATATGAGACACTGCTG & 61,9 \\
\hline D905F - EcoRI & ATAGAATTCTTCAGATCGATGCGCCGA & 63,4 \\
\hline
\end{tabular}




\begin{tabular}{|l|l|c|}
\hline D371R - XhoI & TATCTCGAGGAGCTGAGTGGCCCGGA & 69,5 \\
\hline D585R - XhoI & ATACTCGAGCTTGGTGTAGAAGATGTC & 63,4 \\
\hline D745R - XhoI & ATACTCGAGGTGCTGATAGGCCCAGG & 68,0 \\
\hline D891R - XhoI & ATACTCGAGACTCTCAGCCCACTGTG & 66,4 \\
\hline D1019R-XhoI & ATACTCGAGCTTGGCCTTATAATAATGGG & 63,9 \\
\hline p22vhs_SacI_ff & AATACCGCGGTGCGACGCCGGCGGGTCTGGAGCGCT & 80,9 \\
\hline p22dhs_SacII_f & AATACCGCGGTGCCCAGCAGAAAGAGTCCATCCAGG & 75,2 \\
\hline p22vhs_SalI_r & CATAGTCGACCCCTAGCTCTTCTCGTGTTTTGCCTATTTTTTTG & 72,2 \\
\hline p22vhs_NcoI_r & CATGCCATGGCCCCCTAGCTCTTCTCGTGTTTTGCCTATTTTT & 74,2 \\
\hline p22vhs_SalI_r & ATTGTCGACCCCTAGCTCTTCTCGTGTTTTGCCTATTTTGGG & 73,3 \\
\hline p22vhs_SacII_f & ATTAAACCGCGGTGCGACGCCGGCGGGT & 73,9 \\
\hline p22dhs_SacII_f & GTCTCCGCGGTGCCCAGCAGAAAGAGTCCAT & 73,5 \\
\hline p22_1155_SalI_r & ATTGTCGACCTGAGTTGAAGTGGGTGGAGCTGACG & 73,0 \\
\hline D2_XBAECO_F_ATG & AAATCTAGATGAATTCATGGCGACGCCGGCGGGT & 71,9 \\
\hline DBP2-C NcoI_FOR & ACGTACCCATGGCCCAGCAGAAAGAGTCCATCCAGGCC & 77,0 \\
\hline DBP2-N SalI_REV & AAAAGTCGACAGCTCCACCCACTTCAAC & 66,6 \\
\hline DBP2-V EcoRI_REV & CGCGAATTCTTACCCTAGCTCTTCTCGTGTTTTGCC & 71,7 \\
\hline DBP2-V Esp3I_FOR & ACGTACCGTCTCCCATGGCGACGCCGGCGGGTCTGGAG & 81,3 \\
\hline DBP2-V KpnI_REV & ACGTACGGTACCTTACCCTAGCTCTTCTCGTGTTTTGCC & 73,7 \\
\hline DBP2-V SacII_FOR & AAAACCGCGGACGCCGGCGGGTCTGGAG & 75,4 \\
\hline DBP2-V-EcoRI_FOR & GAATTCGCGACGCCGGCGGGTCTGGAGCGCTGGGTTCAG & 81,0 \\
\hline DBP2-V-NotI+Strep_R & GCGGCCGCTTATTTTTCGAACTGCGGGTGGCTCCATCCAATTCCCCCT & 81,4 \\
\hline P2_NOT_R & AGCTCTTCTCGTGTTTT & 77,6 \\
\hline MU_DBP2_SE & ATGCTAAGAAAATGCCCAAAATAGGCAAAACACGAGAAGAGC & 70,4 \\
\hline MU_DBP2_ANSE & GCTCTTCTCGTGTTTTGCCTATTTTGGGCATTTTCTTAGCAT & 70,4 \\
\hline
\end{tabular}

\begin{tabular}{|l|l|c|}
\hline \multicolumn{2}{|l|}{ Sequenzierprimer hPRP2 } & Tm \\
\multicolumn{2}{|l|}{} & $\left.{ }^{\circ} \mathbf{C}\right]$ \\
\hline p22vhs_110_f & AGCCAGCTCGGGCAGCA & 60,0 \\
\hline p22vhs_220_f & GGGACAAGGATCGGACTC & 58,2 \\
\hline p22vhs_330_f & ACCACATGCCCAAGGAAA & 53,7 \\
\hline p22vhs_550_f & TGGTGGATGAGGCACACG & 58,2 \\
\hline p22vhs_660_f & TCCAGGATCCCTGCCGC & 60,0 \\
\hline p22vhs_770_f & ATACCGCCTGGGCCTATC & 58,2 \\
\hline p22vhs_880_f & CTGTCAACAACTCCATCT & 51,4 \\
\hline P22_0002_FOR & AAAACCGCGGACGCCGGCGGGTCTGGAG & 75,4 \\
\hline P22_1155_REV & AAAAGTCCAGAGCTCCACCCACTTCAAC & 66,6 \\
\hline SP_D2_255r & CAGCAGGGCCCGGGCCTC & 67,4 \\
\hline
\end{tabular}




\begin{tabular}{|l|l|c|}
\hline \multicolumn{2}{|l|}{ Vektorprimer } & Tm \\
& \multicolumn{2}{|l}{$\mathbf{C}]$} \\
\hline pETM11_for & AGAGGATCGAGATCTCGAT & 54,5 \\
\hline pETM11_rev & GGATATAGTTCCTCCTTTC & 52,4 \\
\hline pETM_rev & TCAGCGGTGGCAGCAGCCAACTCA & 67,8 \\
\hline VP_M30_f & AAAACGTATTGAAGCTATCCCACAAATT & 59,3 \\
\hline pPR-IBA1_f & TAATACGACTCACTATAGGGA & 54,0 \\
\hline pPR-IBA1_r & CTAGTTATTGCTCAGCGGTG & 57,3 \\
\hline pQETS1_f & TGGTTATTGTGCTGTCTCATCAT & 57,1 \\
\hline pQETS1_r & GATCGATCTCAGTGGTATTTGTG & 58,9 \\
\hline pQETriSys2_f & CAATCAAAGGAGATATACC & 50,2 \\
\hline pQETriSys2_r & GGTGCTCGAGATCCTCGG & 60,5 \\
\hline pGEX_f & GCTGGCAAGCCACGTTTGGT & 61,4 \\
\hline pGEX_r & CGTCTCCGGGAGCTGCATGT & 63,5 \\
\hline
\end{tabular}

\subsubsection{Vektoren}

\begin{tabular}{|l|l|}
\hline pPR-IBA1 & IBA, Göttingen \\
\hline pASK-IBA3 & IBA, Göttingen \\
\hline pGEX-6P1 & GE Healthcare, München \\
\hline pET-21a & Novagen, Darmstadt \\
\hline pET-22b & Novagen, Darmstadt \\
\hline pET-MZZ & EMBL, Heidelberg \\
\hline pET-M11 & EMBL, Heidelberg \\
\hline pET-M30 & EMBL, Heidelberg \\
\hline pQE-TriSystem1 & Qiagen, Hilden \\
\hline pEG(KT) & Grabowski et al., 1997 \\
\hline pYX & Novagen (Ingenius), Darmstadt \\
\hline
\end{tabular}

\subsubsection{Kristallisationsscreens}

Crystal Screen I / II / Lite / Cryo / PEG/ION

Footprint Screens 1-3

JB Screens 1-10

Magic Screens 1-4

Structure Screens 1-3

Additive Screens 1-4
Hampton Research, USA

Stura et al., 1992

Jena Bioscience, Jena

Biogenova, Kanada

Molecular Dimensions, UK

Hampton Research, USA 
The Classics/The Cryos/The PEGs/pHclear/The AmSO4/The Anions/The Cations/MPD/OptiSalts/PACT/JCSG+/MbClass

\subsubsection{Computersoftware}

AUTOMAR
AUTOSHARP
BUSTER/TNT
CCP4 Package
(ARP/wARP, REFMAC5)
ClustalW
COOT
ESPript 2.2
ExPASy Proteomics Server
HKL2000 - Denzo/Scalepack
HKL2MAP
Mar-Imaging Software am DESY, BESSY
ProCheck
PSIPRED

PYMOL 0.99

SMART

SOLVE / RESOLVE

SWISSMODEL

XPEP, X2SAD, SADABS
Qiagen (Nextal), Hilden

Marresearch, Norderstedt

Globalphasing (Vonrhein et al., 2007)

Globalphasing (Bricogne, 1993)

Collaborative Computational Project

Number 4, 1994

EMBL-EBI (Pearson et al., 1988)

Emsley et al., 2004

Gouet et al., 1999

SIB, Schweiz (http://expasy.org/)

HKL Research, USA

Pape et al., 2004

Marresearch, Norderstedt

Laskowski et al., 1993

Jones, 1999 (http://bioinf.cs.ucl.ac.uk/psipred/)

DeLano Scientific, USA

Schultz et al., 1998 (http://smart.embl-

heidelberg.de/)

Los Alamos National Laboratory, USA

(Terwilliger, 2000)

SIB, Schweiz (Peitsch, 1996;

http://swissmodel.expasy.org/)

Sheldrick et al., 1997 


\subsection{Methoden}

\subsubsection{Molekularbiologische Methoden}

\subsubsection{Polymerasekettenreaktion (PCR)}

Mittels der PCR können Gensequenzen zielgerichtet amplifiziert werden, indem spezifische Oligonukleotide (Primer) eingesetzt werden, welche komplementär zu jenen Sequenzen der Matrizen-DNA sind, welche die zu amplifizierende Gensequenz flankieren (Mullis et al., 1986). Dadurch wird das PCR-Produkt sowohl am 5'- als auch am 3'-Ende in seiner Länge durch die Anlagerungsposition der Primer an die Matrizen-DNA begrenzt. Im Folgenden werden die allgemeinen Reaktionsbedingungen für eine typische PCR aufgeführt:

\begin{tabular}{|c|c|c|c|}
\hline Reaktionszyklus & Temperatur & Dauer & \\
\hline 1. Initiale Denaturierung & $94^{\circ} \mathrm{C}$ bis $96^{\circ} \mathrm{C} *$ & 5 ' & \multirow{6}{*}{ 30-45 Zyklen (2.-4.) } \\
\hline 2. Denaturierung & $94{ }^{\circ} \mathrm{C}$ bis $96^{\circ} \mathrm{C} *$ & $10-30{ }^{\prime}, *$ & \\
\hline 3. Primer-Anlagerung & $\operatorname{Tm}-5^{\circ} \mathrm{C}$ bis $\operatorname{Tm} / 15-30, *$ & $15-30, *$ & \\
\hline 4. Elongation & $68^{\circ} \mathrm{C}$ bis $72{ }^{\circ} \mathrm{C} *$ & $30 " ' / \mathrm{kb}$ bis 2 '/ kb * & \\
\hline 5. Terminale Elongation & $68^{\circ} \mathrm{C}$ bis $72{ }^{\circ} \mathrm{C} *$ & $10^{\prime}$ & \\
\hline 6. Stop & $8^{\circ} \mathrm{C}$ & $\infty$ & \\
\hline
\end{tabular}

*Die Zeit- und Temperaturoptima variieren je nach verwendeter Polymerase. Die entsprechenden Optima sind im Folgenden aufgeführt:

\begin{tabular}{lllll} 
Polymerase & Quellorganismus & & Zeit- und Temperaturoptima \\
\hline & & Denaturierung & Primer- & Elongation \\
& & & Anlagerung & \\
\hline Taq & Thermus aquaticus & $94^{\circ} \mathrm{C} / 30^{\prime}$, & $\mathrm{Tm}-5^{\circ} \mathrm{C} / 30^{\prime}$, & $1{ }^{\prime} / 1 \mathrm{~kb}$ \\
Pfu Turbo & Pyrococcus furiosus & $94^{\circ} \mathrm{C} / 30^{\prime}$, & $\mathrm{Tm}-5^{\circ} \mathrm{C} / 30^{\prime}$, & $2{ }^{\prime} / 1 \mathrm{~kb}$ \\
Phusion & Pyrococcus furiosus & $96^{\circ} \mathrm{C} / 10^{\prime}$, & $\mathrm{Tm} / 15^{\prime}$ & $30^{\prime} / 1 \mathrm{~kb}$ \\
\hline
\end{tabular}

Ein standardisierter PCR-Ansatz setzt sich wie folgt zusammen:

$\begin{array}{ll}5 \mu \mathrm{l} & 10 \mathrm{x} \text { PCR-Puffer } \\ \text { je } 200 \mu \mathrm{M} & \text { dNTPs } \\ 10 \mathrm{pmol} & \text { forward-Primer } \\ 10 \mathrm{pmol} & \text { reverse-Primer } \\ 10-100 \mathrm{ng} & \text { Matrizen-DNA } \\ 1-2 \mathrm{U} & \text { DNA-Polymerase } \\ \text { ad } 50 \mu \mathrm{l} & \mathrm{ddH}_{2} \mathrm{O}\end{array}$


Für die Reinigung von PCR-Produkten wurden die Kit-Systeme Qiaquick PCR Purification Kit (Qiagen, Hilden) oder Nucleospin Extract (Macherey-Nagel, Düren) verwendet. Dabei wurde nach den Angaben des jeweiligen Herstellers verfahren.

\subsubsection{DNA-Restriktionsverdau}

Der Restriktionsverdau von DNA wird nach den Angaben des Herstellers der Restriktionsendonukleasen (Fermentas, St. Leon-Roth) durchgeführt. Die Inkubationszeit beträgt 1h und die Reaktion wird entweder durch Hitzeschock bei $95^{\circ} \mathrm{C}$ für $10^{\prime}$ oder durch Auftrennung der Reaktionsprodukte in einem Agarosegel (2.2.1.3) gestoppt.

\subsubsection{Agarosegelelektrophorese}

Laufpuffer (1x TAE)

\section{Probenpuffer 6x}

$40 \mathrm{mM}$ Tris $0,5 \%(\mathrm{w} / \mathrm{v})$ Bromphenolblau

$20 \mathrm{mM}$ Essigsäure $0,5 \%(w / v)$ Xylencyanol FF

1 mM EDTA pH 8,0 $60 \%$ Glycerin

Es werden ausschließlich Gele mit einem Agaroseanteil von $1 \%(\mathrm{w} / \mathrm{v})$ verwendet. Die aufzutrennenden Nukleinsäureproben werden mit Probenpuffer versetzt und anschließend bei einer konstanten Spannung von 8-12 V/cm Gel elektrophoretisch aufgetrennt. Anschließend erfolgt eine 30-minütigen Inkubation des Gels in einem Ethidiumbromid-Färbebad (0,1\%). Schließlich wird die DNA im UV-Durchlicht bei $280 \mathrm{~nm}$ oder $365 \mathrm{~nm}$ (bei folgender Gelelution) detektiert. Die Archivierung erfolgt über ein Geldokumentationsgerät (GelDoc, BioRad, München). Für die Extraktion von DNA aus Agarosegelen wurden die Kit-Systeme Nucleospin Extract (Macherey-Nagel, Düren) oder Qiaquick Gel Extraction Kit (Qiagen, Hilden) verwendet. Dabei wurde nach den Angaben des jeweiligen Herstellers verfahren.

\subsubsection{DNA-Ligation}

Restringierte doppelsträngige DNA mit überhängenden Enden kann mit linearisierter PlasmidDNA, welche mit den gleichen Restriktionsendonukleasen verdaut worden ist, ligiert werden. Die Ligation erfolgt mit T4-DNA-Ligase nach den Angaben des Herstellers (Fermentas, St. LeonRoth) unter Zusatz von $1 \mathrm{mM}$ ATP bei $4{ }^{\circ} \mathrm{C}$ über Nacht. Dabei wird ein 3-5-facher molarer Überschuss des zu inserierenden DNA-Fragments in Relation zum restringierten Plasmid eingesetzt. 


\subsubsection{Plasmidpräparation}

Die Präparation von Plasmid-DNA erfolgt mit Kit-Systemen (Qiagen, Hilden) durch alkalische Lyse von Bakterienzellen (XL1-Blue), welche mit dem gewünschten Plasmid transformiert worden sind (2.2.2.2) und anschließende Reinigung der Plasmid-DNA über Silica-Säulchen. In Abhängigkeit von der zu präparierenden DNA-Menge werden $5 \mathrm{ml}$ (Mini), $50 \mathrm{ml}$ (Midi) oder 250 $\mathrm{ml}$ (Maxi) LB-Medium (2.2.2.1) mit einem Selektionsantibiotikum versetzt, mit dem transformierten Bakterienstamm inokuliert und über Nacht bei $37{ }^{\circ} \mathrm{C}$ unter Schütteln inkubiert. Die Plasmidpräparation erfolgt nach den Angaben des Herstellers und die DNA wird schließlich in $50-250 \mu 1100 \mathrm{mM}$ Tris $\mathrm{pH} 8$ aufgenommen.

\subsubsection{Mikrobiologische Methoden}

\subsubsection{Medien für die Aufzucht von E.coli}

\begin{tabular}{|c|c|c|c|}
\hline LB-Agar & LB-Medium & 2YT-Medium & 10x PBS \\
\hline 5 g Trypton & 10 g Trypton & 16 g Trypton & $1,36 \mathrm{M} \mathrm{NaCl}$ \\
\hline 2,5 g Hefeextrakt & $5 \mathrm{~g} \mathrm{Hefeextrakt}$ & $10 \mathrm{~g}$ Hefeextrakt & $26,8 \mathrm{mM} \mathrm{KCl}$ \\
\hline $5 \mathrm{~g} \mathrm{NaCl}$ & $10 \mathrm{~g} \mathrm{NaCl}$ & $5 \mathrm{~g} \mathrm{NaCl}$ & $100 \mathrm{mM} \mathrm{Na}_{2} \mathrm{HPO}_{4}$ \\
\hline 7,5 g Agar-Agar & ad $11 \mathrm{dH}_{2} \mathrm{O}$ & ad $11 \mathrm{dH}_{2} \mathrm{O}$ & $17,6 \mathrm{mM} \mathrm{KH}_{2} \mathrm{PO}_{4} \mathrm{pH} 7,4$ \\
\hline 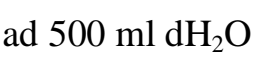 & & & \\
\hline
\end{tabular}

Komponenten für ZYM-5052 (autoinduzierendes Medium) - nach Studier, 2005

\begin{tabular}{rlllrl}
1 & & 1 & \\
\hline 1 & $\%$ & N-Z -Amin (Trypton) & w/v & 10 & $\mathrm{~g}$ \\
0,5 & $\%$ & Hefeextrakt & $\mathrm{w} / \mathrm{v}$ & 5 & $\mathrm{~g}$
\end{tabular}

\begin{tabular}{|c|c|c|c|c|c|}
\hline \multicolumn{4}{|c|}{$50 \times$ M (autoklaviert) } & $\mathrm{M}(\mathrm{g} / \mathrm{mol})$ & \multirow{2}{*}{$\begin{array}{r}1 \\
217725\end{array}$} \\
\hline 1,25 & $\mathrm{M}$ & $\mathrm{K}_{2} \mathrm{HPO}_{4}$ & & 174,18 & \\
\hline 1,25 & M & $\mathrm{NaH}_{2} \mathrm{PO}_{4}$ & $\mathrm{x} \mathrm{H}_{2} \mathrm{O}$ & 137,99 & 172,488 \\
\hline 2,5 & M & $\mathrm{NH}_{4} \mathrm{Cl}$ & & 53,49 & 133,725 \\
\hline 0,25 & M & $\mathrm{Na}_{2} \mathrm{SO}_{4}$ & x $10 \mathrm{H}_{2} \mathrm{O}$ & 322,19 & 80,548 \\
\hline
\end{tabular}

\begin{tabular}{rlllrl}
$\mathbf{5 0} \times 5052$ (autoklaviert) & & 1 & $\mathrm{l}$ \\
\hline 25 & $\%$ & Glycerin $(100 \%)$ & $\mathrm{v} / \mathrm{v}$ & 250 & $\mathrm{ml}$ \\
2,5 & $\%$ & Glucose & $\mathrm{w} / \mathrm{v}$ & 25 & $\mathrm{~g}$ \\
10 & $\%$ & $\alpha$-Lactose & $\mathrm{w} / \mathrm{v}$ & 100 & $\mathrm{~g}$
\end{tabular}




\begin{tabular}{|c|c|c|c|}
\hline $\mathbf{5 0 0 0} \times$ Spurenelementelösung ( & iltriert) & $\mathrm{M}(\mathrm{g} / \mathrm{mol})$ & $0,1 \quad 1$ \\
\hline $50 \mathrm{mM} \quad \mathrm{FeCl}_{3}$ & x $6 \mathrm{H}_{2} \mathrm{O}$ & 270,32 & $1351,60 \mathrm{mg}$ \\
\hline $20 \mathrm{mM} \mathrm{CaCl}{ }_{2}$ & x $2 \mathrm{H}_{2} \mathrm{O}$ & 147,02 & $294,04 \mathrm{mg}$ \\
\hline $10 \mathrm{mM} \mathrm{MnCl}_{2}$ & x $4 \mathrm{H}_{2} \mathrm{O}$ & 197,91 & $197,91 \mathrm{mg}$ \\
\hline $10 \mathrm{mM} \mathrm{ZnSO} 4$ & x $7 \mathrm{H}_{2} \mathrm{O}$ & 287,54 & $287,54 \mathrm{mg}$ \\
\hline $2 \mathrm{mM} \mathrm{CoCl}{ }_{2}$ & x $6 \mathrm{H}_{2} \mathrm{O}$ & 237,93 & $47,59 \mathrm{mg}$ \\
\hline $2 \mathrm{mM} \mathrm{CuCl}{ }_{2}$ & x $2 \mathrm{H}_{2} \mathrm{O}$ & 170,48 & $34,10 \mathrm{mg}$ \\
\hline $2 \mathrm{mM} \mathrm{NiSO}_{4}$ & x $6 \mathrm{H}_{2} \mathrm{O}$ & 262,86 & $52,57 \mathrm{mg}$ \\
\hline $2 \mathrm{mM} \mathrm{Na} \mathrm{NoO}_{4}$ & x $2 \mathrm{H}_{2} \mathrm{O}$ & 241,95 & $48,39 \mathrm{mg}$ \\
\hline $2 \mathrm{mM} \mathrm{Na}_{2} \mathrm{SeO}_{3}$ & & 172,94 & $34,59 \mathrm{mg}$ \\
\hline $2 \mathrm{mM} \mathrm{H} \mathrm{H}_{3} \mathrm{BO}_{3}$ & & 61,83 & $12,37 \mathrm{mg}$ \\
\hline $1000 \times \mathrm{Mg}^{2+}$ (autoklaviert) & & $\mathrm{M}(\mathrm{g} / \mathrm{mol})$ & 11 \\
\hline
\end{tabular}

LB-Agar-Platten werden benutzt, um E.coli-Stämme für einen Zeitraum von etwa 3 Monaten aufzubewahren. Die Flüssigmedien werden entweder zur Plasmidpräparation (LB-Medium) oder zur Proteinexpression (ZYM-5052, LB-Medium, 2YT-Medium) verwendet. Zur Selektion auf plasmidvermittelte Antibiotikaresistenzen können alle Medien mit entsprechenden Antibiotika versetzt werden. Die Komponenten des ZYM-5052-Mediums müssen stets frisch und in steriler Umgebung auf ein Zielvolumen von je $300 \mathrm{ml}$ verdünnt werden. PBS wird zum Waschen von Bakterienzellen nach der Zellernte verwendet.

\subsubsection{Herstellung chemisch kompetenter E.coli-Stämme}

\section{TFB1}

$30 \mathrm{mM}$ Kaliumacetat $\mathrm{pH} 7,0$

$50 \mathrm{mM} \mathrm{MnCl}_{2}$

$10 \mathrm{mM} \mathrm{CaCl}_{2}$

$100 \mathrm{mM} \mathrm{RbCl}$

$15 \%(\mathrm{v} / \mathrm{v})$ Glycerin
TFB2

$10 \mathrm{mM} \mathrm{NaMOPS}$
$75 \mathrm{mM} \mathrm{CaCl}_{2}$
$10 \mathrm{mM} \mathrm{RbCl}$
$15 \%(\mathrm{v} / \mathrm{v})$ Glycerin
pH 6,5 mit NaOH einstellen

pH 5,8 mit 0,2 M Essigsäure einstellen

Eine Kolonie des E.coli-Stammes, welcher chemisch kompetent für eine Transformation gemacht werden soll, wird in $5 \mathrm{ml}$ LB-Medium überimpft und über Nacht unter Schütteln bei $37{ }^{\circ} \mathrm{C}$ inkubiert. Diese Vorkultur wird anschließend in $495 \mathrm{ml}$ LB-Medium überführt und bei $37{ }^{\circ} \mathrm{C}$ unter Schütteln bis zu einer $\mathrm{OD}_{600}$ von 0,6 wachsen gelassen. Die Ernte der Zellen erfolgt durch Zentrifugation ( $3000 \mathrm{x} \mathrm{g,} 4{ }^{\circ} \mathrm{C}, 10^{\prime}$ ). Nach dem Resuspendieren des Pellets in $150 \mathrm{ml}$ eiskaltem TFB1-Puffer werden die Zellen für 5' auf Eis inkubiert. 
Nach einer weiteren Zentrifugation $\left(3000 \mathrm{x} \mathrm{g}, 4^{\circ} \mathrm{C}, 10^{\prime}\right)$ werden die Zellen in $5 \mathrm{ml}$ eiskaltem TFB2-Puffer vorsichtig resuspendiert, aliquotiert und zügig in flüssigem Stickstoff tiefgefroren. Die kompetenten Zellen können nun bei $-80{ }^{\circ} \mathrm{C}$ gelagert werden.

\subsubsection{Transformation chemisch kompetenter E.coli-Zellen}

Zur Transformation von Plasmid-DNA in chemisch kompetente XL-1 blue E.coli-Zellen wird ein $50 \mu \mathrm{l}$-Aliquot des entsprechenden Stammes auf Eis unter Zugabe von 10-100 ng Plasmid-DNA oder eines kompletten Ligationsansatzes aufgetaut und 20' auf Eis inkubiert. Nun werden die Zellen einem Hitzeschock bei $42{ }^{\circ} \mathrm{C}$ für 60 ' ausgesetzt und anschließend 2' auf Eis abgekühlt. Schließlich werden $450 \mu$ LB-Medium (2.2.2.1) zugesetzt und der Transformationsansatz für 30' bei $37{ }^{\circ} \mathrm{C}$ unter Schütteln inkubiert. $100 \mu \mathrm{l}$ des Transformationsansatzes (entsprechend 2 - $20 \mathrm{ng}$ Plasmid-DNA) werden auf einer Agarplatte mit dem nötigen Selektionsantibiotikum ausgestrichen und bei $37^{\circ} \mathrm{C}$ über Nacht inkubiert.

\subsubsection{Induktion der Proteinexpression in E.coli}

Alle verwendeten Vektoren enthalten ein lac-Operon, welches die spezifische Induktion der Expression des Zielgens über das Lactose-Analogon Isopropyl- $\beta$-D-thiogalactopyranosid (IPTG) oder $\alpha$-Lactose ermöglicht.

Für die Autoinduktion der Proteinexpression werden die mit dem entsprechenden Vektor transformierte E.coli-Expressionszellen in eine $3 \mathrm{ml}-\mathrm{LB}$-Vorkultur überführt und das zur Selektion notwendige Antibiotikum wird zugegeben (Ampicillin). Nach der Schüttelinkubation der Zellen für $12-16 \mathrm{~h}$ bei $37{ }^{\circ} \mathrm{C}$ wird die Vorkultur auf $300 \mathrm{ml}$ Gesamtvolumen des ZYM5052-Mediums verdünnt. Das vergleichsweise geringe Volumen in den 2L-Erlmeyerkolben (300 $\mathrm{ml}$ sind etabliert) bewirkt in Verbindung mit einer hohen Schüttelrate eine optimale Durchlüftung der Zellkultur und stimuliert so das Zellwachstum. Die Zellen werden bei $37{ }^{\circ} \mathrm{C}$ unter Schütteln bis zu einer $\mathrm{OD}_{600}$ von 0,2 bis 0,5 wachsen gelassen. Anschließend wird die Temperatur auf $18{ }^{\circ} \mathrm{C}$ reduziert und die Zellen 15 - 30 h unter Schütteln inkubiert. Nachdem die Glucose im Medium verbraucht ist (bei $\mathrm{OD}_{600} 6$ - 8), verstoffwechselt E.coli anschließend die Lactose. Durch diesen verstärkten Lactoseimport wird der Repressor von lac-Operon gelöst und das Zielgen wird exprimiert. Nach der Inkubation und dem Erreichen einer $\mathrm{OD}_{600}$ von 10 - 20 werden die Zellen durch Zentrifugation $\left(4800\right.$ x g, $\left.4{ }^{\circ} \mathrm{C}, 20^{\prime}\right)$ geerntet. Sie werden anschließen mit einem Schaber aus dem Zentrifugenbecher entnommen, in Lysepuffer resuspendiert ( $2 \mathrm{ml}$ Puffer pro g Zellen) und direkt aufgeschlossen.

Bei einer IPTG-induzierten Expression wird die Vorkultur mit $800 \mathrm{ml} \mathrm{LB}$ - oder 2YT-Medium verdünnt und bei $37{ }^{\circ} \mathrm{C}$ bis zu einer $\mathrm{OD}_{600}$ von 0,2 - 0,3 angezogen. Anschließend werden die Zellen in einem auf $16-20^{\circ} \mathrm{C}$ vorgekühlten Inkubator bis zu einer $\mathrm{OD}_{600}$ von $0,6-0,8$ inkubiert. 
Durch Zugabe von IPTG mit einer Endkonzentration 100 - $500 \mu \mathrm{M}$ wird die Expression des Zielgens induziert. Nach 15 - 18 h Schüttelinkubation werden die Zellen geerntet. Die pelletierten Zellen werden in $1 \mathrm{x}$ PBS gewaschen, erneut durch Zentrifugation (4800 x g, $\left.4{ }^{\circ} \mathrm{C}, 20^{\prime}\right)$ sedimentiert. Die Bakterienpellets werden anschließend immer frisch verarbeitet.

\subsubsection{Zellaufschluss}

Frische Bakterienpellets werden als Vorbereitung für den Zellaufschluss in 20-50 ml Lysepuffer resuspendiert, der mit $2 \mathrm{M} \mathrm{LiCl}$ versetzt wurde, um RNA-Interaktionen aufzubrechen. Dieser Puffer richtet sich in seiner Zusammensetzung in der Regel nach dem Puffer des ersten Reinigungsschrittes. Zusätzlich enthält er noch Proteaseinhibitoren, und zwar entweder $1 / 2$ Tablette Protease Inhibitor Cocktail „Edta free“ (Roche Diagnostics, München) oder $500 \mu$ l einer

Proteaseinhibitorlösung folgender Zusammensetzung pro $10 \mathrm{~g}$ Zellen:

\section{Komponente A}

Komponente B

$10 \mathrm{mM}$ PMSF in $\mathrm{ddH}_{2} \mathrm{O}$

$$
\begin{aligned}
& 80 \mu \mathrm{M} \text { Aprotinin } \\
& 2 \mathrm{mM} \text { Leupeptin } \\
& 1 \mathrm{mM} \text { Pepstatin A } \\
& \text { in DMSO }
\end{aligned}
$$

\section{fertige Proteaseinhibitorlösung}

\begin{tabular}{ll}
\hline Komponente A & $125 \mu 1$ \\
Komponente B & $400 \mu 1$
\end{tabular}

Nach dem Resuspendieren werden die Zellen in einem pneumatischen Zelldesintegrator (Fluidizer 110S, Microfluidics, USA) unter Kühlung und hohem Druck (80 psi) mit 5 Zyklen aufgeschlossen und die Zelltrümmer sowie unlösliche Bestandteile des Zelllysats durch Zentrifugation entfernt $\left(30000 \mathrm{x} \mathrm{g}, 4{ }^{\circ} \mathrm{C}, 40^{\prime}\right)$. Der klare Überstand wird nun dem ersten Reinigungsschritt zugeführt. 


\subsubsection{Proteinbiochemische Methoden}

\subsubsection{Affinitätschromatographie über Strep-Tactin-Sepharose}

\begin{tabular}{ll} 
Strep A & Strep B \\
\hline $50 \mathrm{mM}$ Tris/HCl pH 7-9 & Strep A \\
$200-300 \mathrm{mM} \mathrm{NaCl}$ & $2-5 \mathrm{mM}$ D-Desthiobiotin \\
$2 \mathrm{mM}$ DTT & \\
$2 \mathrm{mM}$ EDTA &
\end{tabular}

Affinitätssäulen mit gebundenen Streptavidin oder Strep-Tactin werden zur Reinigung von Proteinen mit einer Strep-Tag-Affinitätssequenz (WSHPQFEK) verwendet. Das Säulenmaterial ist in einem speziellen Regenerationspuffer, bestehend aus $100 \mathrm{mM}$ Tris/ $\mathrm{HCl} \mathrm{pH} 8,150 \mathrm{mM} \mathrm{NaCl}$ und 1 mM HABA (2-[4'-Hydroxy-Benzenazo]Benzoesäure), gelagert. Dieser Puffer muss vor der Benutzung durch Strep A ersetzt werden. Das Zielprotein mit Strep-Markierung wird hochspezifisch gebunden. Proteine ohne diese Affintätssequenz werden von der Säule gewaschen. Nach dem Laden der Probe wird die Säule mit 5 Volumina Puffer gespült und das gebundene Zielprotein bei einer Flussgeschwindigkeit (Äkta Prime) von $0,2 \mathrm{ml} / \mathrm{min}$ mit dem Elutionspuffer Strep B konzentriert eluiert. Das enthaltene D-Desthiobiotin bindet an Strep-Tactin und verdrängt so den Strep-Tag des Zielproteins. Dieses System funktioniert ausschließlich bei pH-Werten von über 7. Es darf kein Biotin verwendet werden, da es kovalent am Strep-Tactin bindet. Nach jeder Nutzung wird die Säule mit Regenerationspuffer gewaschen und bei $4{ }^{\circ} \mathrm{C}$ gelagert. In dieser Arbeit wurden ausschließlich Strep-Tactin-Säulen (IBA, Göttingen) verwendet.

\subsubsection{Affinitätschromatographie über Glutathion-Sepharose}

GSH A

$50 \mathrm{mM}$ Tris/ $\mathrm{HCl} \mathrm{pH} 7-9$

$100-300 \mathrm{mM} \mathrm{NaCl}$

$2 \mathrm{mM}$ DTT

2 mM EDTA

\section{GSH B}

GSH A

$+25 \mathrm{mM}$ reduziertes Glutathion

Zielproteine, die N-terminal mit einer Glutathion-S-Transferase (GST) fusioniert sind, können über eine Säule mit kovalent gebundenem Glutathion (GSH) gereinigt werden. Nach der Äquilibrierung der 30 ml GSH-Sepharose-Säule XK 16/20 (GE Healthcare, München), wird die Probe darüber geleitet. Das GST-Fusionsprotein wird spezifisch immobilisiert und kann nach dem Waschen mit mindestens 3 Säulenvolumina Ladepuffer GSH A in konzentrierter Form mit 25 mM reduziertem Glutathion im Elutionspuffer GSH B von der Säule eluiert werden. Die Säule wird danach mit $6 \mathrm{M}$ Guanidinium-Hydrochlorid gewaschen und in $20 \% \mathrm{EtOH}$ gelagert. 


\subsubsection{Proteolytische Spaltung von GST-Fusionsproteinen mit PreScission Protease}

Die Vektorserie pGEX-6P codiert für GST-Fusionsproteine, die eine spezifische Erkennungssequenz für die PreScission Protease besitzen. Diese Sequenz wird von der Protease erkannt und gespalten. Dabei wird die GST-Komponente des Fusionsproteins vom Zielprotein entfernt. Die Stoffmenge der hierfür benötigten PreScission Protease beträgt etwa $1 \%$ der Stoffmenge des zu verdauenden GST-Fusionsproteins. Der proteolytische Verdau wird über Nacht bei $4^{\circ} \mathrm{C}$ auf einem Rollenmischer inkubiert.

\subsubsection{Größenausschlusschromatographie}

\section{Gelfiltrationspuffer 1}

$10 \mathrm{mM}$ Tris/HCl pH 7,5-8,5

$100-150 \mathrm{mM} \mathrm{NaCl}$

$2 \mathrm{mM}$ DTT

2 mM EDTA

Bei der Größenausschlusschromatographie (Gelfiltration) werden Proteine nach ihrer Größe aufgetrennt.

Für die analytische Gelfiltration werden, je nach zu trennender Molekülgröße, Superdex 75 10/300 GL Säulen und Superdex 200 10/300 GL Säulen verwendet. Hierfür werden 100 - $500 \mu$ 1 Probe aufgetragen und im Gelfiltrationspuffer aufgetrennt.

Für die präparative Gelfiltration werden Superdex 75 XK 26/60 und Superdex 200 XK 26/60 Säulen verwendet. Es können bis zu $7 \mathrm{ml}$ Probe aufgetragen werden. Die Wahl des Puffers ist abhängig vom pI des Proteins (1 pH Einheit Unterschied). Das Konzentrieren der Proteinlösung vor der Gelfiltration wird mit Vivaspin Konzentratoren (Sartorius, Göttingen) durchgeführt. Die Ausschlussgröße der Membranen, angegeben als Molekulargewicht, wird dabei so gewählt, dass sie unter der Hälfte des Molekulargewichts des zu konzentrierenden Proteins liegt. Nach der Gelfiltration werden die Präparate auf eine Konzentration von $5-25 \mathrm{mg} / \mathrm{ml}$ eingeengt und direkt weiterverarbeitet. Eine kurzzeitige Lagerung (max. 5 Tage) bei $4{ }^{\circ} \mathrm{C}$ ist möglich. 


\subsubsection{Diskontinuierliche SDS-Polyacrylamidgelelektrophorese (SDS-PAGE)}

\begin{tabular}{ll} 
Trenngel 15\% & Sammelgel 5 \% \\
\hline $15 \%$ Acrylamid / 0,4 \% Bisacrylamid & $5 \%$ Acrylamid / 0,13 \% Bisacrylamid \\
$375 \mathrm{mM}$ Tris/HCl pH 8,8 & $125 \mathrm{mM}$ Tris/HCl pH 6,8 \\
$0,1 \%(\mathrm{w} / \mathrm{v}) \mathrm{SDS}$ & $0,1 \%(\mathrm{w} / \mathrm{v}) \mathrm{SDS}$ \\
$0,1 \%(\mathrm{w} / \mathrm{v})$ Ammoniumperoxodisulfat & $0,1 \%(\mathrm{w} / \mathrm{v})$ Ammoniumperoxodisulfat \\
$0,03 \%(\mathrm{v} / \mathrm{v})$ TEMED & $0,03 \%(\mathrm{v} / \mathrm{v}) \mathrm{TEMED}$
\end{tabular}

Laufpuffer

192 mM Glycin

$25 \mathrm{mM}$ Tris/ $\mathrm{HCl} \mathrm{pH} 8,3$

$0,1 \%(\mathrm{w} / \mathrm{v}) \operatorname{SDS}$

\section{2x SDS-Probenpuffer}

62,5 mM Tris/HCl pH 6,8

$70 \mathrm{mM}$ SDS

$50 \%$ (v/v) Glycerin

$0,1 \%$ (w/v) Bromphenolblau

$5 \%(\mathrm{v} / \mathrm{v}) \beta$-Mercaptoethanol

\section{Färbelösung}

$10 \%(\mathrm{v} / \mathrm{v})$ Ethanol

$5 \%(\mathrm{v} / \mathrm{v})$ Essigsäure

$0.003 \%$ (w/v) Coomassie G/R 250 in EtOH

Die SDS-PAGE wird mit ein Gelelektrophoresesystem der Firma Hoefer/GE Healthcare (München) durchgeführt. Die zu analysierenden Proben werden 1:1 mit SDS-Probenpuffer versetzt, mit Ausnahme von Proben aus E.coli-Kulturen. Diese werden zunächst zentrifugiert $\left(16.100 \mathrm{x} \mathrm{g}, 4^{\circ} \mathrm{C}, 2^{\prime}\right)$ und das Zellpellet in $0.2 \times \mathrm{OD}_{600} \mathrm{ml}$ SDS-Probenpuffer aufgenommen. Die Auftrennung in der SDS-PAGE erfolgt bei $30 \mathrm{~mA}$ für 65'. Die Gele werden in $50 \mathrm{ml}$ Färbelösung inkubiert und in $\mathrm{H}_{2} \mathrm{O}$ entfärbt. Die Archivierung erfolgt über ein Geldokumentationssystem (BioRad, München).

\subsubsection{Reinigungsprotokolle der verwendeten Proteine}

Die etablierten Reinigungsprotokolle der hPrp22-Deletionsmutanten sind im Folgenden aufgeführt. Alle Aufreinigungen sind bei $4{ }^{\circ} \mathrm{C}$ durchzuführen, um die Stabilität der Proteine zu gewährleisten und Degradationserscheinungen zu verhindern. Auf die Auflistung der Protokolle anderer Fragmente und der Volllängenproteine wird in diesem Rahmen verzichtet, da sie entweder noch in der Optimierungsphase sind oder keine verlässliche Reproduzierbarkeit zeigten. 


\subsubsection{1 hPrp22-H12 (AS 264-351) in pGEX-6P-1}

Die IPTG-induzierte Expression von GST-hPrp22-H12 erfolgt in E.coli Rosetta 2 (DE3) mit 2YTMedium und wird nach den angegebenen Methoden durchgeführt (2.2.2.1 - 2.2.2.3). Nach dem Zellaufschluss (2.2.2.4) in Lysepuffer (100 mM Tris/HCl pH 8, $2 \mathrm{M} \mathrm{LiCl}, 150 \mathrm{mM} \mathrm{NaCl}, 2 \mathrm{mM}$ DTT, 2 mM EDTA) erfolgt eine GSH-Affinitätschromatographie (2.2.3.2). Die Fraktionen des Fluats werden vereinigt, an konzentriert und bei $4{ }^{\circ} \mathrm{C} 12$ - 16 h proteolytische verdaut (2.2.3.3). Es folgt eine Gelfiltration über eine Superdex 75 XK 26/60 Säule (2.2.3.4). Dabei kann beim Puffer auf jegliches Reduktionsmittel verzichtet werden (10 mM Tris pH 8, $100 \mathrm{mM} \mathrm{NaCl})$. Das fertige Präparat wird eingeengt, direkt verarbeitet oder bei $-80^{\circ} \mathrm{C}$ gelagert.

\subsubsection{2 hPrp22-H13 (AS 564-1183) in pPR-IBA1}

Das Fragment hPrp22-H13 in pPR-IBA1 wird in E.coli BL21 (DE3) oder Rosetta (DE3) nach den angegebenen Protokollen autoinduktiv in ZYM-5052 exprimiert (2.2.2.1 - 2.2.2.3). Zudem wurde nach 20 h Inkubationszeit zusätzlich $500 \mu \mathrm{M}$ IPTG zugeführt. Nach dem Zellaufschluss (2.2.2.4) in Lysepuffer (100 mM Tris/HCl pH 7,5, $2 \mathrm{M} \mathrm{LiCl}, 150 \mathrm{mM} \mathrm{NaCl}, 2 \mathrm{mM}$ DTT, $2 \mathrm{mM}$ EDTA, 10\% Glycerin) erfolgt eine Strep-Tactin-Affinitätschromatographie (2.2.3.1). H13 wird dann ankonzentriert und mittels Gelfiltration über eine Superdex 200 XK 26/60 Säule gereinigt (2.2.3.4 - $10 \mathrm{mM}$ Tris pH 7,5, $150 \mathrm{mM} \mathrm{NaCl}, 2 \mathrm{mM}$ DTT). Das fertige Präparat wird eingeengt, direkt verarbeitet oder kurzzeitig bei $4{ }^{\circ} \mathrm{C}$ gelagert.

\subsubsection{3 hPrp22-H15 (AS 564-904) in pPR-IBA1}

Die Expression und Reinigung von hPrp22-H15 verläuft analog zu hPrp22-H13 (2.2.4.2). Die Expression dieses Fragments in HMS174 (DE3) ist ebenfalls möglich. Auf Glycerin im Lysepuffer kann verzichtet werden und die Gelfiltration erfolgt über eine Superdex 75 XK 26/60. Die Probe muss frisch verarbeitet werden.

\subsubsection{4 hPrp22-H20 (AS 950-1055) in pPR-IBA1}

Diese Deletionsmutante von hPrp22 wird als Strep-Tag-Fusionsprotein in E.coli BL21 (DE3) nach den angegebenen Protokollen exprimiert (2.2.2.1 - 2.2.2.3) und nach dem Zellaufschluss (2.2.2.4 - $100 \mathrm{mM}$ Tris/HCl pH 8,5, $2 \mathrm{M} \mathrm{LiCl}, 150 \mathrm{mM} \mathrm{NaCl}, 2 \mathrm{mM}$ DTT, $2 \mathrm{mM}$ EDTA) über eine Strep-Tactin-Sepharose-Säule (2.2.3.1) gereinigt. Danach folgt eine Gelfiltration über eine S75 XK 26/60 Säule (2.2.3.4 - 10 mM Tris pH 8,5, 150 mM NaCl, 2 mM DTT, 2 mM EDTA). Das fertige Präparat wird eingeengt, direkt verarbeitet oder kurzzeitig bei $4{ }^{\circ} \mathrm{C}$ gelagert. Das Protein ist relativ stabil, kristallisiert nach 3-tägiger Lagerung aber nur noch mäßig. 


\subsubsection{5 hPrp22-H20 (AS 950-1055) in pPR-IBA1 Selenomethionin-Derivat}

Die Expression des hPrp22-H20 Selenomethionin-Derivats erfolgt im autoinduktiven PASM5052-Medium (Studier, 1995). Es setzt sich wie folgt zusammen: $50 \mathrm{mM} \mathrm{Na} \mathrm{HPO}_{4}, 50 \mathrm{mM}$ $\mathrm{KH}_{2} \mathrm{PO}_{4}, 25 \mathrm{mM}\left(\mathrm{NH}_{4}\right){ }_{2} \mathrm{SO}_{4}, 2 \mathrm{mM} \mathrm{MgSO}$, 0,5 \% Glycerin, 0,05\% Glucose, 0,2 \% Lactose, 0,2x Spurenelementlösung (2.2.2.1), $125 \mathrm{mg} / 1$ Selenomethionin, $100 \mathrm{nM}$ Vitamin B12, $1 \mathrm{mg} / 1$ Thiamin, 0,5 $\mathrm{mM} \mathrm{CaCl}_{2}$, je $200 \mathrm{mg} / \mathrm{l}$ Aminosäuren (kein C, Y oder M) und Ampicillin (steril filtrieren). Der verwendete methionin-auxotrophe E.coli-Expressionsstamm war B834 (DE3). Nach der Verdünnung der 3ml-LB-Vorkultur mit $300 \mathrm{ml}$ frisch angesetztem Medium folgt eine 24 stündige Schüttelinkubation bei $18{ }^{\circ} \mathrm{C}$. Die Aufreinigung erfolgt analog zu 2.2.4.4, jedoch müssen stets 5 mM DTT zugegeben werde. Die Lagerzeiten müssen kurz gehalten werden, da das Protein schnell oxidiert.

\subsubsection{Spektroskopische Methoden}

\subsubsection{Bestimmung nativer molarer Extinktionskoeffizienten}

Der Extinktionskoeffizient nativer Proteine bei $280 \mathrm{~nm}\left(\varepsilon_{280}\right)$ wird nach Gill \& von Hippel (Gill et $a l ., 1989)$ ausgehend vom Lambert-Beer'schen Gesetz errechnet:

$$
\begin{aligned}
A=\varepsilon \times c \times d & \varepsilon=\text { molarer Extinktionskoeffizient }\left[M^{-1} \mathrm{~cm}^{-1}\right] \\
\mathrm{c} & =\text { Konzentration }[\mathrm{M}] \\
\mathrm{d} & =\text { Schichtdicke der Küvette }
\end{aligned}
$$

Der Extinktionskoeffizient eines denaturierten Proteins $\left(\varepsilon_{280 \mathrm{denat}}\right)$ lässt sich von der Aminosäuresequenz ableiten (Software DNAstar, Lasergene). Der native Extinktionskoeffizient lässt sich schließlich aus dem Vergleich der Absorption einer nativen und einer denaturierten Proteinprobe gleicher Konzentration (c) bei $280 \mathrm{~nm}\left(\mathrm{~A}_{280}\right)$ in einer Küvette gleicher Schichtdicke (d) bestimmen.

$$
\frac{A_{280 \text { denat }}}{A_{280 \text { nat }}}=\frac{\varepsilon_{280 \text { denat }} \times c \times d}{\varepsilon_{280 \text { nat }} \times c \times d} \quad \varepsilon_{\text {nat }}=\frac{\varepsilon_{\text {denat }} \times A_{\text {nat }}}{A_{\text {denat }}}
$$

Dazu wird die Absorption zweier Proteinlösungen identischer Konzentration in je $20 \mathrm{mM}$ Kaliumphosphat $\mathrm{pH} 6,5$ bei $280 \mathrm{~nm}$ und $20^{\circ} \mathrm{C}$ gemessen, wobei die eine Lösung natives Protein enthält, während die zweite Probe zuvor zusätzlich mit $6 \mathrm{M}$ Guanidinium-Hydrochlorid versetzt und für $2 \mathrm{~h}$ bei $37^{\circ} \mathrm{C}$ inkubiert worden ist. Sie stellt die denaturierte Probe dar. 


\subsubsection{Konzentrationsbestimmung von Proteinen und Nukleinsäuren}

Die Konzentration von Proteinlösungen wird entweder mittels Bradford-Reagens oder durch den nativen Extinktionskoeffizienten bei $280 \mathrm{~nm}$ bestimmt.

Die Konzentration von Nukleinsäurelösungen wird photometrisch bei $260 \mathrm{~nm}$ ermittelt. Ausgehend von einem gemittelten Absorptionskoeffizienten für dsDNA, entspricht bei $1 \mathrm{~cm}$ Lichtweg eine $\mathrm{OD}_{260}$ von 1 in etwa einer Konzentration von $50 \mu \mathrm{g} / \mu \mathrm{l}$, während bei ssDNA eine $\mathrm{OD}_{260}$ von 1 einer Konzentration von $33^{\mu \mathrm{g} / \mu \mathrm{l}}$ entspricht.

\subsubsection{Enzymgekoppelter ATPase-Test}

Zum Nachweis der ATPase-Aktivität von hPrp22 und einigen seiner Deletionsmutanten wurde ein enzymgekoppelter photometrischer Test adaptiert (Porter, 1998). Dieser Enzymkinetik-Assay basiert auf der Abnahme der Absorption und somit auch der Konzentration von NADH bei 340 $\mathrm{nm}$ über die Zeit. Die Reaktionsabfolge ist in Abb.11 dargestellt. Die ATPase (hPrp22) hydrolysiert ATP zu ADP und Phosphat. In der Gegenreaktion phosphoryliert die Pyruvatkinase (PK) ADP zu ATP, indem sie ein Phosphat von Phosphoenolpyruvat auf ADP überträgt. ATPasen katalysieren die ATP-Hydrolyse sehr viel langsamer, als PK die Phosphorylierung katalysiert. Somit verläuft die Gegenreaktion schneller und die Substratkonzentration bleibt konstant, was eine gleichbleibende Reaktionsgeschwindigkeit zu Folge hat. In einem weiteren Reaktionsschritt wird das aus PEP entstandene Pyruvat durch die Lactat-Dehydrogenase (LDH) zu Lactat reduziert. Dabei wird NADH verbraucht und NAD gebildet. Die Reaktionsgeschwindigkeit entspricht der, der Phosphorylierung von ATP. PK und LDH haben eine Wechselzahl von ca. 600 $\mathrm{s}^{-1}$. Die Konzentrationsabnahme von NADH kann bei $340 \mathrm{~nm}$ photometrisch bestimmt werden. Aufgrund der hohen Reaktionsgeschwindigkeiten der Hilfsreaktionen entspricht die Konzentrationsabnahne von NADH direkt der Konzentrationsabnahme von ATP bei der Hydrolyse durch die ATPase.

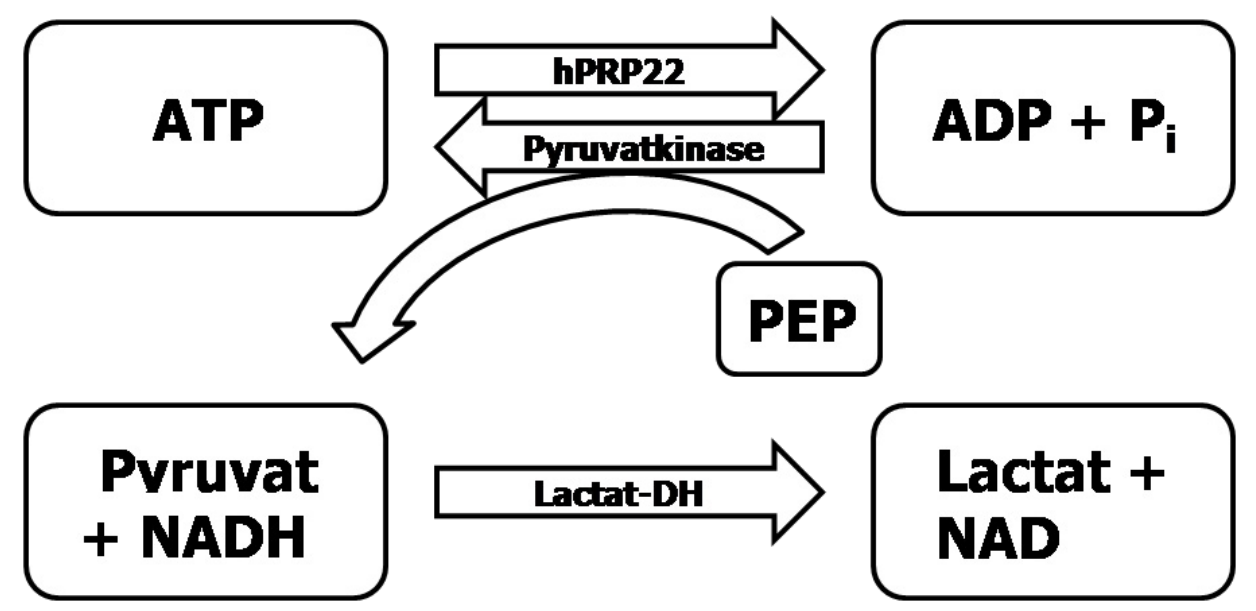

[Abb.11] Schema der Reaktionsabfolge des enzymgekoppelten ATPase-Tests. 
Die Konzentration kann nun durch das Lambert-Beer'sche-Gesetz berechnet werden. Die Konzentration von NADH (c) ist direkt zur Extinktions- bzw. Absorptionsänderung $(\Delta E)$ und indirekt zum Extinktionskoeffizienten $\left(\varepsilon=34000 \mathrm{M}^{-1} \mathrm{~cm}^{-1}\right)$ und der Schichtdicke der Küvette (d) proportional. Somit erhält man auch die ATP-Konzentration.

Lambert-Beer'sches-Gesetz:

$$
c=\frac{\Delta E}{\varepsilon d}
$$

Die Reaktionsgeschwindigkeit $\left(\mathrm{v}_{0}\right)$ lässt sich mittels der Michaelis-Menten-Gleichung berechnen. Sie ist direkt proportional zur maximalen Reaktionsgeschwindigkeit $\left(\mathrm{v}_{\max }\right)$ und der Substratkonzentration ([S]) und indirekt proportional zur Summe aus Substratkonzentration und der Michaelis-Menten-Konstante $\left(\mathrm{K}_{\mathrm{m}}\right)$.

Michaelis-Menten-Gleichung:

$$
v_{0}=\frac{v_{\max } \cdot[S]}{K_{m}+[S]}
$$

Da $K_{m}$ und $v_{\max }$ unbekannt sind, werden beide Gleichungen kombiniert. auf diese Weise kann die Anfangsgeschwindigkeit berechnet werden. Die Abnahme der Substratkonzentration gegen die Zeit ergibt die Reaktionsgeschwindigkeit.

$$
v_{0}=\frac{\Delta c}{\Delta t}
$$

Durch die Linearisierungen der Michaelis-Menten-Gleichung mittels Auftragungen nach Lineweaver-Burk oder Eadie-Hofstee lassen sich dann $\mathrm{K}_{\mathrm{m}}$ und $\mathrm{v}_{\max }$ berechnen.

Zur Bestimmung der Michaelis-Menten-Konstante mussten verschiedene ATP-Konzentrationen verwendet werden $(0,1-20 \mathrm{mM})$, da mit steigender Substratkonzentration auch die Reaktionsgeschwindigkeit asymptotisch anwächst (Annäherung an $\mathrm{v}_{\max }$ ). MOPS/KOH-Puffer stabilisiert den pH-Wert bei 7,5. Für die Katalyse der ATP-Hydrolyse werden Magnesiumionen $\left(\mathrm{MgCl}_{2}\right)$ benötigt. Es wurde jedoch verglichen mit der Konzentration des ATPs nur die Hälfte eingesetzt, um die Autohydrolyse zu minimieren. Die Endkonzentration der getesteten Deletionsmutanten (hPrp22-H13, hPrp22-H15, hPrp22-H20) lag bei ca. $1 \mu \mathrm{M}$. Je $500 \mu \mathrm{l}$ Reaktionsansatz wurden angesetzt. Das ATP wurde erst zum Schluss zugegeben. Nach gründlichem Mischen wurde dieser in UV-Kristallküvetten überführt und die Reaktion im Spektrophotometer bei $20{ }^{\circ} \mathrm{C} 1-2 \mathrm{~h}$ dokumentiert (3.6). 


\begin{tabular}{lll}
\hline Substrat & M & Endkonzentration \\
\hline MOPS/KOH pH 7,5 & $209,27 \mathrm{~g} / \mathrm{mol}$ & $200 \mathrm{mM}$ \\
$\mathrm{MgCl}_{2}$ & $203,3 \mathrm{~g} / \mathrm{mol}$ & $0,1-10 \mathrm{mM}$ \\
\hline ATP & $551,1 \mathrm{~g} / \mathrm{mol}$ & $0,1-20 \mathrm{mM}$ \\
$(\mathrm{ADP}$ & $427,2 \mathrm{~g} / \mathrm{mol}$ & $0,1-20 \mathrm{mM})$ \\
$\mathrm{NADH}$ & $741,6 \mathrm{~g} / \mathrm{mol}$ & $0,4 \mathrm{mM}$ \\
$\mathrm{PEP}$ & $206,13 \mathrm{~g} / \mathrm{mol}$ & $2 \mathrm{mM}$ \\
\hline PK & $166 \mathrm{U} / \mathrm{mg}$ & $10 \mathrm{U} / \mathrm{Ansatz}$ \\
LDH & $143 \mathrm{U} / \mathrm{mg}$ & $10 \mathrm{U} / \mathrm{Ansatz}$ \\
\hline $\mathrm{H} 13$ & $74215 \mathrm{Da}$ & $1,08 \mu \mathrm{M}$ \\
$\mathrm{H} 15$ & $41962 \mathrm{Da}$ & $1,14 \mu \mathrm{M}$ \\
$\mathrm{H} 20$ & $31166 \mathrm{Da}$ & $1,03 \mu \mathrm{M}$ \\
\hline
\end{tabular}

\subsubsection{Röntgenkristallographische Methoden}

\subsubsection{Proteinkristallisation}

Die Proteine werden in sitting drop Kristallisationsschalen (Cryschem, Hampton Research, USA) mittels Dampfdiffusion kristallisiert. In das Reservoir werden 250 - $500 \mu 1$ der Mutterlauge pipettiert. In die Kristallisationssenkung (well) werden 1-2 $\mu 1$ Proteinlösung mit einer Konzentration von $5-25 \mathrm{mg} / \mathrm{ml}$ gegeben und 1:1 oder anderen Mischungsverhältnissen mit der Mutterlauge vermischt. Die Ansätze werden mit klarem Klebeband verschlossen und bei 4 oder $20{ }^{\circ} \mathrm{C}$ inkubiert.

\subsubsection{Seeding-Experimente}

Seeding kann eingesetzt werden, um das Wachstum und die Ordnung von Kristallen zu verbessern. Man unterscheidet zwischen Makro- und Mikroseeding. Beim Makroseeding werden kleine Einkristalle in Kristallisationsansätze überführt, die frisch präpariertes Protein enthalten. So soll die Wachstumsphase der Kristalle ausgedehnt werden, um größere Einkristalle zu züchten. In Mikroseeding-Experimenten werden zunächst Kristalle zerstört. Die resultierenden Kristallsplitter werden als Kristallisationskeime anschließend in frisch angesetzte Kristallisationsexperimente überführt. In dieser Arbeit wurde Mikroseeding erfolgreich eingesetzt, um die Kristalle von hPrp22-H20 verlässlich, in hoher Anzahl und schneller zu reproduzieren.

Einkristalle werden aus einer Kristallisationsbedingung entnommen, zerteilt und in $100 \mu$ einer frischen Kristallisationsbedingung überführt. Diese Kristallsuspension wird kurz gevortext und 
bei 200 x g zentrifugiert, um größere Partikel zu entfernen. Dann wird eine Verdünnungsreihe angesetzt $(1: 100,1: 200,1: 500)$. Die Keime werden nun in frisch präparierte Kristallisationsansätze überführt, welche zuvor $1 \mathrm{~h}$ vorinkubiert worden sind. Dies kann entweder durch Zugabe von $0.2 \mu \mathrm{l}$ unterschiedlich verdünnter Seedsuspension in die Kristallisationsbedingungen geschehen (klassisches Mikroseeding), oder durch Überführung einzelner Kristallisationskeime in die frischen Kristallisationsexperimente mittels eines Katzenschnurrhaares (Wohlis Hauskater Pedro, 2003). Dabei spricht man von Streak-Seeding. Die Anlagerung von Molekülen an einen bereits gebildeten Kristall wird, im Gegensatz zur Kristallneubildung, thermodynamisch begünstigt. Das Wachstum der bestehenden Kristallisationskeime wird bevorzugt, während die Kristallneubildung unterdrückt wird.

\subsubsection{Kryo-Kristallographie}

Der Kryopuffer, in dem ein Kristall für die Kryo-Kristallographie inkubiert wird, hat einen großen Einfluss auf das Beugungsverhalten des Kristalls. Durch den Kryopuffer wird die Bildung von Eiskristallen bei $100 \mathrm{~K}$ verhindert. Eiskristalle können das Beugungsverhalten der Proteinkristalle beeinflussen oder sie gar zerstören. Weiterhin zeigen sich auf den Röntgenaufnahmen Eisringe, die die Datenauswertung erschweren. Reflexe unter und neben den Eisringen können nicht ausgewertet werden und reduzieren die Vollständigkeit der Daten in diesem Auflösungsbereich. In der Regel werden Kristalle mit einer kleinen Nylonschleife aus der Kristallisationsbedingung entnommen und kurz im Kryopuffer inkubiert. Anschließend werden sie für die Messung im 100 $\mathrm{K}$ kalten $\mathrm{N}_{2}$-Strom auf dem Goniometerkopf montiert. Auch der Kryopuffer kann das Beugungsverhalten negativ beeinflussen, so dass eine schrittweise Erhöhung der Konzentration des Kryoprotektans erforderlich ist. Die Kristalle von hPrp22-H20 wurden nach der Entnahme aus der Kristallisationsbedingung für 1' in einer Lösung aus 1,5 $\mathrm{M}\left(\mathrm{NH}_{4}\right) \mathrm{SO}_{4}$ und $25 \%$ Glycerin inkubiert und dann direkt gemessen. Der Kryopuffer kann auch verwendet werden um Schweratome für die Phasenbestimmung in den Kristall einzubringen. Für die Phasierung von hPrp22-H20 wurde ein Kryopuffer mit $1 \mathrm{M} \mathrm{KBr}, 1,5 \mathrm{M}\left(\mathrm{NH}_{4}\right) \mathrm{SO}_{4}$ und $25 \%$ Glycerin eingesetzt.

\subsubsection{Datensammlung}

Bei der Datensammlung werden die Kristalle auf einem Goniometerkopf im Schnittpunkt des Röntgenstrahls mit der Rotationsachse des Goniometers montiert. Ein nativer Datensatz eines Kristalls von hPrp22-H20 wurde am Strahlrohr der BW7B am Deutschen Elektronensynchrotron (DESY) in Hamburg bei einer Wellenlänge von 0,8423 ^ aufgenommen. Der Abstand zum mar345-Detektor betrug $20 \mathrm{~cm}$ und der Kristall wurde um $91^{\circ}$ bei $1^{\circ}$ Rotation und $8^{\prime \prime}$ Belichtungszeit pro Bild gedreht. Ein Selenomethionin-Kristall wurde am Strahlrohr BL14.2 des Berliner Elektronensynchrotrons (BESSY) gemessen. Da ein MAD-Experiment durchgeführt 


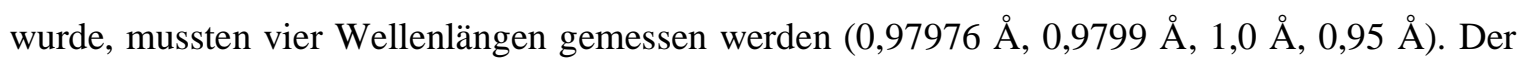
Kristall-Detektor Abstand betrug $28 \mathrm{~cm}$ und die Belichtungszeit war 6". Der Kristall wurde bei allen Wellenlängen beginnend mit dem gleichen Startwinkel um $100^{\circ}$ bei $1^{\circ}$ Rotation pro Bild gedreht. Zur Indizierung, Integration und Datenreduktion wurden das Programm HKL2000 verwendet. Die Raumgruppe wurde mit XPREP (Sheldrick et al., 1997) bestimmt.

\subsubsection{Phasenbestimmung und Kalkulation der Elektronendichteverteilung}

Durchstrahlt Röntgenlicht einen Protein-Einkristall, so tritt aufgrund der Wechselwirkung der elektromagnetischen Strahlung mit der Elektronenhülle der Atome Beugung auf. Diese Beugung der Röntgenstrahlung wird durch konstruktive Interferenz zwischen den Teilstreuwellen benachbarter, um eine Translationsperiode verschobener Atome im Kristall verstärkt und kann als Lichtpunkt (Spot) detektiert werden. Für jeden Reflex gilt dabei die Bragg'sche Gleichung: $\mathbf{n} \boldsymbol{\lambda}=$ $\mathbf{2 d}_{\mathrm{hkl}} \sin \boldsymbol{\theta}$, wobei $\mathrm{d}_{\mathrm{hkl}}$ der Abstand zwischen den reflektierenden imaginären Netzebenen, beschrieben durch die Miller Indizes hkl, $\lambda$ die Wellenlänge des eingestrahlten Röntgenlichts, $n$ die Beugungsordnung und $\theta$ der Reflexionswinkel ist. Die Lage jedes einzelnen Reflexes ist durch Amplitude und Phase charakterisiert und wird durch den als Strukturfaktor bezeichneten Wellenvektor $\mathrm{F}_{\mathrm{hkl}}=\mathrm{F}_{\mathrm{hkl}} \mathrm{ei}^{\alpha(\mathrm{hkl})}$ beschrieben. $\mathrm{F}$ stellt die Amplitude $(\mathrm{F}=|\mathrm{F}|)$ und $\alpha$ die Phase der gebeugten Röntgenwelle dar. Um aus den gemessenen Beugungsdaten eine Elektronendichteverteilung zu berechnen, wird eine Fourier-Transformation angewandt, welche die experimentellen Beugungsdaten im reziproken Raum mit der Elektronendichte im Realraum verbindet.

$$
\rho(x y z)=1 / V \sum_{h} \sum_{k} \sum_{l} \vec{F}_{h k l} e^{-2 \pi i(h x+k y+l z)}
$$

Für Strukturfaktoren $\vec{F}_{h k l}$ gilt:

$\vec{F}_{h k l}=\left|F_{h k l}\right| e^{i \varphi(h k l)}$.

Daraus wird ersichtlich, dass die Kenntnis der Phasen $\varphi(h k l)$ für die Berechnung der Elektronendichte zwingend notwendig ist:

$$
\rho(x y z)=1 / V \sum_{h} \sum_{k} \sum_{l}\left|F_{h k l}\right| e^{-2 \pi i(h x+k y+l z)+i \varphi(h k l)}
$$

Mit den verfügbaren Röntgendetektoren lassen sich die Lage und Intensität der einzelnen Beugungsreflexe bestimmen. Diese sind zum Betrag des Strukturfaktors zum Quadrat proportional $\left(\mathrm{I}(\mathrm{hkl}) \sim\left|\mathrm{F}_{\mathrm{hk}}\right|^{2}\right)$. Die Phaseninformation jedoch geht verloren. Es gibt verschiedene Strategien zur Lösung dieses Phasenproblems. Es gibt direkte Methoden, die Patterson-Methode, molekularer Ersatz mittels eines Modells (MR), einfacher (SIR) oder multipler (MIR) isomorpher 
Ersatz und die Messung der anomalen Dispersion bei einer einzelnen (SAD) oder mehreren Wellenlängen (MAD). Dabei kann die Messung der anomalen Dispersion als ein Spezialfall des isomorphen Ersatzes aufgefasst werden. Wird bei den Methoden des isomorphen Ersatzes zusätzlich das anomale Signal eines Schweratoms bei einer einzelnen Wellenlänge zur Bestimmung der Position dieses Schweratoms verwendet, so wird diese Methode als einfacher bzw. multipler isomorpher Ersatz mit anomaler Streuung (SIRAS/MIRAS) bezeichnet. Zur Bestimmung der Phaseninformation der Struktur von hPrp22-H20 wurden SAD (mit KBr) und MAD (SeMet) verwendet. Direkte Methoden kamen auf Grund der Größe des Proteins nicht in Frage. Es konnte auch kein Modell für den molekularen Ersatz gefunden werden. Isomorpher Ersatz konnte auch nicht verwendet werden, da die derivatisierten und nativen Kristalle nicht isomorph waren.

Trägt man den atomaren Röntgen-Absorptionskoeffizient eines Elements gegen die Wellenlänge der Röntgenstrahlung graphisch auf, erhält man eine Kurve mit einem oder mehreren scharfen Maxima. Im Wellenlängenbereich dieser Absorptionskanten wird das Phänomen der anomalen Streuung beobachtet. Ein Teil der Energie des Röntgenstrahls wird durch die Schwermetal latome absorbiert und mit einer anderen Phase wieder emittiert. Die Konsequenz daraus ist, dass das Friedel-Gesetz nicht mehr gilt. Die Intensitäten (I) der inversionssymmetrischen Reflexe hkl und $-\mathrm{h}-\mathrm{k}-\mathrm{l}$ sind nicht mehr gleich. Aufgrund dieses Unterschieds haben die Friedel-Paare bei anomaler Streuung nicht mehr die gleiche Intensität und auch nicht mehr die genau entgegengesetzten Phasen. Durch diese Unterschiede zwischen den Friedel-Paaren kann die Phaseninformation gewonnen werden. Datensätze mit Schweratomen müssen bei Wellenlängen gemessen werden, bei denen das anomale Streuverhalten am höchsten ist, um maximale Signalausbeute zu gewährleisten. Die für die potentiellen Derivate aufgenommenen Datensätze wurden zunächst auf die Anwesenheit eines anomalen Signals überprüft, indem sie anomal skaliert (ohne Mitteln der Friedel Paare) und dann in HKL2MAP (Pape et al., 2004) prozessiert wurden. Diese Software verbindet verschiedene Programme der SHELX-Suite, von der Analyse skalierter Beugungsdaten (SHELXC), über Substrukturlösung (SHELXD) bis hin zur Phasierung (SHELXE) Jede einzelne Auflösungsschale wird bei der Analyse der Daten in SHELXC nach der Qualität des anomalen Signals bewertet, die als d"/sig (Verhältnis aus Stärke des anomalen Signals und dem Fehler der Daten) Wert dargestellt wird. Ist dieser Wert größer als 0,8, kann vom Vorhandensein eines Schweratoms ausgegangen werden. Weitere grafische Ausgaben dokumentieren anomale Korrelationskoeffizienten mit steigender Auflösung oder zeigen die Belegungswahrscheinlichkeiten der Schwermetallpositionen.

Zur genauen Bestimmung der Schweratompositionen wurde AUTOSHARP (Vonrhein et al., 2007) genutzt. Es bildet eine Bedienoberfläche, die Programme zur Suche von Schweratomen (SHELX) (Schneider et al., 2002), Verfeinerung ihrer Positionen (SHARP) (Bricogne et al., 2003; 
Fortelle et al., 1997) und Optimierung des Solvensgehaltes () (Matthews, 1968, Abrahams et al., 1996) kombiniert. Für die Phasierung mittels Br-SAD wurde ein Datensatz nahe der Absorptionskante von Brom (0,9202 $\mathrm{A})$ bei einer Wellenlänge von 0,91164 $\AA$ am Strahlrohr der BW7A am DESY in Hamburg aufgenommen. Des Weiteren wurde ein Selenomethionin-MADExperiment durchgeführt, bei dem 4 Wellenlängen gemessen wurden (peak 0,97976 ̊, inflection

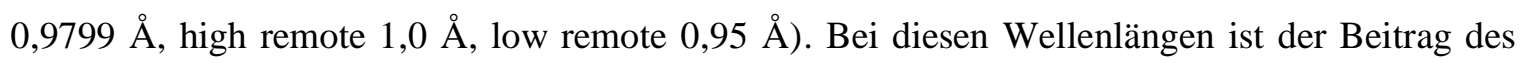
anomalen Signals unterschiedlich groß. Die Daten können so verglichen und die Qualität des Signals verbessert werden.

\subsubsection{Modellbau und Verfeinerung der Struktur}

Mit den experimentellen Elektronedichtekarten (SAD/MAD) aus AUTOSHARP (Vonrhein et al., 2007) wurden die ersten Modelle generiert. Dazu wurde RESOLVE (Terwilliger, 2000) verwendet (Skript siehe Anhang). Basierend auf diesen Modellen wurde die Struktur von hPrp22H20 in COOT (Emsley et al., 2004) gebaut und mit dem CCP4 Softwarepaket (REFMAC5) verfeinert. Die Qualität der Elektronedichtekarten ließ ein direktes Einsetzen der passenden Aminosäuren zu. Mit wachsender Kettenlänge verbesserten sich die Modellphasen und die Elektronendichte flexibler Regionen konnte verbessert werden. Während der Strukturverfeinerung werden sowohl die van-der-Waals-Abstände, polare und ionische Wechselwirkungen und Temperaturfaktoren der einzelnen Atome (B-Faktoren) berïcksichtigt, als auch die beobachteten den berechneten Strukturfaktoren angeglichen.

Die Qualität der Angleichung wird durch Vergleich der beobachteten und der aus dem Modell berechneten Strukturfaktoramplituden abgeschätzt. Als Maß für die Übereinstimmung wird der RFaktor verwendet. Der kristallographische R-Faktor $\mathrm{R}_{\text {cryst }}$ ist der aus diesem Vergleich berechnete Fehler und ist definiert als:

$$
R_{\text {cryst }}=\frac{\sum|| F_{o b s}|-| F_{c a l c}||}{\sum F_{o b s}}
$$

$\mathrm{F}_{\text {obs }}$ entspricht den beobachteten und $\mathrm{F}_{\text {calc }}$ den berechneten Strukturfaktoramplituden. Zur weiteren Kontrolle der Strukturverfeinerung wird der freie R-Faktor $\left(R_{\text {free }}\right)$ herangezogen (Brünger, 1992), der sich auf dieselbe Weise wie $\mathrm{R}_{\text {cryst }}$ berechnet, jedoch von nicht in die Verfeinerung einbezogenen Reflexen (5 \%) Gebrauch macht. Dieser sogenannte Testsatz wird zur Kreuzvalidierung eingesetzt, um die Konvergenz der Strukturverfeinerung zu kontrollieren. Darüber hinaus wird die verfeinerte Elektronendichtekarte mit der ursprünglichen Dichte, berechnet aus der Phaseninformation des molekularen Ersatzes verglichen und die resultierende $\mathrm{F}_{\mathrm{obs}}-\mathrm{F}_{\text {calc }}$ Elektronendichtekarte zum Abgleich während des Modellbaus verwendet. 


\section{Ergebnisse}

\subsection{Klonierung und Reinigung des hPrp2 Volllängenproteins}

$\mathrm{Zu}$ Beginn dieser Arbeit wurden Plasmide mit dem Gen von hPrp2 verwendet, die aus der Plasmidsammlung der Abteilung von R. Lührmann am Max-Planck Institut für Biophysikalische Chemie entstammten. Es standen zwei Expressionsvektoren mit dem Volllängenprotein zur Verfügung, pETMZZ-hPrp2 und pETM10-hPrp2. Leider enthielten die Gene vier schwerwiegende Mutationen. Es wurde versucht die Mutationen mittels Mutagenese-PCR zu entfernen, jedoch gelang dies nicht, da die Mutationen zu zahlreich waren. Dennoch wurde versucht eine Expression- und Aufreinigungsstrategie zu etablieren. Die Expression des Proteins in E.coli war möglich, jedoch war die Löslichkeit sehr schlecht. Die Optimierung der Expression blieb erfolglos.

Um alle störenden Einflüsse durch die Mutationen zu entfernen, wurde das Gen aus einer humanen cDNA-Bank (MegaMan, Stratagene) neu kloniert. Dies gestaltete sich anfangs kompliziert, da das Gen eine Länge von 3123 bp hat. Nach langwieriger Optimierung der PCRBedingungen, gelang es schließlich das Gen zu amplifizieren (Abb.12) und in den Expressionsvektor pETM30 zu ligieren. Als Restriktionsschnittstellen dienten NcoI und EcoRI. Die Sequenzierung bestätigte die Fehlerfreiheit des Gens von hPrp2.

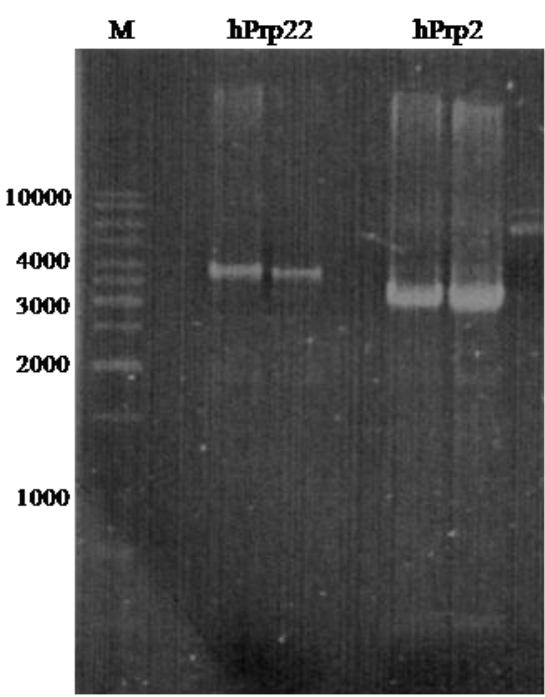

hPrp22 (3663 bp) und hPrp2 (3123 bp). Markerangaben (links) in bp.

Der verwendete Expressionsvektor codierte für ein GST-Fusionsprotein, welches durch eine TEV-Proteaseschnittstelle mit dem Zielprotein verbunden war. Dieses Fusionsprotein hatte eine Masse von ca. $150 \mathrm{kDa}$. Die Optimierung Expressionsbedingungen war kompliziert, da die Bakterienzellen kein reproduzierbares Wachstum zeigten. Bei jeder dritten Expression kam es nach der Induktion durch IPTG zu einer verfrühten Zelllyse der Rosetta 2 (DE3) Zellen. Dennoch wurde versucht das Protein über eine GSH-Sepharose zu reinigen. Nach der schwachen Induktion 
der Expression von GST-hPrp2 (Abb.13a) folgte die Zelllyse im Puffer GSH A (2.2.3.2). Die Löslichkeit war sehr hoch. Nach dem gründlichem Waschen der GSH-Sepharose wurde das Fusionsprotein eluiert (Abb.13a). Jedoch zeigte sich ein hoher Grad an Kontamination durch Fremdproteine. Durch Zugabe von TEV-Protease wurde die GST-Komponente des Fusionsproteins entfernt (Abb.13a). Die Effizienz des Verdaus lag bei 70 - 80\%. Anschließend folgte eine Größenausschlusschromatographie mit einer S 200 XK 26/60. Dabei eluierte das Protein nicht bei einem für ein $120 \mathrm{kDa}$ erwartetem Volumen, sondern im Ausschlussvolumen der Säule. Offenbar haben sich oligomere Strukturen gebildet, die eine Masse oberhalb der maximalen Trenngröße der Säule haben. Auch waren immer noch Kontaminationen erkennbar.
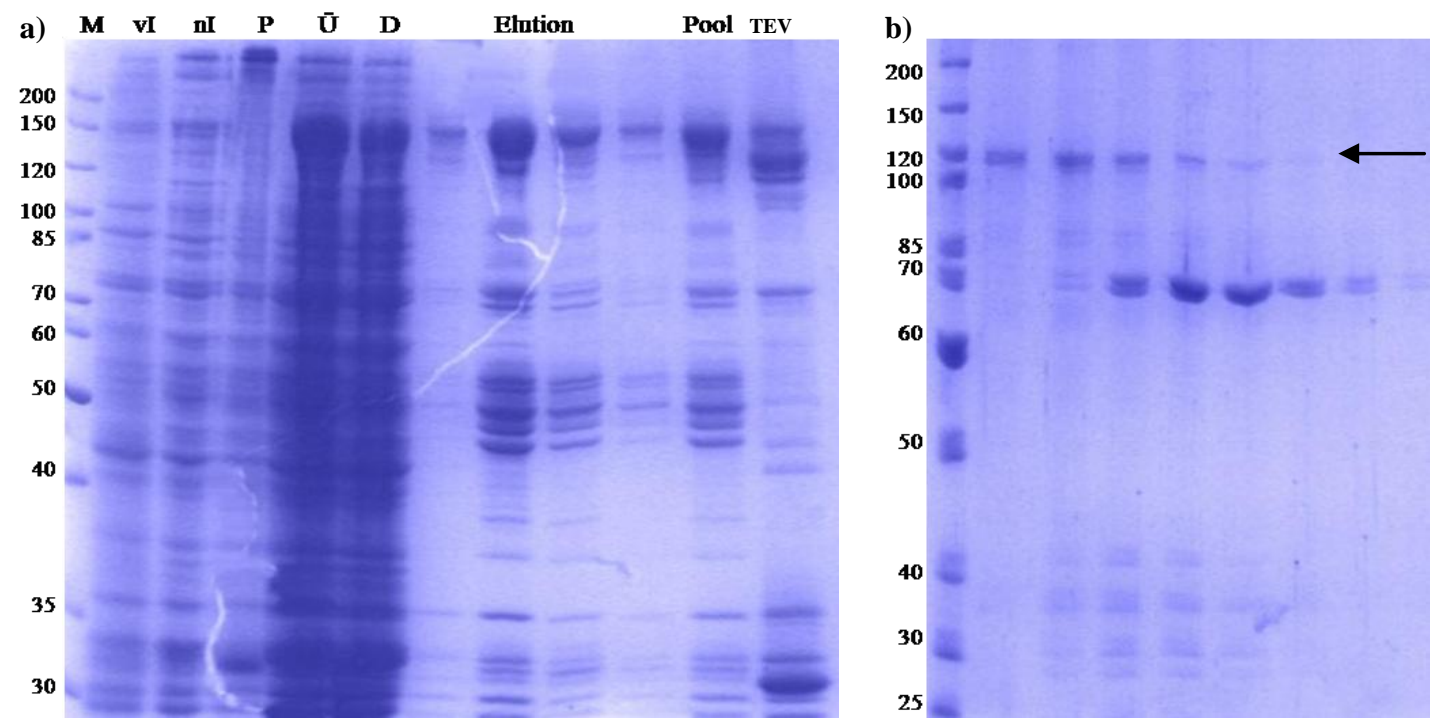

[Abb.13] SDS-PAGE der Aufreinigung von GST-hPrp2. a) Induktion der Expression in Rosetta 2 (DE3): vI = vor Induktion, $\mathrm{nI}=$ nach Induktion. Löslichkeit: $\mathrm{P}=$ Pellet, $\ddot{\mathrm{U}}=$ Überstand. Elution des Fusionsproteins von der GSHSepharose. Proteaseverdau: TEV. GST-hPrp2: 150 kDa, hPrp2: 120 kDa (Pfeil), GST: 29 kDa b) Gelfiltration S200 XK 26/60, Fraktionen des Ausschlussmaximums. starke Kontaminationen bei 70 kDa Markerangaben (links) in kDa.

Durch Erhöhung der Salzkonzentration wurde versucht dieser unspezifischen Oligomerisierung entgegenzuwirken. Eine mehrfache Veränderung der Puffer und das Einsetzen von Ionenaustauschchromatographie (DEAE-/ CM-Sepharose) änderte an diesem Ergebnis nichts. Das Volllängenprotein hatte zudem eine geringe Stabilität, so dass es beim Ankonzentrieren auf der Membran des Zentrikons präzipitierte. Die Ausbeuten waren am Ende so gering, dass eine Weiterverarbeitung unmöglich war. Aus 101 Expressionskultur konnten $100 \mu \mathrm{g}$ hPrp2 gewonnen werden. Das Gen wurde noch in pET-21a kloniert. Bei Reinigungstests zeigte sich jedoch, dass hPrp2-His 6 unlöslich war. Des Weiteren wurde versucht das Gen in Saccharomyces cerevisiae zu exprimieren. Dazu wurde hPrp2 in den pYX Hefevektor kloniert. Expression war jedoch nicht erkennbar. Nach diesen Ergebnissen wurde die Arbeit mit dem Volllängenprotein von hPrp2 eingestellt. 


\subsection{Klonierung und Reinigung des hPrp22 Volllängenproteins}

Da das eigentliche Projekt dieser Arbeit die Strukturaufklärung von hPrp22 war, musste das Volllängenprotein kloniert werden. Das Gen wurde aus einer humanen cDNA-Bank (MegaMan, Stratagene) heraus mittels PCR amplifiziert (Abb.12). Wie die Klonierung von hPrp2 bedurfte es auch hier einer intensiven Optimierung, da das Gen eine Länge von 3663 bp hatte. Es gelang das PCR-Produkt mit den Restriktionsschnittstellen EcoRI und NotI in pGEX-6P1 zu ligieren. Die Sequenzierung bestätigte die Fehlerfreiheit des Gens von hPrp22. Der gewählte Expressionsvektor codierte für ein GST-Fusionsprotein, welches über eine PreScission Proteaseschnittstelle mit dem Zielprotein verbunden war. Das Fusionsprotein hatte eine Masse von ca. $170 \mathrm{kDa}$. Die Expression wurde in E.coli Rosetta 2 (DE3) durchgeführt. Die Induktion und die Reinigung über GSH-Sepharose unter Standardbedingungen (2.2.3.2) funktionierten reibungslos. Die proteolytische Abspaltung des GST funktionierte mit einer Effizienz von 50 - 70 \%. Bei der Größenausschlusschromatographie mit einer Superdex 200 XK 26/60 eluierte das Protein jedoch wie hPrp2 im Ausschlussvolumen. Eine Erhöhung der Salzkonzentration im Gelfiltrationspuffer auf $300 \mathrm{mM} \mathrm{NaCl}$, Lyse in einem Puffer mit $2 \mathrm{M} \mathrm{LiCl}$ und Zugabe von 5\% Glycerin verbesserte das Laufverhalten des Proteins. Ein Teil von hPrp22 konnte in einen monomeren Zustand überführt werden (Abb.14a). Um der unspezifischen Oligomerisierung auf den Grund zu gehen, wurde das SDS-Gel nach der Proteinfärbung einer weiteren Nukleinsäurefärbung mit Ethidiumbromid unterzogen. Dabei zeigte sich, dass die Proben des Ausschlussmaximums (280 nm) stark mit DNA oder RNA kontaminiert waren (Abb.14b).

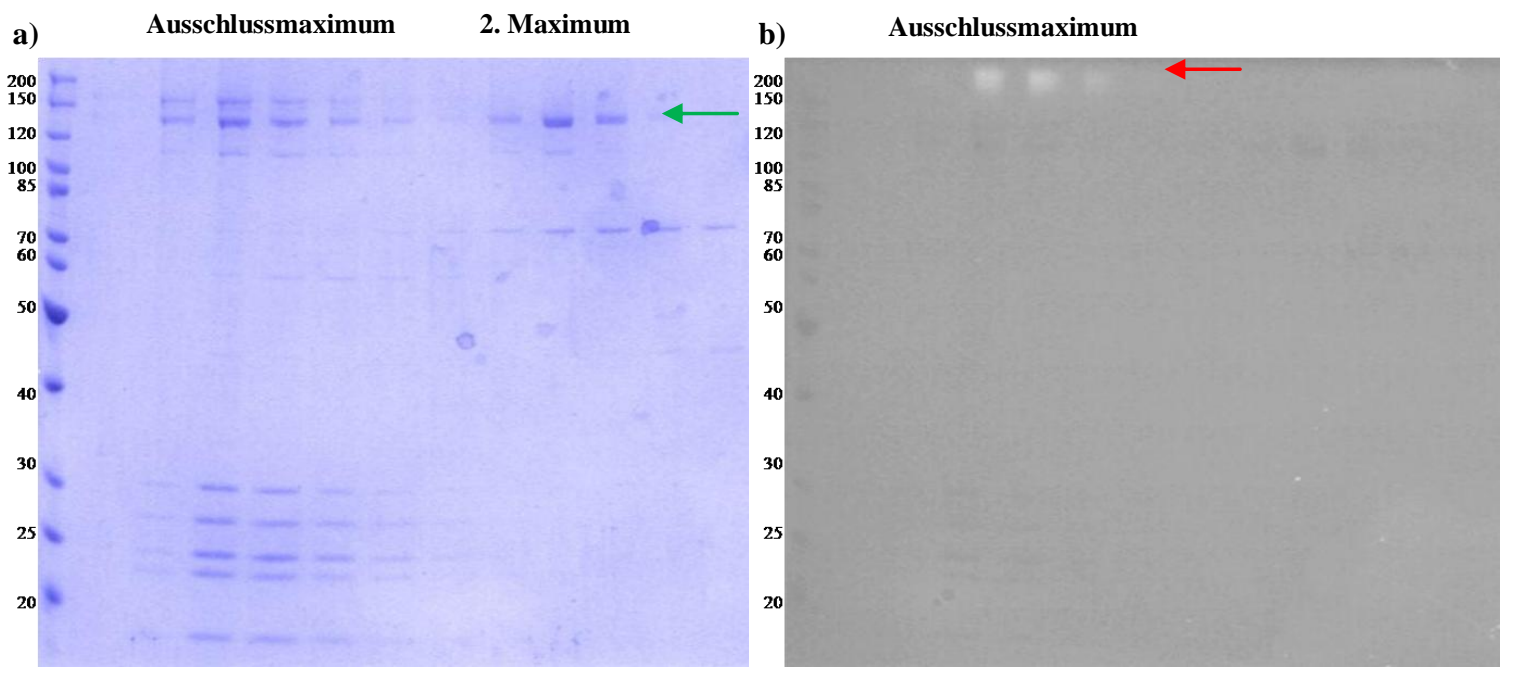

[Abb.14] SDS-PAGE der Gelfiltration von hPrp22 nach der Proteolyse. a) Gelfiltration S200 XK 26/60, Fraktionen des Ausschlussmaximums und des 2. Maximums. GST-hPrp22: 170 kDa, hPrp22: 140 kDa (grüner Pfeil), GST: 29 kDa b) Die Ethidiumbromidfärbung des gleichen SDS-Gels zeigt die Nukleinsäurekontaminationen auf (roter Pfeil) Markerangaben (links) in kDa. 
Da hPrp22 zahlreiche RNA-Bindungsmotive aufweist, bindet es offensichtlich an langkettigen bakteriellen Nukleinsäuren. Diese Vernetzung führt zur Bildung großer Komplexe. Eine Behandlung der Proben mit RNase und DNase oder leichtes Denaturieren des Proteins mit CHAPS führte nicht zur Auflösung dieser Komplexe.

Der monomere Anteil nach Gelfiltration zeigte eine gute Stabilität und konnte bis auf $5 \mathrm{mg} / \mathrm{ml}$ ankonzentriert werden. Aus 101 Expressionskultur konnten bis zu 2 mg hPrp22 gewonnen werden. Trotz der immer noch erkennbaren Kontaminationen wurde versucht das Protein zu kristallisieren. Alle verfügbaren Kristallisationsbedingungen wurden genutzt, jedoch präzipitierte hPrp22 in $99 \%$ aller Ansätze direkt nach dem Pipettieren. Auch eine Verringerung der Proteinkonzentration auf $1 \mathrm{mg} / \mathrm{ml}$ veränderte dieses Verhalten nicht.

Um die Reinheit des Proteins zu verbessern und so störende Einflüsse zu minimieren, wurde versucht die Kontaminationen mittels Ionenaustauschchromatographie (Resource S, Resource Q) zu entfernen. Dies gelang jedoch nicht. Des Weiteren wurde die Expression mit einer zweiten, Cterminalen Strep-Tag-Affinitätssequenz etabliert. Nach Affinitätschromatographie über StrepTactin-Sepharose und Gelfiltration zeigte sich ein ähnliches Bild. Protein mit HexahistidinAffinitätssequenz (pET-21a und pET-22b) war vollständig unlöslich. Weiterhin wurde versucht hPrp22 in Saccharomyces cerevisiae zu exprimieren. Das Gen wurde in die Hefevektoren pYX und pEG(KT) (Grabowski et al., 1997) kloniert. Wie auch bei hPrp2 war eine Induktion der Expression nicht detektierbar. Der Versuch einer Expression in Insektenzellen wurde begonnen, indem hPrp22 in den pQE-TriSystem1-Vektor, ein Hybridvektor für Bakterien-, Insekten- und Säugerzellen, kloniert wurde. Jedoch funktionierte die Generierung des Bacmids nicht und die Insektenzellen konnten nicht transfiziert werden. Nachdem keine weitere Optimierung erfolgreich war, wurde die weitere Arbeit mit dem Volllängenprotein von hPrp22 eingestellt.

\subsection{Design und Klonierung von Deletionsmutanten von hPrp22 und hPrp2}

Da die Kristallisation der Volllängenproteine nicht möglich war, lag es nah verkürzte Varianten zu generieren. Basis der Überlegungen des Designs der Deletionsmutanten war der modulare Domänenaufbau der Proteine. Fragmente, die eine oder mehrere der vorhergesagten Domänen enthalten wurden kreiert (Abb.14/15). Dabei wurden die Grenzen der Proteinfragmente mit Hilfe der Domänenvorhersage von SMART (Schultz et al., 1998) bestimmt. Durch eine Sekundärstrukturvorhersage mit PSIPRED (Jones, 1999) wurde sichergestellt, dass keine Sekundärstrukturmotive ( $\alpha$-Helix, $\beta$-Faltblatt) unterbrochen wurden. Alle Deletionsmutanten beginnen vor und enden nach einer vorhergesagten $\alpha$-Helix. 


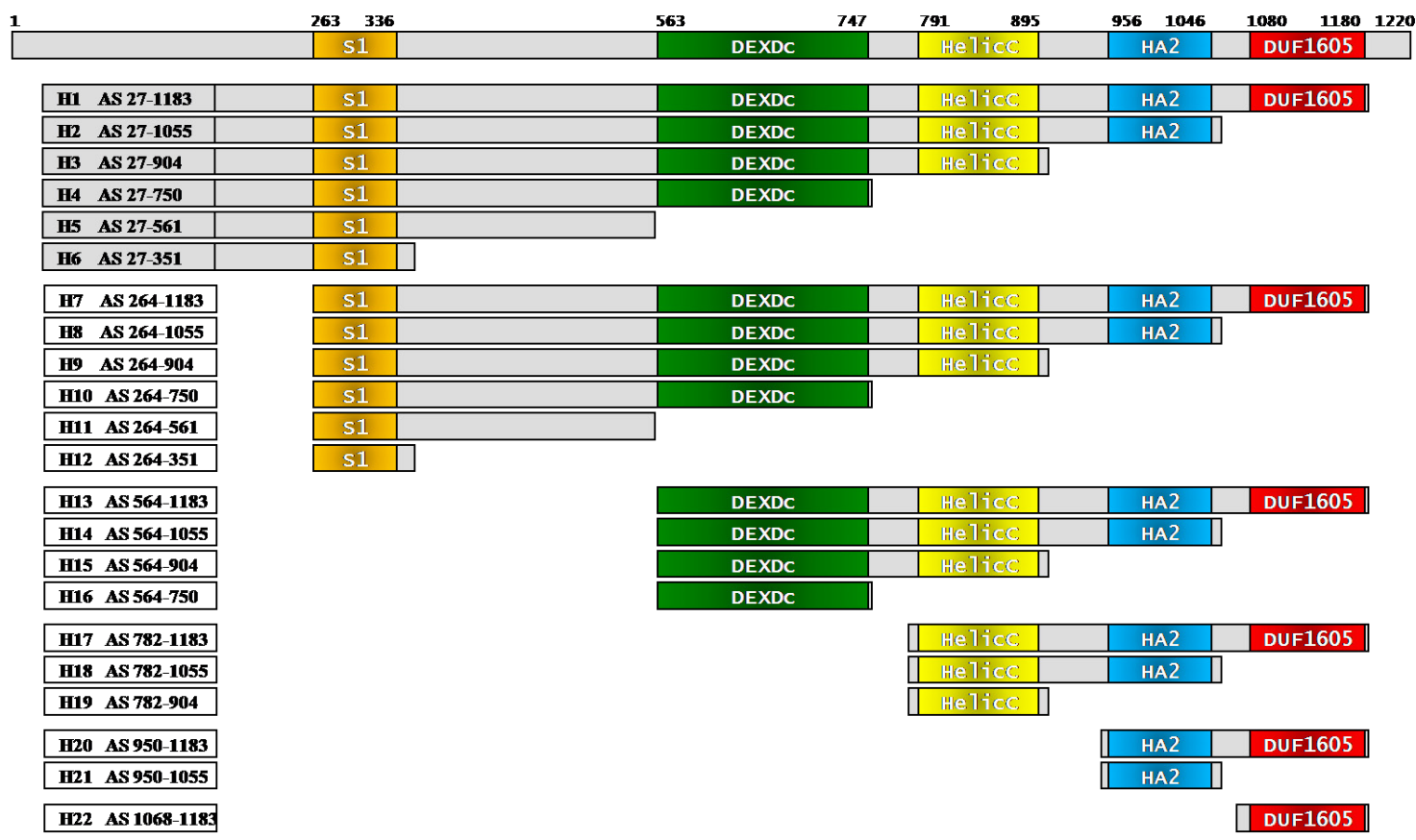

[Abb.15] Deletionsmutanten von hPrp22. Die vorhergesagten Domänen sind eingefärbt: orange: S1-Domäne, grün: DEXDc-Domäne, gelb: HelicC-Domäne, blau: HA2-Domäne, rot: DUF1605-Domäne. Oben: Volllängenprotein.

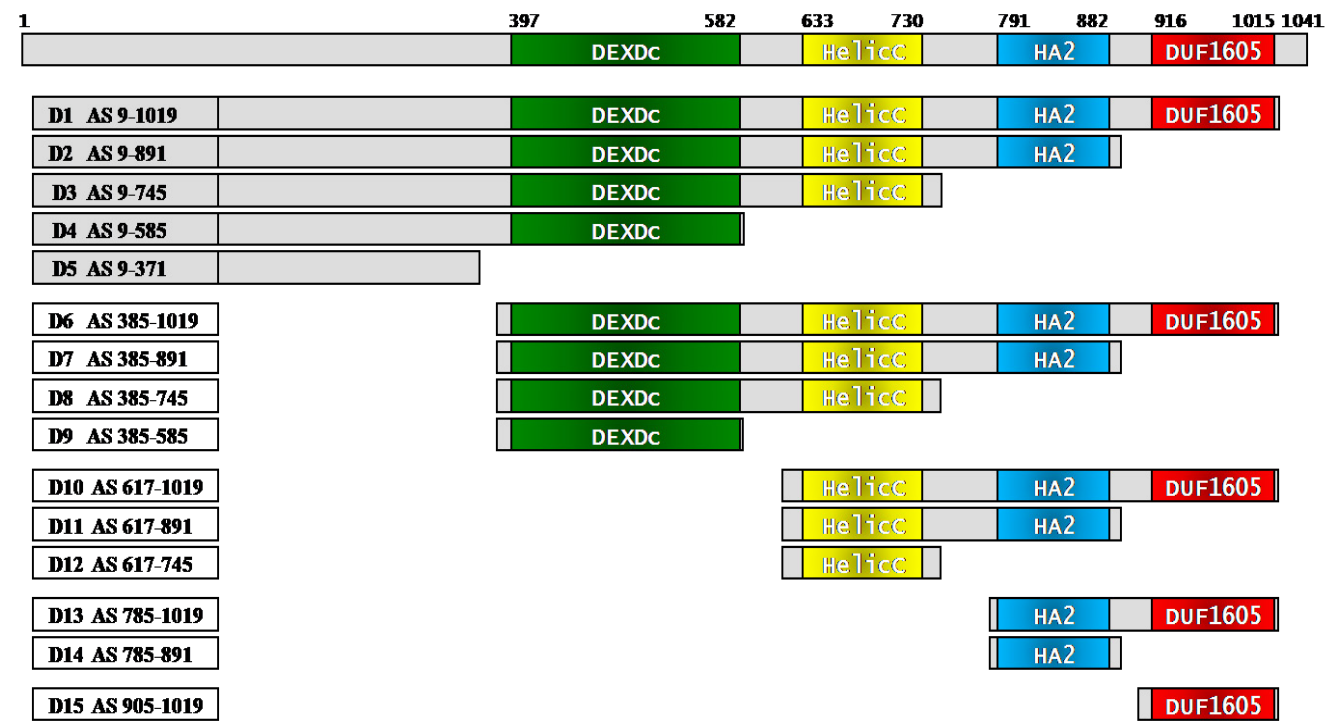

[Abb.16] Deletionsmutanten von hPrp2. Die vorhergesagten Domänen sind eingefärbt: grün: DEXDc-Domäne, gelb: HelicC-Domäne, blau: HA2-Domäne, rot: DUF1605-Domäne. Oben: Volllängenprotein.

Von hPrp22 wurden 22 verkürzte Varianten generiert (Abb.15). Sie wurden über die Restriktionsschnittstellen BamHI und XhoI in die Expressionsvektoren pET-21a, pGEX-6P1 und pPR-IBA1 ligiert. Weiterhin wurden 15 Fragmente von hPrp2 entworfen (Abb.16), die über EcoRI und XhoI in pET-21a, pGEX-6P1 und pPR-IBA1 einkloniert wurden. Die Sequenzen, Längen, Massen und isoelektrischen Punkte aller Deletionsmutanten sind im Anhang aufgelistet. Weiterhin sind dort die Polylinker der gewählten Vektoren abgebildet. 
Die Amplifikation der Deletionsmutanten von hPrp22 und hPrp2 wurde mit einem einzigen PCRProgramm durchgeführt. Mit Phusion Polymerase konnten alle Fragmente beim ersten Versuch amplifiziert werden (Abb.17).

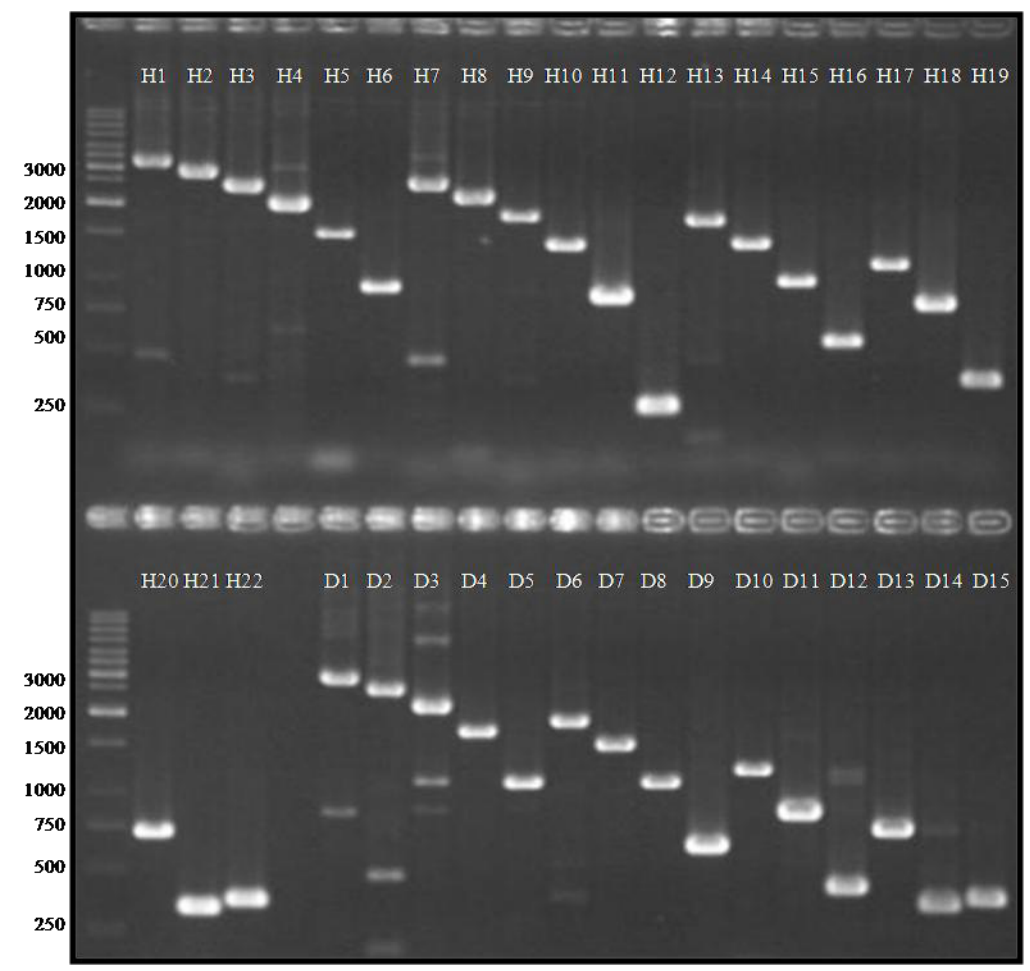

[Abb.17] 1\%iges Agarosegel mit den PCR-Produkten aller Verkürzungen von hPrp22 (H1-H22) und hPrp2 (D1-D15) Markerangaben (links) in kb.

Die Deletionsmutanten von hPrp22, im Folgenden H1 - H22 benannt (nach HRH1), und hPrp2, D1 - D15 (nach DBP2), wurden in die Expressionsvektoren pET-21a, pGEX-6P1 (von Marion Lösing) und pPR-IBA1 (von Christian Nagel) ligiert. Insgesamt wurden 111 Vektorkonstrukte geschaffen.

Bei den anschließenden Expressions- und Löslichkeitstests wurde sich daher auf einige ausgewählte Konstrukte beschränkt. Neben den anschließend aufgeführten Reinigungen der Deletionsmutanten H12, H13, H15 und H20, konnten auch noch weitere Verkürzungen gewonnen werden, auf deren Dokumentation im Rahmen dieser Arbeit jedoch verzichtet wird. Es ließ sich keines der Fragmente von hPrp2 mit zufriedenstellender Reinheit und Stabilität gewinnen. 


\subsection{Reinigung und Kristallisation einiger Verkürzungen von hPrp22}

\subsubsection{Reinigung und Kristallisation der hPrp22-Deletionsmutante H12}

\section{S1}

Die Deletionsmutante H12 enthielt die S1-Domäne von hPrp22 (AS 264 - 351). Das Fragment hatte eine Länge von 88 Aminosäuren, war 9,9 kDa schwer und hatte einem theoretischen isoelektrischen Punkt von 9,58. Es wurde als GST-Fusionsprotein (pGEX-6P1) exprimiert und gereinigt (2.2.4.1). Das Molekulargewicht des Fusionsproteins betrug 37,6 kDa und der pI lag bei 6,73 .

Die Aufreinigung bei pH 8 resultierte in hoher Reinheit und großer Ausbeute des Proteins. Das Fusionsprotein eluierte mit geringen Kontaminationen von der GSH-Sepharose (Abb.18a). Der anschließende PreScission Proteaseverdau (PP) über 8 h hatte eine Effizienz von $80-100 \%$. Bei der Größenausschlusschromatographie mittels Superdex 75 XK 26/60 konnte man zwei scharfe Maxima in der UV-Absorption beobachten. Das hochreine H12 eluierte im zweiten Maximum bei ca. $240 \mathrm{ml}$. Bei einer Aufreinigung nach autoinduktiver Genexpression wurden 0,5 g H12 aus 11 Expressionskultur gewonnen. Das Protein konnte bis auf $50 \mathrm{mg} / \mathrm{ml}$ ankonzentriert werden.

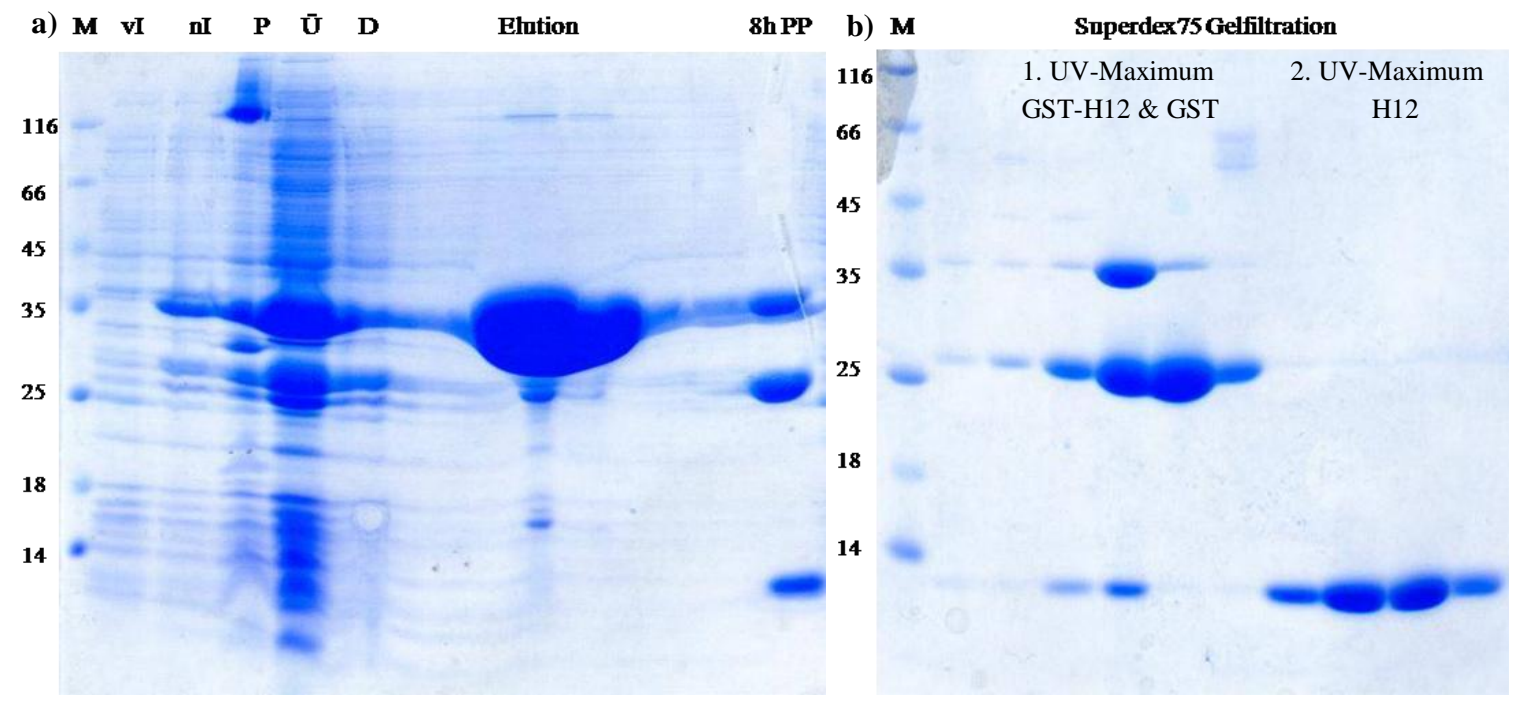

[Abb.18] SDS-PAGE der Aufreinigung von H12. a) Induktion der Expression in Rosetta 2 (DE3): vI = vor Induktion, $\mathrm{nI}=$ nach Induktion. Löslichkeit: $\mathrm{P}=$ Pellet, $\ddot{\mathrm{U}}=$ Überstand. $\mathrm{D}=$ Durchfluss, Elution des Fusionsproteins von der GSHSepharose. Proteaseverdau: 8h PP. GST-H12: 38 kDa, H12: 10 kDa, GST: 29 kDa. b) Gelfiltration S75 XK 26/60, Fraktionen des 1. und 2. UV-Maximums. Markerangaben (links) in kDa. 
Nach der Reinigung wurde versucht $\mathrm{H} 12$ zu kristallisieren. Alle verfügbaren Kristallisationsbedingungen wurden pipettiert. Dabei wurden Proteinkonzentrationen von 7 - 25 $\mathrm{mg} / \mathrm{ml}$ eingesetzt und die Kristallisationsbedingungen bei Temperaturen von 4 und $20{ }^{\circ} \mathrm{C}$ inkubiert. In einigen Kristallisationsbedingungen (Tab.3) zeigten sich nach kurzer Zeit kristalline Strukturen (Abb.19a).

\begin{tabular}{ll} 
Kristallisationsscreen & Zusammensetzung \\
\hline Crystal Screen I \#38 & 1,4 M NaCitrat, 0,1 M HEPES pH 7,5 \\
Crystal Screen II \#17 & $0,1 \mathrm{M} \mathrm{NaCitrat} \mathrm{pH} \mathrm{5,6,35 \%} \mathrm{Butanol}$ \\
Crystal Screen II \#28 & $1,6 \mathrm{M} \mathrm{NaCitrat} \mathrm{pH} \mathrm{6,5}$ \\
Footprint I \#24 & $1,5 \mathrm{M} \mathrm{NaCitrat,} \mathrm{10} \mathrm{mM} \mathrm{Borat} \mathrm{pH} \mathrm{8,5}$ \\
JB 6 \#19 & $0,1 \mathrm{M} \mathrm{NaCitrat} \mathrm{pH} \mathrm{5,6,} \mathrm{2,4} \mathrm{M}\left(\mathrm{NH}_{4}\right)_{2} \mathrm{SO}_{4}$ \\
JB 10 \#13 & $1,5 \mathrm{M} \mathrm{NaCitrat} \mathrm{pH} \mathrm{6,5}$
\end{tabular}

[Tab.3] Initiale Kristallisationsbedingungen von $\mathrm{H} 12$

Die Optimierung der Kristallisationsbedingung führte zu ovalen Kristallen von $50-150 \mu \mathrm{M}$ Größe (Abb.19b). Dabei wurde die NaCitrat-Konzentration auf 1,28 - 1,36 M, der pH Wert auf 6,5 - 6,8 und die Proteinkonzentration auf $15 \mathrm{mg} / \mathrm{ml}$ eingestellt. Die Bedingungen wurden bei 10 und $20^{\circ} \mathrm{C}$ inkubiert. Die Optimierung der initialen Kristallisationsbedingungen Crystal Screen II \#17 und JB 6 \#19 führte zu keiner Verbesserung des Kristallwachstums.
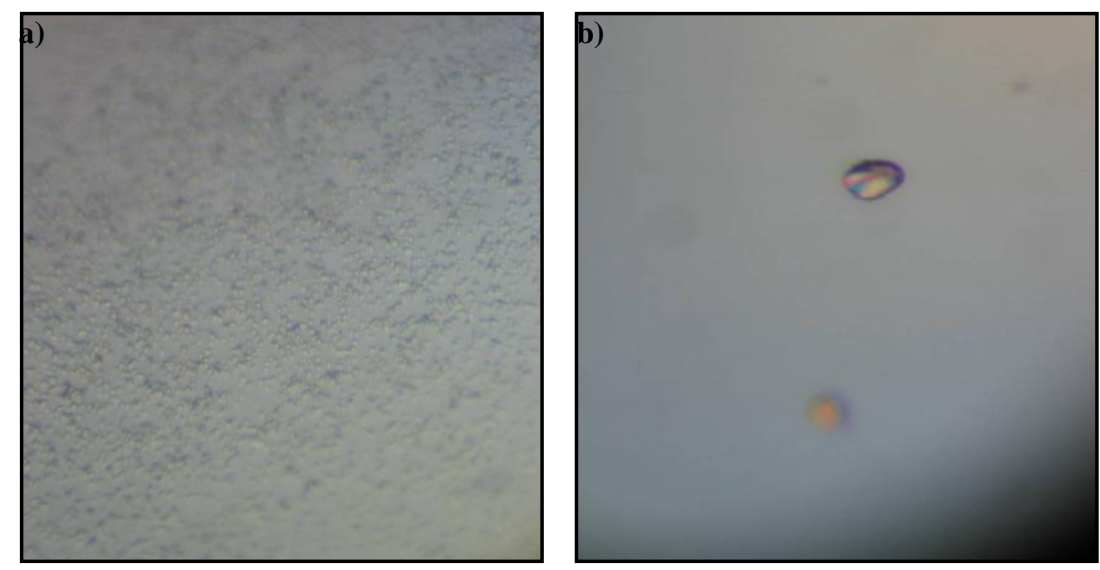

[Abb.19] Proteinkristalle von H12. a) Sphärulithe in initialer Kristallisationsbedingung JB 10 \#13 [1,5 M NaCitrat pH 6,5]. b) Optimierung des Kristallwachstums [1,3 M NaCitrat pH 6,5]. $100 \mu \mathrm{m}$ Durchmesser.

Bei Beugungsexperimenten am Röntgendiffraktometer Micromax 007 zeigte sich jedoch, dass die Proteinkristalle nicht streuten. Ihre innere Ordnung war so heterogen, dass es zu keiner ausreichenden konstruktiven Interferenz zwischen den Teilstreuwellen der Röntgenstrahlung kam. Auf dem Detektor bildeten sich keine Spots ab. Eine weitere Optimierung des Kristallwachstums durch Modifikation der Kristallisationsbedingung und Seeding-Experimente (2.2.6.2) führte zu keiner Verbesserung des Streuverhaltens. 


\subsubsection{Reinigung der hPrp22-Deletionsmutante H13}

Die Deletionsmutante H13 enthielt die für die ATPase- und Helikasefunktion notwendigen Domänen DEXDc und HELICc und die beiden vorhergesagten C-terminalen Domänen HA2 und DUF1605 von hPrp22 (AS 564 - 1183). Das Fragment hatte eine Länge von 620 Aminosäuren, war 70,2 kDa schwer und hatte einen theoretischen isoelektrischen Punkt von 6,27. Es wurde als Strep-Tag-Fusionsprotein (pPR-IBA1) exprimiert und gereinigt (2.2.4.2). Das Molekulargewicht des Proteins mit Strep-Tag-Affinitätssequenz betrug 74,2 kDa und der pI lag bei 5,94. Diese Deletionsmutante von hPrp22 wurde im autoinduzierenden ZYM-5052-Medium exprimiert, da sowohl die Löslichkeit, als auch die Ausbeute pro Liter gegenüber IPTG-induzierter Expression im 2YT-Medium 20-fach höher war. Zusätzliche Induktion mit IPTG nach 12 - 18 h Inkubation erhöhte die Ausbeute nochmals. Das Protein wurde bei pH 7,5 aufgereinigt. Es war zwingend notwendig dem Lysepuffer $2 \mathrm{M} \mathrm{LiCl}$ zuzugeben, da das Protein andernfalls vollständig im Ausschlussvolumen der Superdex 200 XK 26/60 Gelfiltrationssäule eluierte und starke Kontaminationen durch RNA aufwies. Bei der Größenausschlusschromatographie (S200 XK 26/60) eluierte das Protein bei $185 \mathrm{ml}$ (niedriges UV-Absorptionsmaximum). Das Protein ließ sich als Monomer von hoher Reinheit gewinnen (Abb.20). Die Ausbeute pro Liter Expressionskultur betrug $2-5 \mathrm{mg}$. Die Deletionsmutante $\mathrm{H} 13$ konnte bis auf $15 \mathrm{mg} / \mathrm{ml}$ ankonzentriert werden.

[Abb.20] SDS-PAGE. Reinheit von H13-Strep nach der Gelfiltration S200 XK 26/60, Fraktionen des UVMaximums bei $185 \mathrm{ml}$. H13-Strep: 74 kDa. Markerangaben (links) in kDa.

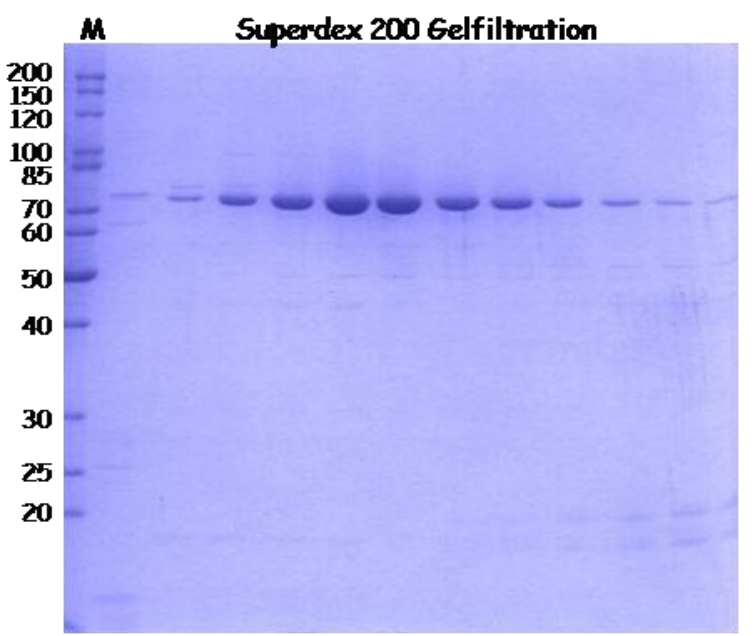

Für die Kristallisation von H13 wurden alle verfügbaren Kristallisationsscreens verwendet. Dabei wurden das Protein in Konzentrationen von $5-10 \mathrm{mg} / \mathrm{ml}$ eingesetzt und bei $4{ }^{\circ} \mathrm{C}$ und $20{ }^{\circ} \mathrm{C}$ gelagert. In den meisten der Bedingungen präzipitierte H13 direkt nach der Zugabe. Trotz intensiver Bemühungen, konnte keine Bildung kristallähnlicher Strukturen der Deletionsmutante H13 beobachtet werden. Mit dem Protein, das nicht für die Kristallisation benötigt wurde, konnten ATPase-Test durchgeführt werden (3.6). 


\subsubsection{Reinigung der hPrp22-Deletionsmutante H15}

\section{DEXDC}

Im Vergleich zu H13 enthielt die Deletionsmutante H15 ausschließlich die für die ATPase- und Helikasefunktion notwendigen Domänen DEXDc und HELICc. Sie hatte eine Länge von 341 Aminosäuren, war $38 \mathrm{kDa}$ schwer und ihr theoretischer isoelektrischer Punkt lag bei 5,43. Das Proteinfragment wurde ebenfalls als Strep-Tag-Fusionsprotein (pPR-IBA1) exprimiert und gereinigt (2.2.4.3). Das Molekulargewicht des Proteins mit Strep-Tag-Affinitätssequenz betrug 42 kDa und der pI lag bei 5,25. Die Deletionsmutante H15 wurde analog zu H13 exprimiert und aufgereinigt. Wiederum war $2 \mathrm{M} \mathrm{LiCl}$ im Lysepuffer essentiell, um Oligomerisierung zu verhindern. Bei der Größenausschlusschromatographie eluierte das Protein mit einem UVAbsorptionsmaximum bei $160 \mathrm{ml}$ (Monomer). Es gab aber auch ein UV-Maximum im Ausschlussvolumen der verwendeten S75 XK 26/60, bei dem ca. $30 \%$ der Gesamtmenge von H15 eluierte (Oligomer). Neben geringfügigen Kontaminationen von ca. 18 kDa Masse war das Protein rein (Abb.21) und konnte für die Kristallisation verwendet werden. Die Ausbeute pro Liter Expressionskultur betrug 1 - 3 mg.

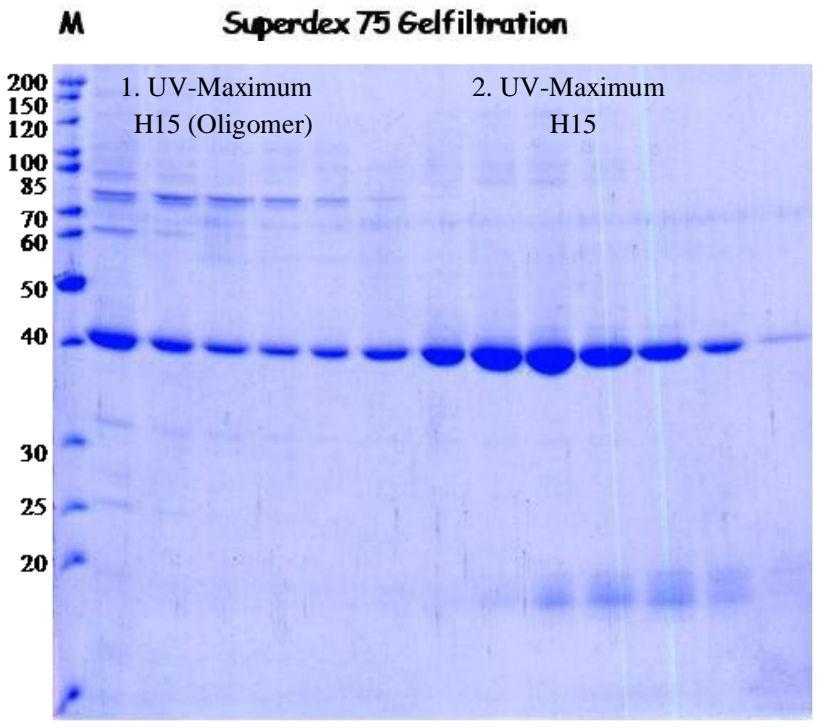

[Abb.21] SDS-PAGE der Gelfiltration (S75 XK 26/60) von H15-Strep. Fraktionen des 1. UV-Maximums kontaminiert durch Fremdproteine (oligomere Strukturen). Fraktionen des 2. UV-Maximums mit monomerem H15-Strep und leichten Kontaminationen bei $18 \mathrm{kDa}$. H15-Strep: 42 $\mathrm{kDa}$. Markerangaben (links) in kDa.

Das Protein konnte bis auf $10 \mathrm{mg} / \mathrm{ml}$ ankonzentriert werden und wurde in allen verfügbaren Kristallisationsscreens verarbeitet. Dabei wurden eine Proteinkonzentration von $5-7 \mathrm{mg} / \mathrm{ml}$ eingesetzt und die Bedingungen wurden bei $4{ }^{\circ} \mathrm{C}$ und $20{ }^{\circ} \mathrm{C}$ inkubiert. Es kam jedoch nicht zu einer Kristallisation der Deletionsmutante H15. Nach erfolgloser Kristallisation wurde das Protein für ATPase-Tests verwendet (3.6). 


\subsubsection{Reinigung und Kristallisation der hPrp22-Deletionsmutante H20}

\section{HA2 $\quad$ DUF1605}

Die letzte hier aufgeführte Deletionsmutante H20 beinhaltete die beiden vorhergesagten Cterminalen Domänen HA2 und DUF1605 von hPrp22 (AS 950-1183). Dieses Proteinfragment war von besonderem Interesse, da weder Struktur, noch Funktion der Domänen bekannt waren. Diese Verkürzung von hPrp22 hatte eine Länge von 234 Aminosäuren, war 27,2 kDa schwer und hatte einem theoretischen isoelektrischen Punkt von 8,93. Es wurde als Strep-Tag-Fusionsprotein (pPR-IBA1) in einer nativen und Selenomethionin-derivatisierten Form exprimiert und gereinigt (2.2.4.4, 2.2.4.5). Das Molekulargewicht des Proteins mit Strep-Tag-Affinitätssequenz betrug $31,2 \mathrm{kDa}$ und der theoretische pI lag bei 7,68. Die Expression der nativen Variante von H20 erfolgte analog zu der von H13. Das Selenomethionin-Derivat von H20 wurde wie unter 2.4.4.5 beschrieben gewonnen. Die Löslichkeit von H20 lag trotz Optimierung bei nur 30 \% (Abb.22a). $\mathrm{LiCl}$ im Lysepuffer verhinderte wiederum unspezifische Zusammenlagerungen des Proteins, was sich an dem geringen Kontaminationsgrad durch Fremdproteine bei der Elution von der StrepTactin-Säule zeigte (Abb.22a). Bei der Größenausschlusschromatographie mit einer Superdex 75 XK 26/60 eluierte mit einem UV-Maximum bei $170 \mathrm{ml}$. Das Laufverhalten und die Reinheit (Abb.22b) beider Varianten von H20 waren identisch. Pro Liter Expressionskultur konnten bis zu $5 \mathrm{mg}$ reines Protein gewonnen werden.
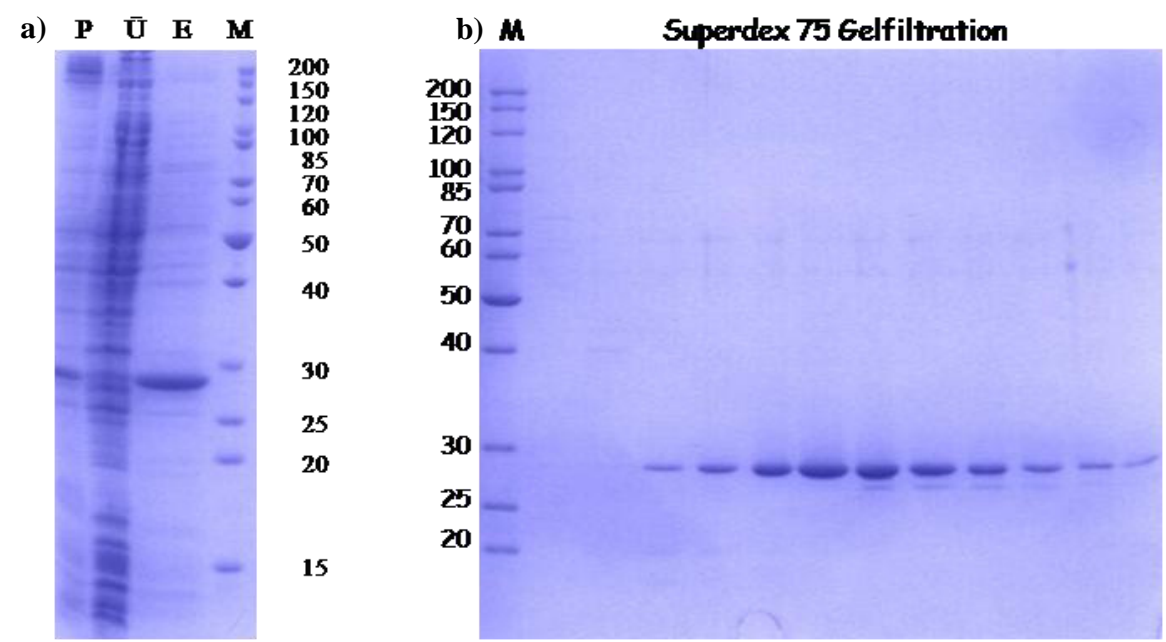

[Abb.22] SDS-PAGE der Aufreinigung von H20-Strep. a) Löslichkeit ca. $30 \%: \mathrm{P}=$ Pellet, $\ddot{\mathrm{U}}=$ Überstand. $\mathrm{E}=$ Elution des Proteins von der Strep-Tactin-Sepharose. b) Gelfiltration S75 XK 26/60, Fraktionen des UV-Maximums bei 170 ml. H20-Strep: $31 \mathrm{kDa}$. Markerangaben in kDa.

Das Protein wurde auf $7 \mathrm{mg} / \mathrm{ml}$ ankonzentriert und in allen verfügbaren Kristallisationsscreens verarbeitet. Die Kristallisationsbedingungen wurden bei $4{ }^{\circ} \mathrm{C}$ und $20{ }^{\circ} \mathrm{C}$ gelagert. 
Nach 2-3 Tagen waren in einigen Kristallisationsbedingungen (Tab.3) linsenförmige Kristalle erkennbar (Abb.23a).

Kristallisationsscreen

Zusammensetzung

Crystal Screen I \#39 $2 \%$ PEG 400, $2 \mathrm{M}\left(\mathrm{NH}_{4}\right)_{2} \mathrm{SO}_{4}, 0,1 \mathrm{M}$ HEPES $\mathrm{pH} 7,5$

JB 6 \#10 $1,6 \mathrm{M}\left(\mathrm{NH}_{4}\right)_{2} \mathrm{SO}_{4}, 0,2 \mathrm{M} \mathrm{NaCl}, 0,1 \mathrm{M}$ HEPES pH 7,5

JB 6 \#16 $2 \mathrm{M}\left(\mathrm{NH}_{4}\right)_{2} \mathrm{SO}_{4}, 0,1 \mathrm{M}$ Tris/ $\mathrm{HCl} \mathrm{pH} \mathrm{8,5}$

Magic Screen \#62 $2 \mathrm{M}\left(\mathrm{NH}_{4}\right)_{2} \mathrm{SO}_{4}, 0,2 \mathrm{M} \mathrm{Li}_{2} \mathrm{SO}_{4}, 0,1 \mathrm{M}$ CAPS pH 10,5

[Tab.4] Initiale Kristallisationsbedingungen von $\mathrm{H} 20$

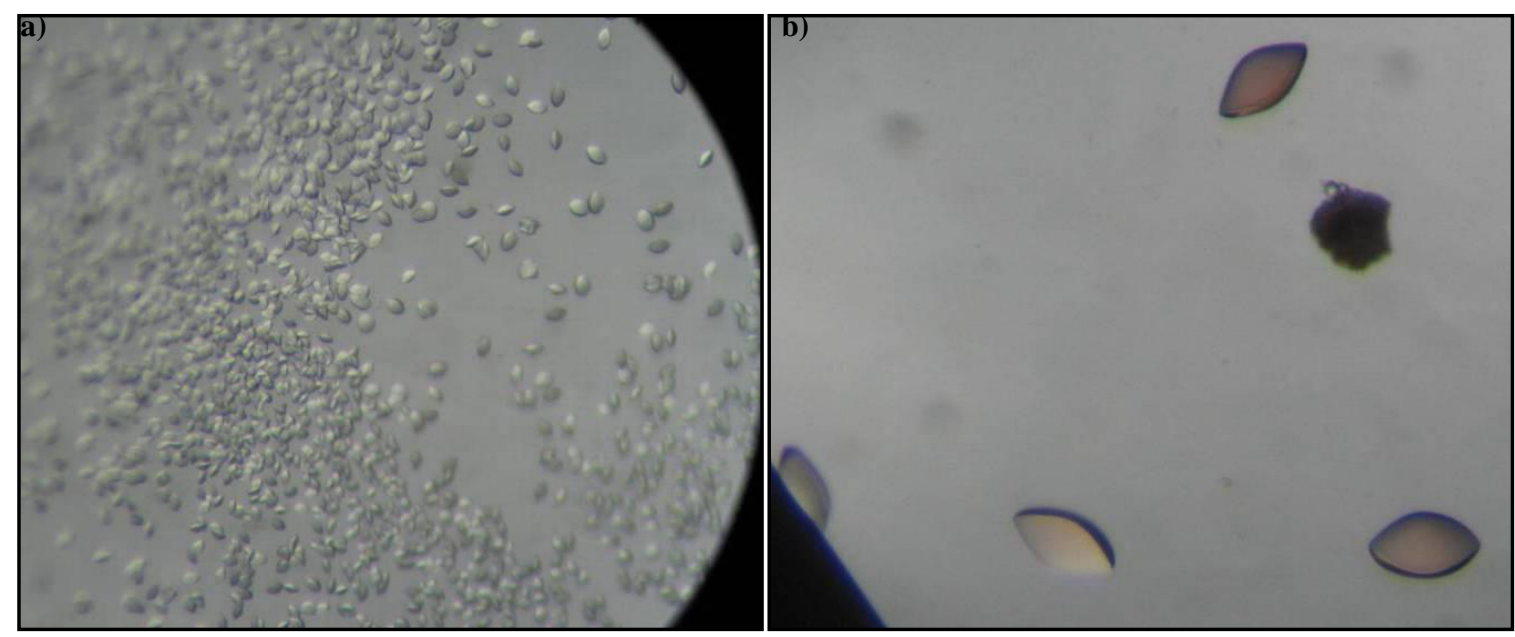

[Abb.23] Proteinkristalle von H20. a) linsenförmige Kristalle in initialer Kristallisationsbedingung Crystal Screen I \#39 [2\% PEG 400, 2M $\left(\mathrm{NH}_{4}\right)_{2} \mathrm{SO}_{4}, 0,1 \mathrm{M}$ HEPES pH 7,5]. b) Optimierung des Kristallwachstums [1,7 $\mathrm{M}\left(\mathrm{NH}_{4}\right)_{2} \mathrm{SO}_{4}$, Tris/ $\left.\mathrm{HCl} \mathrm{pH} 8,5,20^{\circ} \mathrm{C}\right]$.

Die Optimierung der Kristallisationsbedingung führte zu Kristallen mit einer Größe von bis 400 $\mu \mathrm{m}$ Durchmesser. Die optimierten Puffer- und Salzkonzentrationen sind in Tab.5 aufgelistet. Mikroseeding führte $\mathrm{zu}$ zahllosen halblinsenförmigen Kristallen von $50 \mu \mathrm{m}$ Größe. Die Selenomethionin-Variante (SeMet) von H20 kristallisierte unter identischen Bedingungen.

\begin{tabular}{ll}
$\mathbf{4}^{\circ} \mathbf{C}$ & $\mathbf{2 0}{ }^{\circ} \mathbf{C}$ \\
\hline $1,4 \mathrm{M}\left(\mathrm{NH}_{4}\right)_{2} \mathrm{SO}_{4}, 0,1 \mathrm{M}$ Tris/HCl pH 7,5 & $1,6 \mathrm{M}\left(\mathrm{NH}_{4}\right)_{2} \mathrm{SO}_{4}, 0,1 \mathrm{M}$ Tris/HCl pH 7,5 \\
$1,5 \mathrm{M}\left(\mathrm{NH}_{4}\right)_{2} \mathrm{SO}_{4}, 0,1 \mathrm{M}$ Tris/HCl pH 8 & $1,6 \mathrm{M}\left(\mathrm{NH}_{4}\right)_{2} \mathrm{SO}_{4}, 0,1 \mathrm{M}$ Tris/HCl pH 8 \\
$1,5 \mathrm{M}\left(\mathrm{NH}_{4}\right)_{2} \mathrm{SO}_{4}, 0,1 \mathrm{M}$ Tris/HCl pH 8,5 & $1,7 \mathrm{M}\left(\mathrm{NH}_{4}\right)_{2} \mathrm{SO}_{4}, 0,1 \mathrm{M}$ Tris/HCl pH 8,5 \\
$1,6 \mathrm{M}\left(\mathrm{NH}_{4}\right)_{2} \mathrm{SO}_{4}, 0,1 \mathrm{M}$ Tris/HCl pH 9 & $1,7 \mathrm{M}\left(\mathrm{NH}_{4}\right)_{2} \mathrm{SO}_{4}, 0,1 \mathrm{M}$ Tris/HCl pH 9
\end{tabular}

[Tab.5] Optimierte Kristallisationsbedingungen von $\mathrm{H} 20$ in Abhängigkeit von der Temperatur

Beugungsexperimente am Röntgendiffraktometer $R U-H 3 R$ zeigten, dass die Kristalle bis $3 \AA$ streuten. Durch Messungen der Kristalle am DESY in Hamburg wurden Datensätze mit einer Auflösung von $2 \AA$ aufgenommen. Dabei streuten die Kristalle, die bei $4{ }^{\circ} \mathrm{C}$ gewachsen am weitesten. Die SeMet-Kristalle wurden am BESSY in Berlin gemessen. Aus den gewonnenen Daten konnte die Kristallstruktur der C-terminalen Domäne (CTD) von hPrp22 gelöst. 


\subsection{Strukturelle Charakterisierung des C-Terminus von hPrp22 (H20)}

\subsubsection{Datenaufnahme und -prozessierung}

Von Kristallen der Deletionsmutante H20 von hPrp22 (3.4.4) wurden mehrere native Datensätze am Deutschen Elektronensynchrotron (DESY, Hamburg) bei $100 \mathrm{~K}$ aufgenommen. Die maximale Auflösung betrug 2,03 ^ (h20nat, Tab.6). Nach Indizierung, Integration und Skalierung der gemessenen Reflexe mit HKL2000 (DENZO/SCALEPACK) konnten die Kristalle der Raumgruppe P422 zugeordnet werden. Diese Symmetrie ist definiert durch eine vierzählige und zwei darauf senkrecht stehenden zweizähligen Achsen. Auf das Vorliegen einer höher-symmetrischen Raumgruppe (als P422) konnte durch die systematische Abwesenheit jedes vierten Reflexes auf der l-Achse und jedes zweiten Reflexes auf der h-Achse im reziproken Gitter geschlossen werden. Mit XPREP (Sheldrick et al., 1997) konnten die möglichen Raumgruppen auf $\mathrm{P}_{3} 2_{1} 2$ oder $\mathrm{P}_{1} 2_{1} 2$ eingegrenzt werden. Jedoch war allein durch native Daten nicht erkennbar, ob es sich um eine links- oder rechtsgängige Schraubenachse handelt.

Da kein Homologiemodell zur Phasenbestimmung mittels Molekularen Ersatzes (MR) verfügbar war, mussten die Phasen de novo ermittelt werden. Dazu wurden in KBr-Lösung inkubierte Kristalle (2.2.6.3) gemessen, um mittels des anomalen Streuverhaltens der Bromidionen Informationen über die Phasen zu erhalten (SAD). Die maximale Auflösung KBr-derivatisierter Kristalle lag bei 2,1 $\AA$ (h20br, Tab.6). Die Raumgruppe konnte bei der Phasierung mit HKL2MAP (Pape et al., 2004) auf $\mathrm{P}_{1} 2_{1} 2$ (Nr. 92) festgelegt werden. Eine tetragonale Raumgruppe ist durch acht Symmetrieoperatoren definiert und die Einheitszelle setzt sich aus acht asymmetrischen Einheiten zusammen. Bei einem Molekül pro asymmetrischer Einheit ist die Einheitszelle aus acht Molekülen aufgebaut. Bei einem Molekulargewicht von $30 \mathrm{kDa}$ ergab sich ein Lösungsmittelgehalt von ca. 45 \%. Ein Molekül pro asymmetrischer Einheit, stellte die sinnvollste Lösung dar.

Eine weitere Methode der Phasenbestimmung kam bei der Strukturaufklärung von H20 zum Einsatz. Selenomethionin-derivatisierte Kristalle (2.2.4.5) wurden am Berliner Elektronensynchrotron bei vier definierten Wellenlängen gemessen (2.2.6.4, Tab.6, smh20\#\#). Da Selenomethionin anstatt Methionin bei der Synthese des Proteins in E.coli eingebaut wurde, hatte man proteininterne Aminosäuremarker bekannter Position. Dies erleichtert den Einbau der Peptidkette. Des Weiteren war das Phasierungspotential höher, da H20 12 Methionine in seiner Aminosäuresequenz aufweist. Die Statistiken der Datenauswertungen der jeweils hochauflösendsten Kristalle sind in Tab.6 aufgelistet. 


\begin{tabular}{|c|c|c|c|c|c|c|}
\hline Datensatz & h20nat & h20br & smh20pk & smh20ip & smh20lr & smh20hr \\
\hline Schweratom & --- & $\mathrm{KBr}$ & SeMet & SeMet & SeMet & SeMet \\
\hline Wellenlänge $(\AA)$ & 0,8423 & 0,91164 & 0,97976 & 0,9799 & 1 & 0,95 \\
\hline Drehwinkel $\left({ }^{\circ}\right)$ & 91 & 208 & 100 & 100 & 100 & 100 \\
\hline Detektor & mar345 & $\operatorname{mar} 165 \mathrm{ccd}$ & $\operatorname{mar} 225 \mathrm{ccd}$ & $\operatorname{mar} 225 \mathrm{ccd}$ & $\operatorname{mar} 225 \mathrm{ccd}$ & $\operatorname{mar} 225 \mathrm{ccd}$ \\
\hline Detektorabstand (mm) & 200 & 140 & 280 & 280 & 280 & 280 \\
\hline Auflösung & $\begin{array}{c}50-2,03 \\
(2,1-2,03)\end{array}$ & $\begin{array}{c}50-2,1 \\
(2,18-2,1)\end{array}$ & $\begin{array}{c}50-2,6 \\
(2,69-2,6)\end{array}$ & $\begin{array}{c}50-2,6 \\
(2,69-2,6)\end{array}$ & $\begin{array}{c}50-2,6 \\
(2,69-2,6)\end{array}$ & $\begin{array}{c}50-2,7 \\
(2,8-2,7)\end{array}$ \\
\hline Raumgruppe & $\mathrm{P} 4{ }_{1} 2{ }_{1} 2$ & $\mathrm{P} 4{ }_{1} 2{ }_{1} 2$ & $\mathrm{P} 4{ }_{1} 2{ }_{1} 2$ & $\mathrm{P} 4{ }_{1} 2{ }_{1}$ & $\mathrm{P} 4{ }_{1} 2{ }_{1} 2$ & $\mathrm{P} 4{ }_{1} 2{ }_{1}$ \\
\hline Einheitszell- & $a=b=78,67$ & $\mathrm{a}=\mathrm{b}=78,88$ & $\mathrm{a}=\mathrm{b}=79,05$ & $\mathrm{a}=\mathrm{b}=79,10$ & $\mathrm{a}=\mathrm{b}=79,10$ & $\mathrm{a}=\mathrm{b}=79,15$ \\
\hline dimensionen $(\AA)$ & $\mathrm{c}=88,41$ & $\mathrm{c}=88,89$ & $c=88,59$ & $\mathrm{c}=88,64$ & $c=88,66$ & $\mathrm{c}=88,71$ \\
\hline Winkel der Einheitszelle & $\alpha=\beta=\gamma=$ & $\alpha=\beta=\gamma=$ & $\alpha=\beta=\gamma=$ & $\alpha=\beta=\gamma=$ & $\alpha=\beta=\gamma=$ & $\alpha=\beta=\gamma=$ \\
\hline$\left({ }^{\circ}\right)$ & 90 & 90 & 90 & 90 & 90 & 90 \\
\hline Beobachtete Reflexe & 315374 & 557688 & 180763 & 177307 & 168037 & 184036 \\
\hline (einzigartige Reflexe) & (18595) & (31239) & (8926) & (8894) & $(8683)$ & (7942) \\
\hline Mosaizität $\left(^{\circ}\right)$ & 0,50 & 0,28 & 0,97 & 0,96 & 0,96 & 0,93 \\
\hline $\mathrm{R}_{\text {sym }}$ & $5,7(59,9)$ & $6,9(55,7)$ & $7,5(50,2)$ & $6,6(51,6)$ & $5,4(47,2)$ & $6,5(48,5)$ \\
\hline $\begin{array}{l}\text { Signal/Rauschverhältnis } \\
(\mathrm{I} / \sigma)\end{array}$ & $32,6(3,3)$ & $29,2(4,1)$ & $19,8(3,5)$ & $25,6(3,5)$ & $32,3(3,5)$ & $36,6(4)$ \\
\hline Redundanz (-fach) & 7,2 & 9 & 7,5 & 7,6 & 7,5 & 7,7 \\
\hline $\begin{array}{l}\text { Vollständigkeit der } \\
\text { Reflexe (\%) }\end{array}$ & $99,9(100)$ & $99,7(100)$ & $97,7(100)$ & $97,1(100)$ & $94,8(74,7)$ & $96,6(100)$ \\
\hline Einheitszellvolumen $\left[\AA^{3}\right]$ & 547232,4 & 552731,6 & 553624,1 & 554654,2 & 554689,4 & 555754,8 \\
\hline gemittelter B-Faktor $\left(\AA^{2}\right)$ & 31,8 & 36,8 & 63,7 & 64 & 65,5 & 76,3 \\
\hline $\begin{array}{l}\text { Moleküle pro } \\
\text { asymmetrischer Einheit }\end{array}$ & \multicolumn{6}{|c|}{1} \\
\hline
\end{tabular}

[Tab.6] Datensammlungsstatistik der jeweils hochauflösendsten Kristalle. h20nat $=$ nativer Kristall, gemessen an der BW7B (DESY); h20br = KBr-derivatisierter Kristall, gemessen an der BW7A (DESY); smh20pk = SeMet-Kristall peak $($ BESSY); smh20ip = SeMet-Kristall inflection point $($ BESSY $) ; \mathrm{smh} 201 \mathrm{r}=$ SeMet-Kristall low remote $($ BESSY $) ; \mathrm{smh} 20 \mathrm{hr}$ $=$ SeMet-Kristall high remote (BESSY). (Werte in Klammern beziehen sich auf die äußere Auflösungsschale).

$\mathrm{R}_{\mathrm{sym}}=\Sigma_{\mathrm{hkl}} \Sigma_{\mathrm{i}} \mathrm{I}_{\mathrm{hkl}}^{\mathrm{i}}-\left\langle\mathrm{I}_{\mathrm{hkl}}^{\mathrm{i}}>\right| \Sigma_{\mathrm{hkl}} \Sigma_{\mathrm{i}}\left\langle\mathrm{I}_{\mathrm{hkl}}^{\mathrm{i}}\right\rangle$, wobei die Summe i über alle Einzelmessungen des Reflexes hkl berechnet ist. 


\subsubsection{Bestimmung der Phasen durch SAD und MAD}

Zur Bestimmung der Phasen mittels SAD und MAD wurde das Programm AUTOSHARP (Vonrhein et al., 2007) genutzt. Es greift auf die SHELX-Programme zu, die aus den Differenzen der Friedel-Paare die Schweratompositionen und somit die Phasen berechnen können. Anschließend verfeinert SHARP (Bricogne et al., 2003; Fortelle et al., 1997) diese Positionen mehrfach. Ein nativer und ein bis vier anomale Datensätze wurden in das Programm geladen und durch zusätzliche Informationen über Wellenlängen, Schweratomtyp, Raumgruppe und Dimensionen der Einheitszelle ergänzt. Für die Phasierung durch Br-SAD wurden ein Datensatz nahe der Absorptionskante (peak) von Brom (h20br, 0,91164 ̊) und ein nativer Datensatz (h20nat) verwendet. Der KBr-Datensatz wurde auf $180^{\circ}$ beschnitten, um negative Effekte durch Strahlenschäden zu minimieren. Die wurden 13 Schwermetallatompositionen gefunden (Tab.7).

CRYST1 $78.67 \quad 78.67 \quad 88.4190 .00 \quad 90.0090 .00 \quad$ P41212

$\begin{array}{lllll}\text { SCALE1 } & 0.012711 & 0.000000 & 0.000000 & 0.00000 \\ \text { SCALE2 } & 0.000000 & 0.012711 & 0.000000 & 0.00000 \\ \text { SCALE3 } & 0.000000 & 0.000000 & 0.011311 & 0.00000\end{array}$

\begin{tabular}{|c|c|c|c|c|c|}
\hline \multirow[b]{2}{*}{ Atomtyp } & & \multicolumn{4}{|c|}{ Belegung der } \\
\hline & $\mathbf{x}$ & $\mathbf{y}$ & $\mathbf{z}$ & Position & Temperaturfaktor $\mathbf{B}\left[\AA^{2}\right]$ \\
\hline $1 \mathrm{Br}$ & 1.423 & 7.083 & 4.801 & 1.17 & 56.89 \\
\hline $2 \mathrm{Br}$ & -17.449 & 26.135 & -14.353 & 0.64 & 252.99 \\
\hline $3 \mathrm{Br}$ & -21.538 & 25.882 & 4.473 & 0.46 & 80.66 \\
\hline $4 \mathrm{Br}$ & 62.457 & 11.495 & 8.876 & 0.42 & 58.13 \\
\hline $5 \mathrm{Br}$ & 26.201 & 68.567 & 6.781 & 0.35 & 48.74 \\
\hline $6 \mathrm{Br}$ & 1.513 & 71.846 & 8.937 & 0.28 & 85.20 \\
\hline $7 \mathrm{Br}$ & 17.816 & 20.982 & 5.066 & 0.31 & 68.17 \\
\hline $8 \mathrm{Br}$ & 62.202 & 46.696 & 11.400 & 0.38 & 73.41 \\
\hline $9 \mathrm{Br}$ & 18.804 & 9.241 & 3.992 & 0.23 & 60.85 \\
\hline $10 \mathrm{Br}$ & 22.841 & 37.665 & 10.214 & 0.28 & 73.20 \\
\hline $11 \mathrm{Br}$ & 47.564 & 34.812 & 9.513 & 0.21 & 78.71 \\
\hline $12 \mathrm{Br}$ & 41.326 & 6.743 & 0.383 & 0.24 & 79.12 \\
\hline $13 \mathrm{Br}$ & 4.437 & 26.504 & 6.153 & 0.24 & 82.68 \\
\hline
\end{tabular}

[Tab.7] Brompositionen im Kristall. In der ersten Zeile (CRYST1) sind die Einheitszelldimensionen und die Raumgruppe aufgeführt, während in der zweiten bis vierten Zeile (SCALE1-3) die angewandte Rotationsmatrix dargestellt ist. In der ersten Spalte der Tabelle sind die identifizierten Schweratome benannt und durchnummeriert. In der zweiten bis vierten Spalte sind die Koordinaten dargestellt. Die folgenden Spalten fünf und sechs beschreiben die Belegung der Schwermetallposition und den B-Faktor.

Die Selenomethionin-MAD wurde mit vier Wellenlängen durchgeführt. Ein Datensatz des Absorptionsmaximums von SeMet (peak 0,97976 ̊, smh20pk), einer des halbmaximalen Absorptionsmaximums (Wendepunkt, inflection point 0,9799 ^, smh20ip), zwei Datensätze, die bei höherer (high remote 1,0, smh20hr) bzw. niedrigerer Wellenlänge gemessen wurden (low 
remote $0,95 \AA$, smh201r), und der native Datensatz h20nat wurden verwendet. Elf Schweratompositionen konnten verifiziert werden (Tab.8).

Die Auflösung der SeMet-Kristalle war limitiert auf 2,6 A, konnte aber nach Kalkulation der initialen Phaseninformation auf die hochauflösenden Bereiche des nativen Datensatzes übertragen werden.

$\begin{array}{llllllll}\text { CRYST1 } & 79.05 & 79.05 & 88.59 & 90.00 & 90.00 & 90.00 & \text { P41212 }\end{array}$

$\begin{array}{lllll}\text { SCALE1 } & 0.012650 & 0.000000 & 0.000000 & 0.00000\end{array}$

$\begin{array}{lllll}\text { SCALE2 } & 0.000000 & 0.012650 & 0.000000 & 0.00000\end{array}$

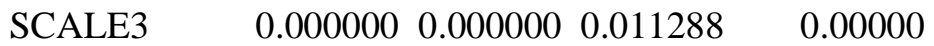

\begin{tabular}{cccccc} 
Atomtyp & $\mathbf{x}$ & $\mathbf{y}$ & $\mathbf{z}$ & $\begin{array}{c}\text { Belegung der } \\
\text { Position }\end{array}$ & Temperaturfaktor B $\left[\mathbf{A}^{2}\right]$ \\
\hline $1 \mathrm{Se}$ & 55.003 & 33.397 & 9.060 & 0.54 & 46.29 \\
$2 \mathrm{Se}$ & 52.717 & 29.347 & 1.922 & 0.46 & 41.28 \\
$3 \mathrm{Se}$ & 44.676 & 31.316 & 9.326 & 0.48 & 38.00 \\
$4 \mathrm{Se}$ & 57.735 & 18.019 & -3.231 & 0.47 & 30.80 \\
$5 \mathrm{Se}$ & 72.318 & 67.692 & 8.701 & 0.44 & 52.41 \\
$6 \mathrm{Se}$ & 27.912 & 50.804 & 1.323 & 0.53 & 58.55 \\
$7 \mathrm{Se}$ & 42.496 & 23.066 & 0.844 & 0.37 & 79.16 \\
$8 \mathrm{Se}$ & 74.373 & 71.914 & 1.268 & 0.48 & 51.05 \\
$9 \mathrm{Se}$ & 47.865 & 19.221 & 5.286 & 0.38 & 55.15 \\
$10 \mathrm{Se}$ & 65.538 & 36.527 & 2.613 & 0.44 & 86.33 \\
$11 \mathrm{Se}$ & 43.738 & 35.221 & 1.200 & 0.47 &
\end{tabular}

[Tab.8] Selenpositionen im Kristall. In der ersten Zeile (CRYST1) sind die Einheitszelldimensionen und die Raumgruppe aufgeführt, während in der zweiten bis vierten Zeile (SCALE1-3) die angewandte Rotationsmatrix dargestellt ist. In der ersten Spalte der Tabelle sind die identifizierten Schweratome benannt und durchnummeriert. In der zweiten bis vierten Spalte sind die Koordinaten dargestellt. Die folgenden Spalten fünf und sechs beschreiben die Belegung der Schwermetallposition und den B-Faktor.

AUTOSHARP optimiert auch den Solvensgehalt, führt eine Dichtemodifikation durch (DM) und gibt eine Elektronendichtekarte $\left(2 \mathrm{~F}_{\mathrm{obs}}-\mathrm{F}_{\text {calc }}\right)$ aus. Der Solvensgehalt nach der Br-SAD lag bei $54,4 \%$ und der nach der SeMet-MAD bei $36,2 \%$.

\subsubsection{Modellbau, Strukturverfeinerung und Qualität des Modells}

Das erste Modell wurde mittels automatischem Sequenzeinbaus erzeugt. Hierzu wurde RESOLVE (Terwilliger, 2000) genutzt (Skript siehe Anhang). In gut definierte Regionen der Elektronendichte baut das Programm die Aminosäuren gemäß der vorgegebenen Sequenz ein. Schlechter definierte Regionen versieht es mit Poly-Alanin Ketten. Des Weiteren wird ein freier R-Faktor erzeugt. 
In der SAD-Elektronendichte konnten ca. 100 Reste (überwiegend Poly-Alanin) und in der MAD-Elektronendichte ca. 180 Reste (überwiegend sequenzspezifisch) platziert werden.

Ausgehend von diesen partiellen Modellen konnte der Einbau weiterer Aminosäuren in die $2 \mathrm{~F}_{\mathrm{obs}}-\mathrm{F}_{\text {calc }}$ Elektronendichtekarte der asymmetrischen Einheit, in welcher die beobachteten Strukturfaktoren zweifach in die Berechnung miteinbezogen wurden, erfolgen. Der Modellbau wurde in COOT (Emsley et al., 2004) weitergeführt. Die erste Elektronendichtekarte war in einigen Bereichen schlecht definiert (Abb.24a, 25a). Durch sukzessive Verfeinerung in REFMAC5 ließen sich diese Bereiche entscheidend verbessern und Aminosäureseitenketten zuzuordnen (Abb.24b, 25a).
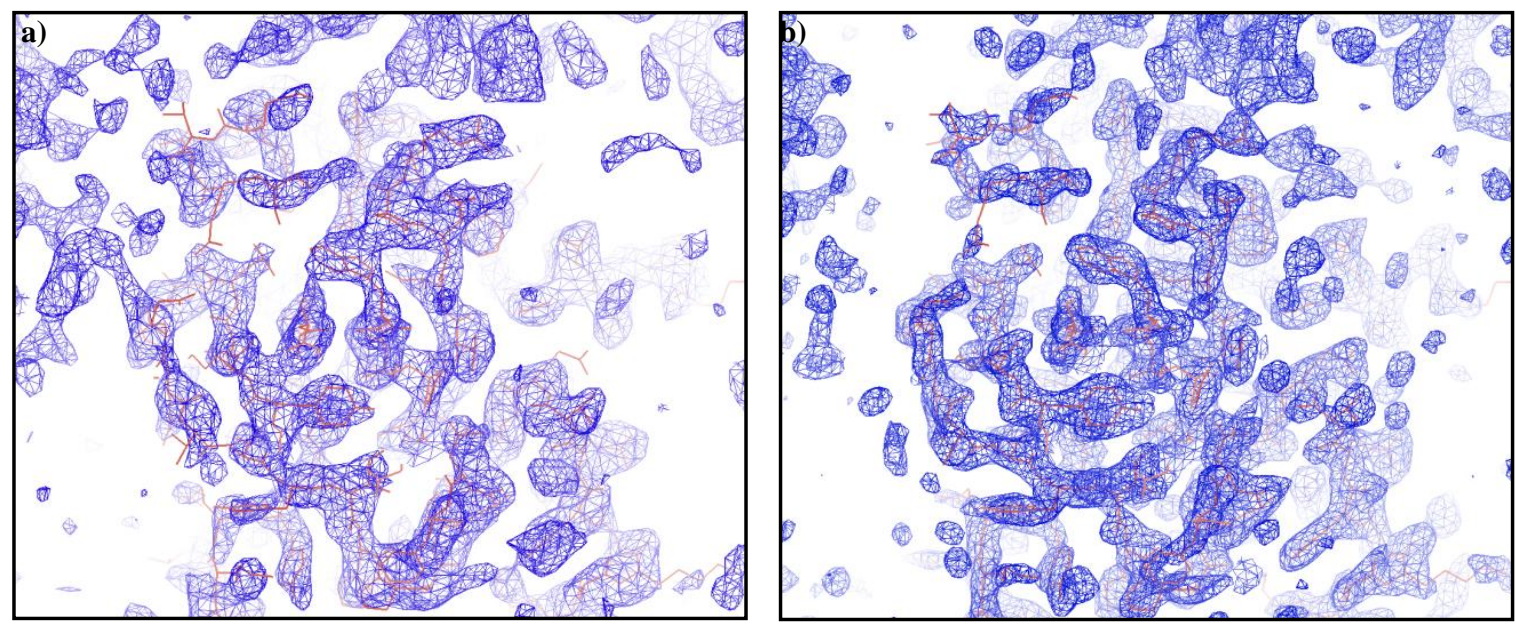

[Abb.24] Vergleich der initialen und verfeinerten Elektronendichtekarte. a) Initiale Elektronendichte nach Annäherung der Phasen mit MAD. b) Elektronendichte nach der letzten Verfeinerung in BUSTER/TNT. Aminosäurereste orange, Elektronendichte $(1 \sigma)$ blau. (COOT).
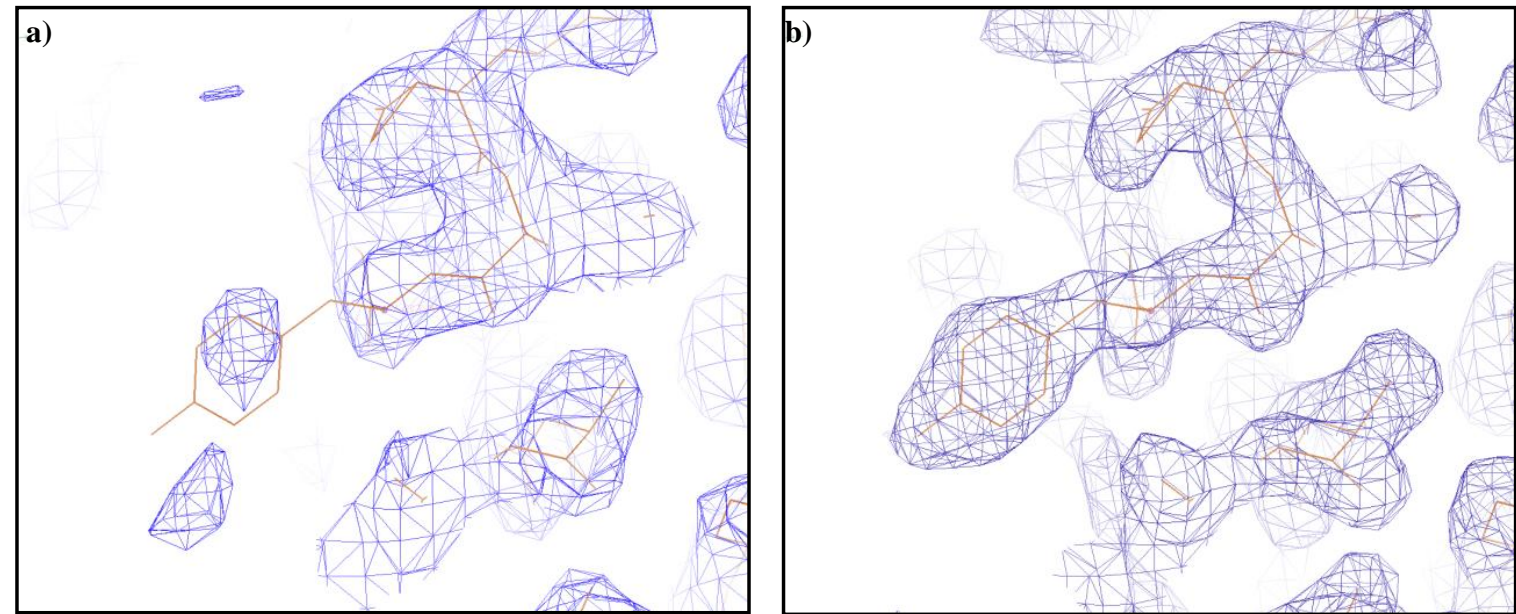

[Abb.24] Vergleich eines Bereichs der initialen und verfeinerten Elektronendichtekarte am Beispiel von Tyrosin 26. a) Initiale Elektronendichte nach Annäherung der Phasen mit MAD. b) Elektronendichte nach der letzten Verfeinerung in BUSTER/TNT. Aminosäurereste orange, Elektronendichte $(1 \sigma)$ blau. (COOT). 
Die Aminosäuresequenz konnte ohne Zuhilfenahme einer Sekundärstrukturvorhersage in die Elektronendichtekarte eingebaut werden. Bis auf lange Aminosäureseitenketten an der Oberfläche des Proteins konnten alle Reste der Deletionsmutante zugeordnet werden.

Bei allen Positions- und Temperaturfaktorverfeinerungen gegen die (nicht anomal skalierte) Elektronendichtekarte von h20br in REFMAC5 wurde ein Gewichtungsfaktor (weighting term) von 0,05 eingestellt, um allzu große Verwindungen der Polypeptidkette zu verhindern. Das Modell wurde anhand der neu berechneten Elektronendichtekarten solange korrigiert, bis die R-Faktoren $\left(\mathrm{R}_{\text {cryst }}, \mathrm{R}_{\text {free }}\right.$ ) sich nicht mehr verringern ließen. Anschließend wurden von $A R P / w A R P$ Wassermoleküle gebaut, die dann wiederum von Hand in COOT verfeinert wurden.

Sowohl bei der Verfeinerung des SAD-Modells, als auch bei der des MAD-Modells, die gegen dieselbe Elektronendichte (h20br) erfolgte, konvergierte $\mathrm{R}_{\text {cryst }}$ bei $27 \%$ und $\mathrm{R}_{\text {free }} 33 \%$. Die Modelle aus SAD- und MAD-Phasierung waren weitestgehend identisch. Jedoch wurde nur das MAD-Modell verfeinert. Durch Beschneiden des Auflösungsbereichs auf 2,05 bis 13,6 A (Markus Rudolph) und die Verfeinerung in BUSTER/TNT (Bricogne, 1993) konnte der kristallographische R-Faktor auf 19,8\% und der freie R-Faktor auf 25,8 \% reduziert werden. Die Verfeinerungsstatistiken sind in Tab.9 aufgelistet. Nach der abschließenden Verfeinerung umfasste das Modell Aminosäurereste 950 - 1183 von hPrp22. Der Elektronendichte konnten 237 von 270 möglichen Resten zugeordnet werden. Von den 36 zusätzlichen Aminosäuren, die durch den Polylinker des Expressionsvektors codiert wurden, konnten nur zwei am NTerminus und eine am C-Terminus lokalisiert werden. Die dem Vektor zugehörigen Reste waren weitgehend ungeordnet bzw. flexibel und deshalb nicht in Form von Elektronendichte sichtbar. Der mittlere Temperaturfaktor (B-Faktor) der C-terminalen Domäne von hPrp22 (CTD, H20) lag bei ca. $31 \%$.

Auflösungsbereich [̊̊]

$\mathrm{R}_{\text {cryst }}[\%]$

$\mathrm{R}_{\text {free }}[\%]$

Vollständigkeit der Daten (\%)

Anzahl der Reflexe für die Verfeinerung

Anzahl der Aminosäuren

Anzahl der Atome des Protein

Anzahl der Wassermoleküle

Standardabweichung der Bindungslängen $[\AA]$
$13,6-2,05(2,17-2,05)$

19,8

25,8

98,7

17870

237

1929

287

0,009 
Standardabweichung der Bindungswinkel $\left[{ }^{\circ}\right]$

B-Faktor Protein $\left[\AA^{2}\right]$

[Tab.9] Verfeinerungsstatistiken und stereochemische Parameter.

Anhand des Ramachandrandiagramms (Laskowski et al., 1993; Ramachandran et al., 1968) wurde nachgeprüft, ob alle Bindungswinkel im Molekül ( $\varphi / \psi$-Winkel) in sterisch erlaubten Bereichen liegen (Abb.25). Bis auf Valin 249, dass zur translatierten XhoIRestriktionsschnittstelle des pPR-IBA1-Vektors gehört, waren alle Aminosäuren in erlaubten Bereichen. Der Plot zeigt, dass 190 (88,4 \%) der Aminosäurereste in favorisierten Regionen (rot) und 24 Reste in erlaubten Regionen liegen.

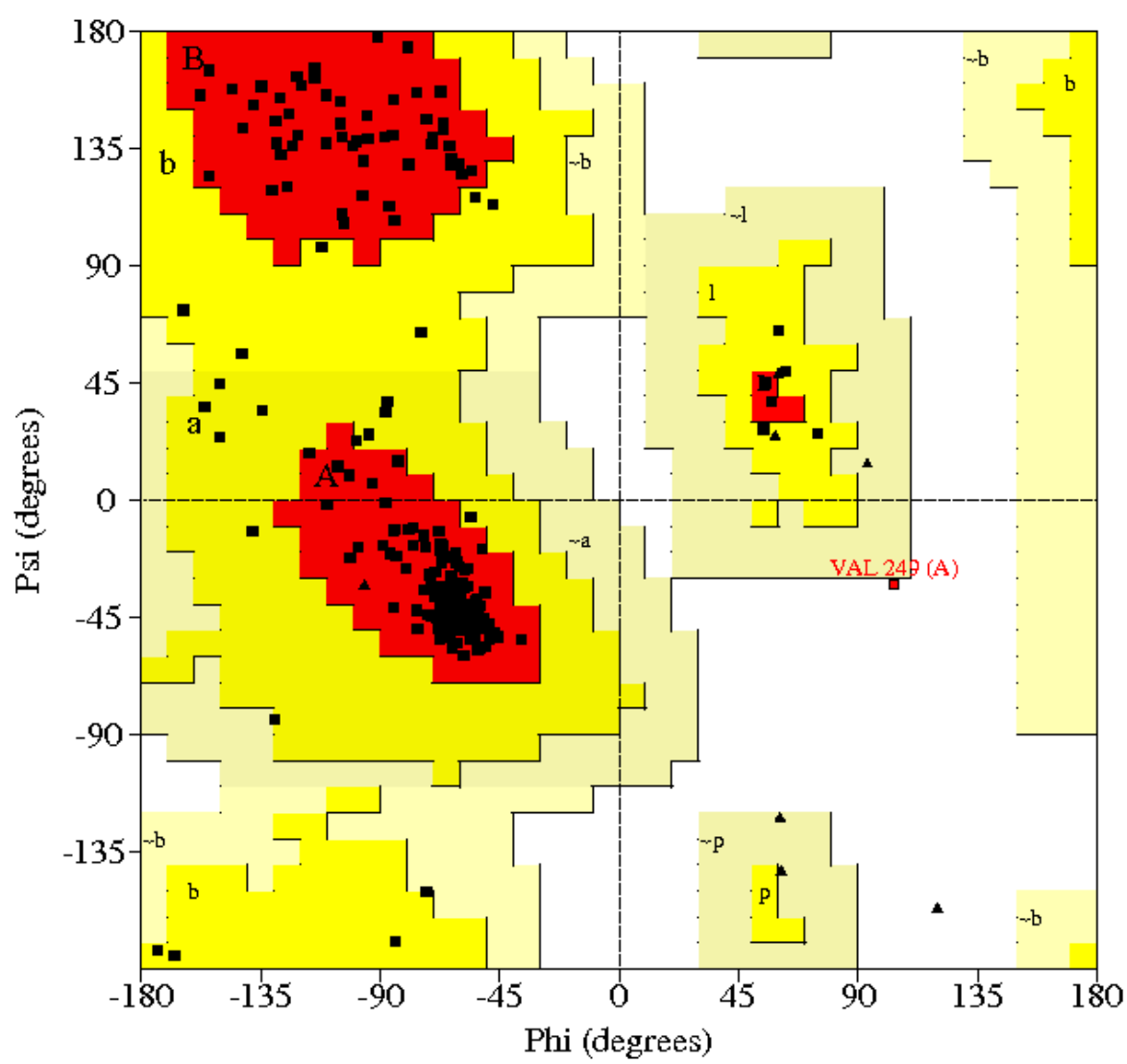

[Abb.24] Ramachandrandiagramm der C-terminalen Domäne von hPrp22. Rote und gelbe Bereiche: favorisierte und erlaubte $\varphi / \psi$-Konformationen, hellgelbe Bereiche: zusätzlich erlaubte Konformationen. Die möglichen Konformationen basieren auf einer Datenbank von hochaufgelösten Strukturen. ( $\boldsymbol{\Delta})$ zeigen Glycinreste an und die restlichen Aminosäuren sind durch (a) markiert. Aminosäuren (außer Glycin), die in tolerierbaren Bereichen liegen, sind im Diagramm benannt. A, B und L markieren favorisierte und erlaubte Bereiche für $\alpha$-Helices, $\beta$-Faltblätter und linksgängige Helices, während a, b und 1 zusätzlich erlaubte und $\sim \mathrm{a}, \sim \mathrm{b}$ und $\sim \mathrm{l}$ tolerierbare Bereiche markieren (Procheck). 


\subsubsection{Beschreibung der Struktur}

Bei der Kristallstruktur der C-Terminus von hPrp22 (AS 950 - 1183) handelt es sich um eine einzelne globuläre Domäne, bestehend aus zehn $\alpha$-Helices und sechs $\beta$-Strängen (Abb.25, 26a). Die $\beta$-Stränge bilden eine leicht verzerrte $O B$-fold-ähnliche Anordnung (oligonucleotide binding). Die $\beta$-Stränge 5 und 6 formen mit dem $\beta$-Strang 4 ein antiparalleles $\beta$-Faltblatt. Ferner formen die $\beta$-Stränge 1, 2 und 3 ein gebogenes, antiparalleles $\beta$-Faltblatt, welches um $90^{\circ}$ zum anderen Faltblatt gedreht ist (Abb.26b). Die $\alpha$-Helices liegen im unteren Teil des Proteins und bilden eine von den $\beta$-Strängen abgegrenzte Struktur. Ein Strukturvergleich mit der Protein-Data-Bank (www.rcsb.org/) durch DALI (www.ebi.ac.uk/dali/) führte zu keinen signifikanten Übereinstimmungen mit bekannten Faltungsmotiven.
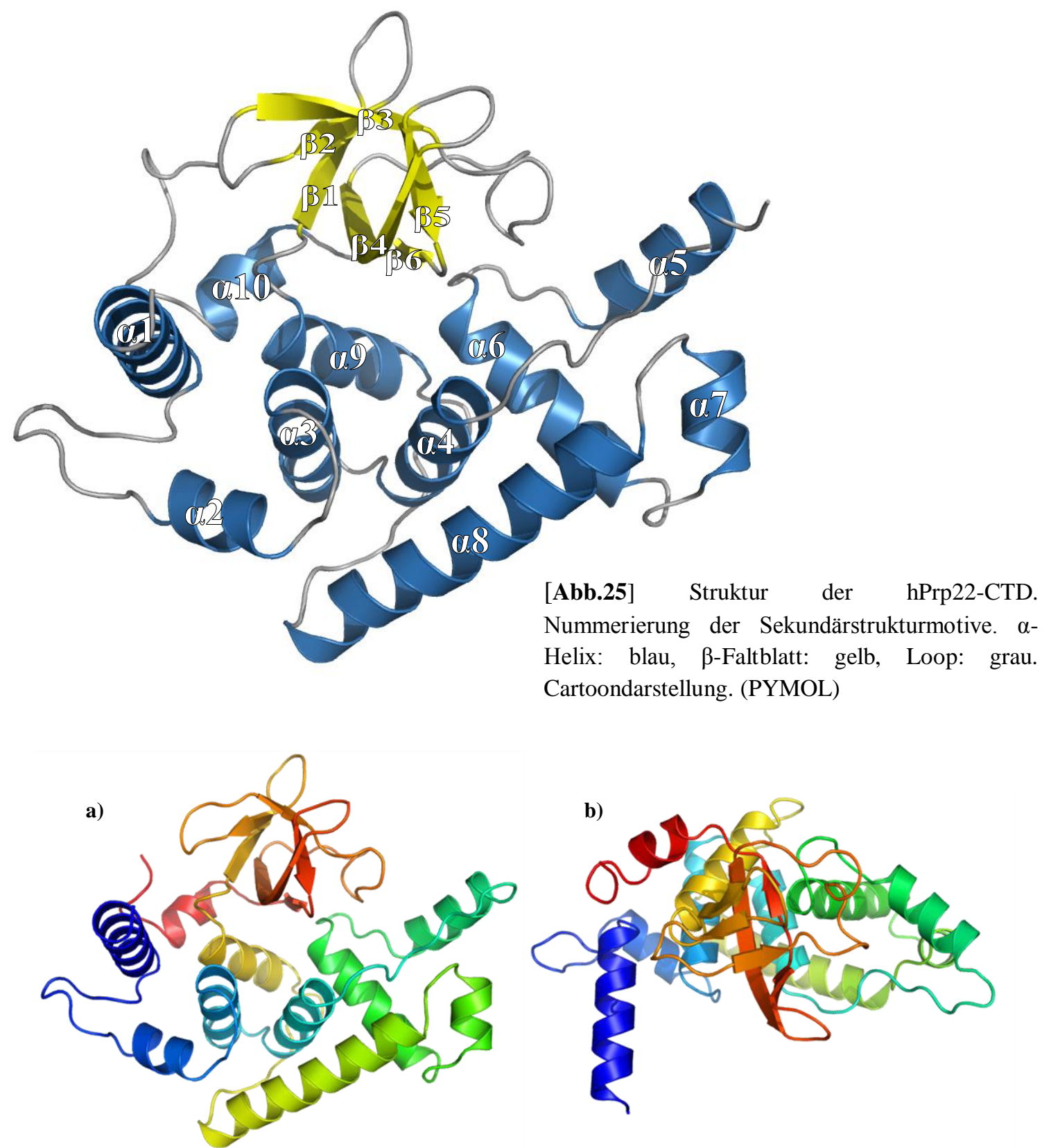

[Abb.26] Struktur der hPrp22-CTD. a) Frontansicht. b) Aufsicht auf gekreuzte $\beta$-Stränge $\left(90^{\circ}\right.$ Drehung um $\mathrm{x}$-Achse). Regenbogenansicht. blau = N-Terminus, rot = C-Terminus. Cartoondarstellung. (PYMOL) 


\subsection{Biochemische Untersuchungen der ATPase-Aktivität}

Bei der biochemischen Untersuchung der ATPase-Aktivität mittels eines enzymatisch gekoppelten Assays, wurde die Abnahme der Extinktion von NADH bei $340 \mathrm{~nm}$ photometrisch aufgezeichnet (2.2.5.3). Es wurden Tests mit den Deletionsmutanten H13, H15 und H20 durchgeführt.

Die Deletionsmutante H20 zeigte, wie erwartet, keine ATPase-Aktivität, da sie nicht die dazu notwendigen Motive beinhaltet. Auch H15 zeigte keine signifikante ATPase-Aktivität, obwohl es über alle notwendigen Aminosäuren verfügt, um ATP zu hydrolysieren. H13 zeigte, nach einiger Optimierung der Reaktionsbedingungen, eine gute ATPase-Aktivität. Es konnten mehrere Messreihen mit ATP-Konzentrationen von 0 - 20 mM (0 mM, 0,1 mM, 0,5 mM, 1 mM, 2 mM, 5 $\mathrm{mM}, 10 \mathrm{mM}, 20 \mathrm{mM}$ ) aufgezeichnet werden. Bei hohen ATP-Konzentrationen war der Abfall der Extinktion jedoch nicht linear und konnte auch nicht ausgewertet werden. Zwischen 0,1 und 2 $\mathrm{mM}$ war die Extinktionsabnahme gleichbleibend (Abb.27).

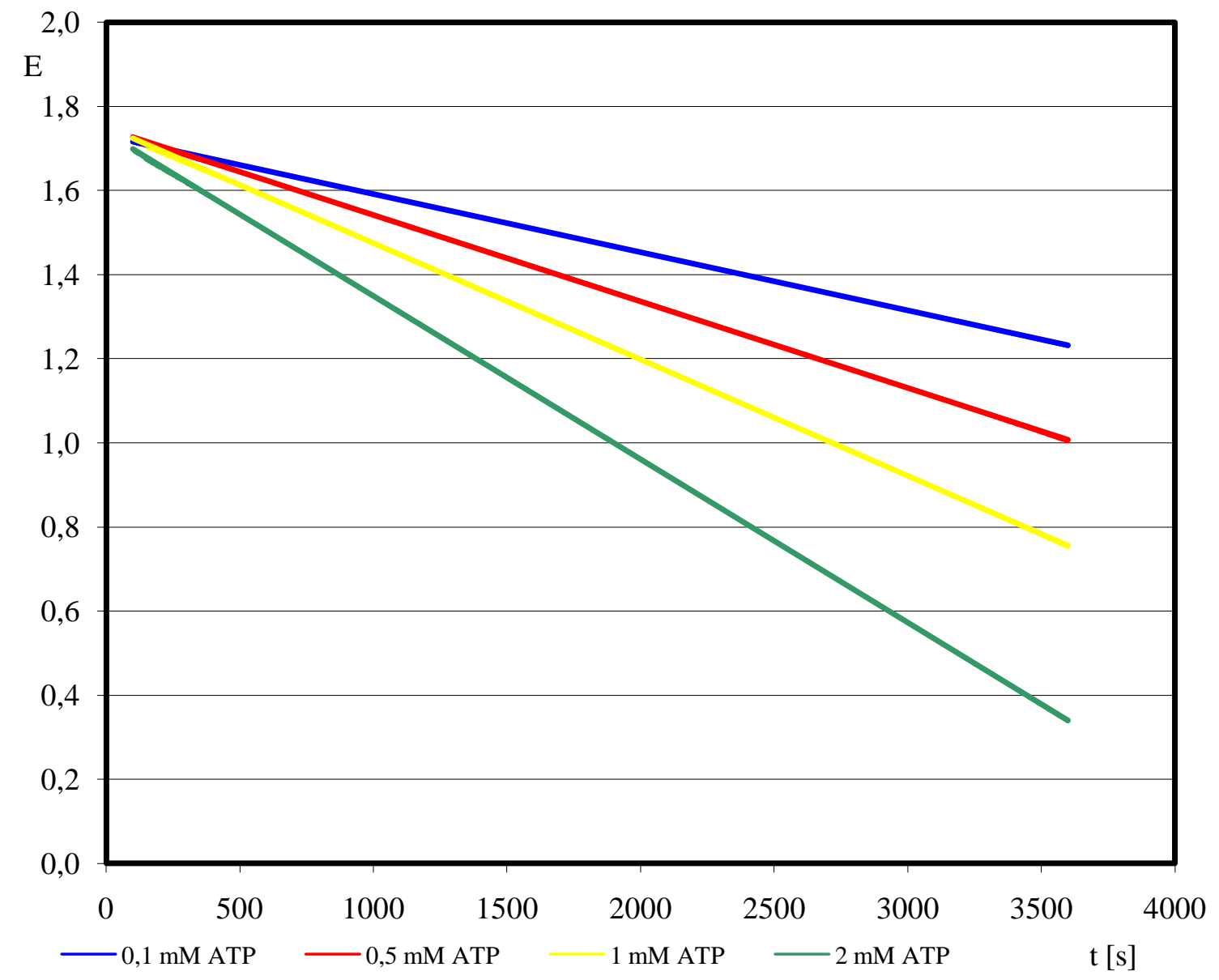

[Abb.27] Auftragung der Extinktionsabnahme (E) von NADH gegen die Zeit (t) eines ATPase-Tests von H13 bei unterschiedlichen ATP-Konzentrationen. 
Anschließend wurden die gewonnen Daten ausgewertet. Durch Umformung des LambertBeer'sches-Gesetzes und der Michaelis-Menten-Gleichung (2.2.5.3) konnte die Reaktionsgeschwindigkeit (v) berechnet werden.

$$
c=\frac{\Delta E}{\varepsilon d} \quad v_{0}=\frac{v_{\max } \cdot[S]}{K_{m}+[S]} \quad v_{0}=\frac{\Delta c}{\Delta t}
$$

Der Anstieg der Extinktion $(\Delta \mathrm{E})$ wurde durch den Extinktionskoeffizienten $(\square)$ geteilt und so die Konzentration des NADH bestimmt. Diese Substratkonzentration (c) wurde dann durch die Länge der Messzeit $(\Delta \mathrm{t})$ geteilt, um die Anfangsreaktionsgeschwindigkeit $\left(\mathrm{v}_{0}\right)$ zu berechnen. Die jeweils eigesetzte ATP-Konzentration wurde gegen die Reaktionsgeschwindigkeit aufgetragen (Abb.28).

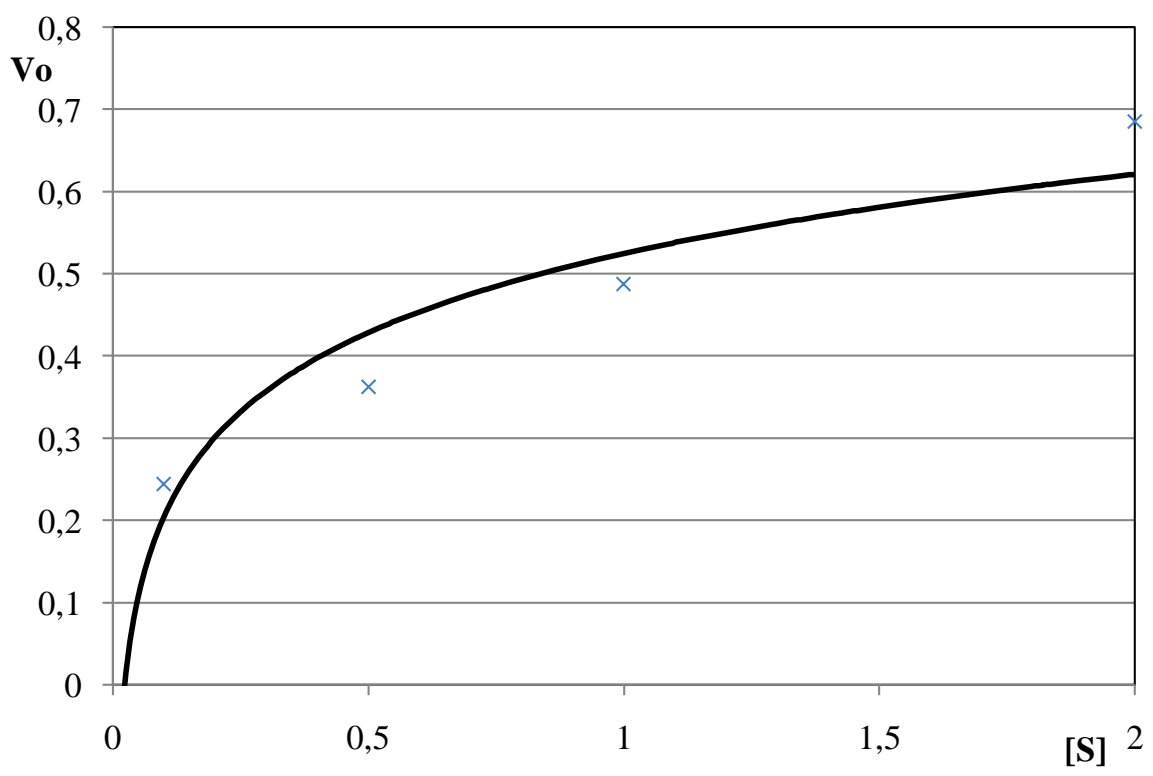

[Abb.28] Auftragung der ATP-Konzentration [S] gegen die Anfangsreaktionsgeschwindigkeit $\left(\mathrm{v}_{0}\right)$. Asymptotische Annäherung der Reaktionsgeschwindigkeit an die max. Reaktionsgeschwindigkeit. Einheiten: $[\mathrm{S}]=\mu \mathrm{M}, \mathrm{v}_{0}=\mu \mathrm{M} / \mathrm{min}$.

Um die Reaktionskonstante $\left(\mathrm{K}_{\mathrm{m}}\right)$ und die maximale Reaktionsgeschwindigkeit $\left(\mathrm{v}_{\max }\right)$ zu bestimmen, wurde die Michaelis-Menten-Gleichung nach Lineweaver-Burk doppelt-reziprok umgekehrt und linearisiert (Abb.29).

$$
\frac{1}{v_{0}}=\frac{K_{m}}{v_{\max } \cdot[S]}+\frac{1}{[S]}
$$




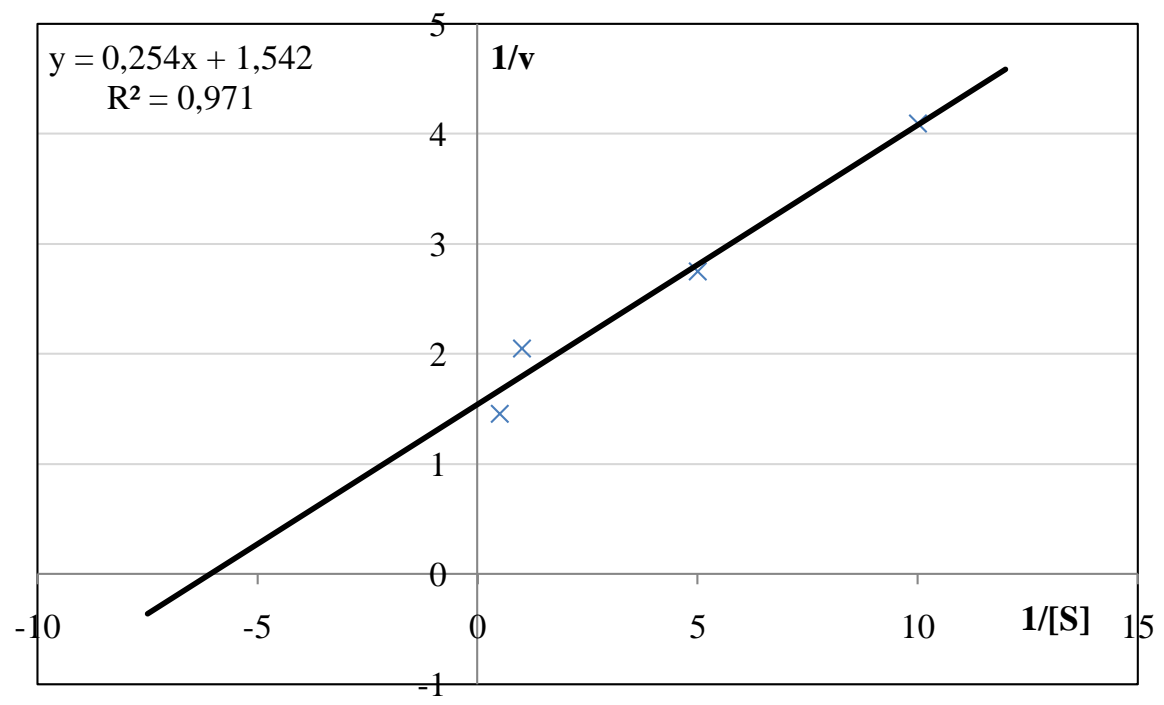

[Abb.29] Doppelt reziproke Auftragung der ATP-Konzentration [S] gegen die Anfangsreaktionsgeschwindigkeit $\left(\mathrm{v}_{0}\right)$. Schnittpunkt der Ordinate $=1 / \mathrm{v}_{\max }$, Schnittpunkt der Abszisse $=-1 / \mathrm{K}_{\mathrm{m}}$. Einheiten: $[1 / \mathrm{S}]=\mu \mathrm{M}, 1 / \mathrm{v}_{0}=\min / \mu \mathrm{M}$.

Die vorläufige Reaktionskonstante $\left(\mathrm{K}_{\mathrm{m}}\right)$ der ATP-Hydrolyse von hPrp22-H13 beträgt $\mathbf{0 , 1 6} \boldsymbol{\mu M}$. Die maximale Reaktionsgeschwindigkeit $\left(\mathrm{v}_{\max }\right)$ ist $\mathbf{0 , 6 5} \boldsymbol{\mu M} / \mathbf{m i n}$.

Diese Werte konnten bislang nicht durch weitere Messungen verifiziert werden.

Zwei Grundaussagen konnte dennoch getroffen werden. Das Enzym hydrolysiert ATP sehr langsam $\left(\mathrm{k}_{3}=0,6 \mathrm{~min}^{-1}\right)$. Die Helikase-Domäne verliert durch die Abwesenheit des C-Terminus ihre ATPase-Aktivität. 


\section{Diskussion}

\subsection{Klonierung und Reinigung der Volllängenproteine und Deletionsmutanten von}

\section{hPrp2 und hPrp22}

$\mathrm{Zu}$ Beginn dieser Doktorarbeit sollte die strukturelle Untersuchung der DExD/H-Box RNAHelikase hPrp22 im Vordergrund stehen. Aufgrund der hohen Sequenzähnlichkeit zu hPrp2 (Abb.30) wurde jedoch entschieden beide Proteine zu bearbeiten. Die Homologie ist in der Mitte und am C-Terminus der Proteine sehr hoch. In diesen Regionen befinden sich auch die vorhergesagten konservierten Domänen.

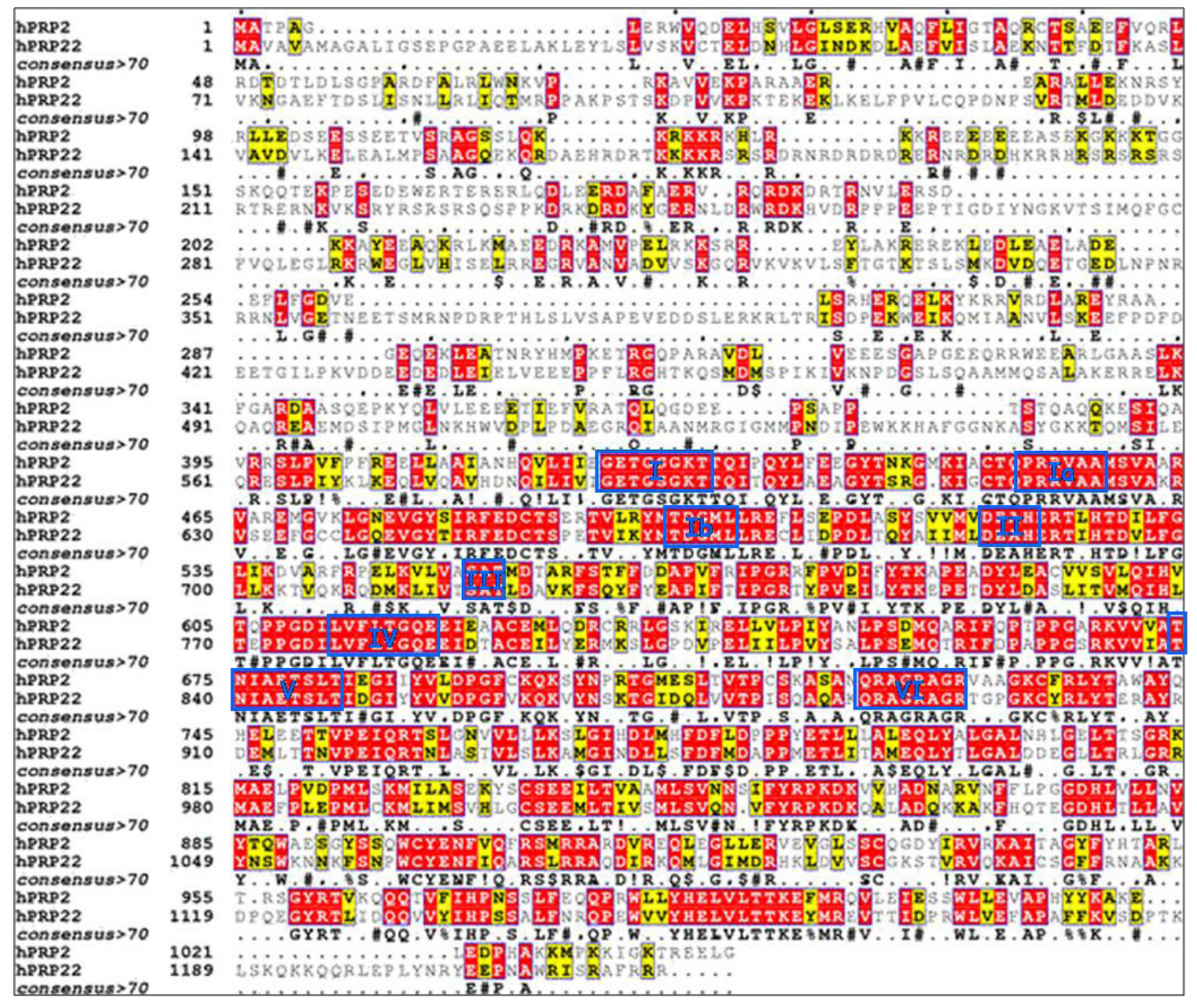

[Abb.30] Sequenzvergleich der DExD/H-Box Proteine hPrp2 und hPrp22 aus Homo sapiens. Die 7 Helikasemotive (1.5) sind blau umrandet und beschriftet. Identische Reste sind rot und konservierte Reste sind gelb unterlegt. (ClustalW; ESPript 2.2).

Im Rahmen dieser Doktorarbeit ist es leider nicht gelungen die Volllängenproteine von hPrp2 oder hPrp22 zu kristallisieren. 
Dies scheiterte in Fall von hPrp2 schon bei der Reinigung. Die Gensequenz von hPrp2 enthält zahlreiche Arginin-Codons, die in Prokaryoten unüblich sind. Trotzdessen, dass E.coli Rosetta 2 (DE3), durch Integration einiger seltener eukaryotischer t-RNAs, auf die Expression solcher Gene optimiert ist, konnte kein stabiles Protein gewonnen werden. Auf Grund der hohen Anzahl der seltenen Codons ist es möglich, dass es bei der Translation zum Fehleinbau falscher Aminosäuren gekommen ist, die die Löslichkeit und Stabilität des Proteins negativ beeinflusst haben. Abhilfe hätte die Expression in einem eukaryotischen System bringen können. Aber sowohl Expressionstests in Saccharomyces cerevisiae, als auch der Versuch Insektenzellen als Expressionssystem zu nutzen, versandeten im Nichts. Folglich stellte die Generierung von Deletionsmutanten ein probates Mittel dar an diesem Protein weiterzuarbeiten. Die Kalkulation von Stabilitätsindices zeigte, dass alle Fragmente theoretisch instabil waren. In der Praxis waren sie es ebenfalls. Die Reinigungen der Proteinfragmente verliefen nicht zufriedenstellend. Wurde eine lösliche Deletionsmutante durch Affinitätschromatographie gewonnen, eluierte sie entweder zusammen mit Fremdproteinen im Ausschlussvolumen der Gelfiltrationssäule oder präzipitierte auf der Membran des Zentrikons. Die Entwicklung einer Reinigungsstrategie war nicht möglich.

Das Volllängenprotein von hPrp22 war zwar löslich, konnte jedoch nicht in zufriedenstellender Reinheit gewonnen werden. Ähnlich verhielt es sich bei der Deletionsmutante H7, die neben der Helikasedomäne und der C-terminalen Domäne auch die S1-Domäne enthielt (Kombination aus H12 und H13). Auch dieses Fragment interagierte stark mit bakteriellen Nukleinsäuren und bildete oligomere Strukturen undefinierter Größe. Es gelang auch hier nicht diese unspezifischen Komplexe unter nativen Bedingungen aufzulösen. Man kann nur mutmaßen warum sich die S1Domäne (H12) und die Helikasedomäne mit C-Terminus (H13), aber nicht die Kombination aus beiden Domänen (H7), reinigen ließ. Zwischen den Domänen liegt laut Vorhersage eine Region geringer Komplexität ohne Sekundärstrukturmotive. Es ist vorstellbar, dass diese Region auf Grund ihrer Flexibilität und strukturellen Unordnung unspezifische, aber starke Wechselwirkungen mit Nukleinsäuren oder Fremdproteinen eingehen kann.

Die Reinheit der anderen Deletionsmutanten war so hoch, dass sie für Aktivitätstests genutzt werden konnten. In Tests konnten auch Fragmente der einzelnen Subdomänen von hPrp22 gereinigt werden. Ihre Gewinnung wurde jedoch aus Zeitgründen nicht weiter vorangetrieben.

\subsection{Strukturaufklärung der Deletionsmutante H20 von hPrp22}

Bei der de novo Strukturaufklärung der C-terminalen Domäne (3.5.1) von hPrp22 gab es einige Probleme zu lösen. Im ersten Moment waren die Daten sehr gut auszuwerten. Die Auflösung lag bei 2,03 $\AA$, die Daten waren vollständig und hatten eine hohe Redundanz, das Signal-/

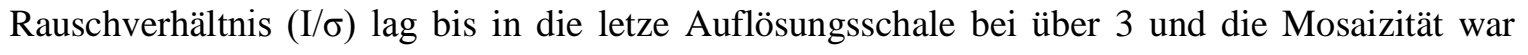
gering. Jedoch gab es auf jedem Beugungsbild 20 - 50 Overloads. 
Die Fehlerrate in den Auflösungsschalen stieg mit geringerer Auflösung unmerklich an. Es war möglich die korrekte Raumgruppe $\left(\mathrm{P}_{1}{ }_{2} 2_{2}\right)$ zu bestimmen und Phasen mittels Br-SAD zu gewinnen (3.5.2). Dabei mussten die Daten des anomalen Datensatzes auf $180^{\circ}$ beschränkt werden, da das anomale Signal des Broms mit fortlaufendem Drehwinkel immer schwächer wurde.

Die erste experimentelle Elektronendichtekarte der Br-SAD Phasierung war in den Bereichen der $\alpha$-Helices sehr gut definiert, jedoch konnten keine $\beta$-Stränge zugeordnet werden. Erst unter Verwendung eines RESOLVE-Skripts, das den automatischen Modellbau mit zyklischer Verfeinerung verknüpfte, konnten diese Regionen in der Elektronendichte besser definiert werden. Jedoch waren einige Bereiche weiterhin kaum zuzuordnen. Dort verzweigte sich die Elektronendichte mehrfach. Es konnte nur schwer eingeschätzt werden, ob die Aminosäurekette eine korrekte Konnektivität hatte. Das erste verfeinerte Modell aus der SAD-Phasierung beinhaltete 220 Reste. Die R-Faktoren waren gemessen an der guten Auflösung zu hoch $\left(\mathrm{R} / \mathrm{R}_{\text {free }}\right.$ $27 \%$ / $33 \%$ ). Es mussten bessere Phaseninformationen gewonnen werden.

Hierzu wurde das SeMet-MAD-Experiment durchgeführt (3.5.2). Verglichen mit den nativen Daten, hatten die SeMet-Daten eine geringere Auflösung (2,6 ̊) und eine etwas schlechtere Qualität. Die Phasierung war jedoch deutlich besser, denn die erste experimentelle Elektronendichte enthielt bereits die $\beta$-Stränge. Mit einem stark vereinfachten RESOLVE-Skript (siehe Anhang) wurden 180 Reste eingebaut. Betrachtet man einige Phasierungsstatistiken (Tab.10), erkennt man deutliche Unterschiede in der Qualität der Phasen. Trotzdessen, dass bei Br-SAD doppelt so viele Reflexe in die Kalkulation eingingen, war der FOM (figure-of-merrit), der die Qualität der Phasen bewertet (je höher desto besser) und die Phasierungsstärke (phasing power) nur weniger als halb so hoch. Basierend auf der experimentellen SeMet-MAD Elektronendichtekarte wurden 237 Reste eingebaut.

\begin{tabular}{|c|c|c|}
\hline & Br-SAD & SeMet-MAD \\
\hline Reflexe acentrisch/centrisch & $15137 / 2660$ & $7220 / 1667$ \\
\hline $\begin{array}{c}\text { figure-of-merrit } \\
\text { acentrisch/centrisch }\end{array}$ & $0.26701 / 0.20404$ & $0.58373 / 0.49452$ \\
\hline $\begin{array}{c}\text { phasing power } \\
\text { acentrisch/centrisch }\end{array}$ & $0.814 / 0.693$ & $1.849 / 1.553$ \\
\hline verwendeter Auflösungsbereich & $25,14-2,05$ & $47,27-2,60$ \\
\hline optimierter Solvensgehalt & 51,4 & 36,2 \\
\hline
\end{tabular}

[Tab.10] Darstellung der Temperaturfaktoren (B-Faktoren).

Trotz der suboptimalen Klonierungsstrategie in pPR-IBA1, bei der 34 zusätzliche Reste hinzukamen, konnten nur drei Reste, die vom Polylinker des Vektors codiert wurden, zugeordnet 
werden. AUTOSHARP konnte elf der zwölf Selenomethionine finden. Das Schweratom an Position eins der Aminosäuresequenz konnte auch nicht in der Elektronendichtekarte gefunden werden. Die ersten zwölf Reste (vom Polylinker des Plasmids codiert) führen in Richtung eines großen Solvenskanals und waren so flexibel, dass keine Rest-Elektronendichte für diesen Bereich des Proteins erkennbar war. Somit konnte die zwölfte Selenposition auch nicht gefunden werden. Des Weiteren konnten 19 C-terminale Reste, die ebenfalls vom Polylinker des Plasmids codiert wurden, mangels Elektronendichte nicht zugeordnet werden. Alle Reste der klonierten Deletionsmutante konnten der Elektronendichtekarte zugeordnet werden. Keine der vektorkodierten Aminosäuren bildete Kristallkontakte.

Die Verfeinerung der Kristallstruktur von H20 basierend auf SeMet-MAD konvergierte wiederum bei einem R-Faktor von $27 \%$ und einem $\mathrm{R}_{\text {free }}$ von $33 \%$. Ein Vergleich der beiden gebauten Modelle zeigte, dass beide eine identische Konnektivität hatten. Die Daten wurden auf Verzwilligung überprüft, jedoch gab es kein Anzeichen dafür. Es war unklar warum die RFaktoren auf so hohem Niveau konvergierten. Letztendlich wurde das Problem, mit der Hilfe von Markus Rudolph behoben, indem die Auflösung bei der Verfeinerung einen Bereich von 2,05 bis 13,6 $\AA$ begrenzt wurde (3.5.3). Die fehlerbehafteten Daten der Reflexe geringer Auflösungsbereiche wurden entfernt. Die R-Faktoren der letzten Verfeinerung lagen bei 19,8\% (R) und $25,8 \%\left(\mathrm{R}_{\text {free }}\right)$.

Neben der Tatsache, dass es sich bei der Kristallstruktur der C-terminalen Domäne um ein neues Faltungsmotiv handelt, gilt es weitere diskussionswürdige Aspekte zu betrachten. Die Darstellung der Temperaturfaktoren (Abb.31) gibt Hinweise auf flexible Regionen innerhalb des Proteins. In der Darstellung sind Bereiche mit niedrigen B-Faktoren blau und erhöhte sind grün/gelb eingefärbt. Das $\alpha$-helikale Grundgerüst im unteren Teil des Proteins hat geringe B-Faktoren, was auf einen reduzierten Flexibilitätsgrad hinweist.

Im Bereich der $\beta$-Stränge sind die B-Faktoren erhöht. Da sie auch in der Elektronendichte mäßig definiert waren, könnte man vermuten, dass es sich hierbei um eine flexible Protein- oder RNABindungsstelle handelt. Das Faltungsmotiv der $\beta$-Stränge ähnelt einem OB-fold (oligonucleotide binding). 


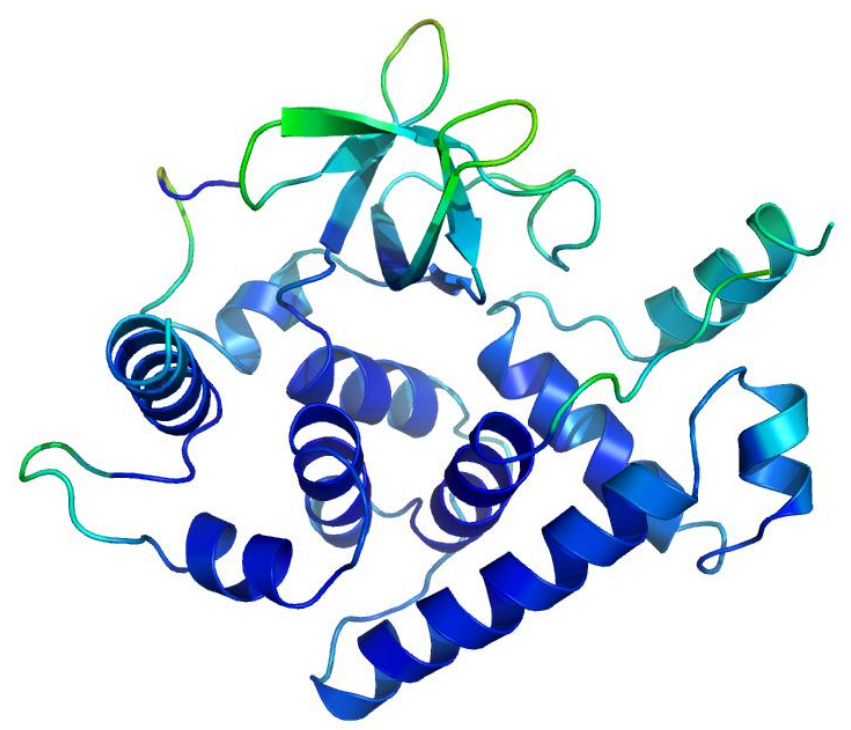

[Abb.31] Darstellung der Temperaturfaktoren von hPrp22-CTD. blau: niedrige B-Faktoren, grün - gelb: erhöhte BFaktoren. Cartoondarstellung. (PYMOL).

Vergleicht man die Domänenvorhersage (Abb.32, SMART) mit dem Faltungsmotiv der Cterminalen Domäne von hPrp22, ist klar ersichtlich, dass die Vorhersage falsch ist. Tatsächlich handelt es sich um eine globuläre Domäne und nicht um zwei Subdomänen. Die "HA2-Domäne" (blau) liegt nahezu planar zwischen der $\alpha$-Helix 8 und den $\beta$-Strängen der "DUF1605-Domäne" (rot), verbunden durch $\alpha$-Helix 7 (grau).

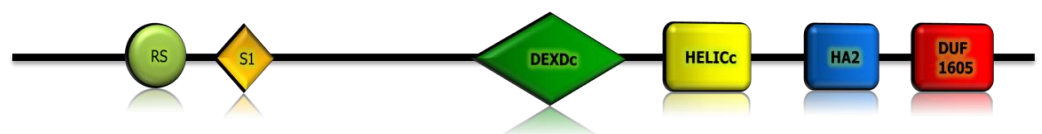

[Abb.32] Voraussage der Domänenanordnung von hPrp22 (smart.embl-heidelberg.de).
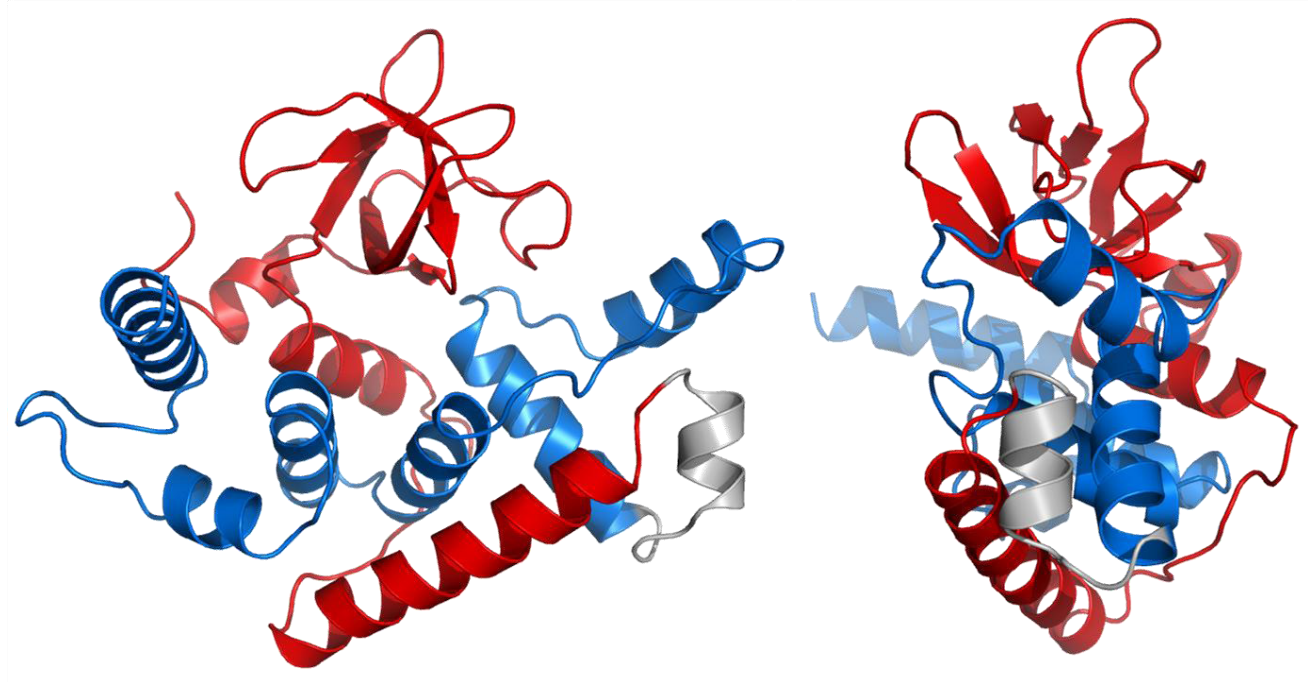

[Abb.33] Ineinandergreifende Strukturen der vorhergesagten Subdomänen von hPrp22-CTD. "HA2-Domäne": blau, "DUF1605-Domäne": rot, Verbindungshelix: grau. Cartoondarstellung. (PYMOL). 


\subsection{Modellierung homologer C-terminaler Domänen}

Die C-terminale DUF-Domäne ist charakteristisch für DExD/H-Proteine in der zweiten Phase des Spleißzyklus, nach der Aktivierung des Spleißosoms. Es handelt sich um vier RNA-Helikasen, hPrp2, hPrp16, hPrp22 und hPrp43 (1.5). Vergleicht man die Sequenzen der C-terminalen Domänen dieser Proteine, erkennt man dass 24,6 \% der Aminosäuren identisch und 62,5\% homolog sind (Abb.34). Auf Grund auf der hohen Sequenzähnlichkeit der C-terminalen Domänen konnten mit SWISSMODEL (Peitsch, 1996) Homologiemodelle generiert werden.

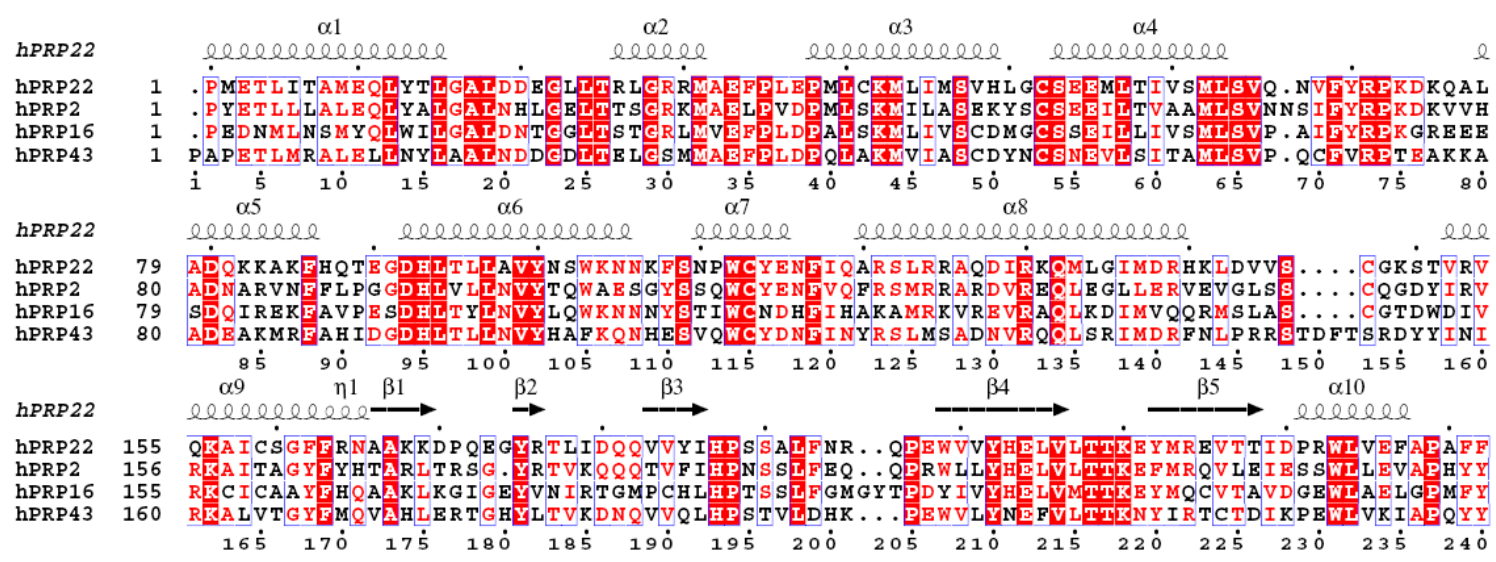

[Abb.34] Sequenzvergleich der C-terminalen Domänen von hPrp22, hPrp2, hPrp16 und hPrp43 aus Homo sapiens. Konservierte Reste sind blau umrandet, wobei ähnliche und teilweise konservierte Reste rot sind und Reste, die in allen homologen Domänen vorkommen rot unterlegt sind. Sekundärstrukturelemente der hPrp22-CTD sind über dem Alignement gezeigt. (ClustalW; ESPript 2.2).

Die Verteilung der Oberflächenladungen der Modelle wurden mit PYMOL kalkuliert (Abb.35 a-d, $36 \mathrm{a}-\mathrm{d})$.

Die Ladungsverteilungen auf der Vorderseite aller Domänen sind sehr ähnlich (Abb.35). Eine zentrale negativ geladene Region (rot) wird rechts und links von positiv geladenen Resten (blau) flankiert. Im oberen Bereich des Proteins, in dem die $\beta$-Stränge angeordnet sind, finden sich Unterschiede. Während in dieser Region bei hPrp2 hauptsächlich positive Ladungen überwiegen (Abb.35a), ist dieser Bereich bei hPrp22 negativ geladen (Abb.35c). Auf Grund dieser Gleichverteilung der Oberflächenladungen und der nahezu identischen Faltung, kann spekuliert werden, dass die C-terminalen Domänen mit denselben Proteinen des Spleißosoms interagieren. Welche das sind lässt sich ohne weitergehende Untersuchungen nicht sagen. 

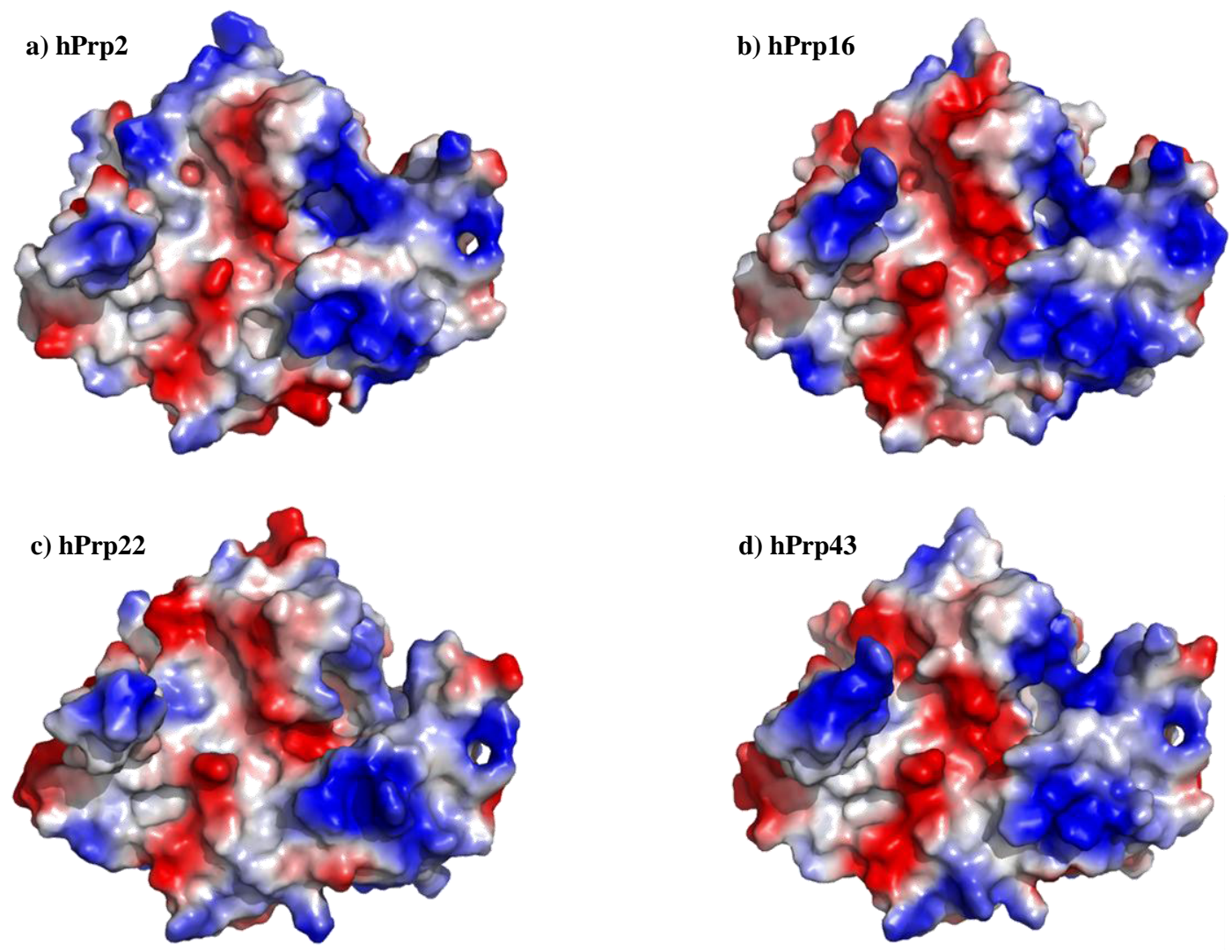

[Abb.35] Oberflächenladungen der Vorderseite der C-terminalen Domänen von a) hPrp2-CTD. b) hPrp16-CTD, c) hPrp22-CTD (H20). d) hPrp43-CTD. rot: negative Ladung, blau: positive Ladung (PYMOL).

Betrachtet man nun die Rückseite der Domäne ergibt sich ein völlig anderes Bild (Abb.36). Die Ladungsverteilungen an der Oberfläche der Domänen weisen keine Ähnlichkeiten miteinander auf. Die CTD von hPrp2 hat im oberen Bereich eine stark positiv geladene Region, während der Rest der Rückseite eher negativ geladen ist. Bei den C-terminalen Domänen von hPrp16 (Abb.36b) und hPrp43 (Abb.36d) ist eine zentrale, negativ geladene Tasche erkennbar. Diese dramatischen Unterschiede in den Ladungsverteilungen lassen darauf schließen, dass verschiedene Bindungspartner möglich sind. Diese Eigenschaft könnte die Spezifität der sehr homologen spleißosomalen DExD/H-Box RNA-Helikasen ausmachen. sie könnte dazu beitragen, dass das jeweilige Protein seine Funktion an vorgesehener Stelle im Spleißosom erfüllt. Ebenso ist es vorstellbar, dass durch definierte Interaktionen mit anderen Proteinen die Aktivität der Helikase reguliert wird. 

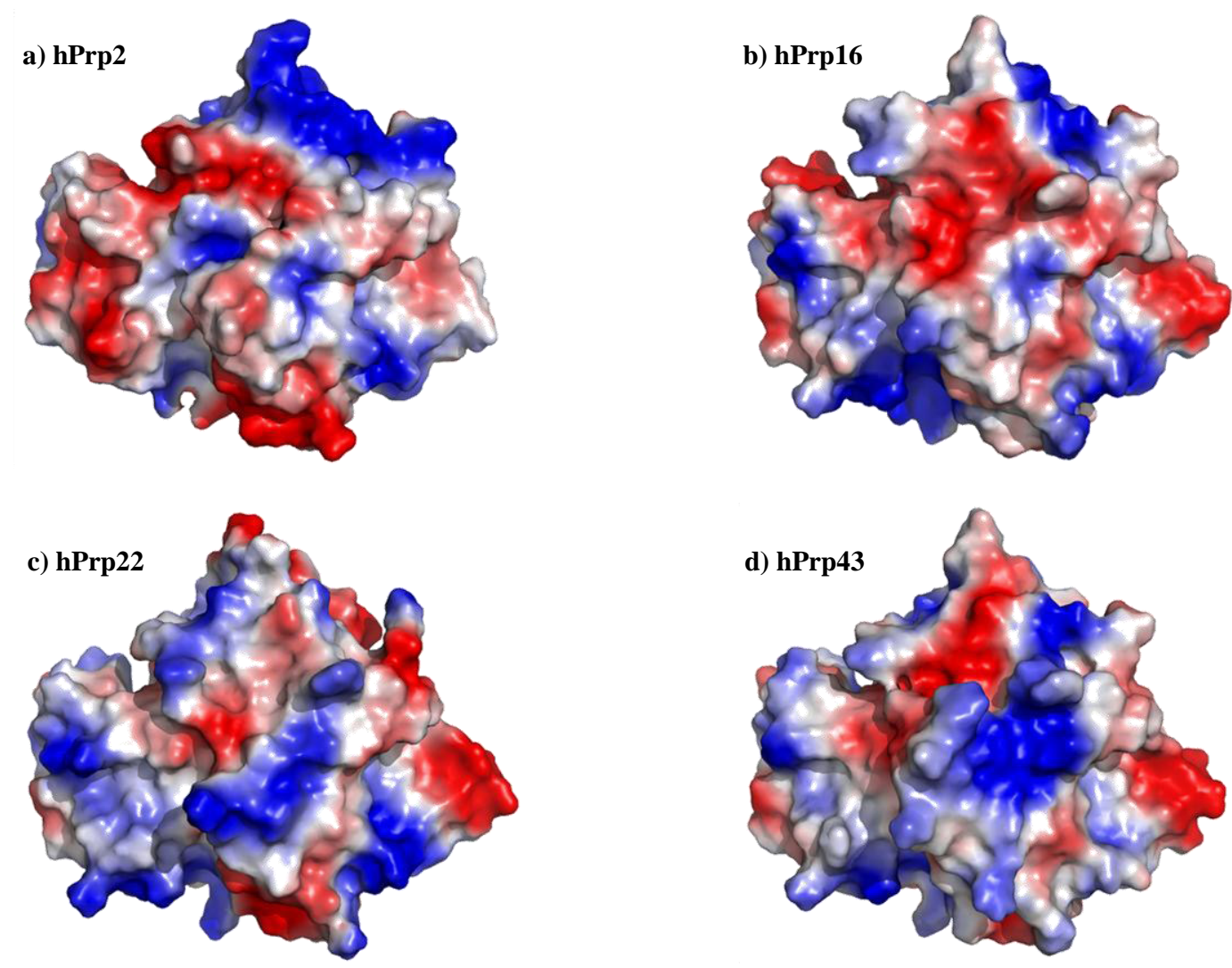

[Abb.36] Oberflächenladungen der Rückseite der C-terminalen Domänen von a) hPrp2-CTD. b) hPrp16-CTD, c) hPrp22-CTD (H20). d) hPrp43-CTD. rot: negative Ladung, blau: positive Ladung (PYMOL).

\subsection{Einfluss der C-terminalen Domäne von hPrp22 auf die ATPase-Aktivität}

Die Ergebnisse der ATPase-Aktivitätstests weisen darauf hin, dass die Helikasedomäne ohne den C-Terminus kein ATP hydrolysieren kann. Vergleicht man die Kristallstrukturen (Abb.37) katalytisch aktiver RNA-Helikasen (Vasa) mit denen katalytisch inaktiver (hPrp28, blau), kann man zwei Konformationen beobachten. In der geschlossenen Konformation (Vasa, rot) können ATP (grün) und RNA (gelb) gebunden werden. Die ATP-Hydrolyse kann stattfinden, weil die Helikasemotive nah beieinander liegen und dsRNA kann entwunden werden. In der offenen oder gestreckten Konformation ist eine Subdomäne (HELICc) vom aktiven Zentrum weggedreht. Die zur ATP-Hydrolyse benötigten Reste sind so weit voneinander entfernt, dass die Dephosphorylierung des ATPs nicht erfolgen kann. Einige Proteine haben eine dauerhaft geschlossene, aktive Konformation, während andere durch Interaktion mit Hilfsproteinen aktiviert werden. 


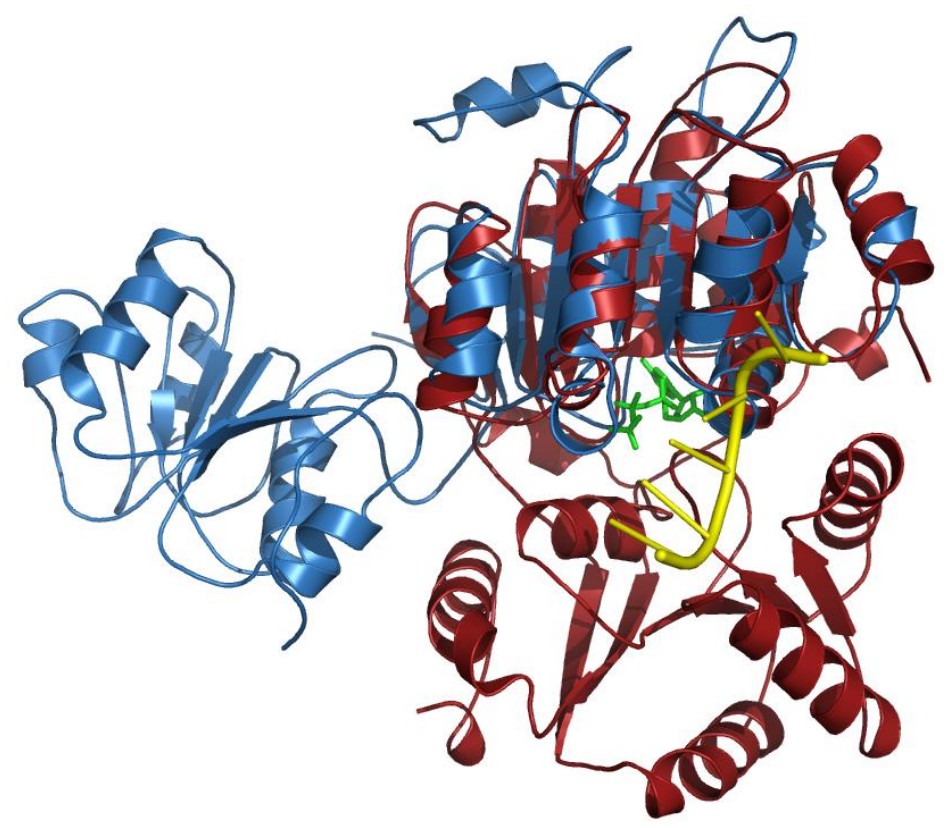

[Abb.37] Strukturvergleich der Helikasedomäne von hPrp28 (Sina Möhlmann) aus Homo sapiens (blau) und Vasa (Sengoku et al., 2006) aus Drosophila melanogaster (rot). gelb: Poly-U, grün: ADPNP. Cartoondarstellung. (PYMOL).

Alle spleißosomalen DExD/H-Box RNA-Helikasen mit der C-terminalen Domäne haben in vitro ATPase-Aktivität. Es ist vorstellbar, dass die C-terminale Domäne ein intramolekularer Aktivator der ATPase-Aktivität ist. Durch Bindung an die erste Subdomäne des Helikasekerns wird eine geschlossene, katalytisch aktive Konformation erzeugt. Die vier modellierten CTDs haben auf der einen Seite eine nahezu identische Ladungsverteilung und die DEXDc-Domänen der zugehörigen Proteine sind sehr homolog zueinander. Denkbar ist, dass die Oberflächenladungen an einer Region der DEXDc-Domäne ebenfalls konserviert sind und die CTD binden kann.

a)

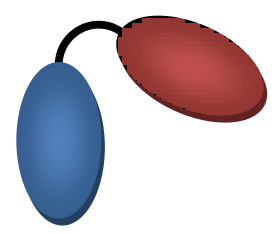

b)

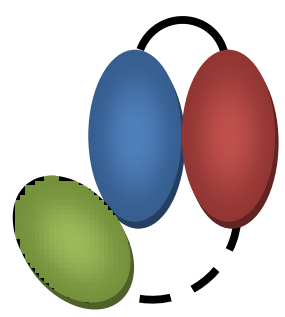

[Abb.38] Modell einer intramolekularen Aktivierung von DExD/H-Box Proteinen. a) ohne C-terminale Domäne offene, inaktive Konformation. b) C-terminale Domäne bindet an DEXDc-Domäne: geschlossene, aktive Konformation 


\section{Zusammenfassung}

Das Spleißen von prä-mRNA ist einer der dynamischsten Prozesse in der eukaryotischen Zelle. Neben den UsnRNAs ist eine Vielzahl von Proteinen am Spleißprozeß beteiligt. Einige dieser Proteine sind mobile Faktoren, während andere Komponenten integrale Bestandteile des spleißosomalen Komplexes sind. Die meisten dieser Proteine sind nicht direkt an der Entfernung der Introns und der Ligation der Exons beteiligt, sondern vermitteln ProteinProtein- bzw. Protein-RNA-Kontakte oder katalysieren Reaktionen, die zur internen Umlagerung des Spleißosoms führen. Eine am Spleißen beteiligte Proteinklasse sind die DExD/H-Box RNA-Helikasen. Sie können interne Basenpaarungen zwischen UsnRNAs oder UsnRNA-mRNA-Basenpaarungen entwinden.

Ein Protein dieser Klasse ist das DEAH-Box Protein Prp22. Es wurde gezeigt, dass das homologe Protein yPrp22 aus Saccharomyces cerevisiae ATP-abhängige RNA-Helikase Aktivität zeigt, die zur Entwindung von RNA-Interaktionen zwischen U5 snRNP und mRNA führt. Dies führt zum Ablösen der reifen mRNA vom post-spleißosomalen Komplex. Nur die vollständig prozessierte genetische Information kann denn Zellkern verlassen und wird an den Ribosomen translatiert.

Im Rahmen dieser Doktorarbeit wurde die dreidimensionale Kristallstruktur der C-terminalen Domäne des spleißosomalen DExD/H-Box Proteins hPrp22 (Aminosäuren 950 - 1183) aus Homo sapiens charakterisiert. Hierzu wurden die Phasen de novo mittels anomaler Dispersion von Brom und Selen bestimmt. Die Kristallstruktur birgt ein neues Faltungsmotiv.

Basierend auf der Struktur der C-terminalen Domäne von hPrp22 wurden Modelle anderer homologer C-terminaler Domänen von hPrp2, hPrp16 und hPrp43 generiert. Durch diese Modelle konnten Aussagen über die Verteilung der Oberflächenladungen getroffen werden. Es zeigte sich, dass auf einer Seite der verschiedenen Domänen die Ladungsverteilung konserviert ist, während auf der gegenüberliegenden Seite signifikante Unterschiede erkennbar sind.

Weiterhin wurden zahlreiche Deletionsmutanten von hPrp22 und hPrp2, einem weiteren spleißosomalen DExD/H-Box Protein, entworfen. Einige dieser verkürzten Proteinfragmente wurden gereinigt und auf ATPase-Aktivität untersucht. Dazu wurde ein enzym-gekoppelter photometrischer ATPase-Test angepasst. Die Absorptionsabnahme durch NADH-Verbrauch wird dabei bestimmt. Erste Ergebnisse weisen darauf hin, dass die Anwesenheit der Cterminalen Domäne die ATPase-Aktivität von hPrp22 stimuliert. 


\section{Summary}

Splicing of pre-mRNA is one of the most dynamic processes in eukaryotic cells. In addition to the U snRNAs, there is a multitude of proteins involved in the splicing cycle. Some of them are mobile factors; others are integral parts of the spliceosomal complex. Most of these proteins are not directly involved in the excision of introns or the ligation of exons. Rather, they mediate protein-protein and protein-RNA contacts, respectively, or catalyze reactions, which result in internal rearrangements of the spliceosome. One class of splicing related proteins are the DExD/H-box RNA helicases. They are capable of unwinding internal base pairings between $\mathrm{U}$ snRNAs or unwinding $\mathrm{U}$ snRNA-mRNA duplexes.

A noteworthy member of this protein class is Prp22, a DEAH-box protein. It was shown, that the yeast homologue of this protein has an ATP-dependent RNA-helicase activity, which is used for unwinding RNA-interactions between U5 snRNP and mRNA. This leads to the release of mature mRNA from the post-spliceosomal complex after the second transesterification step. Only then the processed genetic information is allowed to leave the cytoplasm, where finally translation at the ribosomes takes place.

Within this $\mathrm{Ph} . \mathrm{D}$. thesis the three-dimensional crystal structure of the C-terminal domain of the human spliceosomal DExD/H-box protein hPrp22 (amino acids 950 - 1183) was solved. For this purpose de novo phases were determined by anomalous dispersion of bromine and selenium. The obtained crystal structure showed a new folding motif.

This structure of the C-terminus of hPrp22 was subsequently used to model the homologous C-terminal domains of hPrp2, hPrp16 and hPrp43. The calculation of the electrostatic surface potentials revealed, that the different domains share a well conserved charge distribution on one half of of their surfaces, whereas opposing surfaces differ significantly in their charge distribution with respect to each other.

Furthermore, numerous deletion mutants of hPrp22 and hPrp2, another spliceosomal $\mathrm{DExD} / \mathrm{H}-$ box protein, were designed. Some of those protein fragments were purified and tested for ATPase activity. For this purpose a photometric enzyme linked ATPase assay was adapted, which allows for monitoring the absorption change caused by NADH decay. These experiments indicated, that the presence of the C-terminus stimulates the ATPase activity of hPrp22. 


\section{Abkürzungsverzeichnis}

\begin{tabular}{|c|c|}
\hline , & Minute \\
\hline " & Sekunde \\
\hline A & Absorption \\
\hline$\AA$ & Angström [1 $\AA$ = $0.1 \mathrm{~nm}]$ \\
\hline AS & Aminosäuren \\
\hline AG & Arbeitsgemeinschaft \\
\hline as & antisense \\
\hline ATP & Adenosintriphosphat \\
\hline B & Temperaturfaktor $\left[\AA^{3}\right]$ \\
\hline BESSY & Berliner Elektronensynchrotron \\
\hline bp & Basenpaare \\
\hline c & Konzentration [M] \\
\hline $\mathrm{C}$ & Cytosin \\
\hline cDNA & Zur RNA komplementäre DNA \\
\hline CIP & Calf Intestine Phosphatase \\
\hline $\mathrm{CV}$ & Säulenvolumen \\
\hline $\mathrm{d}$ & Tage \\
\hline $\mathrm{Da}$ & Dalton $[\mathrm{g} / \mathrm{mol}]$ \\
\hline$D E S Y$ & Deutsches Elektronensynchrotron \\
\hline DMSO & Dimethylsulfoxid \\
\hline DNA & Desoxyribonukleinsäure \\
\hline dNTP & Desoxynukleotidtriphosphat \\
\hline dsDNA & Doppelsträngige DNA \\
\hline DTT & Dithiothreitol \\
\hline E.coli & Escherichia coli \\
\hline EDTA & $\mathrm{N}, \mathrm{N}, \mathrm{N}^{\prime}, \mathrm{N}^{\prime}$ Ethylendiamintetraactetat \\
\hline eIF4E & Eukaryotischer Initiationsfaktor 4E \\
\hline $\mathrm{F}$ & Strukturfaktor in Kristallographie \\
\hline $\mathrm{F}_{\text {calc }}$ & Kalkulierte Strukturfaktoren \\
\hline FFT & Fast Fourier Transform \\
\hline $\mathrm{F}_{\mathrm{obs}}$ & Beobachtete Strukturfaktoren \\
\hline G & Guanin \\
\hline GSH & Reduziertes Glutathion \\
\hline GST & Glutathion-S-Transferase \\
\hline GTP & Guanosintriphosphat \\
\hline $\mathrm{h}$ & Stunden \\
\hline HEPES & N-(2-Hydroxyethyl)-piperazin-N'-2-ethansulfonat \\
\hline I & Intensität \\
\hline IPTG & Isopropyl- $\beta$-D-isothiogalactosid \\
\hline $\mathrm{kb}$ & Kilobasen \\
\hline LB & lysogenic broth (Luria Bertani) \\
\hline $\mathrm{m}$ & Steigung der Funktion \\
\hline M & Molarität \\
\hline MAD & Multiple Anomalous Dispersion \\
\hline mAU & Milli-Absorptionseinheiten \\
\hline MIR & Multiple Isomorphous Replacement \\
\hline MOPS & $\gamma$-Morpholino-propansulfonsäure \\
\hline MR & Molecular Replacement \\
\hline
\end{tabular}


mRNA

MW

$\mathrm{N}$

NES

NLS

NMR

NPC

NTF2

OD

PBS

PCR

PDB

PMSF

PRIP

rmsd

RNA

RT

$\mathrm{s}$

SAD

SDS

SDS-PAGE

SIR

SL

Sm

SnRNA

SnRNP

ssDNA

Taq

TBE

TEMED

$\mathrm{T}_{\mathrm{m}}$

Tris

$\mathrm{U}$

UsnRNP

UV

$\mathrm{V}$

$\mathrm{v} / \mathrm{v}$

$\mathrm{w} / \mathrm{v}$

$\mathrm{xg}$

$\varepsilon$
Messenger RNA

Molekulargewicht [g/mol]

Nukleotid

Nuclear export signal, Kernexportsignal

Nuclear Localization Signal, Kernimportsignal

Nuclear magnetic resonance

Nuclear pore complex, Kernporenkomplex

Nuclear transport factor 2, Kerntransportfaktor 2

Optische Dichte

Phosphat-gepufferte Salzlösung

Polymerasekettenreaktion

Proteindatenbank

Phenylmethylsulfonylfluorid

peroxisome prolieferator-activated receptor

interacting protein

Root mean square deviation

Ribonukleinsäure

Raumtemperatur

sense

Single Anomalous Dispersion

Natriumdodecylsulfat

SDS-Polyacrylamidgelelektrophorese

Single Isomorphous Replacement

Spliced leader

Steven Miller

Small nuclear RNA

Small nuclear Ribonucleoprotein

Einzelstränige DNA

Thermus aquaticus

Tris-Borsäure-EDTA-Puffer

$\mathrm{N}, \mathrm{N}, \mathrm{N}^{\prime}, \mathrm{N}^{\prime}$ Tetramethylethylendiamin

Schmelztemperatur

Tris(hydroxymethyl)-aminomethan

Unit (Einheit der Enzymaktivität)

Uridinrich small nuclear ribonucleoprotein

Ultraviolett

Volumen

Volumenprozent

Gewichtsprozent

Vielfaches der Erdbeschleunigung $\left(\mathrm{g}=9.81 \mathrm{~m} / \mathrm{s}^{2}\right)$

Molarer Extinktionskoeffizient $\left[\mathrm{M}^{-1} \mathrm{~cm}^{-1}\right]$ 


\section{Literaturverzeichnis}

Abrahams J. P. \& Leslie A. G. W. (1996): Methods used in the structure determination of bovine mitochondrial $\mathrm{F}_{1}$ ATPase. Acta Cryst. D52: 30-42.

Arenas J.E. \& Abelson J.N. (1997): Prp43: An RNA helicase-like factor involved in spliceosome disassembly. Proc. Natl. Acad. Sci. 99: 11798-11802.

Ares M.Jr. \& Weiser B. (1995): Rearangement of snRNA structure during assembly \& function of the spliceosome. Prog. Nucleic Acids Res. Mol. Biol. 50: 131-159.

Berget S.M., Moore M., \& Sharp P.A. (1977): Spliced segments at the 5'terminus of adenovirus 2 late mRNA. Proc. Natl. Acad. Sci. 74: 3171-3175.

Berglund J.A., Chua K., Abovich N., Reed R., \& Rosbash M. (1997): The splicing factor BBP interacts specifically with the pre-mRNA branchpoint sequence UACUACC. Cell 89: 781-787.

Bizebard T., Ferlenghi I., Iost I., \& Dreyfus M. (2004): Studies on three E.coli DEAD-box helicases point to an unwinding mechanism different from that of model DNA helicases. Biochemistry 43: 7857-7866.

Bono F., Ebert J., Lorentzen E. \& Conti E. (2006): The crystal structure of the exon junction complex reveals how it maintains a stable grip on mRNA. Cell 126: 713-725.

Bricogne G. (1993): Direct Phase Determination by Entropy Maximisation \& Likelihood Ranking: Status Report \& Perspectives. Acta Cryst. D49: 37-60.

Bricogne G., Vonrhein C., Flensburg C., Schiltz M. \& Paciorek W. (2003): Generation, representation and flow of phase information in structure determination: recent developments in and around SHARP 2.0. Acta Cryst. D59: 2023-2030.

Brow D.A. (2002): Allosteric cascade of spliceosome activation. Annu. Rev. Genet. 36: 333-360.

Brünger A. T. (1992): The Free R value: a Novel Statistical Quantity for Assessing the Accuracy of Crystal Structures. Nature 355: 472-474.

Burge C.B., Padgett R.A., \& Sharp P.A. (1998): Evolutionary fates \& origins of U12-type introns. Mol. Cell 2: 773-785. 
Burge C.B., Tuschl T., \& Sharp P.A. (1999): Splicing of precursors to mRNAs by the spliceosomes. In The RNA world, 2.Auflage: 525-560. Cold Spring Habor, NY, Cold Spring Habor Laboratory Press.

Carmel A.B. \& Matthews B.W. (2004): Crystal structure of the BstDEAD N-terminal domain: a novel DEAD protein from Bacillus stearothermophilus. RNA 10: 66-74.

Caruthers J.M., Johnson E.R., \& McKay D.B. (2000): Crystal structure of yeast initiation factor 4A, a DEAD-box RNA helicase. Proc. Natl. Acad. Sci. 97: 3080-3085.

Caruthers J.M. \& McKay D.B. (2002): Helicase structure \& mechanism. Curr. Opin. in Struct. Biol. 12: 123-133.

Cech T.R. (1993): Catalytic RNA: structure \& mechanism. Biochem. Soc. Trans. 2: 33-36.

Cheng S.-C. \& Abelson J. (1987): Spliceosome assembly in yeast. Genes Dev. 1: 1014-1027.

Cheng Z., Coller J., Parker R. \& Song H (2005): Crystal structure \& functional analysis of DEAD-box protein Dhh1p. RNA 11: 1258-1270.

Chow L.T., Gelinas R.E, Broker T.R., \& Roberts R.J (1977): An amazing sequence arrangement at the 59 ends of adenovirus 2 messenger RNA. Cell 12: 1-8.

Collaborative Computational Project, Number 4 (1994): The CCP4 Suite: Programs for Protein Crystallography. Acta Cryst. D50: 760-763.

Company M, Arenas J, \& Abelson J. (1991): Requirement of the RNA helicase-like protein PRP22 for release of messenger RNA from spliceosomes. Nature 349: 463-464/487-493.

Cordin O., Banroques J., Tanner N.K., \& Linder P. (2006): The DEAD-box protein family of RNA helicases. Gene 367: 17-37.

Das R., Zhou Z., Reed R. (2000): Functional association of U2 snRNP with the ATP-independent spliceosomal complex E. Mol. Cell. 5: 779-787.

Du H. \& Rosbash M. (2001): Yeast U1 snRNP-pre-mRNA complex formation without U1 snRNA-premRNA base pairing. RNA 7: 133-142.

Du H. \& Rosbash M. (2002): The U1 snRNP proteine U1C recognizes the 5' splice site in the absence of base pairing. Nature 419: 86-90. 
Edwalds-Gilbert G., Kim D.H., Kim S.H., Tseng Y.H., Yu Y., \& Lin R.J. (2000): Dominant negative mutants of the yeast splicing factor Prp2 map to a putative cleft region in the helicase domain of DExD/H-box proteins. RNA 6: 1106-1119.

Edwalds-Gilbert G., Kim D.H., Silverman E., \& Lin R.J. (2004): Definition of a spliceosome interaction domain in yeast Prp2 ATPase. RNA 10: 210-220.

Emsley P. \& Cowtan K. (2004): Coot: model-building tools for molecular graphics. Acta Cryst. D60: $2126-2132$.

Fortelle E. de la \& Bricogne G. (1997). Maximum-Likelihood Heavy-Atom Parameter Refinement for Multiple Isomorphous Replacement and Multiwavelength Anomalous Diffraction Methods. In Methods in Enzymology 276: 472-494. Macromolecular Crystallography Part A. C.W. Carter and R.M. Sweet ed. Academic Press, San Diego.

Gill S. C. \& von Hippel P. H. (1989): Calculation of protein extinction coefficients from amino acid sequence data. Anal. Biochem. 182: 319-326.

Gouet P., Courcelle E., Stuart D.I. \& Métoz F. (1999): ESPript: analysis of multiple sequence alignments in PostScript. Bioinformatics 15: 305-308.

Grabowski P.J., Padjett P.A., \& Sharp P.A. (1984): Messenger RNA splicing in vitro: an excised intervening sequence and a potenial intermediate. Cell 37: 415-427.

Grabowski R. \& Gallwitz D. (1997): High-affinity binding of the yeast cis-Golgi t-SNARE, Sed5p, to wild-type \& mutant Sly1p, a modulator of transport vesicle docking. FEBS Lett. 411: $169-172$

Guthrie C. \& Patterson B. (1988): Spliceosomal snRNAs. Annu. Rev. Genet. 22: 387-419.

Hartmuth K., Urlaub H., Vornlocher H.P., Will C.L., Gentzel M., Wilm M., \& Lührmann R. (2002): Protein composition of human presspoceosomes isolatd by a tobramycin affinity-selection method. Proc. Natl. Acad. Sci. 99: 16719-16724.

Hastings M.L. \& Krainer A.R. (2001): Pre-mRNA splicing in the new millennium. Curr. Opin. in Cell Biol. 13: 302-309.

Imamura O., Saiki K., Tani T., Ohshima Y., Sugawara M. \& Furuichi Y. (1998): Cloning \& characterization of a human DEAH-box RNA helicase, a functional homolog of fission yeast Cdc28/Prp8. Nucleic Acids Res. 26: 2063-2068. 
Jones D.T. (1999): Protein secondary structure prediction based on position-specific scoring matrices. J. Mol. Biol. 292: 195-202.

Jurica M.S. \& Moore M.J. (2002): Capturing splicing complexes to study structure \& mechanism. Methods 28: 336-345.

Jurica M.S. \& Moore M.J. (2003): Pre-mRNA splicing: awash in a sea of proteins. Mol. Cell. 12: $5-14$.

Kim S.H., Smith J., Claude A., \& Lin R.J. (1992): The purified yeast pre-mRNA splicing factor PRP2 is an RNA-dependent NTPase. EMBO J. 11: 2319-2326.

Kim S.H. \& Lin R.J. (1993): Pre-rRNA splicing within anassambled yeast spliceosome requires an RNAdependent ATPase \& ATP hydrolysis. Proc. Natl. Acad. Sci. 90: 888-892.

Kim S.H. \& Lin R.J. (1996): Spliceosome Activation b PRP2 ATPase prior to the First Transesterification Reaction of Pre-mRNA Splicing. Mol. Cell. Biol. 16: 6810-6819.

Kim J.L., Morgenstern K.A., Griffith J.P., Dwyer M.D., Thomson J.A., Murcko M.A., Lin C., \& Caron P.R. (1998): Hepatitis C virus NS3 RNA helicase domain with a bound oligonucleotide: the crystal structure provides insights into the mode of unwinding. Structure 6: 89-100.

Kim D-H \& Rossi J.J. (1999): The first AT-Pase domain of the yeast 246-kDa protein is required for in vivo unwinding of the U4/U6 duplex. RNA 5: 959-971.

King D.S. \& Beggs J.S. (1990): Interactions of PRP2 proteine with pre-mRNA splicing complexes in Saccharomyces cervisiae. Nucleic Acids Research 18: 6559-6564.

Konarska M.M. \& Sharp P.A. (1987): Interactions between small nuclear ribonucleoproteine particles in formation of spliceosome. Cell 49: 763-774.

Laggerbauer B., Achsel T., \& Lührmann R. (1998): The human U5-200kD DEEXH-box proteine unwinds U4/U6 RNA duplices in vitro. Proc. Natl. Acad. Sci. 95: 4188-4192.

Laskowski R.A., Moss D.S. \& Thornton J.M. (1993): Main-chain bond lengths \& bond angles in protein structures. J. Mol. Biol. 231: 1049-1067.

Lesser C.F. \& Guthrie C. (1993): Mutations in U6 snRNP that alter splice site specificity: implications for the active site. Science 262: 1982-1988. 
Linder P. (2003): Yeast RNA helicases of the DEAD-box family involved in translation initiation. Biol. Cell. 95: 157-167.

Lodish H., Baltimore D, Berk A., Zipursky S.L., Matsudaira P. \& Darnell J. (1995): Molecular Cell Biology, W. H. Freeman \& Company.

Lopez P.J. \& Séraphin B. (1999): Genomicscale quantitative analysis of yeast pre-MRNA splicing: implications for splicesite recognition. RNA 5: 1135-1137.

Lustig A.J., Lin R.J. \& Abelson J. (1986): The yeast RNA gene products are essential for mRNA splicing in vitro. Cell 47: 953-963.

Madhani H.D. \& Guthrie C. (1992): A novel baseppairing interaction between U2 \& U6 snRNAs suggests a mechanism for the catalytic activation of the spliceosome. Cell 71: 803-817.

Madhani H.D. \& Guthrie C. (1994): Dynamic RNA-RNA interactions in the spliceosome. Annu. Rev. Genet. 28: 1-26.

Makarov E.M., Makarova O.V., Urlaub H., Gentzel M., Will C.L., Wilm M., \& Lührmann R. (2002): Small nuclear ribonucleoprotein remodeling during catalytic activation of the spliceosome. Science 298: 2205-2208.

Malca H., Shomron N., \& Ast G. (2003): The U1 snRNP Base Pairs with the 5' Splice Site within a PentasnRNP Complex. Mol. Cell. Biol. 23: 3442-3455.

Martin A., Schneider S., \& Schwer B. (2002): Prp43 in an essential RNA-dependent ATPase required for release of lariat-intron from the spliceosome. J. Biol. Chem. 277: 17743-17750.

Matthews B.W. (1968): The Solvent Content of Protein Crystals. J. Mol. Biol. 33: 491-497.

Mayas R.M. \& Staley J.P.(2006): DEAD on. Nat. Struct. Mol. Biol. 13: 954-955.

Moore M., Query C.C., \& Sharp P.A. (1993): Splicing of precursors to mRNA by the spliceosome. In The RNA world, 1.Auflage: 303-357. Cold Spring Habor, NY, Cold Spring Habor Laboratory Press.

Mougin A., Gottschalk A., Fabrizio P., Lührmann R. \& Branlant C. (2002): Direct probing of RNA structure \& RNA-protein interactions in purified HeLa cell's \& yeast spliceosomal U4/U6.U5 tri-snRNP particles. J. Mol. Biol. 317: 631-49. 
Mullis K., Faloona F., Scharf S., Saiki R., Horn G. \& Erlich H. (1986): Specific enzymatic amplification of DNA in vitro: the polymerase chain reaction. Cold Spring Harb. Symp. Quant. Biol. 51 Pt. 1:263-273.

Murshudov G.N., Vagin A.A., Lebedev A., Wilson K.S. \& Dodson E.J. (1999): Efficient anisotropic refinement of macromolecular structures using FFT. Acta Cryst. D55: 247-255.

Ng R. \& Abelson J. (1980): Isolation \& sequence of the gene for actin in Saccharomyces cervisiae. Proc. Natl. Acad. Sci. 77: 3912-3916.

Nilsen T.W. (1997): Trans-splicing. In Eukaryotic mRNA processing : 310-334. Oxford, IRL Press.

Nilsen T.W. (1998): RNA-RNA interactions in nuclear pre-mRNA splicing. In RNA Structure \& Function, ed.R.Simons, M.Grunberg-Manago: 279-307. Cold Spring Habor, NY, Cold Spring Harbor Lab. Press.

Ohno M. \& Shimura Y. (1996): A human RNA helicase-like protein, HRH1, facilitates nuclear export of spliced mRNA by releasing the RNA from the spliceosome. Genes Dev. 10: 997-1007.

Ono Y., Ohno M. \& Shimura Y. (1994): Identification of a putative RNA helicase (HRH1), a human homolog of yeast Prp22. Mol. Cell. Biol. 14: 7611-7620.

Padgett R.A., Konarska M.M., Grabowski P.J., Hardy P.J., \& Sharp P.A. (1984): Lariat RNAs as intermediates \& products in the splicing of messenger RNA precursors. Science 225: 898-903.

Padgett R.A., Grabowski P.J., Konarska M.M., Seiler S., \& Sharp P.A. (1986): Splicing of messenger RNA procursors. Annu. Rev. Biochem. 55: 1110-1150.

Pape T. \& Schneider T.R. (2004): HKL2MAP: a graphical user interface for phasing with SHELX programs. J. Appl. Cryst. 37: 843-844.

Pearson W.R. \& Lipman D.J.(1988): Improved tools for biological sequence comparison. Proc. Natl. Acad. Sci. 85: 2444-2448.

Peebles C.L., Perlman P.S., Mecklenburg K.L., Petrillo M.L., Tabour J.H., Jarrel K.A. \& Cheng H.L. (1986): A self-splicing RNA excises an intron lariat. Cell 44: 213-223.

Peitsch M.C. (1996): ProMod \& Swiss-Model: Internet-based tools for automated comparative protein modelling. Biochem. Soc. Trans. 24: 274-279. 
Pikielny C.W. \& Rosbash M. (1986): Specific small nuclear RNAs are associated with yeast spliceosomes. Cell 45: 869-877.

Plumpton M., McGarvey M., \& Beggs J.D. (1994): Dominat negative mutation in the conserved RNA helicase motif 'SAT' causes splicing factor PRP2 to stall in spliceosomes. EMBO J. 13: 879-887.

Porter D.J. (1998): A Kinetic Analysis of the Oligonucleotide-modulated ATPase Activity of the Helicase Domain of the NS3 Protein from Hepatitis C Virus. J. Biol. Chem. 273: 14247-14253.

Raghunathan P.L. \& Guthrie C. (1998): RNA unwinding in U4/U6 snRNPs requires ATP hydrolysis \& the DEIH-box splicing factor Brr2. Curr. Biol. 8: 847-855.

Ramachandran G.N. \& Sasisekharan V. (1968): Conformation of polypeptides and proteins. Adv. Protein Chem. 23: 283-438.

Rappsilber J., Ryder U., Lamond A.I., \& Mann M. (2002): Large-scale proteomic analyses of the human spliceosome. Genome Res. 12: 1231-1245.

Rocak S. \& Linder P. (2004): DEAD-box proteins: the driving forces behind RNA metabolism. Nat. Rev. Mol. Cell. Biol. 5: 232-241.

Rogers G.W., Richter N.J. \& Merrick W.C.(1999): Biochemical \& kinetic characterization of the RNA helicase activity of eukaryotic initiation factor 4A. J. Biol. Chem. 274: 12236-12244.

Rogers G.W., Lima W.F., \& Merrick W.C. (2001): Further characterization of the helicase activity of elF4A. Substrate specificity. J. Biol. Chem. 276: 12598-12608.

Ruskin B., Krainer A.R., Maniatis T., \& Green M.R. (1984): Excision of an intact intron an a novel lariat structure during pre-mRNA splicing in vitro. Cell 38: 317-331.

Schneider S. \& Schwer B. (2001): Functional domains of the yeast splicing factor Prp22p. J. Biol. Chem. 276: 21184-21191.

Schneider T. R. \& Sheldrick G. M. (2002): Substructure solution with SHELXD. Acta Cryst. D58: $1772-1779$.

Schubert M., Edge R.E., Lario P., Cook M.A., Strynadka N.C., Mackie G.A. \& McIntosh L.P. (2004): Structural Characterization of the RNase E S1 Domain \& Identification of its Oligonucleotide-binding \& Dimerization Interfaces J. Mol. Biol. 341: 37-54. 
Schultz J., Milpetz F., Bork P. \& Ponting C.P. (1998): SMART, a simple modular architecture research tool: Identification of signaling domains Proc. Natl. Acad. Sci. 95: 5857-5864.

Schwer B. \& Guthrie C. (1991): PRP16 is an RNA-dependent ATPase that interacts transently with the spliceosome. Nature 349: 494-499.

Schwer B. \& Gross C.H. (1998): Prp22, a DExH-box RNA helicase, plays two distinct roles in yeast premRNA splicing. EMBO J. 17: 2086-2094.

Schwer B. \& Meszaros T. (2000): RNA helicase dynamics in pre-mRNA splicing. EMBO J. 19: 6582-6591.

Senapathy P., Sharpiro M. B. \& Harris N. L. (1990): Splice junctions, branch point sites \& exons: sequence statistics, identification, \& applications to genome project. Meth. Enzymol. 183: 252278.

Sengoku T., Nureki O., Nakamura A., Kobayashi S. \& Yokoyama S. (2006): Structural basis for RNA unwinding by the DEAD-box protein Drosophila Vasa. Cell 125: 287-300.

Séraphin B. \& Rosbash M. (1989): Identification of functional U1 snRNA-pre-mRNA complexes comitted to spliceosome assembly \& splicing. Cell 59: 349-358.

Sheldrick G.M. \& Schneider T.R. (1997): Methods Enzymol. 277: 319-343.

Shi H., Cordin O., Minder C.M., Linder P., \& Xu R.M. (2004): Crystal structure of the human ATPdependent splicing \& export factor UAP56. Proc. Natl. Acad. Sci. 101: 17628-17633.

Silverman E., Edwalds-Gilbert G., \& Lin R.J. (2003): DExD/H-box proteins \& their partners: helping RNA helicases unwind. Gene 312: 1-16.

Soultanas P. \& Wigley D.B. (2000): DNA helicase: "inching forward.". Curr. Opin. in Struct. Biol. 10: 124-128.

Soultanas P. \& Wigley D.B. (2001): Unwinding the "Gordian knot" of helicase action. Trends in Biochem. Sci. 26: 47-54.

Staley J.P. \& Guthrie C. (1998): Mechanical Devices of the Spliceosome: Motors, Clocks, Springs, \& Things. Cell 92: 315-326. 
Stevens S.W., Ryan D.E., Ge H.Y., Moore R.E., Young M.K., Lee T.D., \& Abelson J.A. (2002): Composition \& functional characterization of the yeast spliceosomal penta-snRNP. Mol. Cell 9: $31-44$.

Story R.M., Li H., \& Abelson J.N. (2001): Crystal structure of a DEAD box protein from the hyperthermophile Methanococcus jannaschii. Proc. Natl. Acad. Sci. 98: 1465-1470.

Studier F.W. (2005): Protein production by auto-induction in high density shaking cultures. Protein Expr. Purif. 41: 207-34.

Tanaka N, Schwer B. (2005): Characterization of the NTPase, RNA-binding, \& RNA helicase activities of the DEAH-box splicing factor Prp22. Biochem. 44: 9795-803.

Tanner N.K. \& Linder P. (2001): DExD/H box RNA helicases: from generic motors to specific dissosiation functions. Mol. Cell 8: 251-262.

Tarn W.Y. \& Steitz J.A. (1994): SR proteins can compensate for the loss of U1 snRNP functions in vitro. Genes Dev. 8: 2704-2717.

Tarn W.Y. \& Steitz J.A. (1996): A novel spliceosome containing U11, U12; \& U5 snRNPs excises aminor class (AT-CT) intron in vitro. Cell 84: 801-811.

Teigelkamp S., McGarvey M., Plumpton M., \& Beggs J.D. (1994): The splicing factor PRP2, a putativeRNA helicase, interacts directly with pre-mRNA. EMBO J. 13: 888-897.

Terwilliger T. C. (2000): Maximum likelihood density modification. Acta Cryst. D56: 965-972.

Theis K., Chen P.J., Skorvaga M., Van Houten B., \& Kisker C. (1999): Crystal structure of UvrB, a DNAhelicase adapted for nucleotide exision repair. EMBO J. 18: 6899-6907.

Tuteja N. \& Tuteja R. (2004): Unraveling DNA helicases. Motif, structure mechanism \& function. Eur. J. Biochem. 271: 1849-1863.

Van der Veen R., Arnberg A.C., van der Horst G., Bonen L., Tabak H.F., \& Grivell L.A. (1986): Excised group II introns in yeast mitochondria are lariats \& can be formed by self-splicing in vitro. Cell 44: 225-234.

Vonrhein C, Blanc E., Roversi P. \& Bricogne G. (2007): Automated structure solution with autoSHARP. Methods Mol. Biol. 364: 215-30. 
Wagner J.D., Jankowsky E., Company M., Pyle A.M., \& Abelson J.N. (1998): The DEAH-box protein Prp22 is an ATPase that mediates ATP-dependent mRNA release from the spliceosome \& unwinds RNA duplexes. EMBO J. 17: 2926-2937.

Will C.L. \& Lührmann R. (2001): Spliceosomal UsnRNP biogenesis, structure \& function. Curr. Opin. in Cell Biol. 13: 290-301.

Will C.L. \& Lührmann R. (2005): Splicing of a rare class of introns by the U12-dependent spliceosome. Biol. Chem. 386: 713-724.

Will C.L. \& Lührmann R. (2006): Spliceosome Structure \& Funktion. In The RNA world, 3.Auflage: $369-400$. Cold Spring Habor, NY, Cold Spring Habor Laboratory Press.

Yao N., Hesson T., Cable M., Hong Z., Kwong A.D., Le H.V., \& Weber P.C. (1997): Structure of the hepatitis C virus RNA helicase domain. Nature Struct.Biol. 4: 463-467.

Yean S.L. \& Lin R.J. (1991): U4 small nuclear RNA dissociates from yeast spliceosome \& does not participate in the subsequent splicing reaction. Mol. Cell. Biol. 11: 5571-5577.

Zaug A.J., Grabowski P.J., \& Cech T.R. (1983): Autocatalytic cyclization of an excised intervening sequence RNA is a cleavage-ligation reaction. Nature 301: 578-583.

Zavanelli M.I., Britton J.S., Igel A.H., Ares M. Jr. (1994): Mutations in an essential U2 small nuclear RNA structure causes cold-sensitiv U2 small nuclear ribonucleoprotein function by favoring competing alternative U2 RNA structures. Mol. Cell. Biol. 14: 1689-1697.

Zhou Z., Licklider L.J., Gygi S.P., \& Reed R. (2002): Comprehensive proteomic analysis of the human spliceosome. Nature 419: 182-185. 


\title{
9. Anhang
}

\section{Sequenzübersicht aller klonierter Konstrukte von hPrp22}

\author{
hPrp22 1220 AS / 139, 3 kDa / pI 8,54
}

MAVAVAMAGALIGSEPGPAEELAKLEYLSLVSKVCTELDNHLGINDKDLAEFVISLAEKNTTFDTFKASLVKNGAEFTDSLISNLLRLI QTMRPPAKPSTSKDPVVKPKTEKEKLKELFPVLCQPDNPSVRTMLDEDDVKVAVDVLKELEALMPSAAGQEKQRDAEHRDRTKKKKRSR SRDRNRDRDRDRERNRDRDHKRRHRSRSRSRSRTRERNKVKSRYRSRSRSQSPPKDRKDRDKYGERNLDRWRDKHVDRPPPEEPTIGDI YNGKVTSIMQFGCFVQLEGLRKRWEGLVHISELRREGRVANVADVVSKGQRVKVKVLSFTGTKTSLSMKDVDQETGEDLNPNRRRNLVG ETNEETSMRNPDRPTHLSLVSAPEVEDDSLERKRLTRISDPEKWEIKQMIAANVLSKEEFPDFDEETGILPKVDDEEDEDLEIELVEEE PPFLRGHTKQSMDMSPIKIVKNPDGSLSQAAMMQSALAKERRELKQAQREAEMDSIPMGLNKHWVDPLPDAEGRQIAANMRGIGMMPND IPEWKKHAFGGNKASYGKKTQMSILEQRESLPIYKLKEQLVQAVHDNQILIVIGETGSGKTTQITQYLAEAGYTSRGKIGCTQPRRVAA MSVAKRVSEEFGCCLGQEVGYTIRFEDCTSPETVIKYMTDGMLLRECLIDPDLTQYAIIMLDEAHERTIHTDVLFGLLKKTVQKRODMK LIVTSATLDAVKFSQYFYEAPIFTIPGRTYPVEILYTKEPETDYLDASLITVMQIHLTEPPGDILVFLTGQEEIDTACEILYERMKSLG PDVPELIILPVYSALPSEMQTRIFDPAPPGSRKVVIATNIAETSLTIDGIYYVVDPGFVKQKVYNSKTGIDQLVVTPISQAQAKQRAGR AGRTGPGKCYRLYTERAYRDEMLTTNVPEIQRTNLASTVLSLKAMGINDLLSFDFMDAPPMETLITAMEQLYTLGALDDEGLLTRLGRR MAEFPLEPMLCKML IMSVHLGCSEEMLTIVSMLSVONVFYRPKDKQALADQKKAKFHQTEGDHLTLLAVYNSWKNNKFSNPWCYENFIQ ARSLRRAQDIRKQMLGIMDRHKLDVVSCGKSTVRVQKAICSGFFRNAAKKDPQEGYRTLIDQQVVYIHPSSALFNRQPEWVVYHELVLT TKEYMREVTTIDPRWLVEFAPAFFKVSDPTKLSKQKKQQRLEPLYNRYEEPNAWRISRAFRRR

hPrp22 -H1 27-H-1183 1157 AS / 132,2 kDa / pI 8,25

YLSLVSKVCTELDNHLGINDKDLAEFVISLAEKNTTFDTFKASLVKNGAEFTDSLISNLLRLIQTMRPPAKPSTSKDPVVKPKTEKEKL KELFPVLCQPDNPSVRTMLDEDDVKVAVDVLKELEALMPSAAGQEKQRDAEHRDRTKKKKRSRSRDRNRDRDRDRERNRDRDHKRRHRS RSRSRSRTRERNKVKSRYRSRSRSQSPPKDRKDRDKYGERNLDRWRDKHVDRPPPEEPTIGDIYNGKVTSIMQFGCFVQLEGLRKRWEG LVHISELRREGRVANVADVVSKGQRVKVKVLSFTGTKTSLSMKDVDQETGEDLNPNRRRNLVGETNEETSMRNPDRPTHLSLVSAPEVE DDSLERKRLTRISDPEKWEIKQMIAANVLSKEEFPDFDEETGILPKVDDEEDEDLEIELVEEEPPFLRGHTKQSMDMSPIKIVKNPDGS LSQAAMMQSALAKERRELKQAQREAEMDSIPMGLNKHWVDPLPDAEGRQIAANMRGIGMMPNDIPEWKKHAFGGNKASYGKKTQMSILE QRESLPIYKLKEQLVQAVHDNQILIVIGETGSGKTTQITQYLAEAGYTSRGKIGCTQPRRVAAMSVAKRVSEEFGCCLGQEVGYTIRFE DCTSPETVIKYMTDGMLLRECLIDPDLTQYAIIMLDEAHERTIHTDVLFGLLKKTVQKRQDMKLIVTSATLDAVKFSQYFYEAPIFTIP GRTYPVEILYTKEPETDYLDASLITVMQIHLTEPPGDILVFLTGQEEIDTACEILYERMKSLGPDVPELIILPVYSALPSEMQTRIFDP APPGSRKVVIATNIAETSLTIDGIYYVVDPGFVKQKVYNSKTGIDQLVVTPISQAQAKQRAGRAGRTGPGKCYRLYTERAYRDEMLTTN VPEIQRTNLASTVLSLKAMGINDLLSFDFMDAPPMETLITAMEQLYTLGALDDEGLLTRLGRRMAEFPLEPMLCKMLIMSVHLGCSEEM LTIVSMLSVONVFYRPKDKQALADQKKAKFHQTEGDHLTLLAVYNSWKNNKFSNPWCYENFIQARSLRRAQDIRKQMLGIMDRHKLDVV SCGKSTVRVQKAICSGFFRNAAKKDPQEGYRTLIDQQVVYIHPSSALFNRQPEWVVYHELVLTTKEYMREVTTIDPRWLVEFAPAFFKV

hPrp22 - H2 27-H-1055 1029 AS / 117,1 kDa / pI 6,87 YLSLVSKVCTELDNHL GINDKDLAEFVISLAEKNTTFDTFKASLVKNGAEFTDSL ISNLLRL IQTMRPPAKPSTSKDPVVKPKTEKEKL KELFPVLCQPDNPSVRTMLDEDDVKVAVDVLKELEALMPSAAGQEKQRDAEHRDRTKKKKRSRSRDRNRDRDRDRERNRDRDHKRRHRS RSRSRSRTRERNKVKSRYRSRSRSQSPPKDRKDRDKYGERNLDRWRDKHVDRPPPEEPTIGDIYNGKVTSIMQFGCFVQLEGLRKRWEG LVHISELRREGRVANVADVVSKGQRVKVKVLSFTGTKTSLSMKDVDQETGEDLNPNRRRNLVGETNEETSMRNPDRPTHLSLVSAPEVE DDSLERKRLTRISDPEKWEIKQMIAANVLSKEEFPDFDEETGILPKVDDEEDEDLEIELVEEEPPFLRGHTKQSMDMSPIKIVKNPDGS LSQAAMMQSALAKERRELKQAQREAEMDSIPMGLNKHWVDPLPDAEGRQIAANMRGIGMMPNDIPEWKKHAFGGNKASYGKKTQMSILE QRESLPIYKLKEQLVQAVHDNQILIVIGETGSGKTTQITQYLAEAGYTSRGKIGCTQPRRVAAMSVAKRVSEEFGCCLGQEVGYTIRFE DCTSPETVIKYMTDGMLLRECLIDPDLTQYAIIMLDEAHERTIHTDVLFGLLKKTVQKRQDMKLIVTSATLDAVKFSQYFYEAPIFTIP GRTYPVEILYTKEPETDYLDASLITVMQIHLTEPPGDILVFLTGQEEIDTACEILYERMKSLGPDVPELIILPVYSALPSEMQTRIFDP APPGSRKVVIATNIAETSLTIDGIYYVVDPGFVKOKVYNSKTGIDQLVVTPISOAQAKQRAGRAGRTGPGKCYRLYTERAYRDEMLTTN VPEIQRTNLASTVLSLKAMGINDLLSFDFMDAPPMETLITAMEQLYTLGALDDEGLLTRLGRRMAEFPLEPMLCKMLIMSVHLGCSEEM LTIVSMLSVQNVFYRPKDKQALADQKKAKFHQTEGDHLTLLAVYNSWKNN

hPrp22 - H3 27-H-904 878 AS / 99,9 kDa / pI 8,11

YLSLVSKVCTELDNHLGINDKDLAEFVISLAEKNTTFDTFKASLVKNGAEFTDSLISNLLRLIQTMRPPAKPSTSKDPVVKPKTEKEKL KELFPVLCQPDNPSVRTMLDEDDVKVAVDVLKELEALMPSAAGQEKORDAEHRDRTKKKKRSRSRDRNRDRDRDRERNRDRDHKRRHRS RSRSRSRTRERNKVKSRYRSRSRSQSPPKDRKDRDKYGERNLDRWRDKHVDRPPPEEPTIGDIYNGKVTSIMQFGCFVQLEGLRKRWEG LVHISELRREGRVANVADVVSKGQRVKVKVLSFTGTKTSLSMKDVDQETGEDLNPNRRRNLVGETNEETSMRNPDRPTHLSLVSAPEVE DDSLERKRLTRISDPEKWEIKQMIAANVLSKEEFPDFDEETGILPKVDDEEDEDLEIELVEEEPPFLRGHTKQSMDMSPIKIVKNPDGS LSQAAMMQSALAKERRELKQAQREAEMDSIPMGLNKHWVDPLPDAEGRQIAANMRGIGMMPNDIPEWKKHAFGGNKASYGKKTQMSILE QRESLPIYKLKEQL VQAVHDNQIL IVIGETGSGKTTQITQYLAEAGYTSRGKIGCTQPRRVAAMSVAKRVSEEFGCCLGQEVGYTIRFE DCTSPETVIKYMTDGMLLRECLIDPDLTQYAIIMLDEAHERTIHTDVLFGLLKKTVQKRQDMKLIVTSATLDAVKFSQYFYEAPIFTIP GRTYPVEILYTKEPETDYLDASLITVMQIHLTEPPGDILVFLTGQEEIDTACEILYERMKSLGPDVPELIILPVYSALPSEMQTRIFDP APPGSRKVVIATNIAETSLTIDGIYYVVDPGFVKQKVYNSKTGIDQLVVTPISQAQAKQRAGRAGRTGPGKCYRLYT

hPrp22 - H4 27-H-750 724 AS / 83,0 kDa / pI 8,76

YLSLVSKVCTELDNHLGINDKDLAEFVISLAEKNTTFDTFKASLVKNGAEFTDSLISNLLRLIQTMRPPAKPSTSKDPVVKPKTEKEKL KELFPVLCQPDNPSVRTMLDEDDVKVAVDVLKELEALMPSAAGQEKQRDAEHRDRTKKKKRSRSRDRNRDRDRDRERNRDRDHKRRHRS RSRSRSRTRERNKVKSRYRSRSRSQSPPKDRKDRDKYGERNLDRWRDKHVDRPPPEEPTIGDIYNGKVTSIMQFGCFVQLEGLRKRWEG LVHISELRREGRVANVADVVSKGQRVKVKVLSFTGTKTSLSMKDVDQETGEDLNPNRRRNLVGETNEETSMRNPDRPTHLSLVSAPEVE DDSLERKRLTRISDPEKWEIKQMIAANVLSKEEFPDFDEETGILPKVDDEEDEDLEIELVEEEPPFLRGHTKQSMDMSPIKIVKNPDGS LSQAAMMQSALAKERRELKQAQREAEMDSIPMGLNKHWVDPLPDAEGRQIAANMRGIGMMPNDIPEWKKHAFGGNKASYGKKTQMSILE QRESLPIYKLKEQLVQAVHDNQILIVIGETGSGKTTQITQYLAEAGYTSRGKIGCTQPRRVAAMSVAKRVSEEFGCCLGQEVGYTIRFE DCTSPETVIKYMTDGMLLRECLIDPDLTQYAIIMLDEAHERTIHTDVLFGLLKKTVQKRQDMKLIVTSATLDAVKFSQYFYEAPIFTIP GRTYPVEILYTK

hPrp22 - H5 27-H-561 535 AS / 61,7 kDa / pI 9,12

YLSLVSKVCTELDNHLGINDKDLAEFVISLAEKNTTFDTFKASLVKNGAEFTDSLISNLLRLIOTMRPPAKPSTSKDPVVKPKTEKEKL KELFPVLCQPDNPSVRTMLDEDDVKVAVDVLKELEALMPSAAGQEKQRDAEHRDRTKKKKRSRSRDRNRDRDRDRERNRDRDHKRRHRS RSRSRSRTRERNKVKSRYRSRSRSQSPPKDRKDRDKYGERNLDRWRDKHVDRPPPEEPTIGDIYNGKVTSIMQFGCFVQLEGLRKRWEG LVHISELRREGRVANVADVVSKGQRVKVKVLSFTGTKTSLSMKDVDQETGEDLNPNRRRNLVGETNEETSMRNPDRPTHLSLVSAPEVE DDSLERKRLTRISDPEKWEIKOMIAANVLSKEEFPDFDEETGILPKVDDEEDEDLEIELVEEEPPFLRGHTKOSMDMSPIKIVKNPDGS LSQAAMMQSALAKERRELKQAQREAEMDSIPMGLNKHWVDPLPDAEGRQIAANMRGIGMMPNDIPEWKKHAFGGNKASYGKKTQMSILE $\mathrm{Q}$ 
hPrp22 - H6 27-H-351 325 AS / 37,8 kDa / pI 10,06

YLSLVSKVCTELDNHLGINDKDLAEFVISLAEKNTTFDTFKASLVKNGAEFTDSLISNLLRLIQTMRPPAKPSTSKDPVVKPKTEKEKL KELFPVLCQPDNPSVRTMLDEDDVKVAVDVLKELEALMPSAAGQEKQRDAEHRDRTKKKKRSRSRDRNRDRDRDRERNRDRDHKRRHRS RSRSRSRTRERNKVKSRYRSRSRSQSPPKDRKDRDKYGERNLDRWRDKHVDRPPPEEPTIGDIYNGKVTSIMQFGCFVQLEGLRKRWEG LVHISELRREGRVANVADVVSKGQRVKVKVLSFTGTKTSLSMKDVDQETGEDLNPNRR

\section{hPrp22 - H7 264-H-1183 920 AS / 104,2 kDa / pI 5,70}

IGDIYNGKVTSIMQFGCFVQLEGLRKRWEGLVHISELRREGRVANVADVVSKGQRVKVKVLSFTGTKTSLSMKDVDQETGEDLNPNRRR NLVGETNEETSMRNPDRPTHLSLVSAPEVEDDSLERKRLTRISDPEKWEIKQMIAANVLSKEEFPDFDEETGILPKVDDEEDEDLEIEL VEEEPPFLRGHTKQSMDMSPIKIVKNPDGSLSQAAMMQSALAKERRELKQAQREAEMDSIPMGLNKHWVDPLPDAEGRQIAANMRGIGM MPNDIPEWKKHAFGGNKASYGKKTQMSILEQRESLPIYKLKEQLVQAVHDNQILIVIGETGSGKTTQITQYLAEAGYTSRGKIGCTQPR RVAAMSVAKRVSEEFGCCLGQEVGYTIRFEDCTSPETVIKYMTDGML LRECLIDPDLTOYAI IMLDEAHERTIHTDVLFGLLKKTVOKR QDMKLIVTSATLDAVKFSQYFYEAPIFTIPGRTYPVEILYTKEPETDYLDASLITVMQIHLTEPPGDILVFLTGQEEIDTACEILYERM KSLGPDVPELIILPVYSALPSEMQTRIFDPAPPGSRKVVIATNIAETSLTIDGIYYVVDPGFVKQKVYNSKTGIDQLVVTPISQAQAKQ RAGRAGRTGPGKCYRLYTERAYRDEMLTTNVPEIQRTNLASTVLSLKAMGINDLLSFDFMDAPPMETLITAMEQLYTLGALDDEGLLTR LGRRMAEFPLEPMLCKMLIMSVHLGCSEEMLTIVSMLSVONVFYRPKDKOALADOKKAKFHOTEGDHLTLLAVYNSWKNNKFSNPWCYE NFIOARSLRRAODIRKOMLGIMDRHKLDVVSCGKSTVRVOKAICSGFFRNAAKKDPQEGYRTLIDQOVVYIHPSSALFNROPEWVVYHE LVLTTKEYMREVTTIDPRWLVEFAPAFFKV

hPrp22 - H8 264-H-1055 792 AS / 89,1 kDa / pI 5,26

IGDIYNGKVTSIMQFGCFVQLEGLRKRWEGLVHISELRREGRVANVADVVSKGQRVKVKVLSFTGTKTSLSMKDVDQETGEDLNPNRRR NLVGETNEETSMRNPDRPTHLSLVSAPEVEDDSLERKRLTRISDPEKWEIKOMIAANVLSKEEFPDFDEETGILPKVDDEEDEDLEIEL VEEEPPFLRGHTKOSMDMSPIKIVKNPDGSLSQAAMMOSALAKERRELKQAOREAEMDSIPMGLNKHWVDPLPDAEGROIAANMRGIGM MPNDIPEWKKHAFGGNKASYGKKTQMSILEQRESLPIYKLKEQLVQAVHDNQILIVIGETGSGKTTQITQYLAEAGYTSRGKIGCTQPR RVAAMSVAKRVSEEFGCCLGQEVGYTIRFEDCTSPETVIKYMTDGMLLRECLIDPDLTQYAIIMLDEAHERTIHTDVLFGLLKKTVQKR QDMKLIVTSATLDAVKFSOYFYEAPIFTIPGRTYPVEILYTKEPETDYLDASLITVMQIHLTEPPGDILVFLTGQEEIDTACEILYERM KSLGPDVPELIILPVYSALPSEMOTRIFDPAPPGSRKVVIATNIAETSLTIDGIYYVVDPGFVKQKVYNSKTGIDQLVVTPISQAQAKO RAGRAGRTGPGKCYRLYTERAYRDEMLTTNVPEIQRTNLASTVLSLKAMGINDLLSFDFMDAPPMETLITAMEQLYTLGALDDEGLLTR LGRRMAEFPLEPMLCKMLIMSVHLGCSEEMLTIVSMLSVQNVFYRPKDKQALADQKKAKFHQTEGDHLTLLAVYNSWKNN

hPrp22 - H9 264-H-904 641 AS / 72,0 kDa / pI 5,28

IGDIYNGKVTSIMQFGCFVQLEGLRKRWEGLVHISELRREGRVANVADVVSKGQRVKVKVLSFTGTKTSLSMKDVDQETGEDLNPNRRR NLVGETNEETSMRNPDRPTHLSLVSAPEVEDDSLERKRLTRISDPEKWEIKOMIAANVLSKEEFPDFDEETGILPKVDDEEDEDLEIEL VEEEPPFLRGHTKQSMDMSPIKIVKNPDGSLSQAAMMQSALAKERRELKQAQREAEMDSIPMGLNKHWVDPLPDAEGRQIAANMRGIGM MPNDIPEWKKHAFGGNKASYGKKTQMSILEQRESLPIYKLKEQLVQAVHDNQILIVIGETGSGKTTQITQYLAEAGYTSRGKIGCTQPR RVAAMSVAKRVSEEFGCCLGQEVGYTIRFEDCTSPETVIKYMTDGMLLRECLIDPDLTQYAIIMLDEAHERTIHTDVLFGLLKKTVQKR QDMKLIVTSATLDAVKFSQYFYEAPIFTIPGRTYPVEILYTKEPETDYLDASLITVMQIHLTEPPGDILVFLTGQEEIDTACEILYERM KSLGPDVPELIILPVYSALPSEMQTRIFDPAPPGSRKVVIATNIAETSLTIDGIYYVVDPGFVKQKVYNSKTGIDQLVVTPISQAQAKQ RAGRAGRTGPGKCYRLYT

hPrp22 - H10 264-H-750

487 AS / 55,1 kDa / pI 5,42

IGDIYNGKVTSIMQFGCFVQLEGLRKRWEGLVHISELRREGRVANVADVVSKGQRVKVKVLSFTGTKTSLSMKDVDQETGEDLNPNRRR NLVGETNEETSMRNPDRPTHLSLVSAPEVEDDSLERKRLTRISDPEKWEIKOMIAANVLSKEEFPDFDEETGILPKVDDEEDEDLEIEL VEEEPPFLRGHTKOSMDMSPIKIVKNPDGSLSOAAMMOSALAKERRELKOAOREAEMDSIPMGLNKHWVDPLPDAEGROIAANMRGIGM MPNDIPEWKKHAFGGNKASYGKKTQMSILEQRESLPIYKLKEQLVQAVHDNQILIVIGETGSGKTTQITQYLAEAGYTSRGKIGCTQPR RVAAMSVAKRVSEEFGCCLGQEVGYTIRFEDCTSPETVIKYMTDGMLLRECLIDPDLTQYAIIMLDEAHERTIHTDVLFGLLKKTVQKR QDMKLIVTSATLDAVKFSQYFYEAPIFTIPGRTYPVEILYTK

hPrp22 - H11 264-H-561 298 AS / 33,7 kDa / pI 5,18

IGDIYNGKVTSIMOFGCFVOLEGLRKRWEGLVHISELRREGRVANVADVVSKGORVKVKVLSFTGTKTSLSMKDVDOETGEDLNPNRRR NLVGETNEETSMRNPDRPTHLSLVSAPEVEDDSLERKRLTRISDPEKWEIKQMIAANVLSKEEFPDFDEETGILPKVDDEEDEDLEIEL VEEEPPFLRGHTKQSMDMSPIKIVKNPDGSLSQAAMMQSALAKERRELKQAQREAEMDSIPMGLNKHWVDPLPDAEGRQIAANMRGIGM MPNDIPEWKKHAFGGNKASYGKKTQMSILEQ

hPrp22 - H12 264-H-351 88 AS / 9,9 kDa / pI 9,58 IGDIYNGKVTSIMQFGCFVQLEGLRKRWEGLVHISELRREGRVANVADVVSKGQRVKVKVLSFTGTKTSLSMKDVDQETGEDLNPNRR

hPrp22 - H13 564-H-1183 620 AS / 70,2 kDa / pI 6,27

SLPIYKLKEQLVQAVHDNQILIVIGETGSGKTTQITQYLAEAGYTSRGKIGCTQPRRVAAMSVAKRVSEEFGCCLGQEVGYTIRFEDCT SPETVIKYMTDGMLLRECLIDPDLTQYAIIMLDEAHERTIHTDVLFGLLKKTVQKRQDMKLIVTSATLDAVKFSQYFYEAPIFTIPGRT YPVEILYTKEPETDYLDASLITVMQIHLTEPPGDILVFLTGQEEIDTACEILYERMKSLGPDVPELIILPVYSALPSEMQTRIFDPAPP GSRKVVIATNIAETSLTIDGIYYVVDPGFVKQKVYNSKTGIDQL VVTPISQAQAKQRAGRAGRTGPGKCYRLYTERAYRDEMLTTNVPE IQRTNLASTVLSLKAMGINDLLSFDFMDAPPMETLITAMEQLYTLGALDDEGLLTRLGRRMAEFPLEPMLCKMLIMSVHLGCSEEMLTI VSMLSVQNVFYRPKDKQALADQKKAKFHQTEGDHLTLLAVYNSWKNNKFSNPWCYENFIQARSLRRAQDIRKQMLGIMDRHKLDVVSCG KSTVRVQKAICSGFFRNAAKKDPQEGYRTLIDQQVVYIHPSSALFNRQPEWVVYHELVLTTKEYMREVTTIDPRWLVEFAPAFFKV

hPrp22 - H14 564-H-1055 492 AS / 55,2 kDa / pI 5,33

SLPIYKLKEOLVQAVHDNOILIVIGETGSGKTTOITOYLAEAGYTSRGKIGCTOPRRVAAMSVAKRVSEEFGCCLGQEVGYTIRFEDCT SPETVIKYMTDGMLLRECLIDPDLTQYAIIMLDEAHERTIHTDVLFGLLKKTVQKRQDMKLIVTSATLDAVKFSQYFYEAPIFTIPGRT YPVEILYTKEPETDYLDASLITVMQIHLTEPPGDILVFLTGQEEIDTACEILYERMKSLGPDVPELIILPVYSALPSEMQTRIFDPAPP GSRKVVIATNIAETSLTIDGIYYVVDPGFVKQKVYNSKTGIDQLVVTPISQAQAKQRAGRAGRTGPGKCYRLYTERAYRDEMLTTNVPE IORTNLASTVLSLKAMGINDLLSFDFMDAPPMETLITAMEQLYTLGALDDEGLLTRLGRRMAEFPLEPMLCKMLIMSVHLGCSEEMLTI VSMLSVQNVFYRPKDKQALADQKKAKFHQTEGDHLTLLAVYNSWKNN

hPrp22 - H15 564-H-904 341 AS / 38,0 kDa / pI 5,43

SLPIYKLKEQLVQAVHDNQILIVIGETGSGKTTQITQYLAEAGYTSRGKIGCTQPRRVAAMSVAKRVSEEFGCCLGQEVGYTIRFEDCT SPETVIKYMTDGMLLRECLIDPDLTQYAIIMLDEAHERTIHTDVLFGLLKKTVQKRQDMKLIVTSATLDAVKFSQYFYEAPIFTIPGRT YPVEILYTKEPETDYLDASLITVMQIHLTEPPGDILVFLTGQEEIDTACEILYERMKSLGPDVPELIILPVYSALPSEMQTRIFDPAPP GSRKVVIATNIAETSLTIDGIYYVVDPGFVKQKVYNSKTGIDQLVVTPISQAQAKQRAGRAGRTGPGKCYRLYT

hPrp22 - H16 564-H-750 187 AS / 21,1 kDa / pI 6,30

SLPIYKLKEQLVQAVHDNQILIVIGETGSGKTTQITQYLAEAGYTSRGKIGCTQPRRVAAMSVAKRVSEEFGCCLGQEVGYTIRFEDCT SPETVIKYMTDGMLLRECLIDPDLTQYAIIMLDEAHERTIHTDVLFGLLKKTVQKRQDMKLIVTSATLDAVKFSQYFYEAPIFTIPGRT YPVEILYTK

hPrp22 - H17 782-H-1183 402 AS / 45,7 kDa / pI 8,35

GQEEIDTACEILYERMKSLGPDVPELIILPVYSALPSEMQTRIFDPAPPGSRKVVIATNIAETSLTIDGIYYVVDPGFVKQKVYNSKTG IDQLVVTPISQAQAKQRAGRAGRTGPGKCYRLYTERAYRDEMLTTNVPEIQRTNLASTVLSLKAMGINDLLSFDFMDAPPMETLITAME QLYTLGALDDEGLLTRLGRRMAEFPLEPMLCKMLIMSVHLGCSEEMLTIVSMLSVQNVFYRPKDKQALADQKKAKFHQTEGDHLTLLAV 
YNSWKNNKFSNPWCYENFIQARSLRRAQDIRKQMLGIMDRHKLDVVSCGKSTVRVQKAICSGFFRNAAKKDPQEGYRTLIDQQVVYIHP SSALFNRQPEWVVYHELVLTTKEYMREVTTIDPRWLVEFAPAFFKV

hPrp22 - H18 782-H-1055 274 AS / 30,6 kDa / pI 5,54

GQEEIDTACEILYERMKSLGPDVPELIILPVYSALPSEMQTRIFDPAPPGSRKVVIATNIAETSLTIDGIYYVVDPGFVKQKVYNSKTG IDQLVVTPISQAQAKQRAGRAGRTGPGKCYRLYTERAYRDEMLTTNVPEIQRTNLASTVLSLKAMGINDLLSFDFMDAPPMETLITAME QLYTLGALDDEGLLTRLGRRMAEFPLEPMLCKMLIMSVHLGCSEEMLTIVSMLSVQNVFYRPKDKQALADQKKAKFHQTEGDHLTLLAV YNSWKNN

hPrp22 - H19 782-H-904 123 AS / 13,5 kDa / pI 7,93

GQEEIDTACEILYERMKSLGPDVPELIILPVYSALPSEMQTRIFDPAPPGSRKVVIATNIAETSLTIDGIYYVVDPGFVKQKVYNSKTG IDQLVVTPISQAQAKQRAGRAGRTGPGKCYRLYT

hPrp22 - H20 950-H-1183 234 AS / 27,2 kDa / pI 8,93

PMETLITAMEQLYTLGALDDEGLLTRLGRRMAEFPLEPMLCKMLIMSVHLGCSEEMLTIVSMLSVQNVFYRPKDKQALADQKKAKFHQT EGDHLTLLAVYNSWKNNKFSNPWCYENFIQARSLRRAQDIRKQMLGIMDRHKLDVVSCGKSTVRVQKAICSGFFRNAAKKDPQEGYRTL IDQQVVYIHPSSALFNRQPEWVVYHELVLTTKEYMREVTTIDPRWLVEFAPAFFKV

hPrp22 - H21 950-H-1055 106 AS / 12,1 kDa / pI 5,89

PMETLITAMEQLYTLGALDDEGLLTRLGRRMAEFPLEPMLCKMLIMSVHLGCSEEMLTIVSMLSVQNVFYRPKDKQALADQKKAKFHQT EGDHLTLLAVYNSWKNN

hPrp22 - H22 1068-H-1183 116 AS / 13,6 kDa / pI 9,74

QARSLRRAQDIRKQMLGIMDRHKLDVVSCGKSTVRVQKAICSGFFRNAAKKDPQEGYRTLIDQQVVYIHPSSALFNRQPEWVVYHELVL TTKEYMREVTTIDPRWLVEFAPAFFKV

\title{
Sequenzübersicht aller klonierter Konstrukte von hPrp2
}

\author{
hPrp2 1041 AS / 119,2 kDa / pI 6,31
}

MATPAGLERWVQDELHSVLGLSERHVAQFLIGTAQRCTSAEEFVQRLRDTDTLDLSGPARDFALRLWNKVPRKAVVEKPARAAEREARA LLEKNRSYRLLEDSEESSEETVSRAGSSLQKKRKKRKHLRKKREEEEEEEASEKGKKKTGGSKQQTEKPESEDEWERTERERLQDLEER DAFAERVRQRDKDRTRNVLERSDKKAYEEAQKRLKMAEEDRKAMVPELRKKSRREYLAKREREKLEDLEAELADEEFLFGDVELSRHER QELKYKRRVRDLAREYRAAGEQEKLEATNRYHMPKETRGQPARAVDL VEEESGAPGEEQRRWEEARLGAASLKFGARDAASQEPKYOLV LEEEETIEFVRATQLQGDEEPSAPPTSTQAQQKESIQAVRRSLPVFPFREELLAAIANHQVLIIEGETGSGKTTQIPQYLFEEGYTNKG MKIACTQPRRVAAMSVAARVAREMGVKLGNEVGYSIRFEDCTSERTVLRYMTDGMLLREFLSEPDLASYSVVMVDEAHERTLHTDILFG LIKDVARFRPELKVLVASATMDTARFSTFFDDAPVFRIPGRRFPVDIFYTKAPEADYLEACVVSVLQIHVTQPPGDILVFLTGQEEIEA ACEMLQDRCRRLGSKIRELLVLPIYANLPSDMQARIFQPTPPGARKVVVATNIAETSLTIEGIIYVLDPGFCKQKSYNPRTGMESLTVT PCSKASANQRAGRAGRVAAGKCFRLYTAWAYOHELEETTVPEIQRTSLGNVVLLLKSLGIHDLMHFDFLDPPPYETLLLALEQLYALGA LNHLGELTTSGRKMAELPVDPMLSKMILASEKYSCSEEILTVAAMLSVNNSIFYRPKDKVVHADNARVNFFLPGGDHLVLLNVYTQWAE SGYSSQWCYENFVQFRSMRRARDVREQLEGLLERVEVGLSSCQGDYIRVRKAITAGYFYHTARLTRSGYRTVKQQQTVFIHPNSSLFEQ QPRWLLYHELVLTTKEFMRQVLEIESSWLLEVAPHYYKAKELEDPHAKKMPKKIGKTREELG

hPrp2 - D1 9-D-1019 1011 AS / 116,0 kDa / pI 6,37

RWVQDELHSVLGLSERHVAQFLIGTAQRCTSAEEFVQRLRDTDTLDLSGPARDFALRLWNKVPRKAVVEKPARAAEREARALLEKNRSY RLLEDSEESSEETVSRAGSSLQKKRKKRKHLRKKREEEEEEEASEKGKKKTGGSKQQTEKPESEDEWERTERERLQDLEERDAFAERVR QRDKDRTRNVLERSDKKAYEEAQKRLKMAEEDRKAMVPELRKKSRREYLAKREREKLEDLEAELADEEFLFGDVELSRHERQELKYKRR VRDLAREYRAAGEQEKLEATNRYHMPKETRGQPARAVDLVEEESGAPGEEQRRWEEARLGAASLKFGARDAASQEPKYQLVLEEEETIE FVRATQLOGDEEPSAPPTSTQAOOKESIOAVRRSLPVFPFREELLAAIANHOVLIIEGETGSGKTTQIPOYLFEEGYTNKGMKIACTOP RRVAAMSVAARVAREMGVKLGNEVGYSIRFEDCTSERTVLRYMTDGMLLREFLSEPDLASYSVVMVDEAHERTLHTDILFGLIKDVARF RPELKVLVASATMDTARFSTFFDDAPVFRIPGRRFPVDIFYTKAPEADYLEACVVSVLQIHVTQPPGDILVFLTGQEEIEAACEMLQDR CRRLGSKIRELLVLPIYANLPSDMQARIFQPTPPGARKVVVATNIAETSLTIEGIIYVLDPGFCKQKSYNPRTGMESLTVTPCSKASAN QRAGRAGRVAAGKCFRLYTAWAYQHELEETTVPEIQRTSLGNVVLLLKSLGIHDLMHFDFLDPPPYETLLLALEQLYALGALNHLGELT TSGRKMAELPVDPMLSKMILASEKYSCSEEILTVAAMLSVNNSIFYRPKDKVVHADNARVNFFLPGGDHLVLLNVYTQWAESGYSSQWC YENFVQFRSMRRARDVREQLEGLLERVEVGLSSCQGDYIRVRKAITAGYFYHTARLTRSGYRTVKQQQTVFIHPNSSLFEQQPRWLLYH ELVLTTKEFMRQVLEIESSWLLEVAPHYYKAK

hPrp2 - D2 9-D-891 883 AS / 100,7 kDa / pI 5,92

RWVQDELHSVLGLSERHVAQFLIGTAQRCTSAEEFVQRLRDTDTLDLSGPARDFALRLWNKVPRKAVVEKPARAAEREARALLEKNRSY RLLEDSEESSEETVSRAGSSLOKKRKKRKHLRKKREEEEEEEASEKGKKKTGGSKOOTEKPESEDEWERTERERLQDLEERDAFAERVR QRDKDRTRNVLERSDKKAYEEAQKRLKMAEEDRKAMVPELRKKSRREYLAKREREKLEDLEAELADEEFLFGDVELSRHERQELKYKRR VRDLAREYRAAGEQEKLEATNRYHMPKETRGQPARAVDLVEEESGAPGEEQRRWEEARLGAASLKFGARDAASQEPKYQLVLEEEETIE FVRATQLQGDEEPSAPPTSTQAQQKESIQAVRRSLPVFPFREELLAAIANHQVLIIEGETGSGKTTQIPQYLFEEGYTNKGMKIACTQP RRVAAMSVAARVAREMGVKLGNEVGYSIRFEDCTSERTVLRYMTDGMLLREFLSEPDLASYSVVMVDEAHERTLHTDILFGLIKDVARF RPELKVLVASATMDTARFSTFFDDAPVFRIPGRRFPVDIFYTKAPEADYLEACVVSVLQIHVTQPPGDILVFLTGQEEIEAACEMLQDR CRRLGSKIRELLVLPIYANLPSDMQARIFQPTPPGARKVVVATNIAETSLTIEGIIYVLDPGFCKQKSYNPRTGMESLTVTPCSKASAN QRAGRAGRVAAGKCFRLYTAWAYQHELEETTVPEIQRTSLGNVVLLLKSLGIHDLMHFDFLDPPPYETLLLALEQLYALGALNHLGELT TSGRKMAELPVDPMLSKMILASEKYSCSEEILTVAAMLSVNNSIFYRPKDKVVHADNARVNFFLPGGDHLVLLNVYTQWAES

hPrp2 - D3 9-D-745 737 AS / 84,4 kDa / pI 6,52

RWVQDELHSVLGLSERHVAQFLIGTAQRCTSAEEFVQRLRDTDTLDLSGPARDFALRLWNKVPRKAVVEKPARAAEREARALLEKNRSY RLLEDSEESSEETVSRAGSSLQKKRKKRKHLRKKREEEEEEEASEKGKKKTGGSKQQTEKPESEDEWERTERERLQDLEERDAFAERVR QRDKDRTRNVLERSDKKAYEEAQKRLKMAEEDRKAMVPELRKKSRREYLAKREREKLEDLEAELADEEFLFGDVELSRHERQELKYKRR VRDLAREYRAAGEQEKLEATNRYHMPKETRGQPARAVDLVEEESGAPGEEQRRWEEARLGAASLKFGARDAASQEPKYQLVLEEEETIE FVRATQLQGDEEPSAPPTSTQAOOKESIOAVRRSLPVFPFREELLAAIANHOVLIIEGETGSGKTTOIPOYLFEEGYTNKGMKIACTOP RRVAAMSVAARVAREMGVKLGNEVGYSIRFEDCTSERTVLRYMTDGMLLREFLSEPDLASYSVVMVDEAHERTLHTDILFGLIKDVARF RPELKVLVASATMDTARFSTFFDDAPVFRIPGRRFPVDIFYTKAPEADYLEACVVSVLQIHVTQPPGDILVFLTGQEEIEAACEMLQDR CRRLGSKIRELLVLPIYANLPSDMQARIFQPTPPGARKVVVATNIAETSLTIEGIIYVLDPGFCKQKSYNPRTGMESLTVTPCSKASAN QRAGRAGRVAAGKCFRLYTAWAYQH

\footnotetext{
hPrp2 - D4 9-D-585 577 AS / 66,8 kDa / pI 6,16
}

RWVQDELHSVLGLSERHVAQFLIGTAQRCTSAEEFVQRLRDTDTLDLSGPARDFALRLWNKVPRKAVVEKPARAAEREARALLEKNRSY RLLEDSEESSEETVSRAGSSLQKKRKKRKHLRKKREEEEEEEASEKGKKKTGGSKQQTEKPESEDEWERTERERLQDLEERDAFAERVR QRDKDRTRNVLERSDKKAYEEAQKRLKMAEEDRKAMVPELRKKSRREYLAKREREKLEDLEAELADEEFLFGDVELSRHERQELKYKRR VRDLAREYRAAGEQEKLEATNRYHMPKETRGQPARAVDLVEEESGAPGEEQRRWEEARLGAASLKFGARDAASQEPKYQLVLEEEETIE FVRATQLOGDEEPSAPPTSTQAOQKESIQAVRRSLPVFPFREELLAAIANHOVLIIEGETGSGKTTOIPQYLFEEGYTNKGMKIACTOP RRVAAMSVAARVAREMGVKLGNEVGYSIRFEDCTSERTVLRYMTDGMLLREFLSEPDLASYSVVMVDEAHERTLHTDILFGLIKDVARF RPELKVLVASATMDTARFSTFFDDAPVFRIPGRRFPVDIFYTK 


\title{
hPrp2 - D5 9-D-371 363 AS / 42,8 kDa / pI 6,43
}

RWVQDELHSVLGLSERHVAQFLIGTAQRCTSAEEFVQRLRDTDTLDLSGPARDFALRLWNKVPRKAVVEKPARAAEREARALLEKNRSY RLLEDSEESSEETVSRAGSSLQKKRKKRKHLRKKREEEEEEEASEKGKKKTGGSKQQTEKPESEDEWERTERERLQDLEERDAFAERVR QRDKDRTRNVLERSDKKAYEEAQKRLKMAEEDRKAMVPELRKKSRREYLAKREREKLEDLEAELADEEFLFGDVELSRHERQELKYKRR VRDLAREYRAAGEQEKLEATNRYHMPKETRGQPARAVDLVEEESGAPGEEQRRWEEARLGAASLKFGARDAASQEPKYQLVLEEEETIE FVRATQL

hPrp2 - D6 385-D-1019 635 AS / 71,9 kDa / pI 6,77

QAQQKESIQAVRRSLPVFPFREELLAAIANHQVLIIEGETGSGKTTQIPQYLFEEGYTNKGMKIACTQPRRVAAMSVAARVAREMGVKL GNEVGYSIRFEDCTSERTVLRYMTDGMLLREFLSEPDLASYSVVMVDEAHERTLHTDILFGLIKDVARFRPELKVLVASATMDTARFST FFDDAPVFRIPGRRFPVDIFYTKAPEADYLEACVVSVLQIHVTQPPGDILVFLTGQEEIEAACEMLQDRCRRLGSKIRELLVLPIYANL PSDMQARIFOPTPPGARKVVVATNIAETSLTIEGIIYVLDPGFCKOKSYNPRTGMESLTVTPCSKASANORAGRAGRVAAGKCFRLYTA WAYQHELEETTVPEIQRTSLGNVVLLLKSLGIHDLMHFDFLDPPPYETLLLALEQLYALGALNHLGELTTSGRKMAELPVDPMLSKMIL ASEKYSCSEEILTVAAMLSVNNSIFYRPKDKVVHADNARVNFFLPGGDHLVLLNVYTQWAESGYSSQWCYENFVQFRSMRRARDVREQL EGLLERVEVGLSSCQGDYIRVRKAITAGYFYHTARLTRSGYRTVKQQQTVFIHPNSSLFEQQPRWLLYHELVLTTKEFMRQVLEIESSW LLEVAPHYYKAK

hPrp2 - D7 385-D-891 507 AS / 56,6 kDa / pI 5,90

QAQQKESIQAVRRSLPVFPFREELLAAIANHQVLIIEGETGSGKTTQIPQYLFEEGYTNKGMKIACTQPRRVAAMSVAARVAREMGVKL GNEVGYSIRFEDCTSERTVLRYMTDGMLLREFLSEPDLASYSVVMVDEAHERTLHTDILFGLIKDVARFRPELKVLVASATMDTARFST FFDDAPVFRIPGRRFPVDIFYTKAPEADYLEACVVSVLQIHVTQPPGDILVFLTGQEEIEAACEMLQDRCRRLGSKIRELLVLPIYANL PSDMQARIFQPTPPGARKVVVATNIAETSLTIEGIIYVLDPGFCKQKSYNPRTGMESLTVTPCSKASANQRAGRAGRVAAGKCFRLYTA WAYQHELEETTVPEIQRTSLGNVVLLLKSLGIHDLMHFDFLDPPPYETLLLALEQLYALGALNHLGELTTSGRKMAELPVDPMLSKMIL ASEKYSCSEEILTVAAMLSVNNSIFYRPKDKVVHADNARVNFFLPGGDHLVLLNVYTQWAES

hPrp2 - D8 385-D-745 361 AS / 40,3 kDa / pI 8,11

QAQQKESIQAVRRSLPVFPFREELLAAIANHQVLIIEGETGSGKTTQIPQYLFEEGYTNKGMKIACTQPRRVAAMSVAARVAREMGVKL GNEVGYSIRFEDCTSERTVLRYMTDGMLLREFLSEPDLASYSVVMVDEAHERTLHTDILFGLIKDVARFRPELKVLVASATMDTARFST FFDDAPVFRIPGRRFPVDIFYTKAPEADYLEACVVSVLOIHVTOPPGDILVFLTGQEEIEAACEMLODRCRRLGSKIRELLVLPIYANL PSDMQARIFQPTPPGARKVVVATNIAETSLTIEGIIYVLDPGFCKQKSYNPRTGMESLTVTPCSKASANQRAGRAGRVAAGKCFRLYTA WAYQH

hPrp2 - D9 385-D-585 201 AS / 22,8 kDa / pI 7,04

QAOQKESIQAVRRSLPVFPFREELLAAIANHOVLIIEGETGSGKTTOIPOYLFEEGYTNKGMKIACTOPRRVAAMSVAARVAREMGVKL GNEVGYSIRFEDCTSERTVLRYMTDGMLLREFLSEPDLASYSVVMVDEAHERTLHTDILFGLIKDVARFRPELKVLVASATMDTARFST FFDDAPVFRIPGRRFPVDIFYTK

hPrp2 - D10 617-D-1019 403 AS / 45,8 kDa / pI 8,08

GQEEIEAACEMLQDRCRRLGSKIRELLVLPIYANLPSDMQARIFQPTPPGARKVVVATNIAETSLTIEGIIYVLDPGFCKQKSYNPRTG MESLTVTPCSKASANQRAGRAGRVAAGKCFRLYTAWAYQHELEETTVPEIQRTSLGNVVLLLKSLGIHDLMHFDFLDPPPYETLLLALE OLYALGALNHLGELTTSGRKMAELPVDPMLSKMILASEKYSCSEEILTVAAMLSVNNSIFYRPKDKVVHADNARVNFFLPGGDHLVLLN VYTQWAESGYSSQWCYENFVQFRSMRRARDVREQLEGLLERVEVGLSSCQGDYIRVRKAITAGYFYHTARLTRSGYRTVKQQQTVFIHP NSSLFEQQPRWLLYHELVLTTKEFMRQVLEIESSWLLEVAPHYYKAK

hPrp2 - D11 617-D-891 275 AS / 30,5 kDa / pI 6,11

GQEEIEAACEMLQDRCRRLGSKIRELLVLPIYANLPSDMQARIFQPTPPGARKVVVATNIAETSLTIEGIIYVLDPGFCKQKSYNPRTG MESLTVTPCSKASANORAGRAGRVAAGKCFRLYTAWAYOHELEETTVPEIORTSLGNVVLLLKSLGIHDLMHFDFLDPPPYETLLLALE QLYALGALNHLGELTTSGRKMAELPVDPMLSKMILASEKYSCSEEILTVAAMLSVNNSIFYRPKDKVVHADNARVNFFLPGGDHLVLLN VYTQWAES

hPrp2 - D12 617-D-745 129 AS / 14,2 kDa / pI 9,27

GOEEIEAACEMLODRCRRLGSKIRELLVLPIYANLPSDMOARIFOPTPPGARKVVVATNIAETSLTIEGIIYVLDPGFCKOKSYNPRTG MESLTVTPCSKASANQRAGRAGRVAAGKCFRLYTAWAYOH

hPrp2 - D13 785-D-1019 235 AS / 27,2 kDa / pI 8,13

PYETLLLALEQLYALGALNHLGELTTSGRKMAELPVDPMLSKMILASEKYSCSEEILTVAAMLSVNNSIFYRPKDKVVHADNARVNFFL PGGDHLVLLNVYTQWAESGYSSQWCYENFVQFRSMRRARDVREQLEGLLERVEVGLSSCQGDYIRVRKAITAGYFYHTARLTRSGYRTV KQQQTVFIHPNSSLFEQQPRWLLYHELVLTTKEFMRQVLEIESSWLLEVAPHYYKAK

hPrp2 - D14 785-D-891 107 AS / 11,9 kDa / pI 5,22

PYETLLLALEQLYALGALNHLGELTTSGRKMAELPVDPMLSKMILASEKYSCSEEILTVAAMLSVNNSIFYRPKDKVVHADNARVNFFL PGGDHLVLLNVYTQWAES

hPrp2 - D15 905-D-1019 115 AS / 13,7 kDa / pI 9,72

FRSMRRARDVREQLEGLLERVEVGLSSCQGDYIRVRKAITAGYFYHTARLTRSGYRTVKQQQTVFIHPNSSLFEQQPRWLLYHELVLTT KEFMRQVLEIESSWLLEVAPHY

\section{Polylinker (MCS) der gewählten Vektoren mit allen verwendeten Restriktionsschnittstellen (rot) und Affinitätssequenzen (blau)}

\author{
PPR-IBA1-MCS
}

BamHI / XhOI

ATGGGAGACCGCGGTCCCGAATTCGAGCTCGGTACCCGGGGATCC . . . CTCGAGGTCGACCTGCAGGGGGACCATGGTCTCAGCGCTTG GAGCCACCCGCAGTTCGAAAAA 
pGex-6P1-MCS

BamHI / XhoI

ATGTCCCCTATACTAGGTTATTGGAAAATTAAGGGCCTTGTGCAACCCACTCGACTTCTTTTGGAATATCTTGAAGAAAAATATGAAGA GCATTTGTATGAGCGCGATGAAGGTGATAAATGGCGAAACAAAAAGTTTGAATTGGGTTTGGAGTTTCCCAATCTTCCTTATTATATTG ATGGTGATGTTAAATTAACACAGTCTATGGCCATCATACGTTATATAGCTGACAAGCACAACATGTTGGGTGGTTGTCCAAAAGAGCGT GCAGAGATTTCAATGCTTGAAGGAGCGGTTTTGGATATTAGATACGGTGTTTCGAGAATTGCATATAGTAAAGACTTTGAAACTCTCAA AGTTGATTTTCTTAGCAAGCTACCTGAAATGCTGAAAATGTTCGAAGATCGTTTATGTCATAAAACATATTTAAATGGTGATCATGTAA CCCATCCTGACTTCATGTTGTATGACGCTCTTGATGTTGTTTTATACATGGACCCAATGTGCCTGGATGCGTTCCCAAAATTAGTTTGT TTTAAAAAACGTATTGAAGCTATCCCACAAATTGATAAGTACTTGAAATCCAGCAAGTATATAGCATGGCCTTTGCAGGGCTGGCAAGC CACGTTTGGTGGTGGCGACCATCCTCCAAAATCGGATCTGGAAGTTCTGTTCCAGGGGCCCCTGGGATCC . . . CTCGAGCGGCCGCATC GTGAC

ECORI / XhOI

ATGTCCCCTATACTAGGTTATTGGAAAATTAAGGGCCTTGTGCAACCCACTCGACTTCTTTTGGAATATCTTGAAGAAAAATATGAAGA GCATTTGTATGAGCGCGATGAAGGTGATAAATGGCGAAACAAAAAGTTTGAATTGGGTTTGGAGTTTCCCAATCTTCCTTATTATATTG ATGGTGATGTTAAATTAACACAGTCTATGGCCATCATACGTTATATAGCTGACAAGCACAACATGTTGGGTGGTTGTCCAAAAGAGCGT GCAGAGATTTCAATGCTTGAAGGAGCGGTTTTGGATATTAGATACGGTGTTTCGAGAATTGCATATAGTAAAGACTTTGAAACTCTCAA AGTTGATTTTCTTAGCAAGCTACCTGAAATGCTGAAAATGTTCGAAGATCGTTTATGTCATAAAACATATTTAAATGGTGATCATGTAA CCCATCCTGACTTCATGTTGTATGACGCTCTTGATGTTGTTTTATACATGGACCCAATGTGCCTGGATGCGTTCCCAAAATTAGTTTGT TTTAAAAAACGTATTGAAGCTATCCCACAAATTGATAAGTACTTGAAATCCAGCAAGTATATAGCATGGCCTTTGCAGGGCTGGCAAGC CACGTTTGGTGGTGGCGACCATCCTCCAAAATCGGATCTGGAAGTTCTGTTCCAGGGGCCCCTGGGATCCCCGGAATTC . . . CTCGAGC GGCCGCATCGTGAC

PET-21a-MCS

BamHI / XhoI

ATGGCTAGCATGACTGGTGGACAGCAAATGGGTCGCGGATCC . . . CTCGAGCACCACCACCACCACCAC

ECORI / XhOI

ATGGCTAGCATGACTGGTGGACAGCAAATGGGTCGCGGATCCGAATTC . . . CTCGAGCACCACCACCACCACCAC

\section{Vektorabhängige Veränderung der Länge, der Masse und des pI}

\begin{tabular}{|c|c|c|c|c|c|c|}
\hline $\begin{array}{l}\text { H1 } \\
\text { H1-pET21 } \\
\text { H1-pGEX } \\
\text { H1-IBA1 }\end{array}$ & $\begin{array}{l}27-\mathrm{H}-1183 \\
27-\mathrm{H}-1183 \\
27-\mathrm{H}-1183 \\
27-\mathrm{H}-1183\end{array}$ & $\begin{array}{l}1157 \text { aа } \\
1179 \text { aа } \\
1395 \text { aа } \\
1193 \text { aa }\end{array}$ & $\begin{array}{l}-132,2 \\
-134,6 \\
-159,9 \\
-136,1\end{array}$ & $\begin{array}{l}\mathrm{kD} \\
\mathrm{kD} \\
\mathrm{kD} \\
\mathrm{kD}\end{array}$ & $\begin{array}{l}-\mathrm{pI} \\
-\mathrm{pI} \\
-\mathrm{pI} \\
-\mathrm{pI}\end{array}$ & 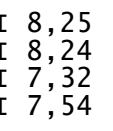 \\
\hline $\begin{array}{l}\text { H2 } \\
\text { H2-pET21 } \\
\text { H2-pGEX } \\
\text { H2-IBA1 }\end{array}$ & $\begin{array}{l}27-\mathrm{H}-1055 \\
27-\mathrm{H}-1055 \\
27-\mathrm{H}-1055 \\
27-\mathrm{H}-1055\end{array}$ & $\begin{array}{l}1029 \text { aa } \\
1051 \text { aa } \\
1267 \text { aa } \\
1065 \text { aa }\end{array}$ & $\begin{array}{l}-117,1 \\
-119,5 \\
-144,8 \\
-121,0\end{array}$ & $\begin{array}{l}\mathrm{kD} \\
\mathrm{kD} \\
\mathrm{kD} \\
\mathrm{kD}\end{array}$ & $\begin{array}{l}\text { - } \mathrm{pI} \\
-\mathrm{pI} \\
-\mathrm{pI} \\
-\mathrm{pI}\end{array}$ & 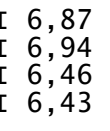 \\
\hline $\begin{array}{l}\text { H3 } \\
\text { H3-pET21 } \\
\text { H3-pGEX } \\
\text { H3-IBA1 }\end{array}$ & $\begin{array}{l}27-\mathrm{H}-904 \\
27-\mathrm{H}-904 \\
27-\mathrm{H}-904 \\
27-\mathrm{H}-904\end{array}$ & $\begin{array}{r}878 \text { aа } \\
900 \text { aa } \\
1116 \text { aa } \\
914 \text { aa }\end{array}$ & $\begin{array}{l}-\quad 99,9 \\
-\quad 102,4 \\
-\quad 127,7 \\
-\quad 103,9\end{array}$ & $\begin{array}{l}\text { KD } \\
\text { kD } \\
\text { kD } \\
\mathrm{kD}\end{array}$ & $\begin{array}{l}\text { - } \mathrm{pI} \\
\text { - } \mathrm{pI} \\
\text { - } \mathrm{pI} \\
-\mathrm{pI}\end{array}$ & 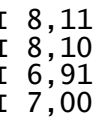 \\
\hline $\begin{array}{l}\text { H4 } \\
\text { H4-pET21 } \\
\text { H4-pGEX } \\
\text { H4-IBA1 }\end{array}$ & $\begin{array}{l}27-\mathrm{H}-750 \\
27-\mathrm{H}-750 \\
27-\mathrm{H}-750 \\
27-\mathrm{H}-750\end{array}$ & $\begin{array}{l}724 \text { aa } \\
746 \text { aa } \\
962 \text { aa } \\
760 \text { aa }\end{array}$ & $\begin{array}{l}-\quad 83,0 \\
-\quad 85,5 \\
-\quad 110,7 \\
-\quad 87,0\end{array}$ & $\begin{array}{l}\text { kD } \\
\text { kD } \\
\text { kD } \\
\mathrm{kD}\end{array}$ & $\begin{array}{l}-\mathrm{pI} \\
-\mathrm{pI} \\
-\mathrm{pI} \\
-\mathrm{pI}\end{array}$ & 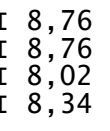 \\
\hline $\begin{array}{l}\text { H5 } \\
\text { H5-pET21 } \\
\text { H5-pGEX } \\
\text { H5-IBA1 }\end{array}$ & $\begin{array}{l}27-H-561 \\
27-H-561 \\
27-H-561 \\
27-H-561\end{array}$ & $\begin{array}{l}535 \text { aa } \\
557 \text { aa } \\
773 \text { aa } \\
571 \text { aa }\end{array}$ & $\begin{array}{l}-\quad 61,7 \\
-\quad 64,1 \\
-\quad 89,4 \\
-\quad 65,6\end{array}$ & $\begin{array}{l}\mathrm{kD} \\
\mathrm{kD} \\
\mathrm{kD} \\
\mathrm{kD}\end{array}$ & $\begin{array}{l}-\mathrm{pI} \\
-\mathrm{pI} \\
-\mathrm{pI} \\
-\mathrm{pI}\end{array}$ & 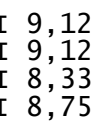 \\
\hline $\begin{array}{l}\text { H6 } \\
\text { H6-pET21 } \\
\text { H6-pGEX } \\
\text { H6-IBA1 }\end{array}$ & $\begin{array}{l}27-H-351 \\
27-H-351 \\
27-H-351 \\
27-H-351\end{array}$ & $\begin{array}{l}325 \text { aa } \\
347 \text { aa } \\
563 \text { aa } \\
361 \text { aa }\end{array}$ & $\begin{array}{l}-\quad 37,8 \\
-\quad 40,3 \\
-\quad 65,6 \\
-\quad 41,8\end{array}$ & $\begin{array}{l}\text { kD } \\
\text { kD } \\
\text { kD } \\
\mathrm{kD}\end{array}$ & $\begin{array}{l}-\mathrm{pI} \\
-\mathrm{pI} \\
-\mathrm{pI} \\
-\mathrm{pI}\end{array}$ & 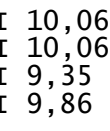 \\
\hline $\begin{array}{l}\text { H7 } \\
\text { H7-pET21 } \\
\text { H7-pGEX } \\
\text { H7-IBA1 }\end{array}$ & $\begin{array}{l}264-\mathrm{H}-1183 \\
264-\mathrm{H}-1183 \\
264-\mathrm{H}-1183 \\
264-\mathrm{H}-1183\end{array}$ & $\begin{array}{r}920 \text { aa } \\
942 \text { aa } \\
1158 \text { aa } \\
956 \text { aa }\end{array}$ & $\begin{array}{l}-104,2 \\
-\quad 106,7 \\
-\quad 132,0 \\
-\quad 10,8\end{array}$ & $\begin{array}{l}\mathrm{kD} \\
\mathrm{kD} \\
\mathrm{kD} \\
\mathrm{kD}\end{array}$ & $\begin{array}{l}-\mathrm{pI} \\
-\mathrm{pI} \\
-\mathrm{pI} \\
-\mathrm{pI}\end{array}$ & $\begin{array}{l}5,70 \\
{\left[\begin{array}{l}5,89 \\
{[} \\
{[}\end{array}\right], 74} \\
\end{array}$ \\
\hline $\begin{array}{l}\text { H8 } \\
\text { H8-pET21 } \\
\text { H8-pGEX } \\
\text { H8-IBA1 }\end{array}$ & $\begin{array}{l}264-\mathrm{H}-1055 \\
264-\mathrm{H}-1055 \\
264-\mathrm{H}-1055 \\
264-\mathrm{H}-1055\end{array}$ & $\begin{array}{r}792 \text { aa } \\
814 \text { aa } \\
1030 \text { aa } \\
828 \text { aa }\end{array}$ & $\begin{array}{lr}- & 89,1 \\
- & 91,6 \\
- & 116,9 \\
- & 93,1\end{array}$ & $\begin{array}{l}\mathrm{kD} \\
\mathrm{kD} \\
\mathrm{kD} \\
\mathrm{kD}\end{array}$ & $\begin{array}{l}-\mathrm{pI} \\
-\mathrm{pI} \\
-\mathrm{pI} \\
-\mathrm{pI}\end{array}$ & 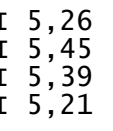 \\
\hline $\begin{array}{l}\text { H9 } \\
\text { H9-pET21 } \\
\text { H9-pGEX } \\
\text { H9-IBA1 }\end{array}$ & $\begin{array}{l}264-\mathrm{H}-904 \\
264-\mathrm{H}-904 \\
264-\mathrm{H}-904 \\
264-\mathrm{H}-904\end{array}$ & $\begin{array}{l}641 \text { aa } \\
663 \text { aa } \\
879 \text { aa } \\
677 \text { aa }\end{array}$ & $\begin{array}{l}-\quad 72,0 \\
-\quad 74,4 \\
-\quad 99,7 \\
-\quad 75,6\end{array}$ & $\begin{array}{l}\mathrm{kD} \\
\mathrm{kD} \\
\mathrm{kD} \\
\mathrm{kD}\end{array}$ & $\begin{array}{l}-\mathrm{pI} \\
-\mathrm{pI} \\
-\mathrm{pI} \\
-\mathrm{pI}\end{array}$ & $\begin{array}{l}5,28 \\
{\left[\begin{array}{l}5,52 \\
{[} \\
{[} \\
{[}\end{array}\right], 23} \\
5,22\end{array}$ \\
\hline $\begin{array}{l}\text { H10 } \\
\text { H10-pET21 } \\
\text { H10-pGEX } \\
\text { H10-IBA1 }\end{array}$ & $\begin{array}{l}264-\mathrm{H}-750 \\
264-\mathrm{H}-750 \\
264-\mathrm{H}-750 \\
264-\mathrm{H}-750\end{array}$ & $\begin{array}{l}487 \text { aa } \\
509 \text { aa } \\
725 \text { aa } \\
523 \text { aa }\end{array}$ & $\begin{array}{l}-\quad 55,1 \\
-\quad 57,5 \\
-\quad 82,8 \\
-\quad 59,0\end{array}$ & $\begin{array}{l}\mathrm{kD} \\
\mathrm{kD} \\
\mathrm{kD} \\
\mathrm{kD}\end{array}$ & $\begin{array}{l}-\mathrm{pI} \\
-\mathrm{pI} \\
-\mathrm{pI} \\
-\mathrm{pI}\end{array}$ & 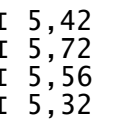 \\
\hline
\end{tabular}




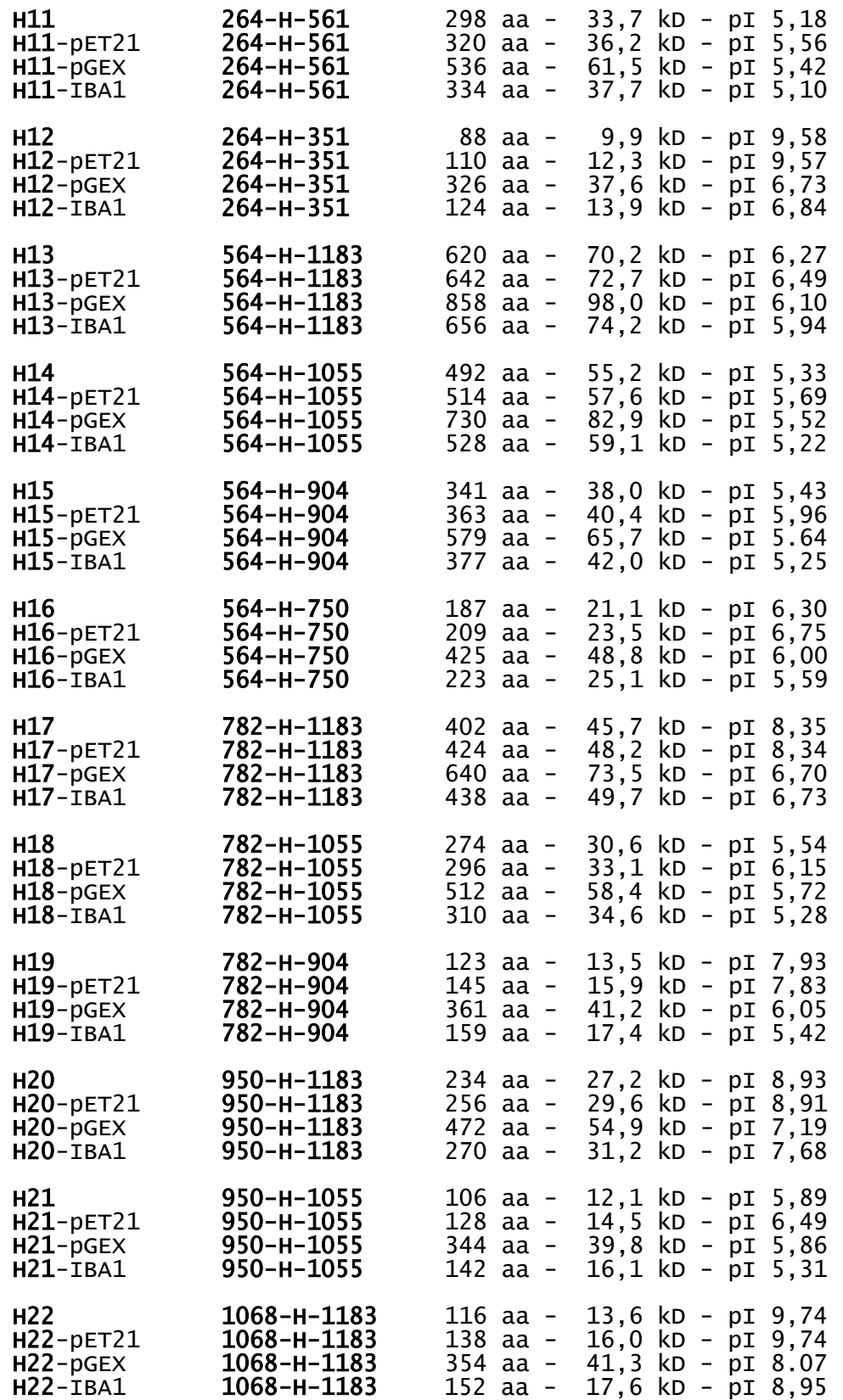

\begin{tabular}{|c|c|c|c|c|c|}
\hline $\begin{array}{l}\text { D1 } \\
\text { D1-pET21 } \\
\text { D1-pGEX } \\
\text { D1-IBA1 }\end{array}$ & $\begin{array}{l}\text { 9-D-1019 } \\
\text { 9-D-1019 } \\
\text { 9-D-1019 } \\
\text { 9-D-1019 }\end{array}$ & $\begin{array}{l}1011 \text { aa } \\
1035 \text { aa }- \\
1251 \text { aa } \\
1040 \text { aa }-\end{array}$ & $\begin{array}{l}-116,0 \mathrm{kD} \\
-118,7 \mathrm{kD} \\
-144,0 \mathrm{kD} \\
-119,2 \mathrm{kD}\end{array}$ & $\begin{array}{l}-\mathrm{pI} \\
\text { - } \mathrm{pI} \\
\text { - } \mathrm{pI} \\
-\mathrm{pI}\end{array}$ & $\begin{array}{l}6,37 \\
6,41 \\
6.17 \\
6,15\end{array}$ \\
\hline $\begin{array}{l}\text { D2 } \\
\text { D2-pET21 } \\
\text { D2-pGEX } \\
\text { D2-IBA1 }\end{array}$ & $\begin{array}{l}\text { 9-D-891 } \\
9-D-891 \\
9-D-891 \\
9-D-891\end{array}$ & $\begin{array}{r}883 \text { aa } \\
907 \text { aa } \\
1123 \text { aa } \\
912 \text { aa }-\end{array}$ & $\begin{array}{l}-100,7 \mathrm{kD} \\
-103,4 \mathrm{kD} \\
-128,7 \mathrm{kD} \\
-103,9 \mathrm{kD}\end{array}$ & $\begin{array}{l}-\mathrm{pI} \\
\text { - } \mathrm{pI} \\
\text { - } \mathrm{pI} \\
-\mathrm{pI}\end{array}$ & $\begin{array}{l}5,92 \\
6,03 \\
5.86 \\
5,78\end{array}$ \\
\hline $\begin{array}{l}\text { D3 } \\
\text { D3-pET21 } \\
\text { D3-pGEX } \\
\text { D3-IBA1 }\end{array}$ & $\begin{array}{l}\text { 9-D-745 } \\
\text { 9-D-745 } \\
\text { 9-D-745 } \\
\text { 9-D-745 }\end{array}$ & $\begin{array}{l}737 \text { aa } \\
761 \text { aa } \\
977 \text { aa } \\
766 \text { aa }\end{array}$ & $\begin{array}{l}-\quad 84,4 \mathrm{kD} \\
-\quad 87,1 \mathrm{kD} \\
-\quad 112,4 \mathrm{kD} \\
-\quad 87,6 \mathrm{kD}\end{array}$ & $\begin{array}{l}-\mathrm{pI} \\
\text { - } \mathrm{pI} \\
\text { - } \mathrm{pI} \\
-\mathrm{pI}\end{array}$ & $\begin{array}{l}6,52 \\
6,54 \\
6.17 \\
6,14\end{array}$ \\
\hline $\begin{array}{l}\text { D4 } \\
\text { D4-pET21 } \\
\text { D4-pGEX } \\
\text { D4-IBA1 }\end{array}$ & $\begin{array}{l}9-D-585 \\
9-D-585 \\
9-D-585 \\
9-D-585\end{array}$ & $\begin{array}{l}577 \text { aa } \\
601 \text { aa } \\
817 \text { aa } \\
606 \text { aa }\end{array}$ & $\begin{array}{l}-\quad 66,8 \mathrm{kD} \\
-\quad 69,6 \mathrm{kD} \\
-\quad 94,9 \mathrm{kD} \\
-\quad 70,1 \mathrm{kD}\end{array}$ & $\begin{array}{l}\text { - } \mathrm{pI} \\
\text { - } \mathrm{pI} \\
\text { - } \mathrm{pI} \\
\text { - } \mathrm{pI}\end{array}$ & $\begin{array}{l}6,16 \\
6,27 \\
5.98 \\
5,89\end{array}$ \\
\hline
\end{tabular}




\begin{tabular}{|c|c|c|c|c|c|c|}
\hline $\begin{array}{l}\text { D5 } \\
\text { D5-pET21 } \\
\text { D5-IBA1 } \\
\text { D5-pGEX }\end{array}$ & $\begin{array}{l}9-D-371 \\
9-D-371 \\
9-D-371 \\
9-D-371\end{array}$ & $\begin{array}{l}363 \text { aa }- \\
387 \text { aa }- \\
392 \text { aa }- \\
603 \text { aa }-\end{array}$ & $\begin{array}{l}-\quad 42,8 \mathrm{k} \\
-\quad 45,5 \mathrm{k} \\
-\quad 46,1 \mathrm{k} \\
-\quad 70,8 \mathrm{k}\end{array}$ & $\begin{array}{l}\mathrm{kD} \\
\mathrm{kD} \\
\mathrm{kD} \\
\mathrm{kD}\end{array}$ & $\begin{array}{l}-\mathrm{pI} \\
\text { - } \mathrm{pI} \\
\text { - } \mathrm{pI} \\
-\mathrm{pI}\end{array}$ & $\begin{array}{l}6,43 \\
6,49 \\
5,94 \\
6.04\end{array}$ \\
\hline $\begin{array}{l}\text { D6 } \\
\text { D6-pET21 } \\
\text { D6-pGEX } \\
\text { D6-IBA1 }\end{array}$ & $\begin{array}{l}385-D-1019 \\
385-D-1019 \\
385-D-1019 \\
385-D-1019\end{array}$ & $\begin{array}{l}635 \text { aa }- \\
659 \text { aa }- \\
875 \text { aa }- \\
664 \text { aa }-\end{array}$ & $\begin{array}{l}-\quad 71,9 \mathrm{k} \\
-\quad 74,6 \mathrm{k} \\
-\quad 99,9 \mathrm{k} \\
-\quad 75,2 \mathrm{k}\end{array}$ & $\begin{array}{l}\mathrm{kD} \\
\mathrm{kD} \\
\mathrm{kD} \\
\mathrm{kD}\end{array}$ & $\begin{array}{l}-\mathrm{pI} \\
\text { - } \mathrm{pI} \\
\text { - } \mathrm{pI} \\
\text { - } \mathrm{pI}\end{array}$ & $\begin{array}{l}6,77 \\
6,72 \\
6.28 \\
6,29\end{array}$ \\
\hline $\begin{array}{l}\text { D7 } \\
\text { D7-pET21 } \\
\text { D7-pGEX } \\
\text { D7-IBA1 }\end{array}$ & $\begin{array}{l}385-D-891 \\
385-D-891 \\
385-D-891 \\
385-D-891\end{array}$ & $\begin{array}{l}507 \text { aa }- \\
531 \text { aa }- \\
747 \text { aa }- \\
536 \text { aa - }\end{array}$ & $\begin{array}{l}-\quad 56,6 \mathrm{k} \\
-\quad 59,3 \mathrm{k} \\
-\quad 84,6 \mathrm{k} \\
-\quad 59,8 \mathrm{k}\end{array}$ & $\begin{array}{l}\mathrm{kD} \\
\mathrm{kD} \\
\mathrm{kD} \\
\mathrm{kD}\end{array}$ & $\begin{array}{l}-\mathrm{pI} \\
\text { - } \mathrm{pI} \\
-\mathrm{pI} \\
-\mathrm{pI}\end{array}$ & $\begin{array}{l}5,90 \\
6,09 \\
5.82 \\
5,66\end{array}$ \\
\hline $\begin{array}{l}\text { D8 } \\
\text { D8-pET21 } \\
\text { D8-pGEX } \\
\text { D8-IBA1 }\end{array}$ & $\begin{array}{l}385-D-745 \\
385-D-745 \\
385-D-745 \\
385-D-745\end{array}$ & $\begin{array}{l}361 \text { aa }- \\
385 \text { aa }- \\
601 \text { aa }- \\
390 \text { aa }-\end{array}$ & $\begin{array}{l}-\quad 40,3 \mathrm{k} \\
-\quad 43,0 \mathrm{k} \\
-\quad 68,3 \mathrm{k} \\
-\quad 43,6 \mathrm{k}\end{array}$ & $\begin{array}{l}\mathrm{kD} \\
\mathrm{kD} \\
\mathrm{kD} \\
\mathrm{kD}\end{array}$ & $\begin{array}{l}-\mathrm{pI} \\
\text { - } \mathrm{pI} \\
\text { - } \mathrm{pI} \\
-\mathrm{pI}\end{array}$ & $\begin{array}{l}8,11 \\
7,64 \\
6.36 \\
6,42\end{array}$ \\
\hline $\begin{array}{l}\text { D9 } \\
\text { D9-pET21 } \\
\text { D9-pGEX } \\
\text { D9-IBA1 }\end{array}$ & $\begin{array}{l}385-D-585 \\
385-D-585 \\
385-D-585 \\
385-D-585\end{array}$ & $\begin{array}{l}201 \text { aa }- \\
225 \text { aa }- \\
441 \text { aa }- \\
230 \text { aa - }\end{array}$ & $\begin{array}{l}-\quad 22,8 \mathrm{k} \\
-\quad 25,5 \mathrm{k} \\
-\quad 50,8 \mathrm{k} \\
-\quad 26,0 \mathrm{k}\end{array}$ & $\begin{array}{l}\mathrm{kD} \\
\mathrm{kD} \\
\mathrm{kD} \\
\mathrm{kD}\end{array}$ & $\begin{array}{l}-\mathrm{pI} \\
\text { - } \mathrm{pI} \\
\text { - } \mathrm{pI} \\
-\mathrm{pI}\end{array}$ & $\begin{array}{l}7,04 \\
6,76 \\
6.01 \\
5,80\end{array}$ \\
\hline $\begin{array}{l}\text { D10 } \\
\text { D10-pET21 } \\
\text { D10-pGEX } \\
\text { D10-IBA1 }\end{array}$ & $\begin{array}{l}617-D-1019 \\
617-D-1019 \\
617-D-1019 \\
617-D-1019\end{array}$ & $\begin{array}{l}403 \text { aa }- \\
427 \text { aa }- \\
643 \text { aa }- \\
432 \text { aa }-\end{array}$ & $\begin{array}{l}-\quad 45,8 \mathrm{k} \\
-\quad 48,5 \mathrm{k} \\
-\quad 73,8 \mathrm{k} \\
-\quad 49,1 \mathrm{k}\end{array}$ & $\begin{array}{l}\mathrm{kD} \\
\mathrm{kD} \\
\mathrm{kD} \\
\mathrm{kD}\end{array}$ & $\begin{array}{l}-\mathrm{pI} \\
\text { - } \mathrm{pI} \\
\text { - } \mathrm{pI} \\
-\mathrm{pI}\end{array}$ & $\begin{array}{l}8,08 \\
7,67 \\
6.52 \\
6,65\end{array}$ \\
\hline $\begin{array}{l}\text { D11 } \\
\text { D11-pET21 } \\
\text { D11-pGEX } \\
\text { D11-IBA1 }\end{array}$ & $\begin{array}{l}617-D-891 \\
617-D-891 \\
617-D-891 \\
617-D-891\end{array}$ & $\begin{array}{l}275 \text { aa }- \\
299 \text { aa }- \\
515 \text { aa - } \\
304 \text { aa - }\end{array}$ & $\begin{array}{l}-\quad 30,5 \\
-\quad 33,2 \\
-\quad 58,5 \\
-\quad 33,8\end{array}$ & $\begin{array}{l}\mathrm{kD} \\
\mathrm{kD} \\
\mathrm{kD} \\
\mathrm{kD}\end{array}$ & $\begin{array}{l}-\mathrm{pI} \\
-\mathrm{pI} \\
-\mathrm{pI} \\
-\mathrm{pI}\end{array}$ & $\begin{array}{l}6,11 \\
6,31 \\
5.88 \\
5,66\end{array}$ \\
\hline $\begin{array}{l}\text { D12 } \\
\text { D12-pET21 } \\
\text { D12-pGEX } \\
\text { D12-IBA1 }\end{array}$ & $\begin{array}{l}617-D-745 \\
617-D-745 \\
617-D-745 \\
617-D-745\end{array}$ & $\begin{array}{l}129 \text { aa }- \\
153 \text { aa }- \\
369 \text { aa }- \\
158 \text { aa }-\end{array}$ & $\begin{array}{l}-\quad 14,2 \\
-\quad 17,0 \\
-\quad 42,2 \\
-\quad 17,5\end{array}$ & $\begin{array}{l}\mathrm{kD} \\
\mathrm{kD} \\
\mathrm{kD} \\
\mathrm{kD}\end{array}$ & $\begin{array}{l}-\mathrm{pI} \\
-\mathrm{pI} \\
-\mathrm{pI} \\
-\mathrm{pI}\end{array}$ & $\begin{array}{l}9,27 \\
9,10 \\
7.07 \\
8,30\end{array}$ \\
\hline $\begin{array}{l}\text { D13 } \\
\text { D13-pET21 } \\
\text { D13-pGEX } \\
\text { D13-IBA1 }\end{array}$ & $\begin{array}{l}785-D-1019 \\
785-D-1019 \\
785-D-1019 \\
785-D-1019\end{array}$ & $\begin{array}{l}235 \text { aa }- \\
259 \text { aa }- \\
475 \text { aa }- \\
264 \text { aa }-\end{array}$ & $\begin{array}{l}-27,2 \\
-\quad 29,9 \\
-\quad 55,2 \\
-\quad 30,5\end{array}$ & $\begin{array}{l}\mathrm{kD} \\
\mathrm{kD} \\
\mathrm{kD} \\
\mathrm{kD}\end{array}$ & $\begin{array}{l}-\mathrm{pI} \\
-\mathrm{pI} \\
-\mathrm{pI} \\
-\mathrm{pI}\end{array}$ & $\begin{array}{l}8,13 \\
7,23 \\
6.30 \\
6,32\end{array}$ \\
\hline $\begin{array}{l}\text { D14 } \\
\text { D14-pET21 } \\
\text { D14-pGEX } \\
\text { D14-IBA1 }\end{array}$ & $\begin{array}{l}785-D-891 \\
785-D-891 \\
785-D-891 \\
785-D-891\end{array}$ & $\begin{array}{l}107 \text { aa - } \\
131 \text { aa - } \\
347 \text { aa - } \\
136 \text { aa - }\end{array}$ & $\begin{array}{l}-\quad 11,9 \\
-\quad 14,6 \\
-\quad 39,9 \\
-\quad 15,2\end{array}$ & $\begin{array}{l}\mathrm{kD} \\
\mathrm{kD} \\
\mathrm{kD} \\
\mathrm{kD}\end{array}$ & $\begin{array}{l}-\mathrm{pI} \\
\text { - } \mathrm{pI} \\
\text { - } \mathrm{pI} \\
-\mathrm{pI}\end{array}$ & $\begin{array}{l}5,22 \\
5,94 \\
5.55 \\
4,95\end{array}$ \\
\hline $\begin{array}{l}\text { D15 } \\
\text { D15-pET21 } \\
\text { D15-pGEX } \\
\text { D15-IBA1 }\end{array}$ & $\begin{array}{l}905-D-1019 \\
905-D-1019 \\
905-D-1019 \\
905-D-1019\end{array}$ & $\begin{array}{l}115 \text { aa }- \\
139 \text { aa }- \\
355 \text { aa }- \\
144 \text { aa }-\end{array}$ & $\begin{array}{l}-\quad 13,7 \\
-\quad 16,5 \\
-\quad 41,7 \\
-\quad 17,0\end{array}$ & $\begin{array}{l}\mathrm{kD} \\
\mathrm{kD} \\
\mathrm{kD} \\
\mathrm{kD}\end{array}$ & $\begin{array}{l}-\mathrm{pI} \\
\text { - } \mathrm{pI} \\
\text { - } \mathrm{pI} \\
-\mathrm{pI}\end{array}$ & $\begin{array}{l}9,72 \\
9,56 \\
7.17 \\
8,73\end{array}$ \\
\hline
\end{tabular}

\section{RESOLVE Skript für initialen, automatisierten Strukturbau in eine experimentelle Elektronendichtekarte}

\#!/bin/csh

setenv SYMOP /xtal/solve-2.11/lib/symop.lib

setenv SYMINFO /xtal/solve-2.11/lib/syminfo.lib

setenv CCP4_OPEN UNKNOWN

resolve <<EOD $>$ ! resolve.log\#

hklin \#input.mtz

LABIN FP=FP PHIB=PHIC FOM=FOM SIGFP=SIGFP

hklout \#output_resolve.mtz

build_only

no_find_ncs

solvent_content 0 .\#\#

seq_file \#\#\#.seq

EOD

\# Now "resolve.mtz" has the output amplitudes, phases, and figure of merit

\# in columns labelled: FP PHIM FOMM. A model of your structure is in resolve.pdb. 


\section{Danksagung}

Abschließend möchte ich natürlich nicht auf ein paar warme Worte verzichten.

Mein Dank geht in erster Linie an Ralf Ficner, der die Anfertigung dieser Doktorarbeit erst ermöglicht hat. Er stand mir stets mit gutem Rat beiseite und hat meine Moral nach wissenschaftlichen Tiefschlägen immer wieder aufgebaut.

Desweiteren danke ich Oliver Einsle, der sich nie gegen Fragen aller Art gewehrt und hat stets darauf geachtet hat, dass das letzte Bier an ihn ging.

Auch Achim Dickmanns muss unbedingt gedankt werden. Sein unumstößlicher Optimismus und sein Wille die Abteilung zusammen zu halten, haben mich stets motiviert.

Besonderer Dank gebührt auch Thomas Monecke. Er war mein Begleiter über das komplette Studium und die Promotion. Dabei reichte das Repertoire vom kreativen fachlichen Rat über unglaubliche Böcke bis hin zum Händchenhalten nach privaten Katastrophen.

Auch Daniel Wohlwend sei gedankt, der er ein Intelligenzbolzen par excellence und ein guter Freund geworden ist.

Ich danke Jens Brinkmann für das verlässliche Nicht-Auslassen von friesischen Flachwitzen. Ich danke Eike Schulz für das infernale Lachen nach diesen Witzen.

Desweiteren danke ich den Familienmitgliedern unserer kleinen Helikasefamilie, Jana Schmitzova, Sina Möhlmann und Winni. Allen anderen Mitglieder und Ex-Mitgliedern des MSB wird an dieser Stelle natürlich auch gedankt, da sich niemand geweigert hat mit gutem Rat beiseite zu stehen oder ihn gar anzunehmen. Besonders hervorzuheben ist die selbstlose Hilfe von Markus Rudolph, ohne die die R-Faktoren der Struktur immer noch im roten Bereich drehen würden.

Meine Diplomandin Kristina Lakomek und meinen Praktikanten Marion Lösing und Christian "Schnitzel” Nagel haben ihre Leidensfähigkeit unter meiner Führung stets unter Beweis gestellt. Ich danke ihnen, dass sie all das ohne Murren hingenommen haben. Gerd danke ich nicht.

Schlussendlich möchte ich Marion und Til danken, denen dieses Büchlein auch gewidmet ist. Ich danke ihnen für die außerdienstliche Betreuung und Zerstreuung innerhalb unserer kleinen kaputten Familie. Für Spaß, für Liebe, für Zorn und für Trauer. Auch wenn die Zeiten nicht einfach waren, kommen sie nicht wieder zurück. Ich vermisse jede Sekunde. Ich liebe euch und behalte euch für immer in meinem Herzen. 


\section{Lebenslauf}

Denis Kudlinzki

Hauptstraße 2

99998 Volkenroda

E-Mail:dkudlin@yahoo.de

Geburtsdatum

Geburtsort

Familienstand

Kinder

Staatsbürgerschaft

\section{Schulbildung}

01. 09. 1986

01. 10. 1991

09. 07. 1998

\section{Wehrdienst}

01. 09. 1998 - 25. 07. 1999
18. 10.1979

Mühlhausen/Thüringen

ledig

1

deutsch
Grundschule POS Körner

Staatliche Gymnasium Schlotheim

Abschluss der Schulausbildung mit dem Abitur

\section{Studium}

23. 11. 1999 - 31. 08.2004

Biologiestudium (Diplom) an der Universität Göttingen

\section{Promotion}

seit dem 01. 09. 2004

an der Universität Göttingen Abt. Mol. Strukturbiologie

Göttingen, den 10. 12. 2007 